\title{
ARCHITECTURE FOR A
}

POST WORK WORLD 

ARCHITECTURE FOR A

POST-WORK WORLD

by

Toffazzal Hussain Patwary,

Bachelor of Design, Ontario College of Art and Design , 2008

Bachelor of Architectural Design, Carleton University, 2012

A thesis

presented to Ryerson University

in partial fulfillment of the

requirements for the degree of

Master of Architecture

in the Program of Architecture

Toronto, Ontario, Canada, 2018

(C) Toffazzal H. Patwary, 2018 



\section{Author's Declaration}

I hereby declare that I am the sole author of this thesis. This is a true copy of the thesis, including any required final revisions, as accepted by my examiners.

I authorize Ryerson University to lend this thesis to other institutions or individuals for the purpose of scholarly research.

I further authorize Ryerson University to reproduce this thesis by photocopying or by other means, in total or in part, at the request of other institutions or individuals for the purpose of scholarly research.

I understand that my thesis may be made electronically available to the public.

Toffazzal H. Patwary 

Toffazzal Hussain Patwary

Master of Architecture, 2018

Ryerson University

\begin{abstract}
$47 \%$ to $80 \%$ of today's jobs can be automated in the next twenty years. Most people continue to work in low skill, low wage, manual and service jobs. Only a small number are engaged in high-skilled, high wage, non-routine, cognitive jobs. What will happen to the surplus population- the workers who are most at risk of being replaced by automation?

If left at the current trajectory, the private sector, via technological means, will take over traditional public services including: health, environment, and sovereignty. A dystopic condition will emerge in which governments are dissolved and the working class is exterminated.

This thesis attempts, via the use of critical architecture, to challenge the hegemonic order of capitalism and align the future toward a post-work condition. The devised semiotic code is an innovative signifier for a new truth - a new language of rebellion against the established hierarchies of contemporary architecture.
\end{abstract}





\section{Acknowledgments}

I would like to express my gratitude to my thesis supervisor, Arthur Wrigglesworth, for his patience, guidance, support, insightful conversations, and belief entrusted in me over the last two years. Thank you for helping me successfully complete a major milestone in my life.

I would also like to thank Colin Ripley, Paul Floerke, and John Cirka for asking the tough questions, providing helpful criticism, and thoughtful provocations. I truly appreciate all of your interest, insights, and personal perspectives.

To my colleagues, thank you for constantly challenging my work and keeping me on my toes. 


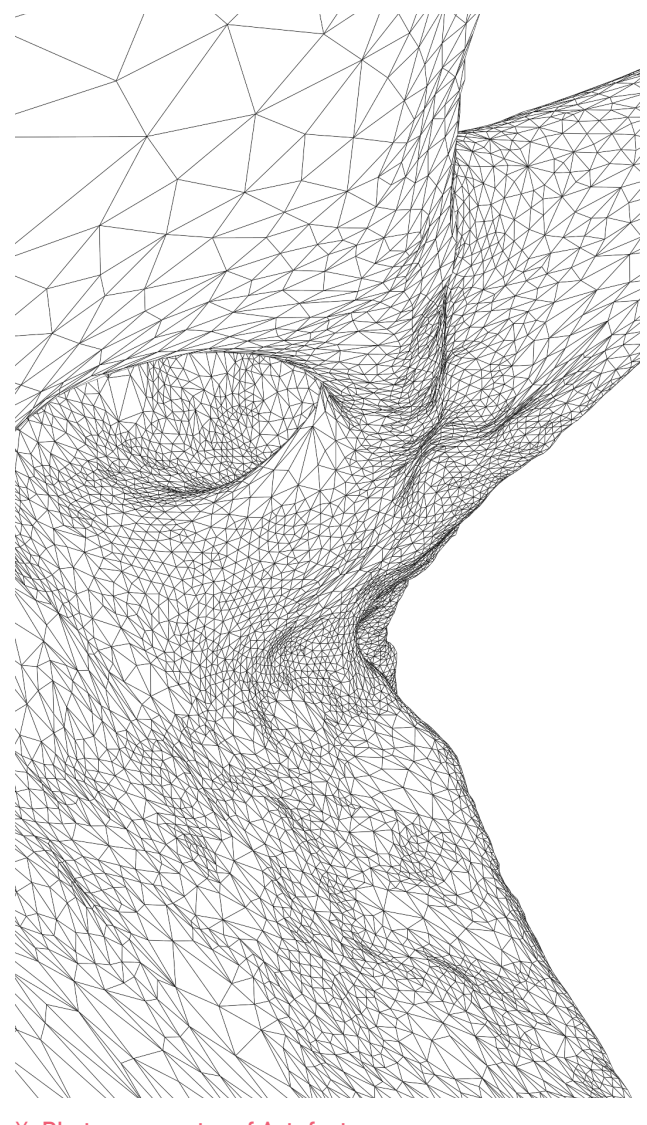

X: Photogrammetry of Artefact 


\section{Table of Contents}

Author's Declaration

Abstract

Acknowledgments

Table of Contents

List of Figures

Preface

1.0 Introduction

2.0 Design Research Outline

3.0 Intended Design Research

4.0 Background: Constant Nieuwenhuys

4.1 New Babylon

4.2 Situationist International

5.0 Jacques Attali: A Brief History

$5.1 \quad$ First Wave of the Future

5.2 The Nomadic Object

5.3 Planetary Empire: Samsung

5.4 Planetary Empire as Dystopia

6.0 A Commodified Future: Cash Crash Jubilee

7.0 Hieronymus Bosch: Garden of Earthly Delights

8.0 Four Futures

8.1 Communism: Egalitarianism and Abundance

8.2 Rentism: Hierarchy and Abundance

8.3 Socialism: Egalitarianism and Scarcity

8.4 Exterminism: Hierarchy and Scarcity

8.5 Insights on Future Scenarios

9.0 Return to Critical Architecture

9.1 Post Critical

9.2 Semiotics

9.3 Political Engagement

10.0 Government as Leading Innovation

10.1 Work Progress Administration

10.2 Semiopolitical to Semiosocial 
11.0 Monuments to the Future

11.1 Synthetic Typologies for a Post-Work Future

11.2 [1] Criticism Through Strategic Insertion

11.3 [2] Polemic Through Morphology and Program

11.4 [3] Strategy of Withdrawal

12.0 Monument to Culture

12.1 Architecture of Horizontality

13.0 Monument to Housing

13.1 Fujian Toulou Homes

14.0 Monument to Institution

14.1 Infosphere: Expo 67 US Pavilion

15.0 Monument to Recreation

15.1 Playground for the Flaneur

16.0 The Uncanny

16.1 The Uncanny as Cultural Innovation

16.2 Automation as Uncanny

16.3 Architecture as Uncanny

16.4 Strange Objects as Uncanny

16.5 Making the Uncanny Object

16.6 Uncanny Methodologies for the Uncanny Object

17.0 Architecture for a Post-work World

17.1 Discovery via the Architectural Object

17.2 Discovery via Drawing/ Collage

17.3 Discovery via the Architectural Artefact

17.4 Discovery via Scanning

17.5 Discovery via Photography

17.6 Discovery via Light \& Shadows

17.7 Discovery via Extrusion

17.8 Discovery via Photogrammetry

17.9 Discovery via Duplication

17.10 Discovery via Extraction

17.11 Discovery via Prototype

C Conclusion

R References: Works Cited

EN End Notes 
F Figures

X Photogrammetry of Artefact

Hussain Patwary, 2018

1.0 Introduction

1.0a Monthly UBI Initiatives

Hussain Patwary, 2018

1.0b Daily Activity Breakdown of a Typical Working Person in America Hussain Patwary, 2018

\subsection{Background: \\ Constant Nieuwenhuys}

4.1a Snakes and Ladders

By Constant Nieuwenhuys, 1949

https://www.tate.org.uk/context-

comment/articles/snakes-

and-ladders-the-cobra-group

Accessed 22 Jul. 2018

4.2b View of Babylonian Sectors

By Constant Nieuwenhuys, 1971

https://www.stylepark.com/en/

news/higher-stakes

Accessed 22 Jul. 2018

4.3c Psycho-geographical Map of Paris

By Constant Nieuwenhuys, 1963

http://ryanraffa.com/parsons/

blog/images/09_fall/major

studio/finalproject/precedence/

new-babylon-paris-1000.jpg

Accessed 22 Jul. 2018

\section{3d Photogrammetry Capture of}

Artefact

Hussain Patwary, 2018
5.0 Jacques Attali:

A Brief History

5.2a I phone 6 Disassembled

Hussain Patwary, 2018

5.3b $15 \%$ South Korean Economy

Hussain Patwary, 2018

5.3c Ichon Rex Tower by

Samsung C\&T Corporation

http://joelsandersarchitect.com/

project/ichon-rex/

Accessed 22 Jul. 2018

5.3d Samsung Medical Center

Samsung C\&T Corporation

https://bookimed.com/clinic/

samsung-medical-center/

Accessed 22 Jul. 2018

5.3e Sungkyunkwan University

Samsung C\&T Corporation http://www.wiu.edu/sao/study_ abroad/programs/semesterabroad/studentexchanges/skku/ Accessed 22 Jul. 2018

5.3f Everland Resort

Samsung C\&T Corporation

http://www.tourist-destinations. com/2014/06/everland-kyonggido-south-korea.html

Accessed 22 Jul. 2018

5.4g Samsung City

Liam Young, 2014

http://www.

tomorrowsthoughtstoday.com/

slow/wp-content/uploads/2014/10/

Samsung-City_liam-young.jpg

Accessed 22 Jul. 2018ry, 2018 


\subsection{A Commodified Future:} Cash Crash Jubilee

6.0a Tokyo's ImmaNet

Hussain Patwary, 2018

6.0b Digimake

Hussain Patwary, 2018

6.0c Jubilee

Hussain Patwary, 2018

7.0 Hieronymous Bosh: Garden of Earthly Delights

7.0a Garden of Earthly Delights: Trypti Hieronymus Bosch, 1480-1505

https://tuinderlusten-

jheronimusbosch.ntr.nl/en

Accessed 22 Jul. 2018

7.0b Garden of Earthly Delights:

Center Panel

Hieronymus Bosch, 1480-1505

Edited by Hussain Patwary, 2018

7.0c Garden of Earthly Delights:

Center Panel Re-Imagined

Hieronymus Bosch, 1480-1505

Edited by Hussain Patwary, 2018

7.0d Garden of Earthly Delights:

Detail 01: Re-Imagined

Hieronymus Bosch, 1480-1505

Edited by Hussain Patwary, 2018

7.0e Garden of Earthly Delights:

Detail 02: Re-Imagined

Hieronymus Bosch, 1480-1505

Edited by Hussain Patwary, 2018 7.0f Garden of Earthly Delights:

Detail 03: Re-Imagined

Hieronymus Bosch, 1480-1505

Edited by Hussain Patwary, 2018

7.0g Garden of Earthly Delights:

Detail 04: Re-Imagined

Hieronymus Bosch, 1480-1505

Edited by Hussain Patwary, 2018

7.0h Garden of Earthly Delights:

Detail 05: Re-Imagined

Hieronymus Bosch, 1480-1505

Edited by Hussain Patwary, 2018

9.0 Return to

Critical Architecture

9.1a WTC Winning Proposal

Studio Daniel Libeskind, 2012

https://libeskind.com/work/

ground-zero-master-plan/

Accessed 22 Jul. 2018

9.2b Lincoln Memorial

https://www.nps.gov/linc/learn/

historyculture/memorial-features.

$\mathrm{htm}$

Accessed 22 Jul. 2018

9.3c Exodus, or the Voluntary Prisoners of Architecture

Rem Koolhaas, Madelon

Vreisendorp, Elia Zenghelis, and

Zoe Zengheli, 1972

http://socks-studio.

com/2011/03/19/exodus-or-

the-voluntary-prisoners-of-

architecture/

Accessed 22 Jul. 2018 
10.0 Government as

Leading Innovation

10.1a Griffith Observatory

https://travel.usnews.com/

Los_Angeles_CA/Things_To_Do/

Griffith_Observatory_13463/

Accessed 22 Jul. 2018

10.1b Jackson Pollock

http://www.gstatic.com/

hostedimg/3cc74fc810363784_

large

Accessed 22 Jul. 2018

$11.0 \quad$ Monuments

to the Future

11.1a Aerial of Monument to Culture

Hussain Patwary, 2018

11.2b Maker Space Insertion

Hussain Patwary, 2018

11.3c Disruptive Horizon

Hussain Patwary, 2018

11.4d Exodus, or the Voluntary Prisoners of Architecture

Rem Koolhaas, Madelon

Vreisendorp, Elia Zenghelis, and

Zoe Zengheli, 1972
12.0 Monument

to Culture

12.0a Monument at Financial Zone

Hussain Patwary, 2018

12.0b Aerial View of Monument at

Financial Zone

Hussain Patwary, 2018

12.0c Sketch Model

Hussain Patwary, 2018

12.0d Concept Diagram

Hussain Patwary, 2018

12.0e View from King St. E

Hussain Patwary, 2018

12.0f Formal Exploration

Hussain Patwary, 2018

12.0g Sectional Conditions 01

Hussain Patwary, 2018

12.0g Sectional Conditions 02

Hussain Patwary, 2018

12.1 h Horizontal as Heterarchical

By Constant Nieuwenhuys, 1964

https://veredes.es/blog/en/

constant-la-utopia-cobra-vida-

miquel-lacasta-codorniu/

Accessed 22 Jul. 2018

12.0i Vertical as Hierarchical

http://urbantoronto.ca/database/

projects/bay-adelaide-centre

Accessed 22 Jul. 2018 
12.0j Berlin Free Zones, Lebbeus Woods https://www.nytimes. com/2008/08/25/arts/ design/25wood.html Accessed 22 Jul. 2018

12.0k Formal Exploration Hussain Patwary, 2018

\subsection{Monument to}

Housing

13.0a Monument at Residential Zone Hussain Patwary, 2018

13.0b Sketch Model

Hussain Patwary, 2018

13.0c Courtyard with Inverted Ziggurat Hussain Patwary, 2018

13.0d Street View

Hussain Patwary, 2018

13.0e Internalized Programming

Hussain Patwary, 2018

13.0f Communal Core

Hussain Patwary, 2018

13.0g Leisure as Central

Hussain Patwary, 2018

13.1h Toulou Homes in Fujian, China https://en.wikipedia.org/wiki/ Chuxi_Tulou_cluster Accessed 22 Jul. 2018 13.1i Condo Development, Toronto https://www.blogto.com/ city/2016/10/average_cost_to_ rent_a_condo_in_toronto_goes_ way_up/

Accessed 22 Jul. 2018

\subsection{Monument to} Institution

14.0a Monument at Institutional Zone Hussain Patwary, 2018

14.0b Sketch Model

Hussain Patwary, 2018

14.0c Infosphere Hussain Patwary, 2018

14.0d View from Younge \& Gould St Hussain Patwary, 2018

14.1e Dome as Inclusive Insert Source

14.1f Institutions as Exclusionary Google Maps Edited by Hussain Patwary, 2018

\section{$15.0 \quad$ Monument to} $\underline{\text { Recreation }}$

15.0a Monument at Industrial Zone Hussain Patwary, 2018

15.0b Sketch Model

Hussain Patwary, 2018

15.0c Body at Play

Hussain Patwary, 2018 
15.0d Street View

Hussain Patwary, 2018

15.1e The Naked City

By Asger Jorn and Guy Debord, 1957

http://rpi-cloudreassembly.

transvercity.net/wp-content/

uploads/2012/09/original-nakedcity.

jpg

Accessed 22 Jul. 2018

15.1f Factories as Corporeal Supression

Google Maps

Edited by Hussain Patwary, 2018

\subsection{The Uncanny}

16.2a Rice Fields in Bangladesh

Hussain Patwary, 2018

16.2b Typhoon Shelter in Bangladesh

Insert Source

16.3c Parc De La Villette, Axo

Insert Source

16.4d Strange Objects as Revealing 01

Hussain Patwary, 2018

16.4e Strange Objects as Revealing 02

Hussain Patwary, 2018

16.5f Parliament Building

Lebbeus Woods, 2009

https://lebbeuswoods.wordpress. com/2009/08/01/meta-institutes/

Accessed 22 Jul. 2018 16.6g Automatic Drawing

Andre Masson, 1924

https://www.moma.org/collection/ works/38201

Accessed 22 Jul. 2018

16.6h Number 23

Jackson Pollock, 1948

https://www.tate.org.uk/art/

artworks/pollock-number-

23-t00384

Accessed 22 Jul. 2018

17.0 Architecture for a

Post-Work World

17.0a Sectional Condition of Monument Hussain Patwary, 2018

17.0b Cartesian Facade of Mies Towers Hussain Patwary, 2018

17.1 Discovery via the Architectural Object

17.1a Architectural Object:

Conceptual Model 01

Hussain Patwary, 2018

17.1b Sectional Qualities

Hussain Patwary, 2018

17.1c Sculptural/ Formal Qualities 01

Hussain Patwary, 2018

17.1d Sculptural/ Formal Qualities 02 Hussain Patwary, 2018 
17.1e Architectural Objects B1, B2

Longitudinal Section

Hussain Patwary, 2018

17.1f Architectural Objects C1, C2

Longitudinal Section

Hussain Patwary, 2018

17.1g Architectural Objects Conceptual Model 02 Longitudinal Section

Hussain Patwary, 2018

17.1h Architectural Objects A1, A2

Longitudinal Section

Hussain Patwary, 2018

17.2 Discovery via

Drawing/Collage

17.2a Collage at Section of Object 02A

Hussain Patwary, 2018

17.2b Collage at Section of Object 02B

Hussain Patwary, 2018

17.2c Collage at Section of

Concept Model 01

Hussain Patwary, 2018

17.3 Discovery via the Architectural Artefact

17.3a Drawing of Architectural

Artefact (02B)

Hussain Patwary, 2018

17.3b Photo of Architectural

Artefact (02B)

Hussain Patwary, 2018
17.4 Discovery via

Scanning

17.4a Scan of Architectural Artefact C2 Hussain Patwary, 2018

17.4b Scan of Architectural Artefact C1 Hussain Patwary, 2018

17.4c Scan of Architectural Artefact B2 Hussain Patwary, 2018

17.4d Scan of Architectural Artefact A1 Hussain Patwary, 2018

17.4e Scan of Architectural Artefact B1 Hussain Patwary, 2018

17.4f Scan of Architectural Artefact A2 Hussain Patwary, 2018

17.5 Discovery via Light \& Shadows

17.5a Architectural Artefact B2 Hussain Patwary, 2018

17.5b Light Study 01

Hussain Patwary, 2018

17.5c Light Study 02

Hussain Patwary, 2018

17.5d Architectural Artefact C2 Hussain Patwary, 2018

17.5e Architectural Artefact B2 with Multiple Perspective Extrusion Hussain Patwary, 2018 
17.5e Architectural Artefact B2 with Multiple Perspective Extrusion Hussain Patwary, 2018

17.5g Longitudinal Collage Hussain Patwary, 2018

\subsection{Discovery via} Extrusion

17.6a Extruded Object Plan Hussain Patwary, 2018

17.6b Extruded Object Isometric Hussain Patwary, 2018

17.7 Discovery via Photography

17.7a Architectural Artefact A1 Hussain Patwary, 2018

17.7b Architectural Artefact B1 Hussain Patwary, 2018

17.7c Architectural Artefact C1 Hussain Patwary, 2018

17.7d Architectural Artefact A2 Hussain Patwary, 2018

17.7e Line Drawing of Moment 02 Hussain Patwary, 2018

17.7f Moment 01,02,03

Hussain Patwary, 2018

17.7g Moment 04

Hussain Patwary, 2018 17.7h Line Drawing of Moment 08

Hussain Patwary, 2018

17.7i Moment 05,06,07

Hussain Patwary, 2018

17.7j Line Drawing of Moment 08 Hussain Patwary, 2018

17.7k Moment 09,10,11

Hussain Patwary, 2018

17.7L Line Drawing of Moment 12,13,14 Hussain Patwary, 2018

17.7m Moment 02,13,14,15

Hussain Patwary, 2018

17.7n Moment 16,17,18,19,20

Hussain Patwary, 2018

17.8 Discovery via

Photogrammetry

17.8a Capture 01

Hussain Patwary, 2018

17.8b Capture 02

Hussain Patwary, 2018

17.8c Capture 03

Hussain Patwary, 2018

17.8d Architectural Artefact C2

Hussain Patwary, 2018

17.8e Capture 04

Hussain Patwary, 2018

17.8f Capture 05

Hussain Patwary, 2018 
17.8g Capture 06

Hussain Patwary, 2018

17.8h Architectural Artefact B1

Hussain Patwary, 2018

17.8i Capture 07

Hussain Patwary, 2018

17.8j Capture 08

Hussain Patwary, 2018

17.8k Capture 09

Hussain Patwary, 2018

17.81 Architectural Artefact C1

Hussain Patwary, 2018

17.9 Discovery via

Duplication

17.9a Monument 7, 3D Capture

Hussain Patwary, 2018

17.9b Monument 7, 3D Capture

Isometric

Hussain Patwary, 2018

17.9c Monument 01-06, 3D Capture Isometric

Hussain Patwary, 2018

17.9d Monument 01-06, 3D Capture

Hussain Patwary, 2018

17.9e Artefact C1, 3D Capture

Hussain Patwary, 2018

17.9f Artefact B1, 3D Capture

Hussain Patwary, 2018
$17.9 \mathrm{~g}$ Artefact C2, 3D Capture

Hussain Patwary, 2018

17.9h Monument 06, Detail

Hussain Patwary, 2018

17.9i Monument 04, Detail

Hussain Patwary, 2018

17.9j Monument 03, Detail

Hussain Patwary, 2018

17.9k Monument 05, Detail

Hussain Patwary, 2018

17.91 Monument 02, Detail

Hussain Patwary, 2018

17.9m Monument 07, Detail

Hussain Patwary, 2018

17.9n Monument 06, Detail

Hussain Patwary, 2018

17.10 Discovery via

Extraction

17.10a Moment 01,02,05 Surface Capture Hussain Patwary, 2018

17.10b Monument 01, 02 Surface Details Hussain Patwary, 2018

17.10c Monument 01, Translucency Detail Hussain Patwary, 2018

17.10d Moment 05, Surface Detail Hussain Patwary, 2018

17.10e Monument 01, 02 Light \& Shadow Hussain Patwary, 2018 
17.11 Discovery via

Prototype

17.11a Prototype A: Plan

Hussain Patwary, 2018

17.11b Prototype B: Inverted Plan

Hussain Patwary, 2018

17.11c Prototype C: Elevation/ Section

Hussain Patwary, 2018

17.11d Prototype B: Detail

Hussain Patwary, 2018

17.11e Prototype A: Details

Hussain Patwary, 2018

17.11f Prototype A: Shadows

Hussain Patwary, 2018

17.11g Prototype A: Light \& Shadows

Hussain Patwary, 2018

17.11h Prototype B: Details

Hussain Patwary, 2018

17.11i Prototype C: Details

Hussain Patwary, 2018

17.11j Prototype B: Details

Hussain Patwary, 2018

17.11k Prototype A: Light \& Shadows

Hussain Patwary, 2018 



\section{P Preface}

$47 \%$ to $80 \%$ of today's jobs can be automated in the next twenty years.' Companies increasingly need fewer employees to provide the same kind of value to consumers. The nature of work will invariably change to adapt to this emerging condition. But the fact is, most people continue to work in low skill, low wage, manual and service jobs such as: fast food, retail, hospitality, and transportation. Only a small number are engaged in high-skilled, high wage, non-routine, cognitive jobs. ${ }^{2}$ What will happen to the surplus population, the workers who are most at risk of being replaced by automation?

The accelerated rise of capitalist hyperempires that are at the forefront of the development of automation and artificial intelligence has dangerous implications for the future. If left at the current trajectory the private sector, via technological means, will take over traditional public services including: health, environment, and sovereignty. A dystopic condition will emerge in which governments are dissolved and the working class is exterminated. ${ }^{3}$ 
This thesis attempts, via the use of critical architecture as monuments, to challenge the hegemonic order of this distopian projection of capitalism and to realign the future toward a postwork condition in which the individual is freed from the coercive and inescapable structures of labour.

The contemporary practice of architecture now operates in a post-critical state in which established process and methodologies for producing architecture are locked in the economic logic of capitalism. Deconstructing the semiotics of capitalism is the only way to disrupt its codes. As such, this work explores an architecture that is in critical opposition against the language of capitalism. The devised semiotic code is an innovative language of rebellion against the established hierarchies of contemporary architecture.

Design methodologies that operate outside the currently dominant strategies and linear logics are used to develop and reveal uncanny architectural tectonics. Alternative modes of representation are deployed to explore the boundaries of various 
mediums in order to extract unique qualities of the architectural object. The result is an architectural expression that is simultaneously referential and in opposition to the contextual framing.

This thesis ultimately unravels a design process that emerges out of experimentation, chance operations, and intuitive interaction with materials. The combination of intentional and unintentional operations arrives at a grotesque form of architecture that is abstract, primitive yet, sophisticated. 



\subsection{Introduction}

Often referred to as the third industrial revolution, ${ }^{1}$ automation is quickly destabilizing established cultural, social, and economic frameworks. Many tasks in most occupations are either in the process of, or hold the potential for, being automated. Futurists argue that the best way to remain relevant under this changing landscape of automation is to gain agility. ${ }^{2}$ The future employee will need to develop a wide range of creative skill-sets to simultaneously work for different companies under different roles.

The shift towards non-full-time work is already noticeable in the rise of part-time employment and increase of informal labour markets. ${ }^{3}$ It is perhaps no surprise that developments in software automation along with employment precarity are propelling the emergence of the sharing economy as a mass cultural phenomenon. 
This emerging socio-economic system is reducing our need to own assets by enabling access to other people's resources. The concept of ownership is undergoing a radical shift as millennials increasingly see ownership as an obstacle due to the ongoing care and maintenance. New ridesharing, lodging, and skills-trading platforms are facilitating a future of collective access, not individual ownership.

Despite a departure from previously normative conditions of work, the sharing economy only provides alternative wages without any job security. The gig economy is only a temporary solution to alleviate the anxieties posed by automation. Automation is thus an emergent condition we need to prepare for. Failing to do so will increase unemployment and low wage jobs and therefore, poverty.

To use automation for the benefit of society will require social systems that enable us to take advantage of it. The radical idea of a post-work world is gaining traction in the current climate of political and financial uncertainty. What are the conditions necessary for this shift in paradigm?

Nick Srnicek and Alex William's in “Inventing the Future: Post-capitalism and a World Without Work" imagine the possibility of a post-work world with the following requirements: ${ }^{4}$

\section{Full automation}

$47 \%$ to $80 \%$ of today's jobs are capable of being automated. Full automation requires a recognition and acceptance of society under automation, secondly it requires a co-opting of the capitalist regime of profitability through automation. Fully automated societies is contingent upon a redistribution of wealth from those who own the technology of the future to the people who want to buy it.

\section{Reduce work ethic:}

Work has become central to our sociocultural identity. It is problematic to view work as the utmost important value in society. In truth, most people are frustrated with work, have increased anxiety and struggle to stay employed. The work ethic needs to be transformed. 


\section{Universal Basic Income:}

UBI will be funded by increasing taxes on wealthy corporations that have the most to gain from automated production economies. UBI will alleviate the low-waged labour class out of the labour market. The surplus population (Those who are the most in danger of being replaced by automation. $85 \%$ of jobs in Ethiopia could be automated in the next two decades) $)^{5}$ will be ejected from the capitalist system- without jobs, defenseless, and coerced into informal labour markets.

Currently Germany has a UBI project financed through crowd funded donations. The winners of this lottery based campaign receive 1,000 euros every month. Over 30,000 donations have been made for the cause. ${ }^{6}$
In Finland, under the two-year, nationwide pilot scheme, 2,000 unemployed Finns will receive a guaranteed sum of $\$ 825$. The income will replace their existing social benefits and will be paid even if they find work. ${ }^{?}$

Starting in 2017, about 4000 residents in various parts of Ontario received a monthly payment of about $\$ 1,425$. People with disabilities received an additional $\$ 500$ a month. ${ }^{8}$ The program was canceled in June of 2018 with the when a different political party took over.

So far, the studies suggest that under UBI people feel liberated, lead healthier lives, do more creative work. Additionally, UBI will overturn the asymmetry that exists between labour and capital as it will make it difficult to exploit workers by tightening the labour supply.

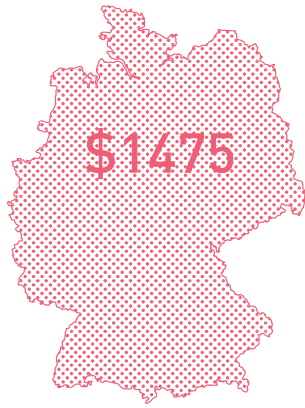

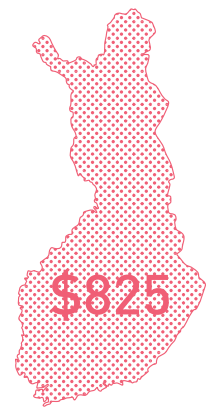

Finland: 2000 Recipients

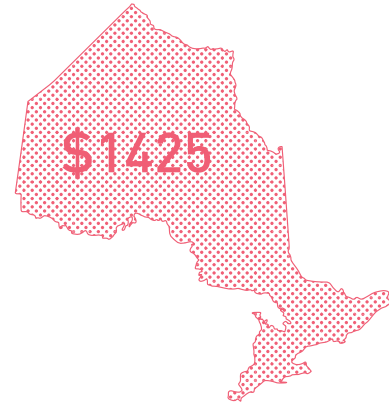

Ontario: 4000 Recipients 


\section{Reduce working week:}

A three-day weekend along with a reduction of working hours will result in a new-found freedom. Individuals will have more time for recreation, education, families and the possibility of doing more fulfilling creative work.

Currently, the average American worker spends about nine hours on weekdays doing work and workrelated activities. ${ }^{9}$ In a fully-automated economy, working hours can be reduced to less than three.
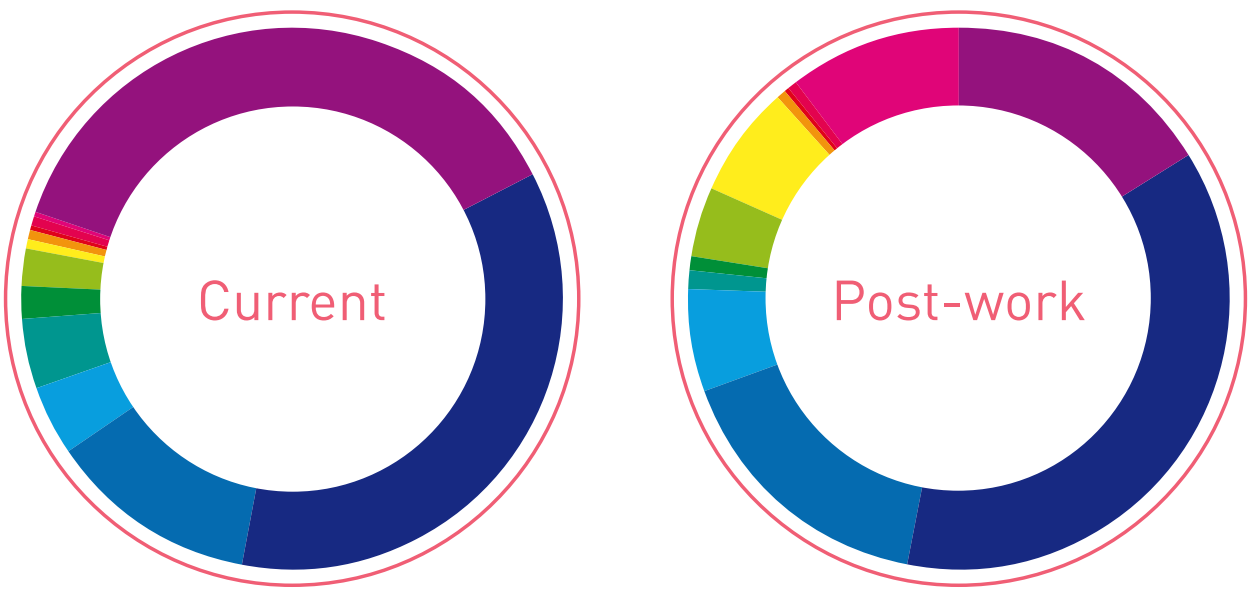
A vision for an alternative future is needed in the face of such a radical transformation. A utopia that is not dependent upon the premise of work is needed to cope with the takeover by automation. This thesis investigates emerging situations for dwelling within the city in a post-work condition. The intention of this thesis is to speculate an emerging condition that will drastically change the way we inhabit our cities and the architecture within. Furthermore, envisioning the situation in a near future of year 2050 will frame this polemic as within reach.

Toronto is a mega-city that can serve as playground for exploring this utopian scenario. This city has undergone an unprecedented development in the last few decades. Unfortunately, the majority of the construction was led by private markets which operate with the goal of speculative financial gains and little effort for civic responsibility. This condition makes Toronto an ideal ground zero to test out the prototypes.
Nick Srnicek

A lecturer in the Digital

Economy department at

King's College at London,

Nick Srnicek writes

about political theory of

accelerationism, post-

scarcity economy, and post-

work politics.

"Perhaps the most

defining feature of the

present era- and the one

that poses the biggest

challenge for capitalism-

is the rise of surplus

populations". 10

Sharing Economy

The Sharing Economy

is a disruptive cultural

movement that is

increasingly challenging

conventional norms of

private ownership. ${ }^{11}$ 


\subsection{Design Research Outline}

Arguably, cities are planned systematically around the movement, separation (or lack thereof), of people and from places of production. When production, and economies are fully automated, how will people dwell within the city? How will urban planning facilitate the emerging behavior of the Homo Ludens? I believe that in the wake of such a socio-economic and cultural transformation, existing architectural typologies will be rendered obsolete. Alternative new typologies need to be explored in order to anticipate a post-work condition. To set up a program for the future, postwork typologies will require an investigation of the aspirations and motivations of work-less residents of the megalopolis.

My thesis research begins with a precedent study of New Babylon by Constant Nieuwenhuys. He was an artist and designer who assembled a comprehensive vision of speculative architectural constructs for a post-work future. His work will serve as a point of departure to formulate some of the concepts for my thesis.

The destabilizing effects of automation promise a very uncertain future. As such, an analysis of proposed hypothesis by futurists and radical thinkers including Jacques Attali (chapter 5) and Peter Frase will (chapter 8) be conducted to paint a clearer vision of the future I will be designing for.

In the next step, I will investigate the capacity for architecture to operate at a critical level (chapter 9) in order to influence the direction of the proposed future. Thus, radical ideas that enable a post-work condition will be investigated and applied to my work. What follows is a design research into the process and methodology to create a new and innovative language for the intended future.
Homo Ludens

(Man the Player) Term coined by Johan Huizinga to express the importance of play in the production and consumption of culture. ${ }^{1}$ 


\subsection{Intended Design Research}

Post-war artist and designer Constant Nieuwenhuys generated a large body of work for New Babylon to create a discourse beyond the architectural discipline, within the public sphere.' A similar methodology that makes use of a variety of mediums, can be used for brainstorming and prototyping to create a range of concepts and narratives that are able to operate and engage with the popular culture.

In 1909, a popular magazine named "The old Life" published an illustration which in fact was the first theorem that expressed the ideal performance of the modern skyscraper typology. The skyscraper concept was first formulated by a cartoonist - the architect was not involved in the conceptualization. ${ }^{2}$ This thesis will conduct literature reviews beyond the discipline of architecture-across multiple territories such as art, media, and culture to comprehensively formulate theories and speculate built environments for a postwork reality.

Taking a futurist approach, I will explore how a post-work world will emerge from present condition. Storytelling is a tool that will be used to investigate the experiential qualities, and complex concepts of this conjectural future condition. I will speculate regarding what is possible, probable, and preferable for an Architecture that responds to a postwork society.

Under contemporary capitalism, dictatorial digital technologies that place emphasis on production efficiency have become the established agency in the designing of built artefacts. A post-work condition will invariably result in a radical departure from the process and methodologies that value efficiency over the unique and imaginative agency of the maker and his/ her interaction with the built artefact. A focus on experimentation and discovery via the making of the architectural artefact can lead to a new and innovative semiotic code.
Constant Nieuwenhuys

Was a post-war artist who imagined an evolved form of society that is liberated from the coercive structures of labour. He constructed a speculative architecture that would enable future citizens to live in a state of play, selfdiscovery, for the pursuit of poetry. ${ }^{3}$

New Babylon

As a trained artist, not architect, Constant produced architectural visions with unique representational techniques. Rich in materials, textures, and colors, his numerous models radiate a naïve yet optimist scenario about the future. New Babylon is explored via architectural models, maps, paintings, drawings, prints, films, texts, installations, and presented through numerous lectures. 


\subsection{Background: Constant Nieuwenhuys}

Despite not having any formal architectural training, Constant Nieuwenhuys was able to create a compelling architectural narrative centered on utopian visions for "New Babylon”. For over two decades, he used paintings, sketches, models, and texts to assemble a polemic critical of postwar urban conditions in Europe.' Nieuwenhuys expressed his idealistic concepts for New Babylon, through speculative art and architecture as provocations to pose questions instead of providing implementable answers. 


\section{"The only activity that will remain beyond automation is the unique act of imagination- by which a} human being is distinguished." 2

Early on in his career in post-war Europe, Nieuwenhuys surrounded himself with avant-garde thinkers including; Asger Jorn, a Danish artist who was part of the Danish Experimental Group, with communist affiliations. Composed of poets, thinkers, and artists, the group was known for its playful, free spirited art work that made use of primitive language and techniques that were highly inspired by the art made by children and the mentally ill. Snakes \& Ladders (fig.4.0a) was painted in a highly expressionistic style that attempts to break free from the imposing orders of classical art, and rigidity of geometric abstractions.

The group changed its name to Cobra International in 1948 but disbanded in 1951. Soon after, Nieuwenhuys began working together with influential architect Aldo Van Eyck. ${ }^{3}$ This collaboration allowed Nieuwenhuys to explore new materials and theories which helped him synthesize art with architecture. Jorn and Nieuwenhuys come together again in 1953 for the Movement International pour un Bauhaus Imaginiste, which would serve as the catalyst for the formulation of the ideas for New Babylon. ${ }^{4}$

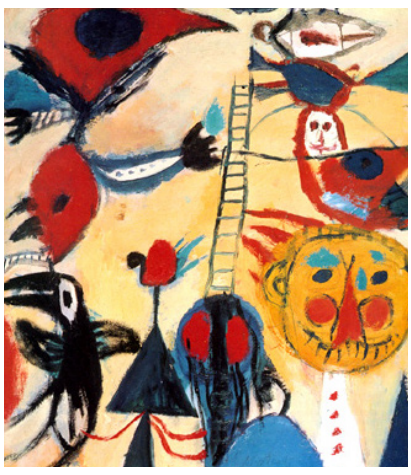

4.0a: Snakes \& Ladders

Primitive Art

Nieuwenhuys was inspired by the ability of children to spontaneously express their feelings with of purity. As such, the highly expressionist style of COBRA imitated children's art as criticism of the modern condition of cities resulting from the atrocities of the Second World War. ${ }^{5}$ 


\subsection{New Babylon}

Constant Nieuwenhuys borrows Johan Huizinga's term Homo Ludens to suggest a future society in which people live in a creative state of play. This leads Nieuwenhuys to design New Babylon- a post-work and total automation world in which the program is organized for nomads continually seeking new experiences. As a kind of hyperstructure that hovers over the city below, the concept proposes a continuous interior space in which people are able to explore their freedom through creative play, adventure, and collective experiences. This architecture of horizontality operates as a collectively owned social space in an endless chain of varying atmospheric environments. The flaneur drifts through these situations, arranging the spaces in his / her own free will. ${ }^{6}$

“...Creative human has an active relationship with the world around him, he wants to intervene, change things, and rather than arranging space in such a way that he can reach a predetermined destination as quickly as possible, he will make the space increasingly complex and multiply its utilization." 7
Homo Faber

(Man the maker) Daily life, and place of residence is determined by his work. ${ }^{7}$

Flaneur

A term used by Charles Beaudelaire to describe the impacts of experience on people as they move through the urban fabric of the city. Originating from the post-industrial urban setting, the flaneur is a passive figure, an observer who experiences the city from a removed perspective. $^{8}$

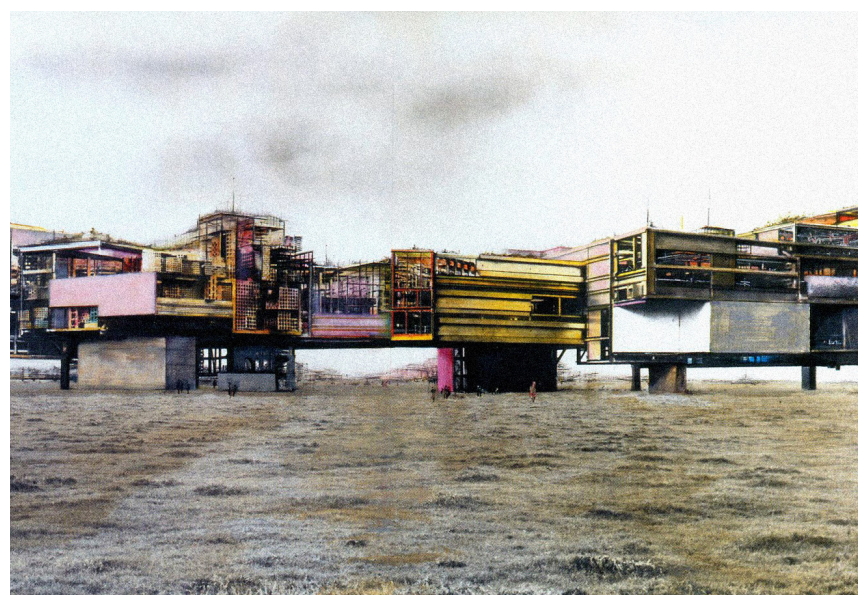

4.1b: View of Babylonian Sectors 


\subsection{Situationist International}

Guy Debord, an influential Marxist writer and film maker, in collaboration with Jorn formed the Situationist International (SI) which developed ideas behind Unitary Urbanism. The Situationists were a radical art and political group that critiqued the post-war capitalist condition that accelerated alienation in contemporary urban culture. The group made the argument that modern society is a series of spectacles in which the common individual did not have the opportunity for participation in the production and experience of lived reality. As such, they intended to dismantle the barriers between the makers and consumers to make cultural production part of everyone's life.

The SI wanted to liberate society from the sterility of the built environment that removed any possibility for playfulness and spontaneity. They hoped to destabilize the capitalist structures of power by empowering the citizens to choose the kind of spatial constructs they wished to live in. ${ }^{?}$

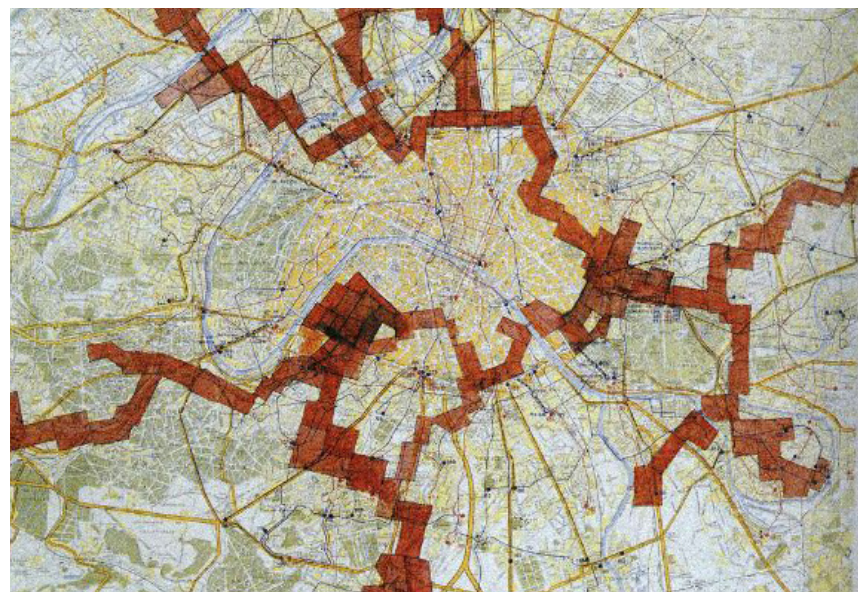

4.2c: Experiential Map of Paris
Johan Huizinga

Homo Ludens (Man at playl, a book written by Johan Huizinga in 1938, serves as a major source of inspiration for the development of Unitary Urbanism. For Huizinga, play is the most important and necessary condition for the generation of culture.

Huizinga defines the five characteristics of play as: Play is free, is in fact freedom. Play is not "ordinary" or "real" life. Play is distinct from "ordinary" life both as to locality and duration. Play creates order, is order. Play demands order absolute and supreme. Play is connected with no material interest, and no profit can be gained from it. ${ }^{10}$ 


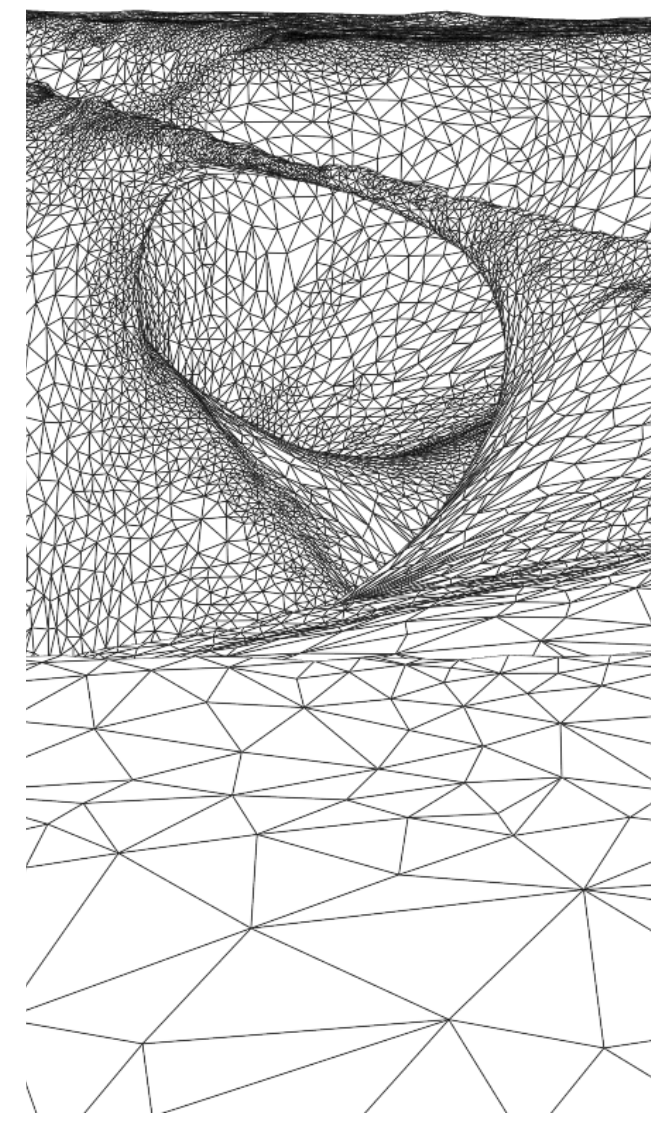

4.2d: Photogrammetry of Artefact 


\subsection{Jacques Attali: A Brief History of the Future}

Jacques Attali served as a chief counselor to the French former president Francois Mitterand from 1981 to 1991 . Under president Sarcosy during 20082010, he led the government committee responsible for the growth of the French economy. He is an economist, social theorist, writer, political advisor, and civil servant. ${ }^{1}$

Attali's seminal book "A Brief History of the Future: A Brave and Controversial Look at the Twenty-first Century" published in 2006 offers a timeline 50 year into the future. Attali predicted the first wave of future scenarios in which the growth of technology along with the pressures of market demands will give rise to a planetary and stateless market called a hyperempire. In the chapter "First Wave of the Future: Planetary Empire", Attali foresees nomadic objects as tools for the commodification of state run services and their ubiquitous adoption as instruments for selfsurveillance. 
The following is a summary of Attali's timeline for the first wave of the future, this section will first investigate the accuracy of Attali's predictions. Second, insights will be extracted to develop an understanding of the social, economic, and technological conditions of year 2050. 


\subsection{First Wave of the Future: Planetary Empire}

In the chapter "First Wave of the Future: Planetary Empire", Jacques Attali discusses the emergence of the market economy as a dominant structure that will result in a global and stateless world. He predicts that the private sector, via technological means, will take over traditional public services including: health, environment, and sovereignty.

Nomadic objects or watchers are described as mass-produced machines that will infiltrate the everyday life of consumers in order to dissolve state run services such as education, health, sovereignty. The market will make use of these objects for the commodification of these services. Nomadic objects are expected to provide more efficient, less expensive services while enhancing our use of time. As a result, private companies will compete with public institutions on behalf of insurance and commercial companies. Soon, users will become completely reliant or be coerced into becoming consumers of private services. ${ }^{2}$

Private insurance companies will require individuals to comply with universal norms. This will push society to behave within the company's image and competence. Such a compliance will require a monitoring of one's health, knowledge, vigilance, and property. The development of biometric devices and products will make it possible to monitor health of body and mind. The data gathered via the nomadic objects will allow insurance companies perform predictive tests. Everyone will have to agree to be monitored. "Being thrifty with rare resources, keeping an eye on one's health, training, and protecting oneself (and more generally staying in shape) will become socially necessary behaviors."3 Society will favor transparency over privacy as the latter will become increasingly problematic for insurance \& commercial companies. Self-surveillance is predicted to become the norm for social well-being by 2050 . Attali notes, "Everyone will have now become his own prison guard." ${ }^{4}$
Planetary Empire:

Google's Smart City

Sidewalk Labs, a firm

owned by Google's parent

Alphabet, is currently

developing a new smart city

for Toronto's post-industrial

eastern waterfront. The

proposal makes use

of self-driving robots,

sensors of multiple kinds,

cameras, smart objects,

and deep neural networks

to essentially create a

condition in which everyone

and everything is tracked

for the improved efficiency

of the system. ${ }^{5}$

The citizens of this

"city within a city" will

serve as guinea pigs for the research and development

of an architecture that

is integrated with the

nomadic object platforms of

Planetary Empires.

\section{Nomadic Objects}

“Objects such as lenses,

glasses, and prostheses

of different kinds that

will miniaturize the

means of receiving

information, entertainment,

communication, and

transport, leading

to a massive rise in

nomadic ubiquity". 6 
Attali forecasts the emergence of nomadic objects, specifically watchers, by the year 2040 . Smartphones have become the contemporary equivalent of such ubiquitous nomadic objects. Despite the inaccurate timeline, Attali's prediction of the role of these nomadic objects is convincing. Today's smartphones, enabled by developments in artificial intelligence and automation have accelerated the commodification of many services in a wide range of industries. Adopted religiously by the mass population, smartphones are used to ubiquitously track everything about our daily lives. Smartphones are packed with sensors, biometric devices, and software including: accelerometer, gyroscope, GPS, proximity sensors, environmental sensors, biometric fingerprint, and facial recognition software.

As predicted by Attali, the combination of these technologies has led to self-surveillance, particularly the monitoring of one's own physical and mental health. Smartphone health applications are used for the pervasive monitoring of one's diet, physical activity, sleep, weight, physical shape, and heartrate. Smartphones are mass consumed watcher objects that have become indispensable in our daily lives because they improve our cognition, increase efficiencies, and allow us to make better use of time.

\section{Ubiquitous Technology}

The miniaturization and decrease in production costs of sensors and computing tech is leading to pervasive computing/ internet of all things. In a state of ubiquitous computing, an active interaction with the physical object is not necessary. The subject being tracked is unaware of the devices in the network as they are pervasive, distributed at all scales throughout everyday life.

\section{Biometric Sensors}

Swedish startup Epicenter makes use of microchips the size of grains of rice to allow its employees to open doors, operate printers, and buy food. ${ }^{7}$ Unlike nomadic objects, the gathered data within the NFC implant is inseparable from the individual's body.

Many throughout the world are now voluntarily embedding biometric sensors in their bodyeffectively enslaving themselves to the network of ubiquitous technology. 
“Sensors and miniature cameras installed in all public places, in offices and in recreation areas, and finally on the nomadic objects themselves, will monitor all comings and goings." 8 


\subsection{Nomadic Object: Deconstructing the I-Phone 6}

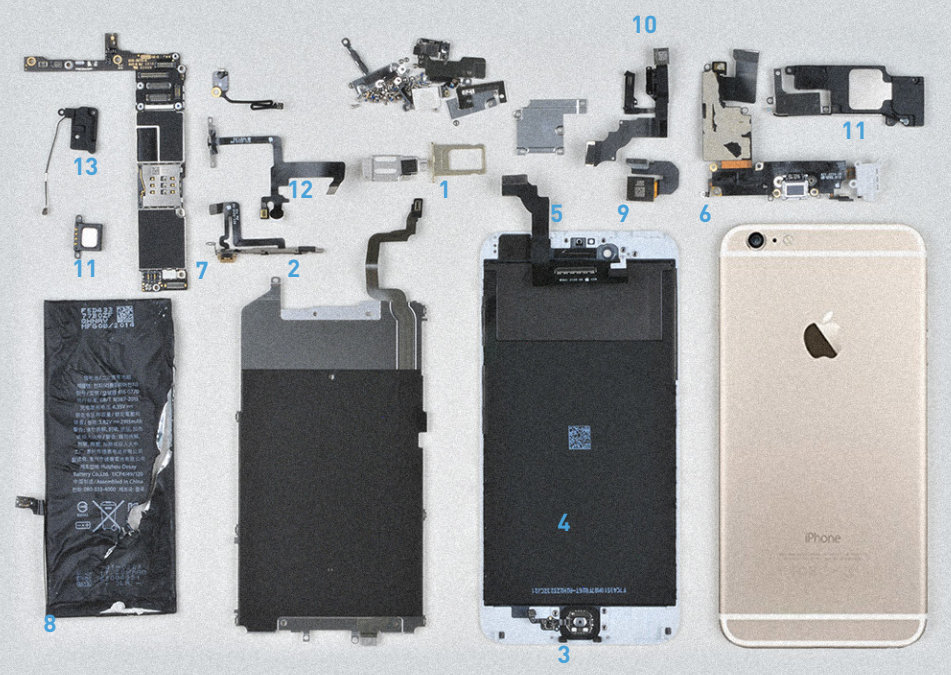

5.2a: I Phone 6 Disassembled

1. Sim Card
2. Volume Up/Down, Ring/Silent PCB
3. Home Button With Fingerprint Sensor
4. Display, Touchscreen Module
5. Secondary Camera Module
6. Main I/O Audio Jack PCB
7. Logic Board

8. Battery

9. Primary Camera Module

10. Lightning Connector Assembly

11. Loudspeaker Assembly

12. Camera Flash/ Power Button PCB

13. Taptic Engine Assembly

\section{“Everyone will now (2050) have become his own prison guard." 9 \\ -Jacques Attali}




\section{Logic Board}

A9 chip with 64-bit

architecture and embedded

M9 motion coprocessor.

Dual-core $1.85 \mathrm{GHz}$ with 2

GB of RAM. The M9 motion

coprocessor services the

accelerometer, gyroscope,

compass, and barometer.

The combination of these

tools allows for the self-

tracking of movement,

sleep patterns, running

distance, walking steps etc.

The evolution of processing

power in combination with

motion sensors has led to a

society of self-monitoring.

There are more than

27,000 health and fitness

applications available in the

United States on iTunes. ${ }^{10}$

\section{Camera Flash}

Smartphones can now

measure heart rate

using only its camera

and flash through a

photoplethysmography

process. The illumination of

the flash allows the camera

to measure minuscule

color changes that happens

at every heartbeat.

Applications allow

individuals to accurately

self-monitor, track, and

record their heart rate.

\section{Sim Card}

Subscriber identity module:

Stores the international

mobile subscriber

identity number used to

authenticate subscribers on

mobile telephony devices.

When on, the phone is

constantly communicating

information including; IMEI

number, IMSI number, TMSI

number, network cell and

an individual's location via

triangulation. Government

security forces are actively

working with telecom

corporations to track

suspected individuals.

\section{Taptic Engine}

Provides force feedback via a linear actuator to produce the sensation of motion and unique tactile experiences.

Haptic responses are coordinated with actionable commands. The taptic feedback enables a more "natural" user experience by using of precise feedback with associated actions and with subtle variations.

\section{Camera Module}

The i-phone 6 s offers an 8-megapixel camera with a f/ 2.2 aperture combined with optical image stabilization. Smartphone cameras are the new paradigm for a society of the spectacle. The normalization of selfies to express social life has led to unintended side effects mainly the loss of individual privacy. Sharing in open social platforms invites scrutiny into the personal life by other individuals, governments, and private corporations. Most alarming is the collection of private data lenabled by selfies) by corporations in an effort to seamlessly insert themselves into our daily lives. 


\subsection{Planetary Empire: Samsung}

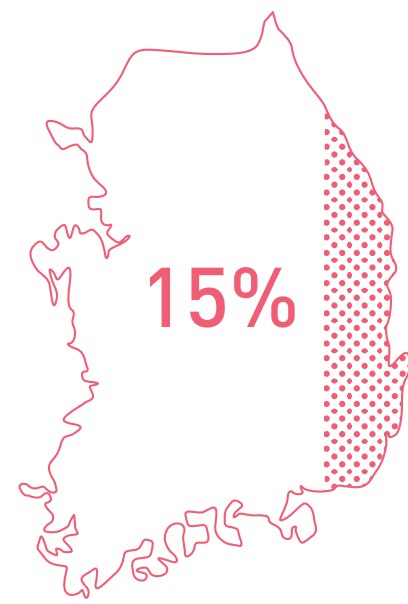

5.3b: $15 \%$ of South Korea's GDP

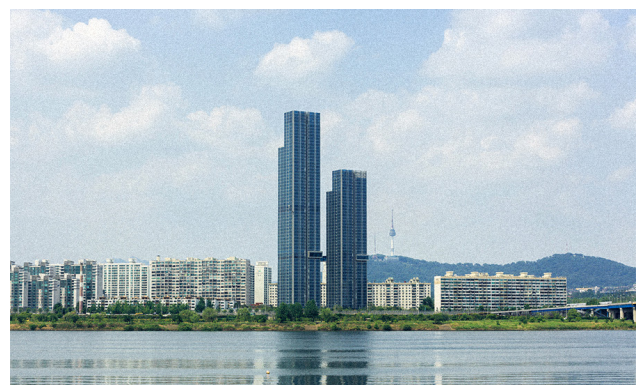

5.3c: Ichon Rex Tower, Samsung C\&T Corp.

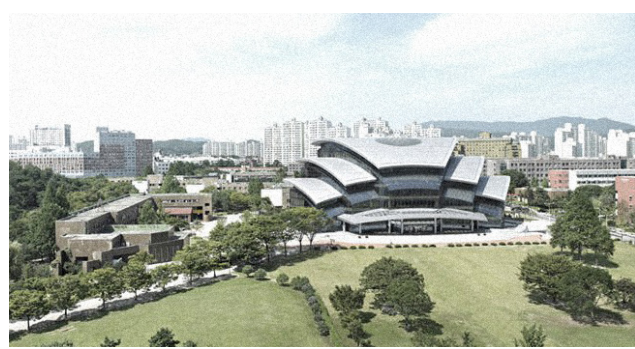

5.3e: Sungkyunkwan University, Samsung C\&T Corp.

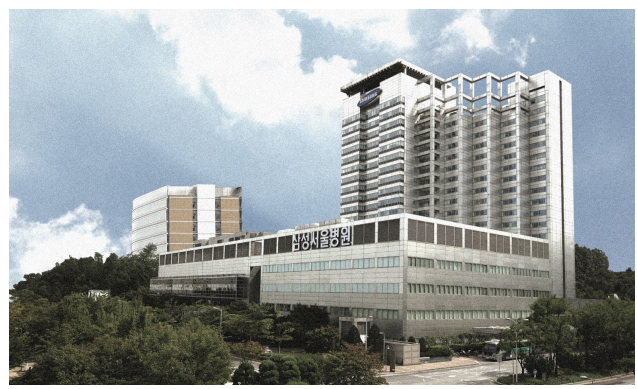

5.3d: Samsung Medical Center, Samsung C\&T Corp.

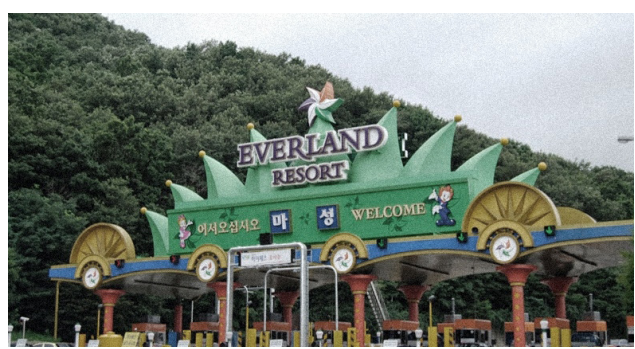

5.3f: Everland Resort, Samsung C\&T Corp. 
At the next stage, Attali predicts a planetary empire.

This condition, he believes will emerge though a systematic dissolution of the role of the state because of the pressures imposed by private companies. Attali hypothesizes that a gradual privatization of public services by conglomerates aided by the mechanisms of nomadic objects will undermine the role of the state. There is evidence that a planetary empire is already taking form.

Samsung is a conglomerate that has deeply infiltrated South Korean economy, politics, and the citizen's lives. ${ }^{11}$ South Koreans are born in Samsung owned medical centers, get educated using Samsung tablets, attend Samsung-affiliated universities, live in Samsung-built apartment complexes lof course fitted out with Samsung appliances) and finally, end up at a Samsung funeral home. In effect, Samsung is estimated to own about $15 \%$ of the country's entire economy. ${ }^{12}$ Despite ongoing claims of corruption, Koreans continue to support this private economy that has helped propel the country as a global leader of technological progress.

Samsung is already establishing the platforms for the hegemonic order of a planetary empire. The company has ubiquity over the mass market in South Korea by the use of nomadic objects and privatization of everyday services. Furthermore, Samsung is ingrained in the sovereignty of South Korea by establishing its presence in the country's organization of governance. Samsung's strengthening dominion over South Korea suggests that universal norms that are dictated by the brand's image are overtaking the role of the state in forming citizenship and social wellbeing. It can be argued that South Korean consumers really live in the republic of Samsung.
Universal Norms

Planetary norms
established by the
insurance companies that
dictate what to eat, what
to know, how to drive, how
to protect oneself, how to
consume, how to produce.
Mass produced nomadic
objects will allow one
to monitor his/ her own
conformity to the norms.

Planetary norms

stablished by the

insurance companies that

dictate what to eat, what

to know, how to drive, how

to protect oneself, how to

consume, how to produce.

objects will allow one

to monitor his/ her own

conformity to the norms. 


\subsection{Planetary Empire is Dystopia}

There are strong indications that by 2050, market economies will dominate and dissolve today's polycentric world. We will not live in nations, instead we will inhabit the values impressed upon us by the brands we consume. Our citizenship to the brand will be assessed by the rate of our consumption.

A state of self-surveillance and self-monitoring seems inevitable because of our insatiable reliance on nomadic objects. As such, we will be increasingly concerned with self-monitoring and self-healing through the use of mass consumed objects.

What happens when conglomerates begin to treat architecture as an integrated part of their nomadic object platforms? If the efficiencies of private industries and their tendency toward disruption are any indication, very different forms of architectural typologies will emerge that will challenge the built environment. 
Samsung City

By exaggerating today's current trends, Liam Young envisions Samsung City. A speculative future where the urban landscape is owned and operated by massive tech conglomerates. Samsung city is stitched together from photos of its residential developments in South Korea and Hong Kong, where the company has expanded beyond the production of technology products to move into public projects and private property development. Tech brands are becoming so big that they are infiltrating into all aspects of our lives, Including the built environment. This condition is reinforcing brand allegiances-creating a new form of patriotism for these commercial entities.

\section{Polycentricism}

A situation involving

several important elements

or powerful parties; a

system or theory having or proposing many centres or focal points. ${ }^{13}$

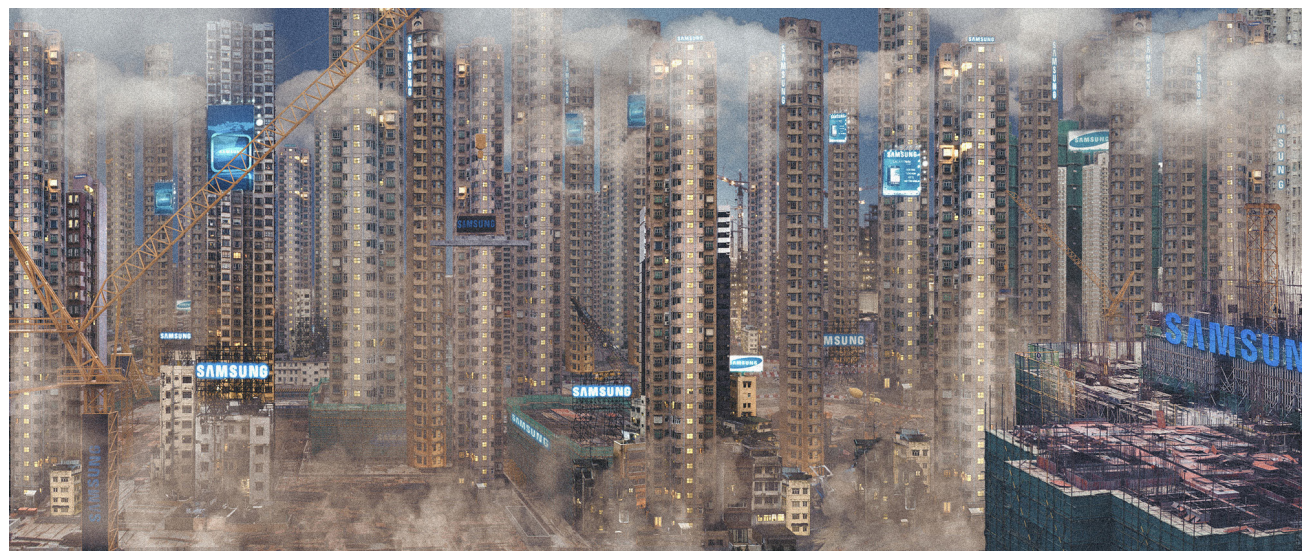

5.4g: Samsung City, Liam Young (2014) 


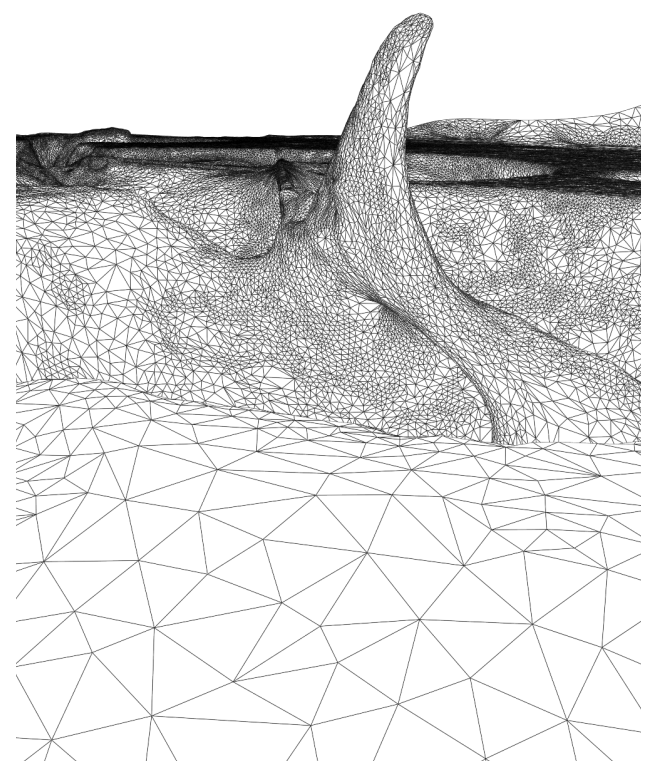

5.4h: Photogrammetry of Artefact 


\subsection{A Commodified Future: Cash Crash Jubilee}

The sci-fi novel written by Eli K.P. William is a satire against the inescapable reach of capitalism. The novel is a speculative fiction that explores an evolved socio-political order in which technology is used by the market economy to turn every action into a transaction. This new world operates on the idea of "All the freedom you can earn." In effect, every action performed by the citizen is considered to be the intellectual property of large corporations that charge licensing fees. The book uncovers what happens in a world where the free market has commodified everything in the built environment, nature, and even the human body. Sidewalks, moon, sky, rainbows, walls, windows, clothes, bodies- every surface of the world is viewed as a potential ad space, a tool for revenue.

William uses architecture and the urban condition to explore themes of privatization of the public and private sphere, corporate greed, the diminishing division between the physical and artificial realities, and the natural as utopia. 



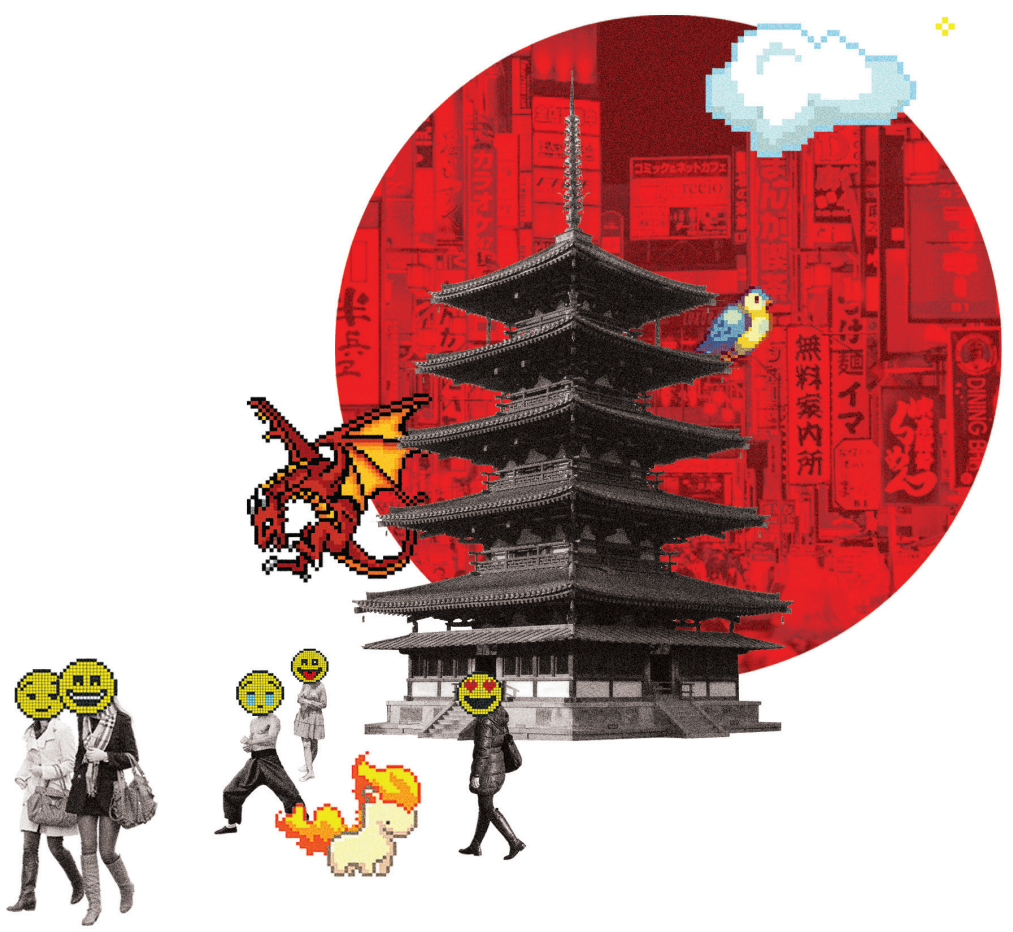

6.0a: Tokyo's ImmaNet 
In the ImmaNet, everything is susceptible to the forces of the free market. As such, there is a total privatization of the public sphere. This is achieved via the thoroughly pervasive and advanced form of the internet, resulting in environments that are constantly bombarded by advertisements. In fact, just finding a blank wall to rest the eyes is a difficult proposition. "Amon found a blank wall to rest his eyes, but it immediately divided into slats and opened like venetian blinds, revealing clear plastic pedestals, each one topped with a miniature mannequin woman reclining on a posture-healing bed."1

Further intensification of pervasive monitoring technologies is achieved via the BodyBank interface that constantly registers every action performed by the user. The Bodybank is described as a system of network sensors and chips implanted invisibly under the skin which detects muscle movements and nerve signals which are then analyzed and sent to Global Action Transaction Authority (GATA) for transaction processing by the respective corporation who owns the action performed. ${ }^{2}$ The BodyBank dissolves the traditional distinction between the public and private spheres. The device results in a space of continual presence and scrutiny by the capitalist regime.

Architectural effects are also used to explore themes of corporate greed. William establishes that class divisions can be reinforced through architecture even in a world where everything is virtually constructed. The getaway residence of Lawrence Barrow IChief
Executive Minister at GATA) is described as a cross between a Buddhist temple and a skyscraper. Standing forty-stories high, the structure is inhabited by the corporate leader, his twenty bodyguards, and servants. The use of traditional Japanese joineryinterlocking wooden beams stacked in a puzzling feat of carpentry- creates a visual juxtaposition against the colorful condominiums in the neighborhood. Natural materials continue in the interior of the building. Rice-straw tatami mats, carpet flooring, paper partitions and cedar wood form a setting in which compelling sensory experiences are achieved without the aid of digital overlays. ${ }^{3}$

In a world of scarcity, wood is an expensive commodity. In fact, Amon (protagonist) states that even the material's digital equivalent isn't cheap. Architecture, using authentic and natural tectonics, becomes a tool for conspicuous consumption that reinforces class distinction. Additionally, opting-out of technology and the absence of digital overlays to achieve luxury is the ultimate act of ostentation.

Parallels can be drawn between Barrow's tower and the Antilia residence in Mumbai. Owned by corporate mogul Mukesh Ambani, this 27-storey double-height levels (60-storey typical) with over 400,000 sf is located in Mumbai only a few kilometers away from the most densely populated slums in the country. A staff of 600 workers is needed to maintain this $\$ 1.0$ Billion private home for Ambani, his wife, and three children. ${ }^{4}$ 
Unlike the traditional vernacular of Barrow's residence, an ultramodern tectonic expression is used to distinguish the tower from the rest of the skyline. Curtain walls, expressive structural columns, continuous glazed surfaces, stacked programming, are used to convey an imperial level of wealth.

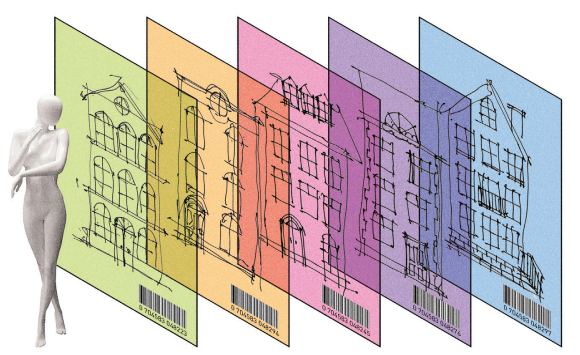

6.0b: Digimake

In a not-to-distant future Tokyo, everything is digitally enhanced to seamlessly integrate with reality. Digimake allows for augmented overlays that pervasively enrich the built environment. Paver tiles are turned into a walking game, walls are rendered into portals, people are transformed into perfectly manicured avatars. The city becomes a digital playground on which its citizens simultaneously engage in multiple layers of realities.

The digital world is indeed inextricably bound to the naked world and separation of the two is an illegal act. Under the governance of GATA, it is a "credi-crime" to look beyond the digital body, onto the naked body. The same is true for environments. The digital environment becomes a veneer that cannot be peeled off to reveal the physical armature. The artificial is perfectly glued to the physical thus normalizing the virtual as the dominant and inescapable state of reality.

This proposition is problematic because it posits a future with a perfect alignment of the artificial and physical, effectively eliminating the duality that currently exists between the two realities. Under such circumstances, the built environment always remains in the background - forsaken at the expense of pervasive digital overlays. The perfect architecture in such a proposition is one that is generic, removed from material tectonics and beauty, efficiently built and simplest to overlay with the virtual skin.

Lastly, it is also important to examine the utopian concepts in "Cash Crash Jubilee". As the story evolves, Amon gradually loses faith in the utopian ambitions of GATA, a government organization that functions more like a corporation to which he devotes his entire working life. And, as the limitations and corruptions of the technocratic regime become evident, Amon clings to his vision of the forest. He dreams of the sky into a mountainous region covered by a forest. Amon romanticizes what the forest has to offer: "There was something awe inspiring about the forest; those tangled, warring canopies, those dark, hidden recesses, and the lurking presence of unseen creatures. Yet it gave him a sense of comfort..." 5 . 
William suggests that a regression into nature- the forest is the only possible hope of an utopia for Amon. It serves as the antithesis of the megapolis. It is a virgin space- unhindered by the draconian influences of control, implemented through technology.

"Cash Crash Jubilee" compellingly constructs a hyperbole of the contemporary megapolis. This fictional dystopia is uncomfortably close to reality; the BodyBank is essentially an exaggeration of surveillance enabled by our smartphones, the ImmaNet is not far removed from the current state of total access and surveillance, and GATA is a regulatory body whose technocratic regime is very much in parallel to the structural workings of today's megacorporations.

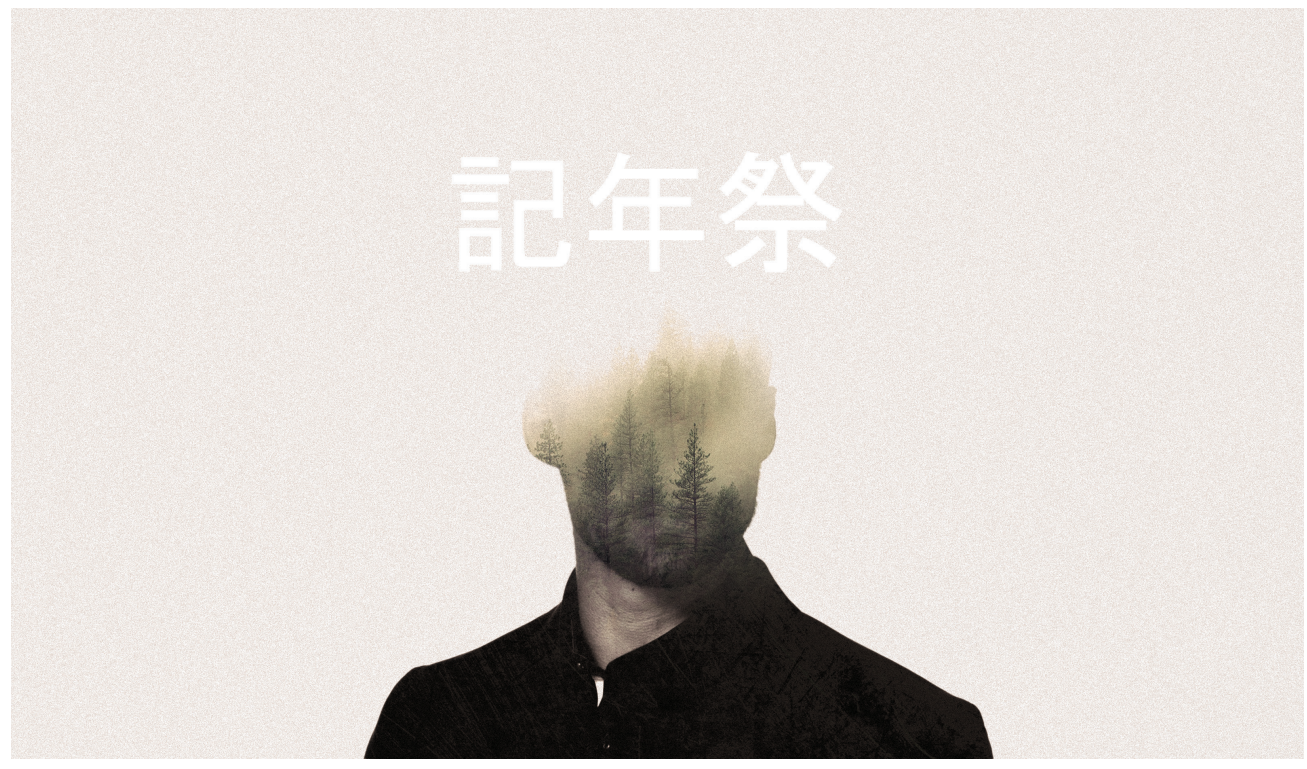




\subsection{Hieronymus Bosch: Garden of Earthly Delights}

Painted in 1515 by Hieronymus Bosch, the center panel of the "Garden of Earthly Delights" depicts a surrealistic and utopian landscape teeming with activity. Bosch uses nature as iconography to convey man's relationship with divinity. Nature; flowers, creatures, marbles and stones are elevated as the celestial typologies of paradise.

The following design exercise explores a condition where, instead of nature, machines are elevated to a state of spirituality. Bosch's painting is re-contextualized into the contemporary condition by investigating man's inseparable and insatiable relationship with technology. 


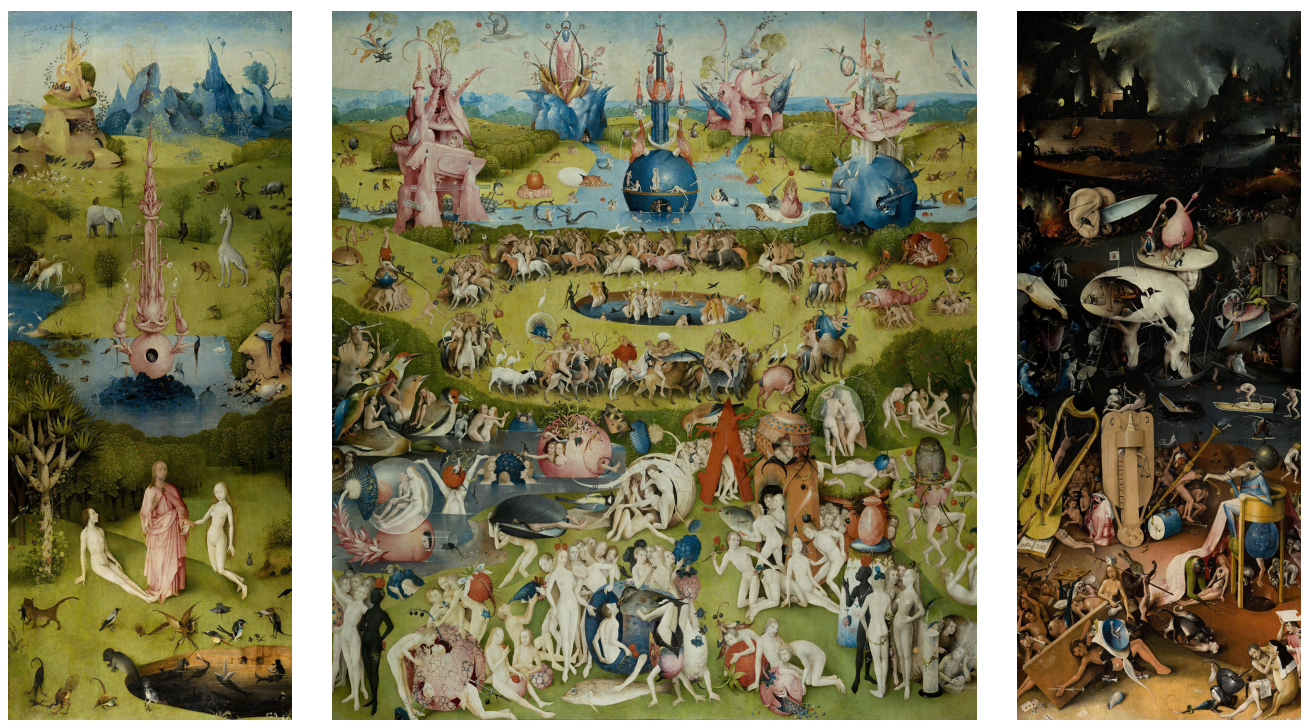

7.0a: Garden of Earthly Delights Trypctic 


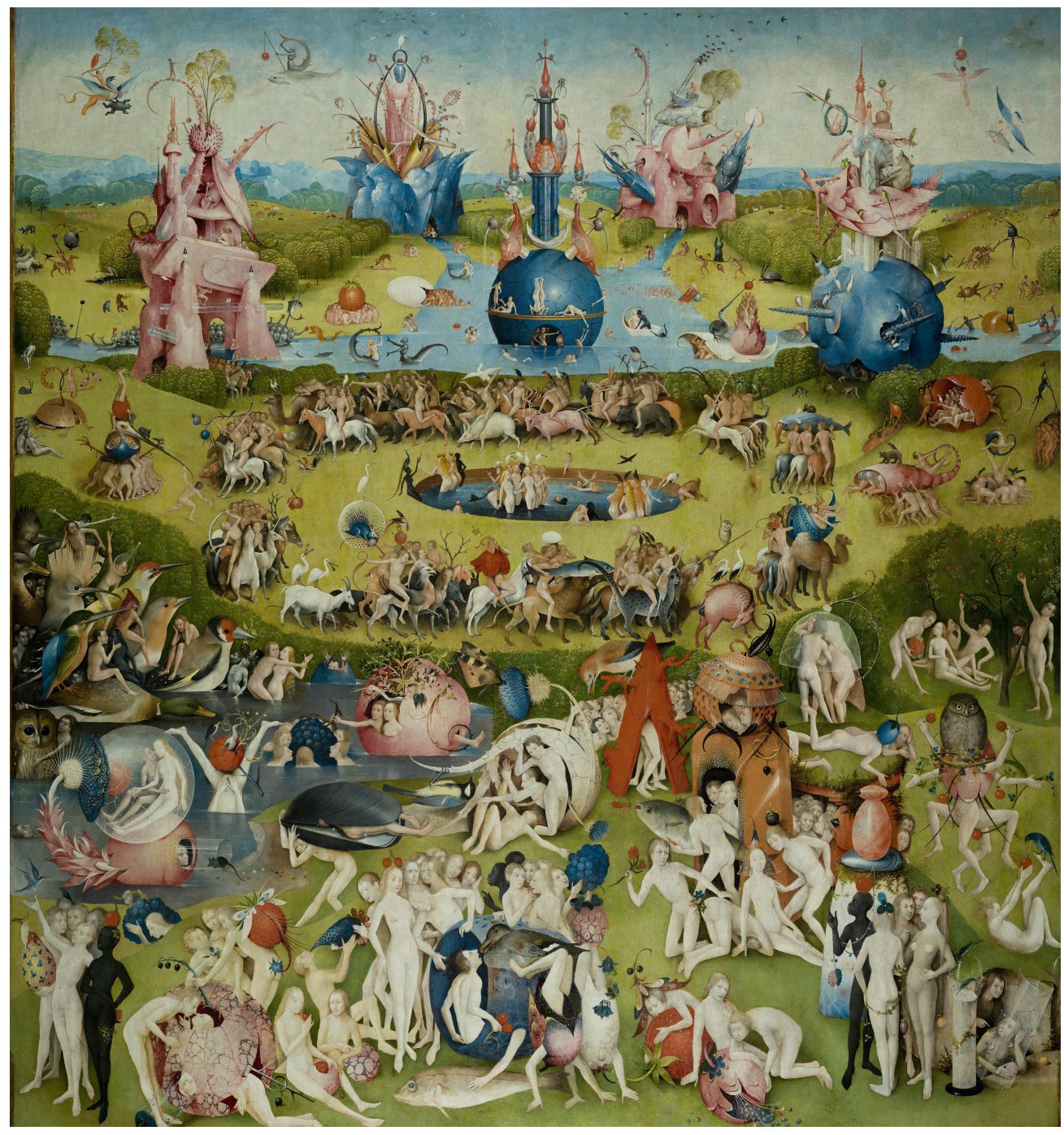

7.0b: Garden of Earthly Delights/ Center Panel 


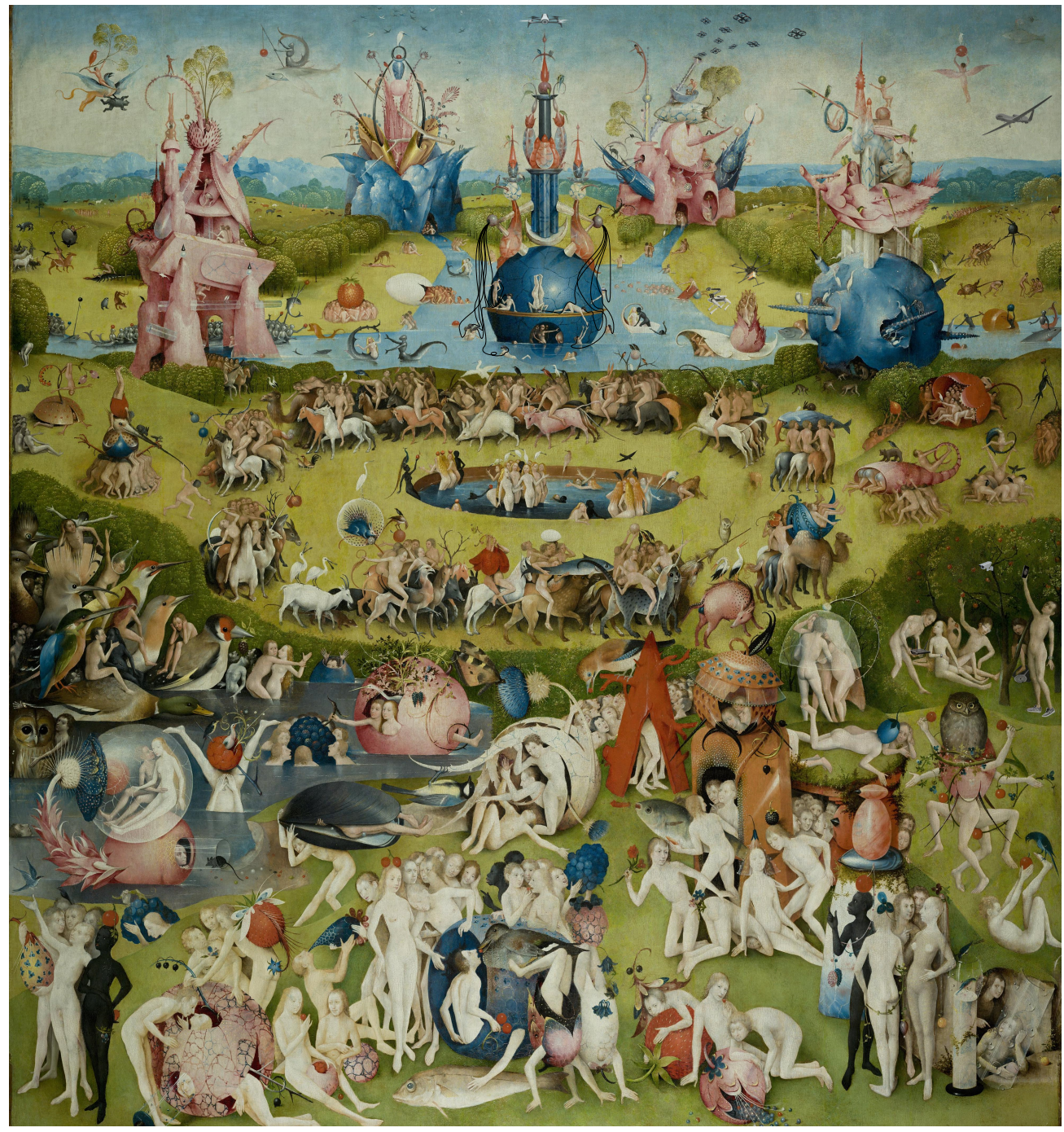

7.0c: Garden of Earthly Delights/ Center Panel Re-imagined 


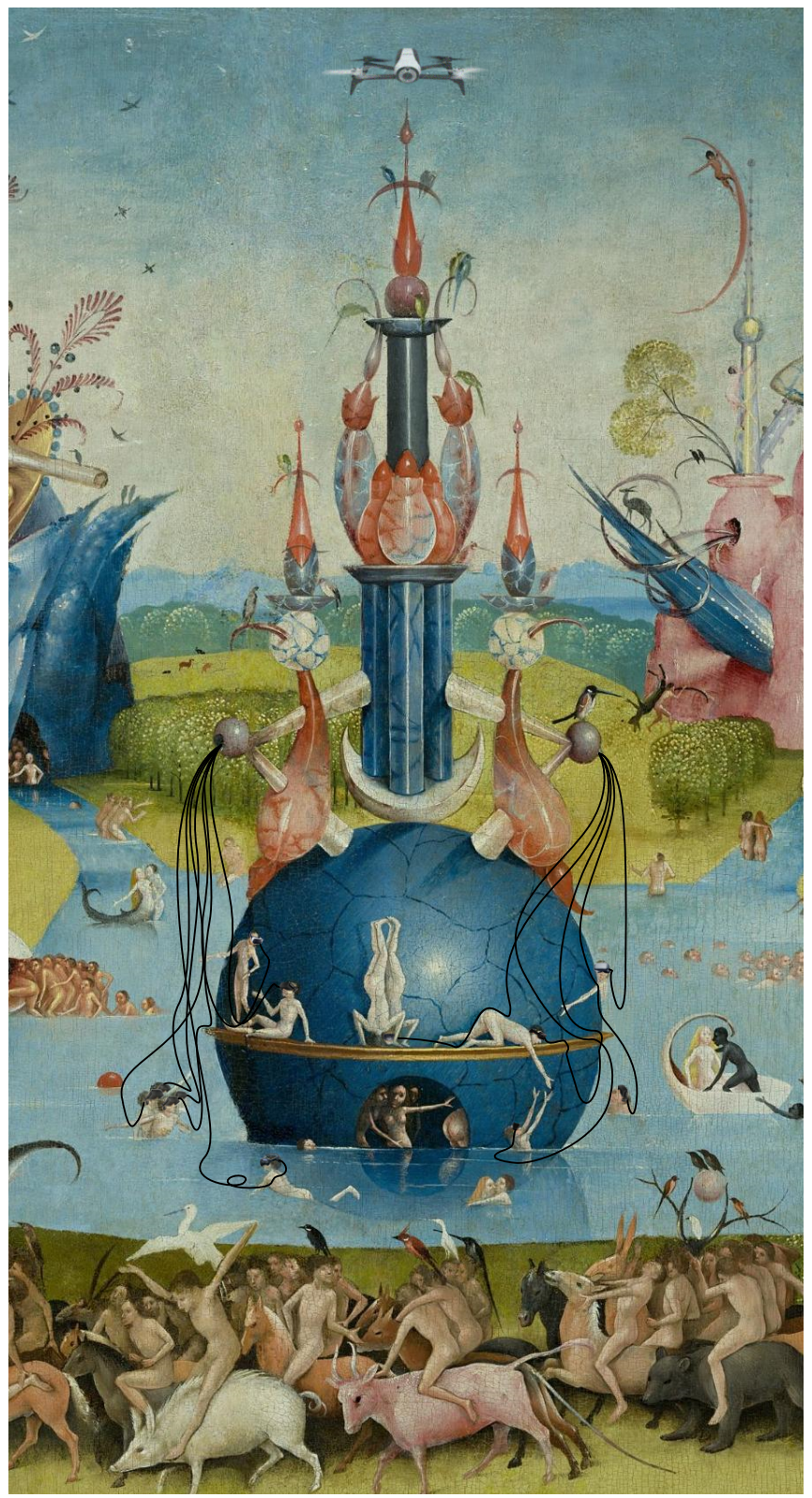

7.0d: Garden of Earthly Delights Detail 01: Re-imagined 


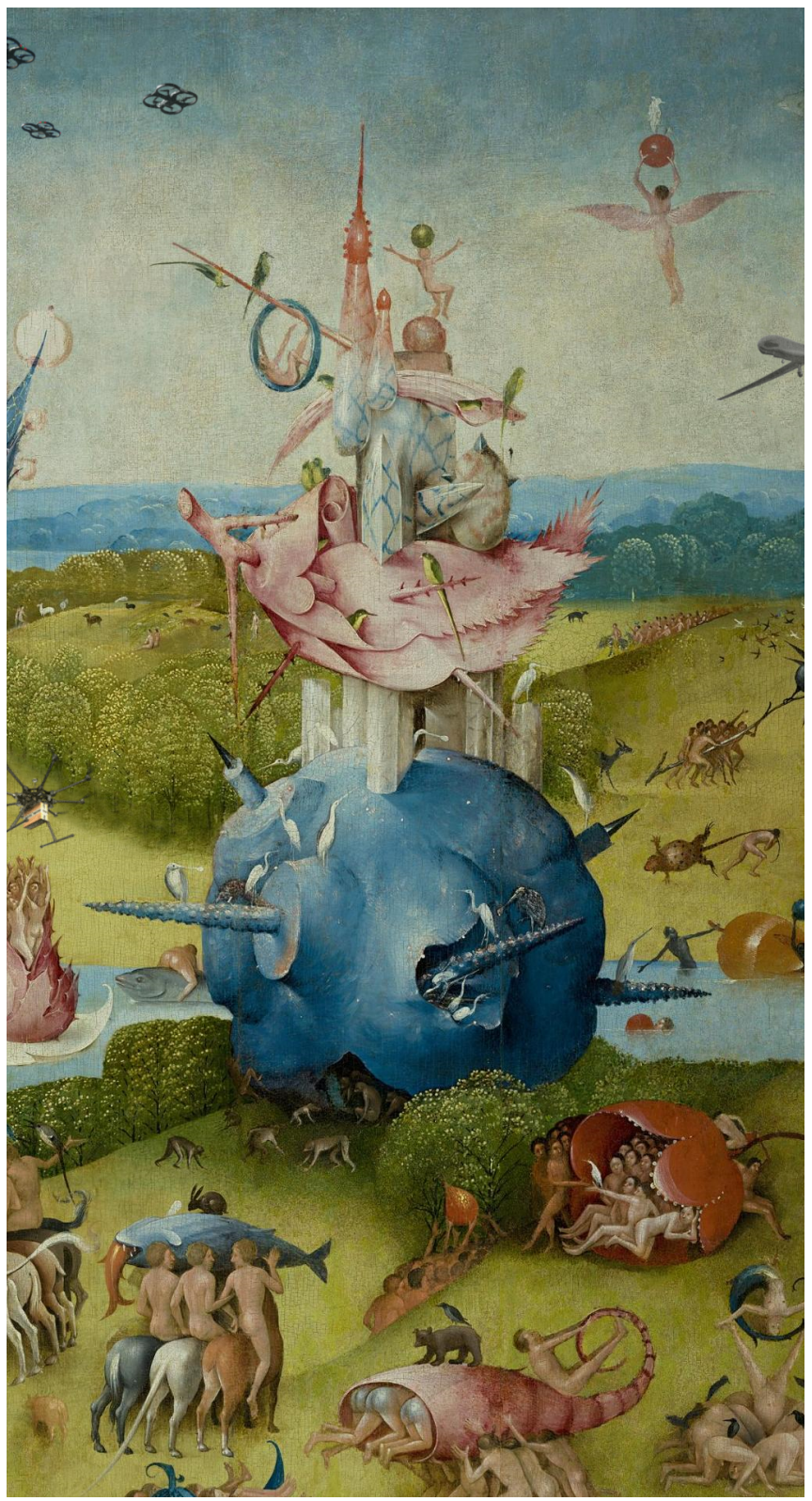

7.0e: Garden of Earthly Delights Detail 02: Re-imagined 


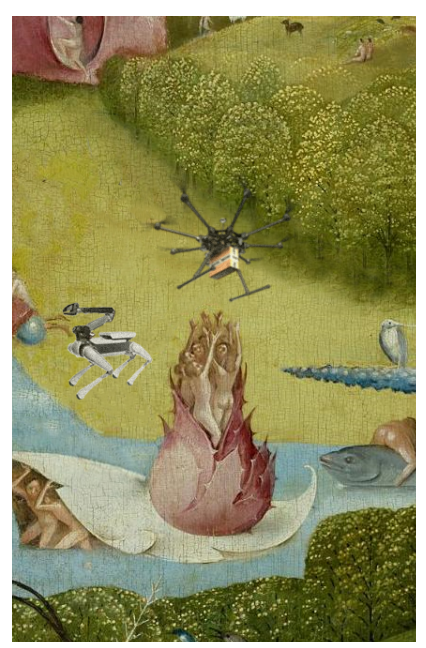

7.0f: Garden of Earthly Delights Detail 03: Re-imagined

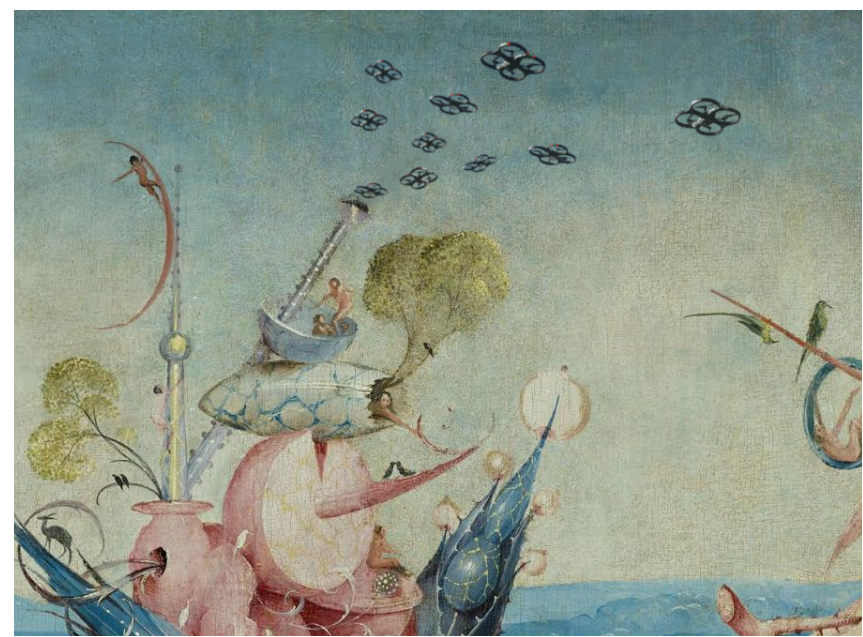

7.0g: Garden of Earthly Delights Detail 04: Re-imagined

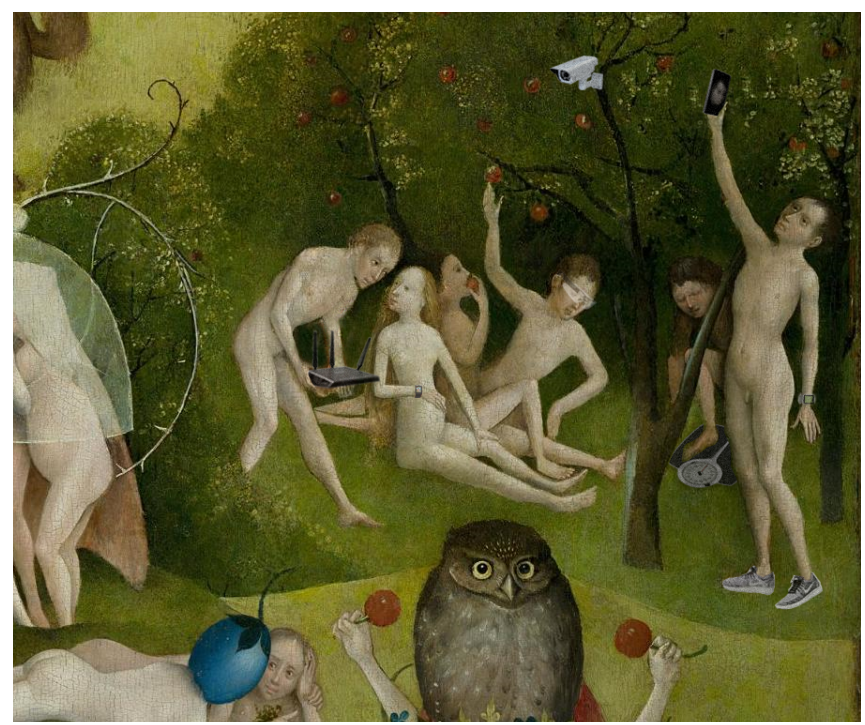

7.0h: Garden of Earthly Delights Detail 04: Re-imagined 


\subsection{Four Futures}

Peter Frase begins "Four Futures: Life After

Capitalism" by noting that capitalism is going to end due to our historic inability to manage an eternal social system while also pointing to the present volatility of the economic and political system. ${ }^{1}$ He observes that capitalism's tendency towards automation has led to unparalleled efficiencies of production that challenge the system's ability to create jobs, and thus sustain the demand for what is being produced. Frase hypothesizes that by means of automation, the economy will no longer require human labour. This emerging condition might not bring the end of labour but has the potential to free us from current exploitative labour structures.

Two different societies emerge. In the first, all people are treated as free and equal beings, with equal rights to wealth. Otherwise, a hierarchical order in which the elites dominate and control the masses and their access to social resources. Four logical combinations arise out of this situation: Resource Abundance, Scarcity, Egalitarianism, and Hierarchy. 



\subsection{Communism: Egalitarianism and Abundance}

Frase's idea of a future of communism speculates that developments in automation combined with alternative energy management can free us from the power structures of labour and scarcity of resources. This leads Frase to poses the question:

"If cheap energy and automation are combined with methods of efficiently fabricating or recycling raw materials, then we have truly left behind 'the economy' as a social mechanism for managing scarcity. What lies over that horizon?"2

In this imaginary future, advancements in fabrication technologies, namely 3D printers have the potential to decentralize production without sacrificing productivity. Labour is minimized, and production becomes the responsibility of collectives or government-run firms, rather than capitalist regimes.

Frase believes that despite the promise of minimal labour and an abundance of resources, this future society will remain un-utopian. He envisions that many kinds of hierarchies will remain, albeit not ones determined by the ability to accumulate capital and money. Instead of money, conflict will be based on hierarchies of status.

Frase's projection about a future of communism is the most optimistic of the four possibilities as it promises a liberation from today's inescapable paradigms of control established by labour structures in capitalism. A future dependent on a decentralized means of production is reminiscent of the technological imperative of the mid-century space age period. In effect, rapid development in consumer products and spaceflight generated an unprecedented optimism and faith in technology. The many large scale, utopian architectural proposals of the 1950's and 60's are emblematic of a cultural belief that technology could solve humanity's greatest issues. This position is problematic because of the dualistic and paradoxical effects of technology. Technology has resulted in better living conditions but only at the expense of an accelerated extraction of resources and the resulting environmental degradation. 


\subsection{Rentism: Hierarchy and Abundance}

Under the conditions of energy abundance and automation, a new synthetic form of economy emerges: rentism: hierarchy and abundance. Frase asserts that the tools of production; machines that enable automation and $3 \mathrm{D}$ printing will be maintained under the control of capitalism. 3D printers, despite allowing a decentralization of production, will be designed by large tech conglomerates that will maintain a continuous cycle of progression, and patents for the objects being printed will be possessed by the same agencies. A future of pervasive 3D printing raises serious issues of copyright. Printing illegally without purchasing the rights to the item will be considered a crime with strict penalties - just as it is today with digital media.

It is undeniable that contemporary laws and regulations that govern copyright violations of digital media such as music, video, and image will evolve concurrently with the $3 D$ printing technology to include the material world of objects.

Frase believes that the elite bourgeois class will maintain power through the structural application of rentism. The rich will passively accept rewards via the tools of production and the application of licensing fees on the things being produced. As noted by Richard Freeman, "who owns the robots owns the world"3. The combination of such control mechanisms will make ownership impossible. Furthermore, Frase, like many others, hypothesizes that a universal guaranteed income enabled by a form of redistribution of money back to the consumers will be a necessary intervention to hold the system together.

Frase's exploration of the concept of ownership under rentism is an accurate and problematic prediction. In effect, the concept of ownership is already going through a mutation as evidenced by the recent growth of sharing economy platforms. Millennials increasingly prefer the ease of access to things and services instead of individual ownership. Despite their socialist ambition at the nascent stage, sharing economy platforms have evolved into tools of capitalism for passive income generation.

\section{D Printing}

Also known as Additive

Manufacturing, 3D

printing is changing the

way things are designed,

made, and used. In the

near future, what will be

sold is not the product

but the codes to make

the products. 3D printers

will invariably be used as

part of ecosystems of tech

conglomerates to eliminate

production and shipping

time, thereby accelerating

consumption rates. 
Frase suspects that the only type of employment that will remain under rentism will be for the creative class; designers and artists will ensure a continuous development of new products, lawyers will fight over patents and copyright infringement, marketing and advertising professionals will safeguard the popularity of licenses, and guards and military personnel will enforce aggressive intellectual property laws. He is also quick to point out that even these sectors of employment are susceptible to the threat of automation.

Speaking of hierarchy, Frase makes the argument that in a state of under employment, the bourgeois elite will hire people to maintain a status of class power. The lower class will be employed by the ruling class for personal services to perpetuate class distinctions and divisions even if automation makes it unnecessary.

Frase presents ideas of hierarchy that are consistent with Thorstein Veblen's theories of class distinction. 20th century economist and sociologist, Veblen in "The Theory of the Leisure Class" argues that class hierarchies are formed through conspicuous consumption and conspicuous leisure. The bourgeoisie is able to maintain social status by openly displaying a life of non-productive activity, and by visibly consuming goods for the value of social power and prestige. ${ }^{4}$ In a future of rentism, the rich, by unnecessarily employing the lower class for redundant labour, can exercise a similar, albeit aggressive, form of conspicuous consumption.

\section{Creative Class}

Term coined by Richard

Florida, a professor at

Rotman at the University of

Toronto. Florida proposes

that under a post-industrial

economy, the new drivers

of wealth are the super-

creative urban core and

creative professionals who

are made up of an emergent

class of knowledge

workers, intellectual, and artists.

In-turn, cities such

as Toronto are attracting

the creative class via the

use of favorable cultural/

lifestyle amenities. The

focus of cities towards a

creative class economy

comes at the expense of the working class who are being marginalized out of the urban core. $^{5}$

Conspicuous Consumption

The acquisition of luxury

goods and services to

publicly display economic

status is easier than ever

in the age of Instagram.

Affluence in lifestyle is

documented via digital

mediums much like they

were with oil paintings

commissioned by European

elites during the 17 th \&

18 th century. 


\subsection{Socialism: Egalitarianism and Scarcity}

In his third version of the future, Frase poses the critical question “... what if energy and resources remain scarce?". In a world of resource scarcity, the control of production is achieved through heavy handed economic interventions imposed by the government. Contrary to capitalism, a socialist form of governing body is in place for the planning and management of consumption, not production. The population is liberated from labour through mechanisms such as universal basic income yet still isn't able to consume freely.

Referring to Michael Lowy, Frase notes that a type of "global democratic planning" would result in a rational planning for the global imperative of resource scarcity and sustainability. ${ }^{6}$ The global initiatives for carbon emissions are used as an example of a contemporary coordinating mechanism that seeks to curb environmental destruction.

Frase foresees that conflicts will be inevitable under conditions of scarcity. Struggles between those who want to preserve the environment and those who prefer material consumption (instead of conflicts of class) will dominate this future.

This prediction presents a plausible future under the current accelerated consumption of resources. The Kyoto Protocol is an example of a socialist intervention, initiated by the United Nations, that aims to reduce climate damaging emissions through government legislation. Unfortunately, climate accords also exemplify the limitations of global agreements.
Despite an undeniable need for intervention, the US has yet to commit to any reduction of pollution.

Instead of a global form of governance, an alternate form of capitalism will shift to adapt to resource scarcity. Conditions of scarcity combined with an steady infiltration of capitalism into governance will most likely result in an oligopoly. A few multinational corporations will control the production and supply of limited material goods. There is of course the risk of collusion. OPEC is an example of a top oligopoly that controls oil la limited resourcel production and prices in the global economy. 


\subsection{Exterminism: Hierarchy and Scarcity}

The one percent who own the world's monetary wealth already live under conditions of socialism as virtually all goods and leisure are already accessible to them. Frase quotes William Gibson who remarked, "...the future is already here; it's just unevenly distributed." 7

In this version of the future, he examines a scenario under which automation removes the need for the proletariat's labour but is unable to maintain a base level of consumption. In effect, automation has the potential to be a dangerous mode of production by which the elite, those who own the technologies, can neglect the needs of the masses. This is a future in which the rich do not depend on the service of labour from the poor. The relationship of co-dependence between the workers and capitalist is removed, and the proletariat becomes unnecessary collateral.

Under scarcity of labour and resources, the rich will be under constant threat of expropriation by the impoverished. Frase concludes that the rich will retreat into enclave societies- a term coined by Bryan Turner that is used to describe a society in which "...governments and other agencies seek to regulate spaces and where necessary, immobilize flows of people goods and services." ${ }^{8}$ In effect, the elite already live in gated communities protected by structural barriers that are both physical and political.

If strategies of enclosure fail to contain revolts by the poor, a final solution is possible: exterminism. A genocidal war against the superfluous proletariat population can ensure that the rich live without danger. Frase points to current military practices that use algorithms that automate the process of identifying and carrying out drone strikes to kill terrorists. This practice is problematic as it demonstrates automation's ability for massive consequence by the one percent who own the automation technologies.
Collateral

Leaving automation in the hands of capitalist hyperempires could result in the working class becoming collateral; a surplus population that is of no use to the evolved economy. A post-work economy is a necessary condition for the preservation of the threatened proletariat.

\section{Enclave Societies}

An enclave can be defined as the structural and physical barriers to keep the poor from infringing on the livelihood of the rich. In a future dominated by technological hyperempires, what happens when a non-consumer enters the physical space of highly territorialized and private zones of consumption? 
Exterminism presents the darkest of all possibilities for an automated future. Frase constructs a convincing scenario in which the end game of the elite turns from repression to eradication of the poor. In effect, repressive structural effects of an enclave societyare prevalent in contemporary reality. The segmentation of ethnic minorities into communities under hypersurveillance enabled by cutting-edge automated monitoring technologies is commonplace in ghettos in many cities across America.

Historically, one of the main motivations of genocides is to "Eliminate a real or potential threat". When one group is convinced that its existence is in jeopardy from another group, it may feel that they have no other choice but to destroy the competing group. Jacques Attali in "A Brief History of the Future" discusses the emergence of a future dominated by technology conglomerates. Five of the ten richest people in the world are men who are in the business of technology. ${ }^{9}$ Frase's dystopian conclusion of a genocide facilitated by automation is not that implausible. 


\subsection{Insights on Future Scenarios}

Frase concedes that these are four trajectories of the future that negate many complexities of how society will evolve. Communism, rentism, socialism, and exterminism are simplified lines of flight that predict the future of humanity at the present impasse of automation. These examinations of the future present a timely discourse so that we can "...avoid setting off in the wrong direction."

Contrary to Frase's position, I predict that capitalism will not end. Capitalism is a resilient and global system that is not likely to collapse in the future. Instead, established structures of production will shift to deal with resource scarcity. China, through governmental investment is now leading research and development of sustainable technologies. ${ }^{10}$ Scarcity of fossil fuels combined with a decreasing demand already has the energy sector moving into the production sustainable technologies.

The destabilizing effects of automation are undeniable and are only going to accelerate in the near future. Consequently, there is an increasing traction towards the concept of universal basic income from both government and private sector. Thus, a coordinated intervention from both parties will be necessary to transition society into a postwork world in order to avoid a collapse of the economy and or a full-on genocide. This will likely be some combination of the strategies discussed by Frase in the four distinctive futures.
Genocide

A fully automated economy
risks making the working
class not just collateral
but worthless. Without a
redistribution of wealth via
automation, the economic
disparity between the rich
and the poor will increase
to alarming levels. The rich
might wage a genocidal war
against the poor to protect
the growing threat of revolt.

A fully automated economy class not just collateral but worthless. Without a redistribution of wealth via automation, the economic disparity between the rich and the poor will increase to alarming levels. The rich might wage a genocidal war the growing threat of revolt. 


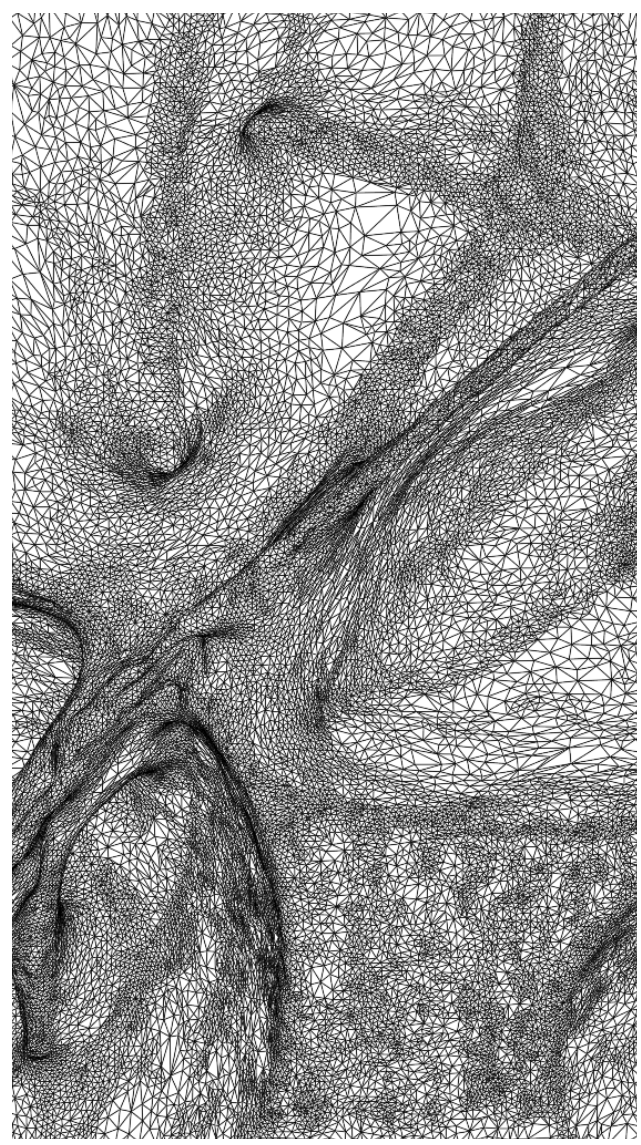

8.5a: Photogrammetry of Artefact 


\subsection{Return to Critical Architecture}

This chapter will attempt to extrapolate the characteristics of a critical architecture and to unravel its capacity to challenge the hegemonic structures of capitalism. Felicity D Scott's “Architecture or Techno-Utopia: Politics after Modernism" and Franco Berardi's "After the Future" will be analyzed to examine architecture's current post-critical state, its relation to the semiotic structures of capitalism, and its capacity for political engagement through opposition and subversion. Insights will be used to develop a polemic against the hyperempire. 



\subsection{Post-critical}

Scott uses to the World Trade Center Site Memorial Competition initiated by the Lower Manhattan Development Corporation (LMDC) to express his general concern about the lack of ideas embodied in the submissions to what was the largest design competition in history. She asserts that architecture now operates within a post-critical state. In effect, today's architectural hegemony is described by Scott as lacking political, ethical and critical engagement. She believes that proposals for the LMDC failed to address contemporary concerns, instead making use of clichéd social tropes: heroes, monuments, rebirth, public space, visionary architecture, defensible space, spiritual and symbolic legibility.

Berardi would attribute the lack of critical architecture in the WTC competition by asserting that capitalism has destroyed our capacity for recomposition. For Berardi, the established structures of labour via the use of digital infrastructures, have become too complex for us to untangle. In effect, these oppressive new forms of exploitation have resulted in a fragmented society, making a social consciousness impossible. ${ }^{2}$

\section{Insights}

As key participatory agents of capitalism, architects operate within a post-critical condition in which passivity reigns, and critical thought is absent. Instead of ideology, the contemporary discipline of architecture is engaged in producing only simulacra: clichéd social tropes, grandiose, and symbolic architecture.

Today's architectural practices miss the opportunity for political engagement. In effect, examining the cultural economic logic governing the established standards for producing architecture in the contemporary reality reveals a hyper-rational logic that pertains to be as universal as the economic language of capitalism. The resulting expression makes for an architecture without the need for architects, in which the market expression dominates.

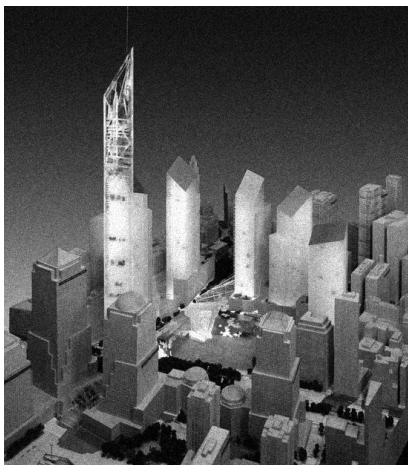

9.1a: WTC Winning Proposal

Out of over 5,200 participants for the design of the WTC memorial, only 8 proposals made the final list. These were characterized by iconic gestures that employed themes of absence, light, inversion, and memory. Entries included; Votives in Suspension, Suspending Memory, Lower Waters, Passages of Light: Memorial Cloud, Inversion of Cloud, Garden of Lights, Dual Memory, and the winning proposal: Reflecting Absence. ${ }^{3}$

Recomposition

Social recomposition is the cultural process that unifies the social body through the fusion of imaginary and cultural flows. ${ }^{4}$ 


\subsection{Semiotics}

Berardi refers to Christian Marazzi who argues that "Language and capital tighten their relationship: language becomes the economic resource, the productive force, and the market". ${ }^{5}$ Semiotics and capital are invariably intertwined. Viewed through the lens of semiotics, architecture is an integrated tool of the capital flow that reinforces the paradigms of control; the built environment of the city is designed to produce a hyperreality through which the pervasive simulacra has dissolved our capacity for critical thought.

Referring to "Equipments of Power", a conversation between Guttari, Deleuze, and Foucault in the 1970's, Scott takes a similar position to Berardi when examining signs and architecture. She notes that "The city emerges in this discussion as a paradigm of an unstable or variable coding. with architecture cast as a sort of eruption of signs of power."' Scott elaborates on the topic of signs by suggesting that the discipline of architecture must understand the role it plays in constructing the equipment of power.

\section{Insights}

Architecture is semio-capital. It is the processes, codes, and institutional structures of capitalism materialized. Arguably, the city only exists to reinforce the institutional controls of capitalism. The ability to understand the semiotics of capitalism is the only way to disrupt its codes, to challenge current conditions, "to make language shake."

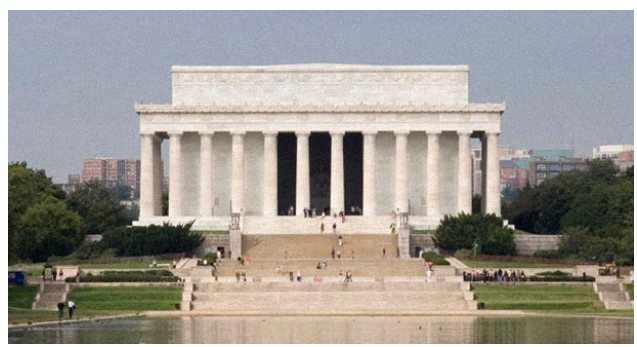

9.2b: Lincoln Memorial
Semio-capital

“Semio-capital is in a crisis of overproduction, but the form of this crisis is not only economic but also psychopathic. Semiocapital, in fact, is not about the production of material goods, but about the production of psychic stimulation. The mental environment is saturated by signs that create a sort of continuous excitation, a permanent electrocution, which leads the individual as well as the collective mind to a state of collapse".? -Franco Berardi 


\subsection{Political Engagement}

Scott uses Rem Koolhaas' 1972 Architectural

Association thesis (together with Madelon

Vreisendorp, Elia Zenghelis, and Zoe Zenghelis)

"Exodus, or the Voluntary Prisoners of Architecture" as a counterpoint to the LMDC proposals for the World Trade Centre Site Memorial Competition. The contemporary practice of architecture is argued as post-critical; post-theoretical, and post-political. She examines the ambivalence of today's post critical condition to call for a return to a discipline that plays an active role in the engagement of social commentary. This is possible through a critical opposition.

Scott makes use of historical precedents to articulate architecture's capacity to operate within the critical. Koolhaas' thesis proposes a hypothetical scenario of London in which the inhabitants, from the bad half of the city, undertake a mass migration to the good half. In an effort to contain the undesired exodus, the bad half make "...savage use of architecture." $\mathrm{A}$ wall is built around the good area of the city rendering it inaccessible. Instead of division, the wall becomes the subject of desire. The new metropolitain strip is an internalized utopian community in which monuments and collective programs generate a new hedonistic urban culture.

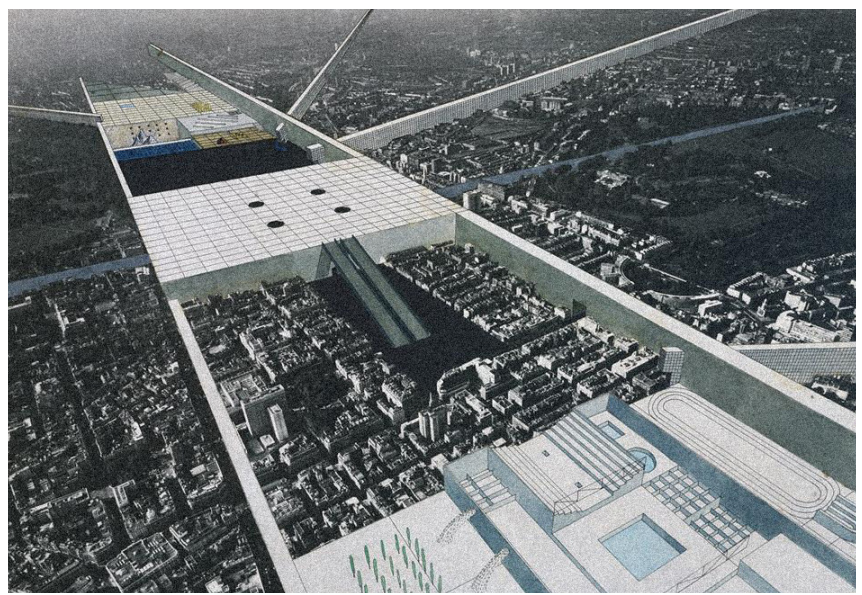

9.3c: Exodus, or the Voluntary Prisoners of Architecture

\section{Critical Design}

A term used to describe speculative design

strategies that are used to challenge the established, and normalized culture.

Critical designs make use of subversion, humor, and irony to reveal the lack of emotional and psychological experiences offered by everyday objects and spaces. ${ }^{10}$ 


\section{Insights}

"Exodus" presents a withdrawal from the city: an exit from the social, economic, spatial, and other pervasive controls of capitalism that dominate contemporary urban life. The project demonstrates a critical and subversive strategy that attempts for the dissolution of the city as an institution of capitalism. Exodus operates as a critical opposition to the hegemonic formations of the city.

Characteristics of Exodus include: new alternative social formations, collective facilities for individual desires, and the removal of undesirable conditions of urban life.

Exodus can be described as what Berardi calls a singularity; a withdrawal and building of nontemporary autonomous zones. Berardi envisions a future under which communities will abandon existing institutions, and instead create their own networks, new modes of wealth distribution, sharing of goods and services, and a liberation of time for the development of culture, pleasure, and affection. Berardi further elaborates that such singularities are zones of human resistance what will act against the hegemony of capitalism.

In effect, Scott and Berardi develop very similar ideas of political engagement against power. Albeit, Berardi's sentiments towards social recomposition are more nihilistic than Scott's; referring to suicide as the most efficient form of political action against power. 


\subsection{Government as Leading Innovation}

Automation is predicted to evolve from the algorithmic phase, followed by augmentation, and finally autonomy in the next 20 years. It is projected that up to $30 \%$ of jobs could be automated by 2030. 'As countries shift to a knowledge economy, governments aggressively fund sectors such as advanced manufacturing, agri-food, clean technology, digital industries, health and biosciences, and clean resources. ${ }^{2}$ Ironically, this creates a paradoxical condition in which investments generate new types of jobs for the well-educated but displaces many of the existing ones which the working-class depends on.

This script is already playing out across many cities around the world that are actively attracting the creative class by pushing for employment growth in the high-skilled technology sector. In 2017, the city of Toronto saw almost 30,000 jobs created in the tech industry. A total of more than 241,000 tech workers are now employed in the downtown core. That's up $42 \%$ over the past five years. ${ }^{3}$ 
Unfortunately, this formula for urban growth has been proven to: mostly benefit the already rich; fuel out-of-control property speculation; gentrification and inequality by displacing long-term residents out of the urban core. ${ }^{4}$

Automation's impact on employment will unquestionably require a massive government intervention to anticipate and adapt to the emergence of a post-work reality. Cities need to devise more inclusive and humanistic solutions that guarantee the well-being of the discarded working class. 


\subsection{Work Progress Administration}

During the great depression of the 1930's, the Work Progress Administration (WPA) provided stable employment to many Americans. At its peak, this government campaign employed over 8.5 million people. WPA provided work to millions of (mostly) unskilled workers for public works projects including the construction of bridges, parks, roads, and public buildings. Legacy projects include the Griffith Observatory in Los Angeles and the Midway International Airport in Chicago.

The WPA, through Federal Project Number One, also provided employment for over 40,000 cultural workers that were involved in everything from music, theatre, murals, paintings, tourism etc. The initiative employed musicians, artists, writers, actors, directors etc. Notable artists that emerged from WPA programs include: Jackson Pollock, Mark Rothko, Willem de Kooning, Lee Krasner. ${ }^{5}$

\section{Insights}

The WPA was a government intervention with positive and lasting impacts for infrastructure and culture in the US during a time of major economic and social turbulence. The destabilizing effects of automation will invariably necessitate a similar government intervention to anticipate the emergence of a postwork reality. Common side effects of unemployment include loneliness, at an individual level and the hollowing out of community pride. In the absence of full employment, a massive WPA-like government intervention will be necessary to preserve virtues of responsibility, agency, and industriousness while establishing platforms for community engagement.

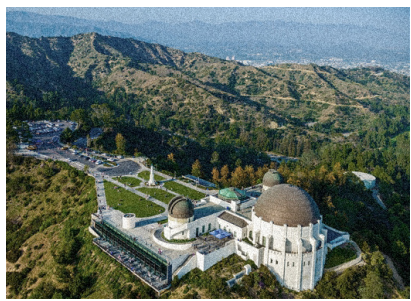

10.1a: Griffith Observatory

Designed in the Art Deco style by John C. Austin, the Griffith Observatory was completed in 1935. Using Greek classical orders, the edifice was built as a monument to last. Since it's opening, this free-admission civic building has seen over 81 million visitors.

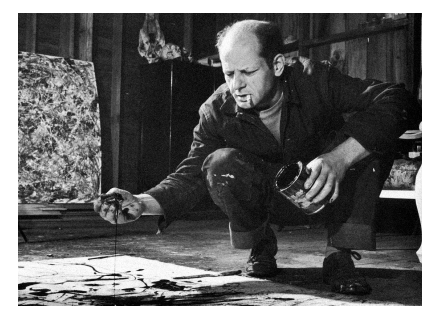

\section{1b: Jackson Pollock}

The WPA provided Jackson Pollock with a necessary source of income during the great depression. This support allowed Pollock to craft and develop the uniquely personal style of his later paintings. 


\subsection{Semiopolitical to Semiosocial}

In "After the Future", Berardi uses the term semiopolitcal to examine the relationship between semiotics and the institutional structures of capitalism. Quoting Christian Marrazzi, he notes that “... language and capital tighten their relationship: language becomes the economic resource, the productive force, and the market". ${ }^{6}$ In effect, the built environment of the city is a semiopolitcal infrastructure of capitalism that "shapes our societies into individualistic, carbonbased, competitive forms..."7

Technology is used by capitalism for short-term gains, typically operating and developing without any consideration for the well-being of society. The rapid expansion of technology under capitalism constrains its potential to achieve lasting societal impacts. In the contemporary landscape, technology is first-and-foremost a vehicle for generating profit and controlling workers. An alternative approach is the development of technology with cultural intentions; choosing to develop technologies for social change challenges the technological hegemony of capitalism.

Srnicek calls for a greater democratic control over the design and implementation of infrastructure and technologies. He notes that historically, governments have played a critical role in the development of longterm, high-risk, or mission-oriented projects. Innovations arising from the government sector financing such as: the Internet, sustainable technologies, nanotech, microprocessor, touchscreen, battery tech, and GPS have led to major innovative and long-lasting changes. ${ }^{8}$

\section{Insights}

A critical architecture developed through the democratic government sector has the potential to challenge the semiopolitical infrastructures of capitalism while also influencing the direction of the built environment. Freed from the economic constraints of capitalism, architecture can be used as a mission oriented project to achieve long-lasting social change. The development of synthetic architectural typologies for a post-work society will create neighborhoods for social good and civic engagement instead of just neighborhoods for consumerism. 


\subsection{Monuments to the Future}

The etymology of the word monument is rooted in the Greek term mnemosynon and the Latin word moneo, which means: to remind, advise, or warn - suggesting that monuments allow us to see the past in order to anticipate the future.' Typically built to commemorate an important person or event, monuments are often located at key geographical sites. Such artefacts are rich with language that delineates cultural aspirations, historic roots, structures of power, cultural heritage etc. Furthermore, institutions such as UNESCO's World Heritage Site program and the World Monuments Fund are involved in the preservation of history; dedicated to protecting and preserving relics of the past that have natural and cultural significance.

A Monument to the Future proposes the preservation of a utopian idea in the face of an uncertain future. A Monument to the Future is symbolic as it represents potential: the promise of an automated economy in which humanity is liberated from labour, combined with the 
development of infrastructure and technologies that are used to expand our freedoms.

As explored earlier, we are crossing a threshold of automation that is going to have massive technological, social, cultural, and political consequences. Scenarios that have been explored in the previous chapters outline a wide range of possibilities for an automated future. At one end of the spectrum, automation can bring us to the liberation from the coercive structures of labour, while at the other is an accelerated form of capitalist exploitation that can potentially lead to the extermination of the proletariat. Proactive measures are needed so that we avoid setting off in the wrong direction. The future cannot be left in the hands of capitalist hyperempires.

Capitalism produces technologies as a vehicle for generating profit and controlling workers.

The construction of the built environment by private companies is no different. Increasingly, developments are designed for the goal of 
speculative financial gains and little effort is made toward civic responsibility. An alternative approach is the development of socially useful goods through political intent. Mission-oriented monuments can challenge the technological hegemony of capitalism. A greater democratic control over the design and implementation of infrastructure and technologies can ensure a greater control over an intended direction for the future. 



\subsection{Synthetic Typologies for a Post-work Future}

Synthetic architectural typologies are deployed as monuments to simultaneously challenge present urban conditions and propose alternative futures for a post-work society. Typologies of culture, housing, institution, and recreation will be designed to anticipate the conditions of a post-work world.

These monuments operate as singularities that offer a critique of existing urban frameworks; functioning as zones of human resistance against the hegemony of capitalism. Ultimately, Monuments to a Post-Work World facilitate a recomposition of society through political engagement through architecture, while challenging the current semiopolitical infrastructures of capitalism. In effect, these interventions propose a slow recomposition from within; not calling for a violent overthrow of capitalism, but instead proposing a realignment of capitalism toward the production of social good.

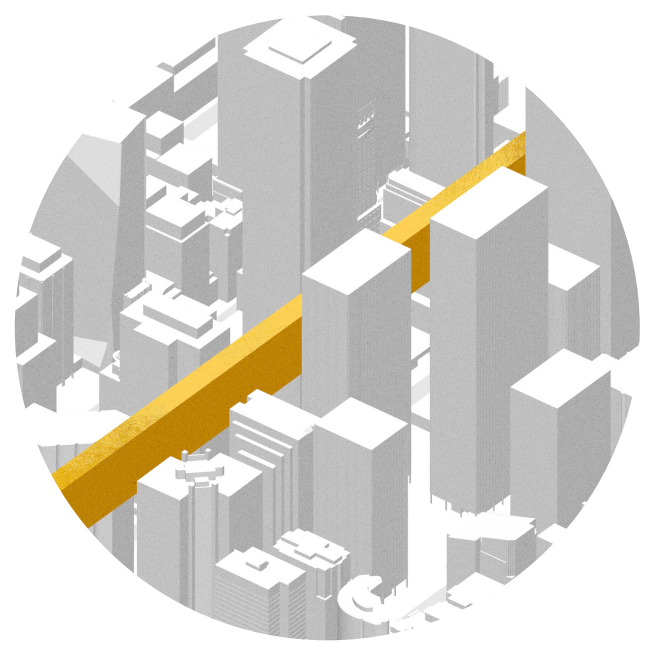

Synthetic

An irresistible simulacrum accomplished through the combination of concepts from seemingly different categories. The inauthentic combination achieves a maximum pleasure effect through an alternative reality that is more real than the real.

Singularity

"By the world singularity, I mean an agency that does not follow any rule of conformity or repetition, and is not framed in any historical necessity or sequential understanding of history-it is an emergent, self-creative process". ${ }^{2}$ 


\section{2 [1] Criticism Through Strategic Insertion}

Synthetic architectural monuments are strategically inserted at key points across the contemporary city. Monuments are erected in contested territories; zones within the metropolis that will undergo major paradigm shifts with the advent of full automation. The city of Toronto is the testing ground for the implementation of such a mission-oriented project. But synthetic typologies for a post-work future are designed to be inserted in any major metropolis.

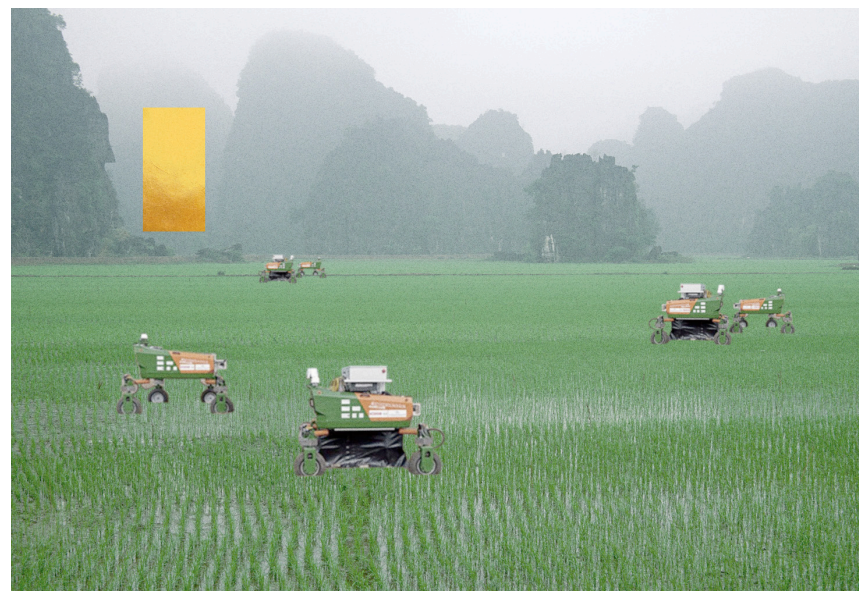

11.2b: Maker Space
Strategic Insertion

In a fully automated production of agriculture, a maker space is inserted in the rice fields of rural Vietnam, allowing farmers to explore a life of craft instead of labour. 


\section{3 [2] Polemic Through Morphology \& Program}

Morphologies of the synthetic typologies work in opposition to the existing semio-capital infrastructure into which they are introduced. A confrontational architectural language in the form of monuments are used to critically examine current conditions, to disrupt the hegemonic codes of power, "...to make language shake." ${ }^{3}$

Inside the various monuments, residents are presented with post-work realities that enable new subjectivities. Programs that are designed for collectivity facilitate the possibility for social consciousness through which a recomposition is possible.

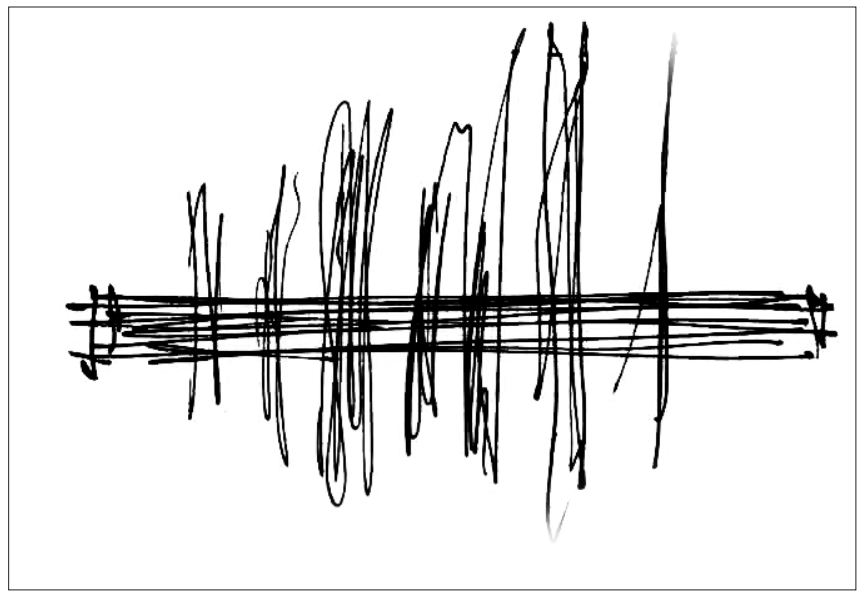

Confrontational Morphology

A horizontal morphology

challenges vertical and

hierarchical constructs of

the modern metropolis (i.e. skyscrapers as symbols of capitalism). The structure serves as an Iconoclastic monument to the future. 


\section{4 [3] Strategy of Withdrawal}

"Exodus, or the Voluntary Prisoners of Architecture" operates as a singularity; an autonomous condition within a larger city. In Exodus the wall is used as a monument loaded with meaning; it embodies a paradoxical condition of freedom through voluntary imprisonment. A similar strategy is applied to the Monuments for a Post-Work World. Synthetic typologies enable a withdrawal for citizens from the present social, economic, and spatial relations of capitalism.

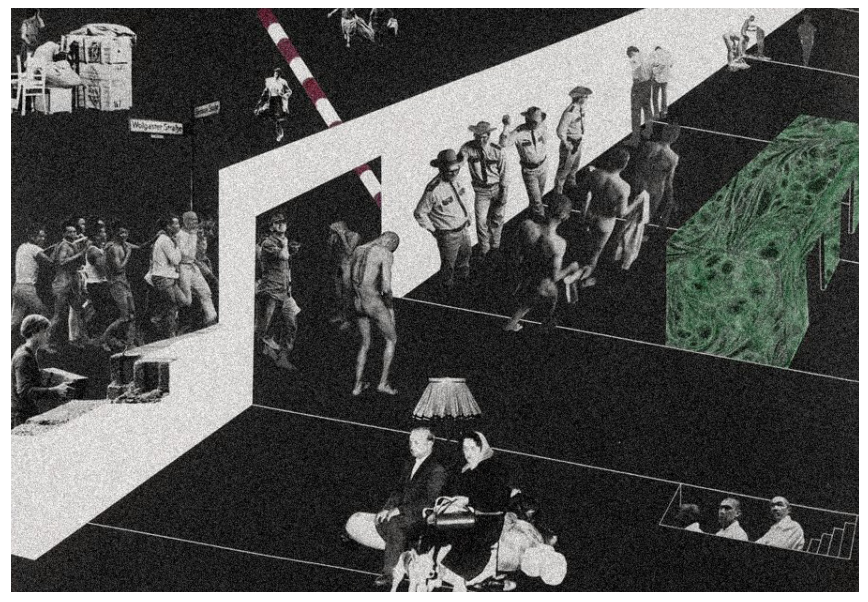

11.4d: Exodus
Withdrawal

Removing oneself from the churn of everyday life helps to provide catharses that enable the establishment of new ways of thinking, feeling, and finding perspectives in our lives. 
12.0

Monument to

Culture 



\subsection{Monument to Culture}

The intersection of King and Bay streets has long been synonymous with corporate Canada. Considered the epicenter of the country's finance industry, the district is filled with gleaming modernist glass towers housing a wide variety of banking companies, corporate headquarters, legal and accounting firms, insurance companies, stockbrokers, and advertising and marketing firms, etc.

Placed along King Street West, at the intersection of Bay, and spanning through the center of the financial district, this typology anticipates the exodus of the financial district as a result of a fully-automated production of wealth. Instead of capital, the financial district can become the epicenter for the production of culture.
As stated by Nieuwenhuys, "The only activity that will remain beyond automation is the unique act of imagination - by which a human being is distinguished." As such, a long horizontal bar floating high above the street creates an architecture of liberation that works in opposition to the hierarchical verticality of the office tower typology. Within are programs that facilitate and promote communal creativity, virtues of independence, ability for mastery, and a sense of purpose.

The internal conditions induce craftsmanship and artistry; skills that will enable people to live as cultural producers instead of instruments of consumer capital. The monument to culture is a landscape for the flaneur. Citizens live in a state of play and self-discovery for the pursuit of a life of poetry.

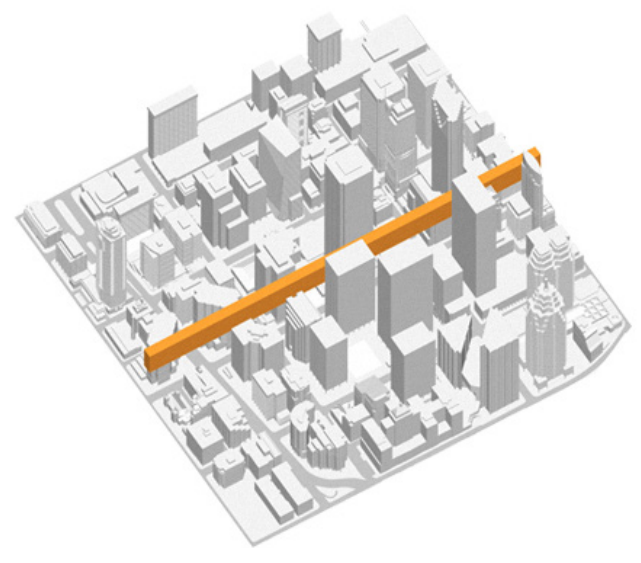




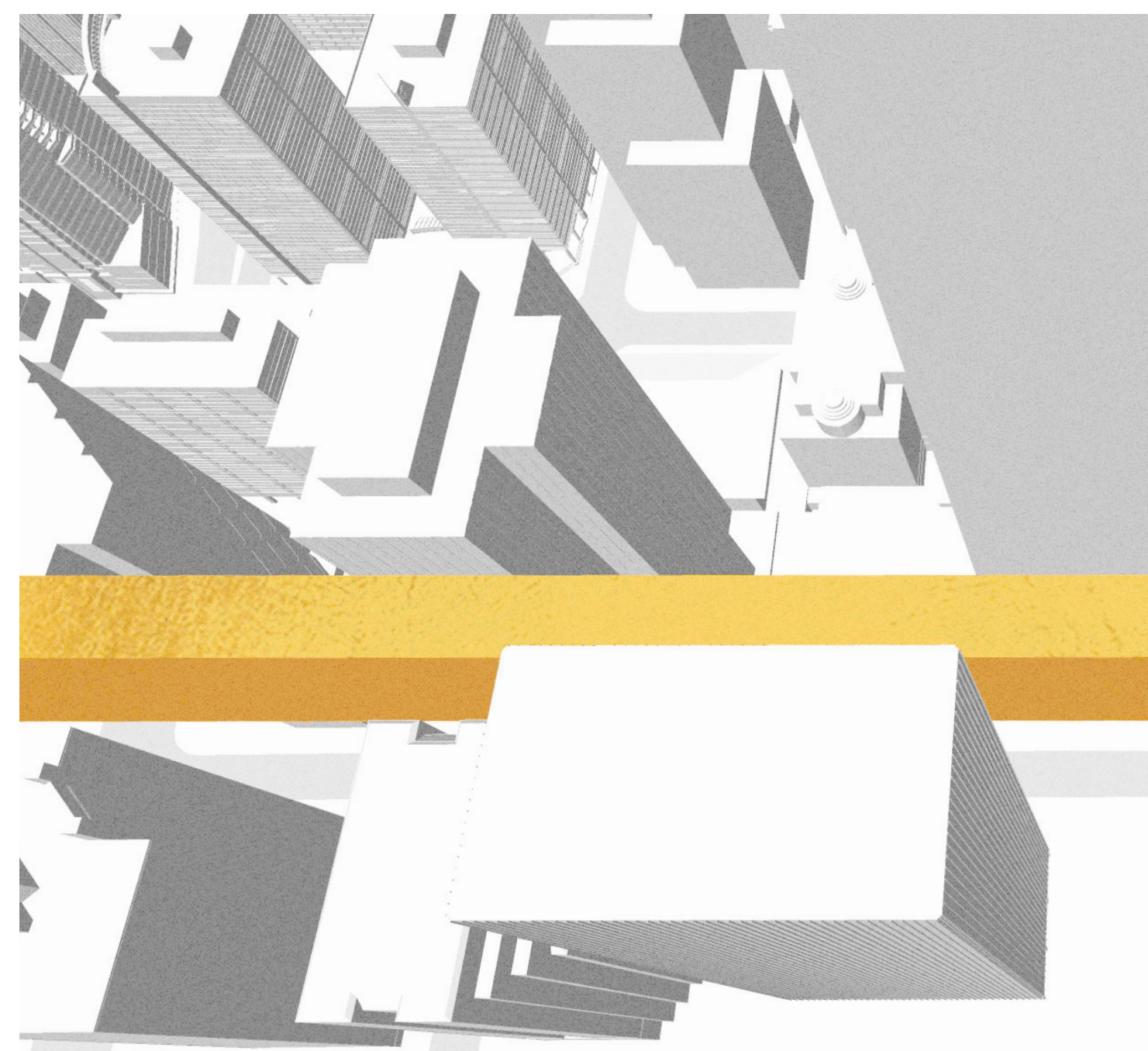

12.0b: Aerial View of Financial District 


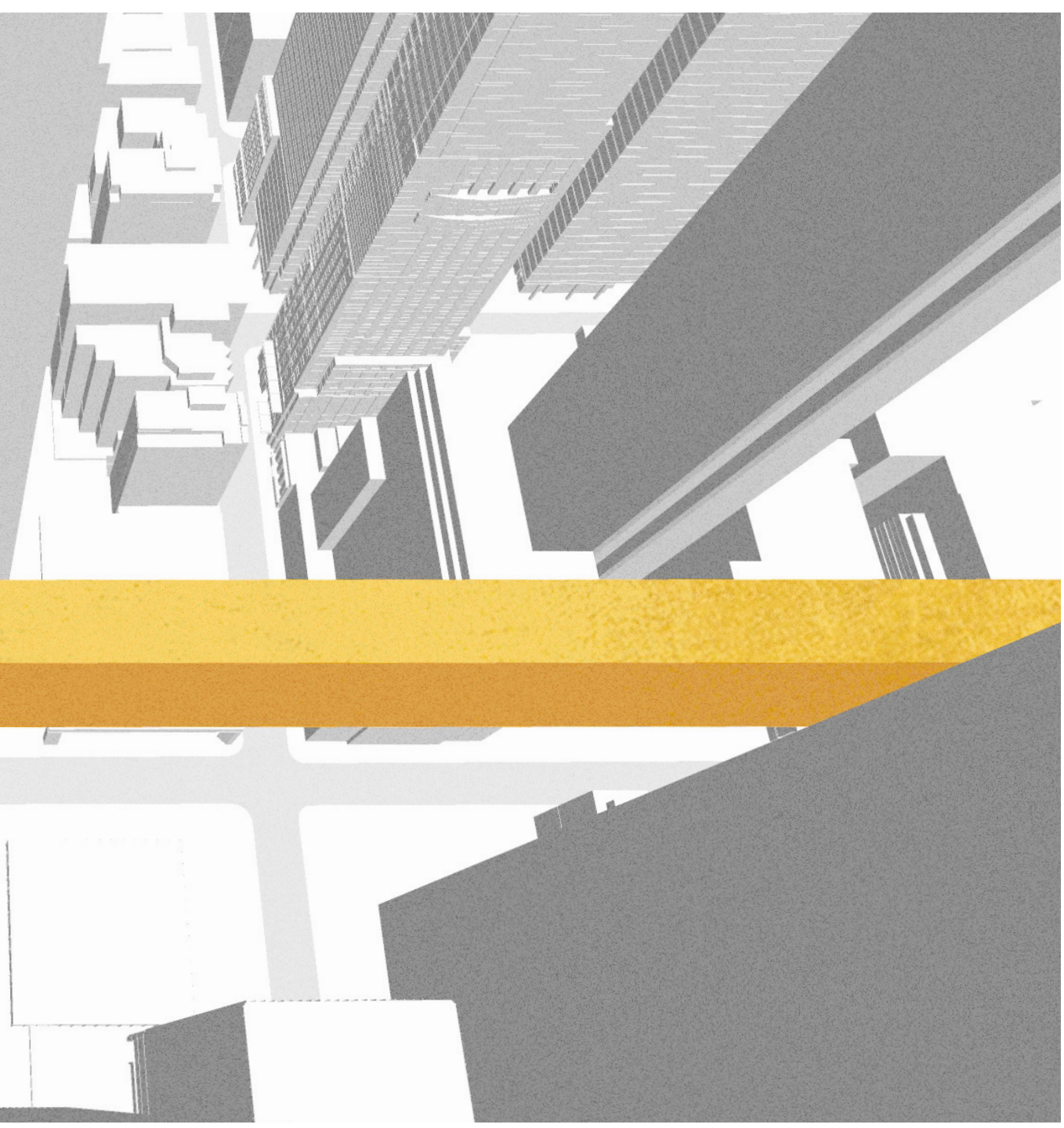

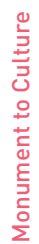




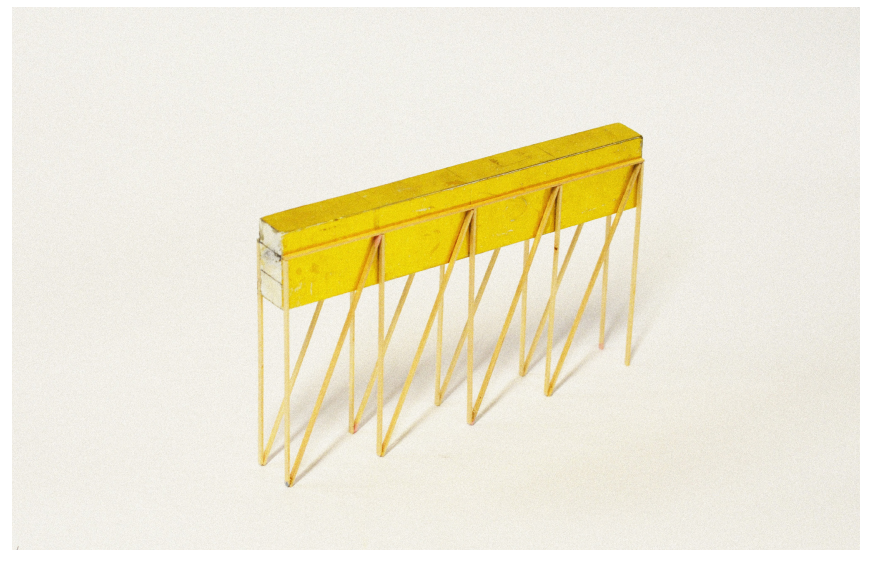

Ghost Town

A depopulation of the

financial district in Toronto

occurs at the end of every

business day. This is a

stark contrast to the

bustling and overcrowded

streets during work hours.

Under a fully automated

economy, this district will

undergo a complete and

permanent exodus.

12.0c: Sketch Model

\section{Characteristics}

- Located at the intersection of King \& Bay Streets

- Government run WPA like task distribution center

- Creative, intellectual, humanistic

- Theatre/studios/library/maker spaces/auditorium/kitchen

- Cultural sustainability

- Enables cultural production - a future of creativity, not labour

- Communal creativity/a life of art

- Enables a creative life instead of being just an instrument of production (Life as creation instead of life as dutyl

- Acts as a monument towards a post-work life

- Combats loneliness, develops community pride

- Hub of future activity in urban centres

- Technology learning center/ tech playground

- Enables productive communities in the absence of the workplace
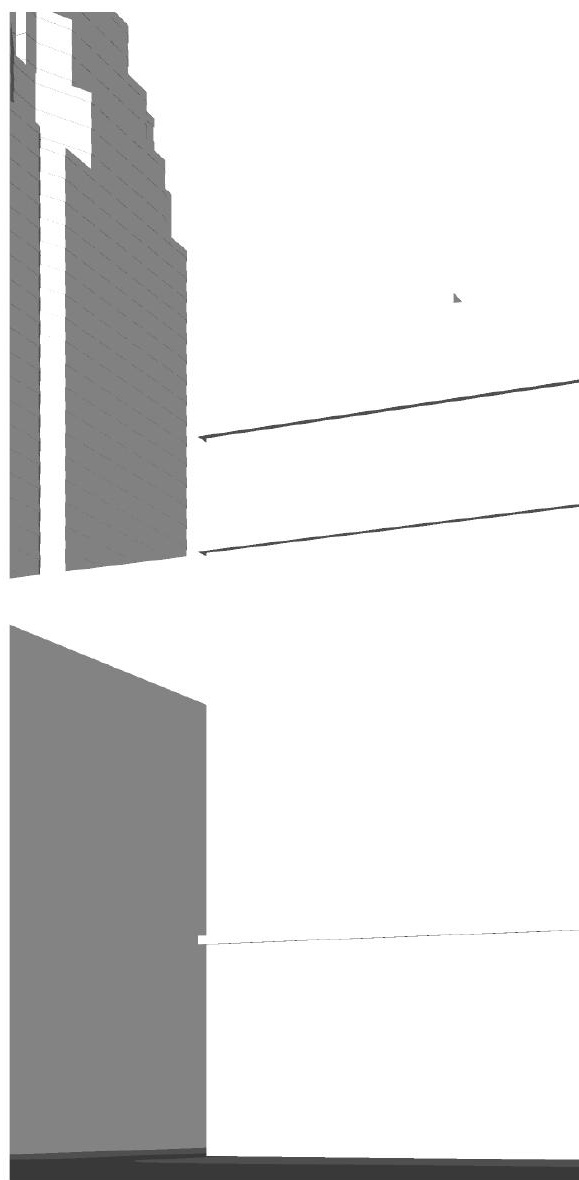


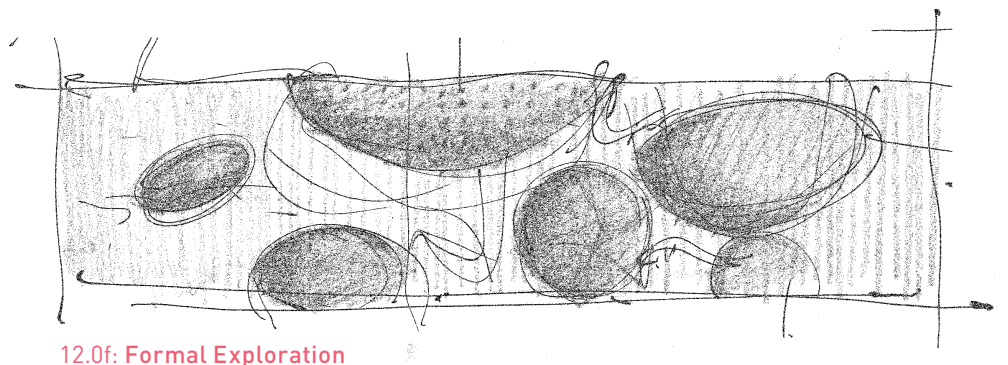

12.0f: Formal Exploration

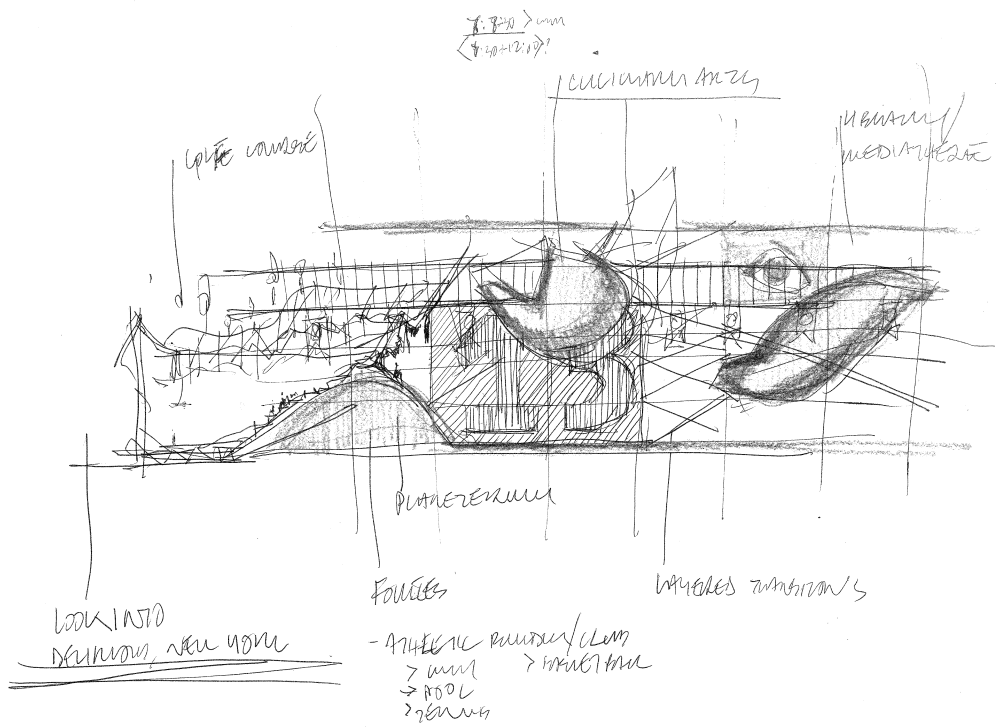

12.0g: Sectional Conditions 01 


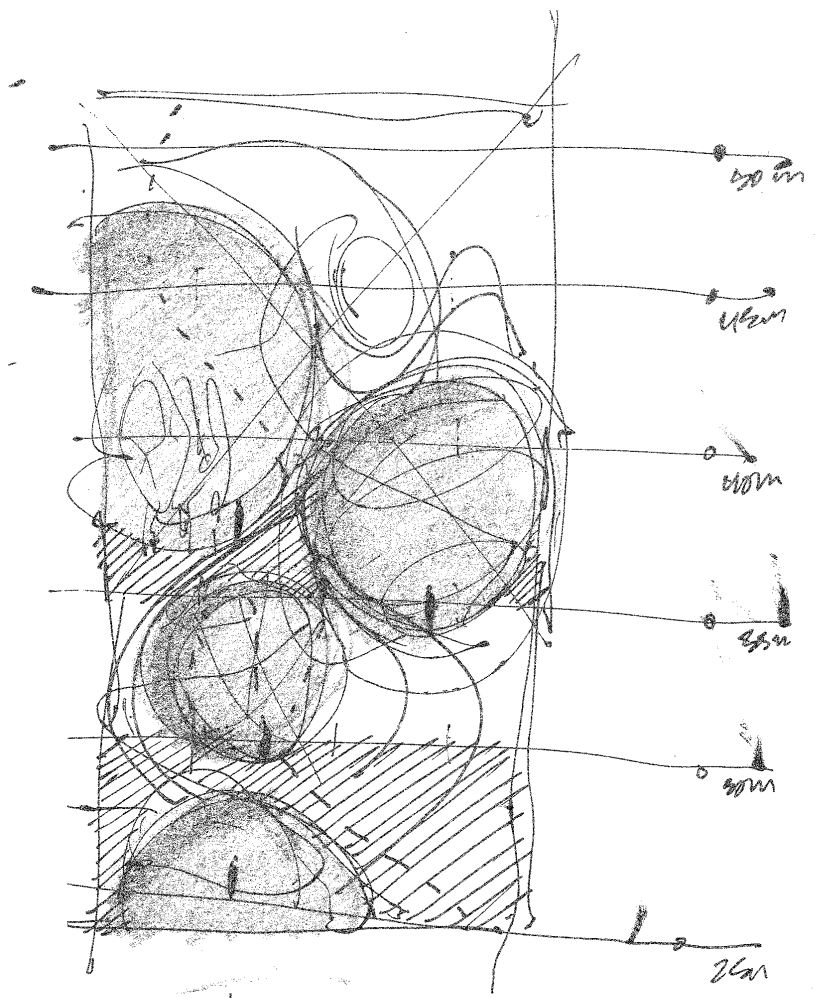

12.0h: Sectipnal Conditions 02 


\subsection{Architecture of Horizontality}

The Monument to Culture typology takes inspiration from the strategies of unitary urbanism applied in New Babylon. A continuous flow of exploration and experiences of atmospheres and situations is made available inside this macro-structure, spanning across the east-west axis of Toronto and centered on the Financial District. The Monument to Culture offers an urban condition with a continuous network of activities that permits the flaneur to free him/her self from the daily grind of labour.

The interconnectivity of this flat world allows the dwellers to stream through adventurous and heterarchical spatial organizations. Lacking any clear delineation of territorial hierarchies, it is a place that cultivates social and cultural exchange in an unobstructed and unlimited way.
Heterarchy

“Heterarchy may be defined as the relation of elements to one another when they are unranked or when they possess the potential for being ranked in a number of different ways". 2

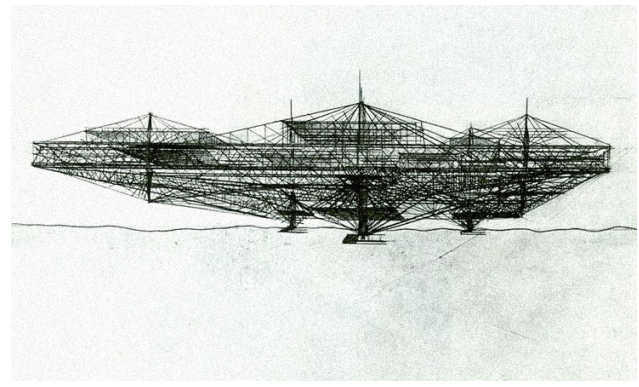

12.1i: Horizontal as Heterarchical

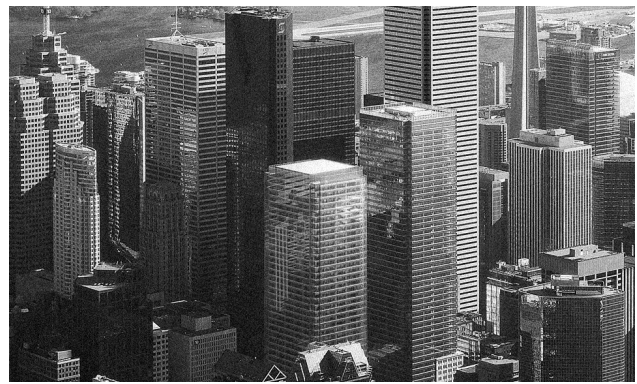

12.1j: Vertical as Hierarchical 


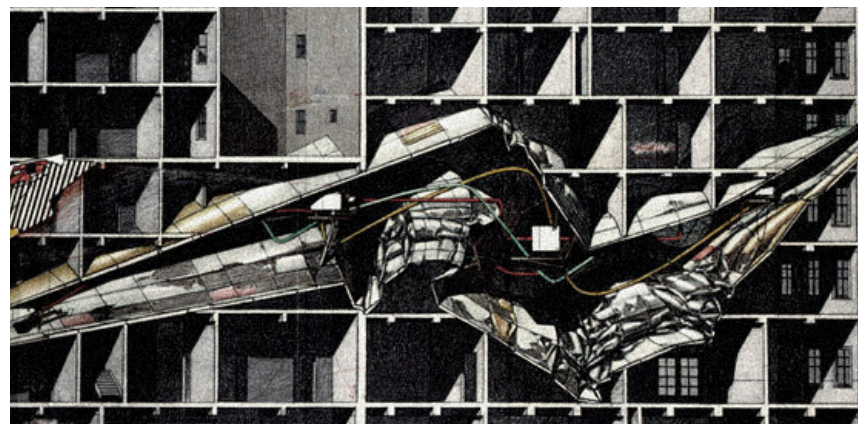

12.1k: Berlin Free Zones, Lebbeus Woods

\section{Heterarchy of Space (Lebbeus Woods) ${ }^{3}$}

So long as the concept of hierarchy dominates architecture (as it presently does), architecture will stay rooted in classical models, at the urban and building scales alike.

So long as architecture stays rooted in classical models (as it presently does), it will continue to express an old, even archaic, idea of knowledge.

So long as architecture expresses another idea of knowledge than that which best serves the present conditions of living (as it presently does), architecture will be a regressive force in the world of human affairs, even of human existence itself. 


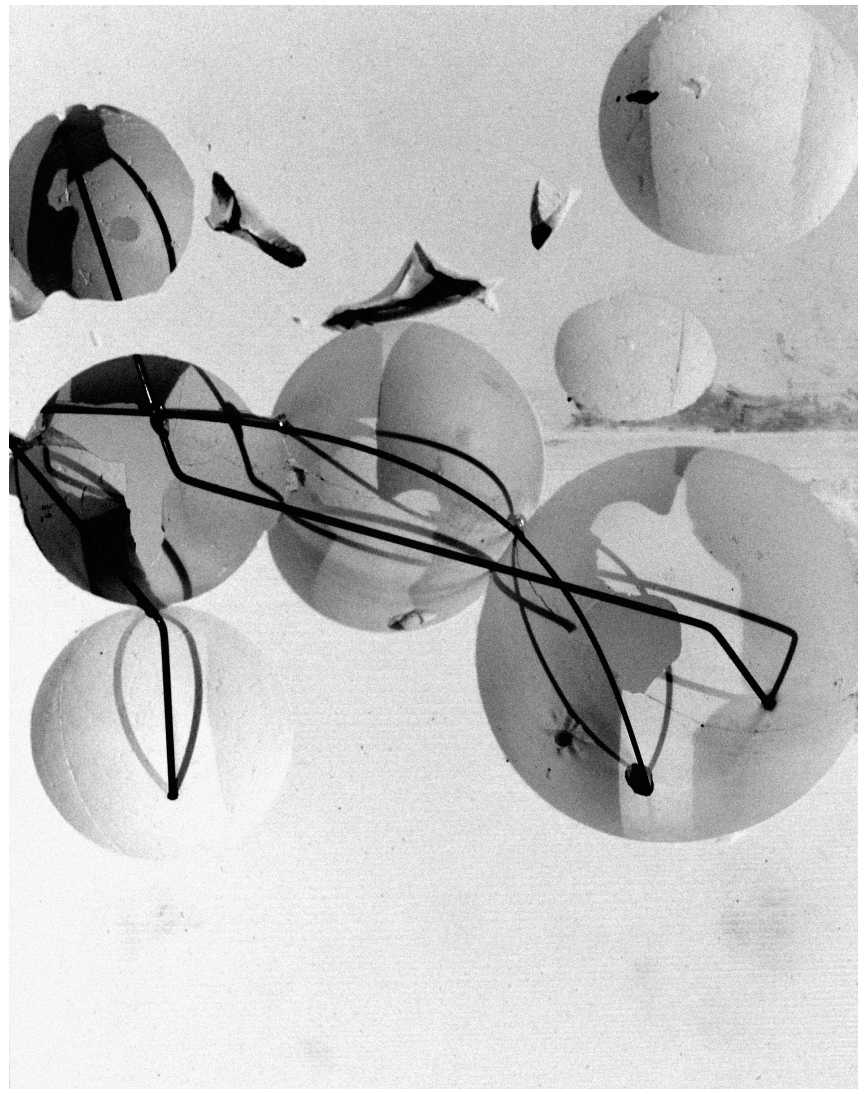

12.11:Light \& Shadow Study of Artefact B2 
13.0

Monument to

Housing 



\subsection{Monument to Housing}

In the last ten years, Toronto has experienced an unprecedented growth of development. 683 condominium projects were built between the beginning of 2012 and the end of 2016 in the downtown core alone. Another 3,200 projects are on their way in the next few years. ${ }^{1}$ Needless to say, the condominium tower is the established typology of the contemporary metropolis.

Tafuri constructs the argument that the skyscraper is both the instrument of and the expression of capital. ${ }^{2}$ His criticism is poignant when looking at the hyper-speed urbanization of the downtown core of Toronto. In the contemporary urban economy, the condominium is not perceived as a home but primarily as a speculative investment for capital gains.

The point tower typology is arguably a form of architecture without architects. The condominium tower leaves no space for imagination, as each floor is almost identically multiplied on a vertical axis, and then again on the horizontal axis.

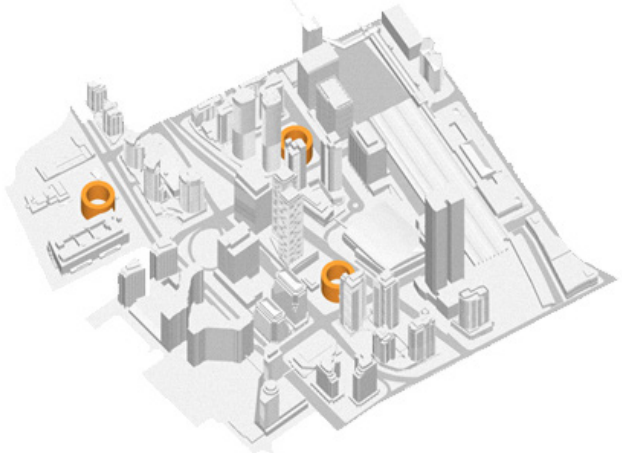

In a post-work society, citizens will devote more of their time caring for their families, friends, and neighbours. Positive to our well-being are things such as purpose, meaning, identity, fulfillment, creativity, and autonomy. Collective living can foster these qualities that are largely absent from the contemporary urban environment. A return to extended family / communal living is also likely in a postwork condition.

The architectural form of this typology takes inspiration from the Toulou buildings of the Fujian province in China that were built between the 15th and 20th centuries. Large hollow cylindrical buildings with fortified outer walls and a thriving courtyard culture worked as a small fortified city. The Toulou housing typology was designed to accommodate a dense population (housing up to 800 people) in which all inhabitants had equal rights, access to shared space, amenities, etc. A similar typology can be inserted within dense residential neighborhoods in the city to work in opposition to the point tower typology. ${ }^{3}$ 


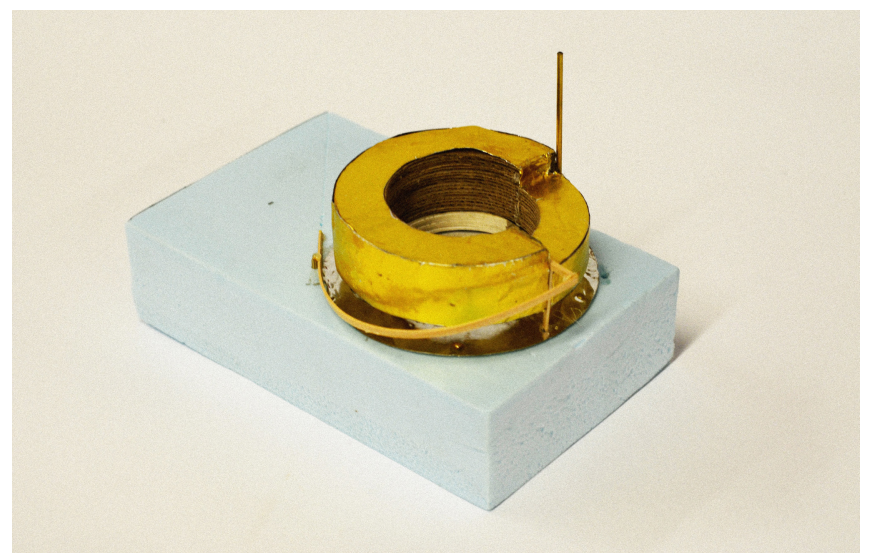

\section{Collective Living}

With increasing rent in major cities across the world, micro-housing and communal living is gaining in popularity as an alternative housing option. Residents typically live in small bedrooms with shared kitchen, living, and other communal spaces.

13.0b: Sketch Model

\section{Characteristics}

- Modeled after Toulou Homes

- Courtyard surrounded by homes

- $\quad$ Single gated entrance is celebrated threshold.

- $\quad$ Each building has its own identity reflected through ornament

- Establishes tight-knit communities with multi-generational living

- Courtyard is place of congregation for all the families

- $\quad$ Living spaces in each unit face courtyard Single loaded corridor faces the courtyard

- Housing typology inserted in dense urban centres

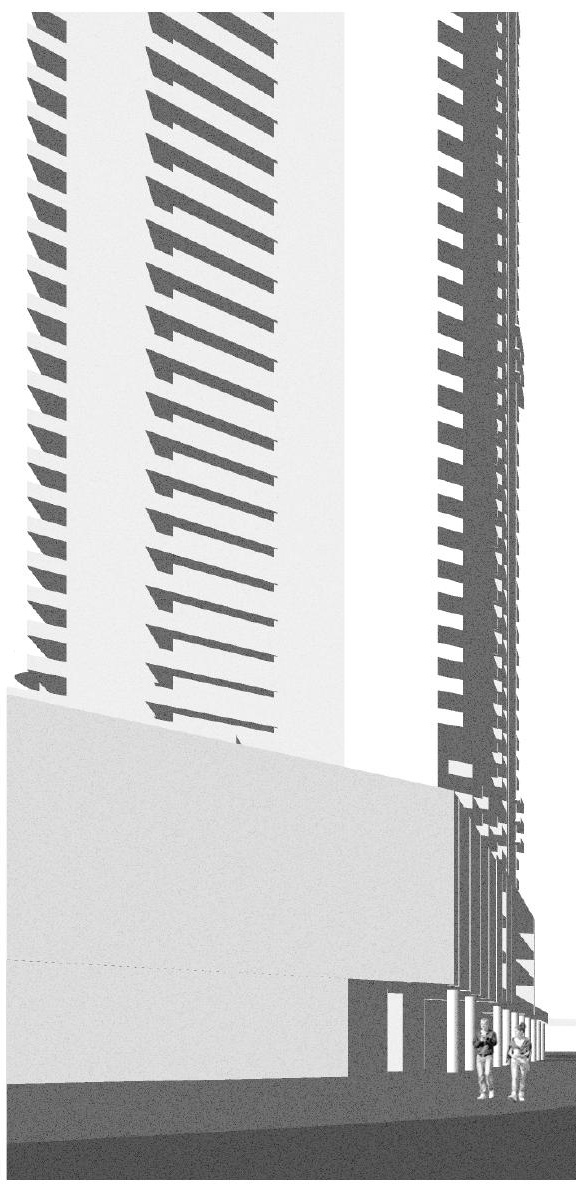




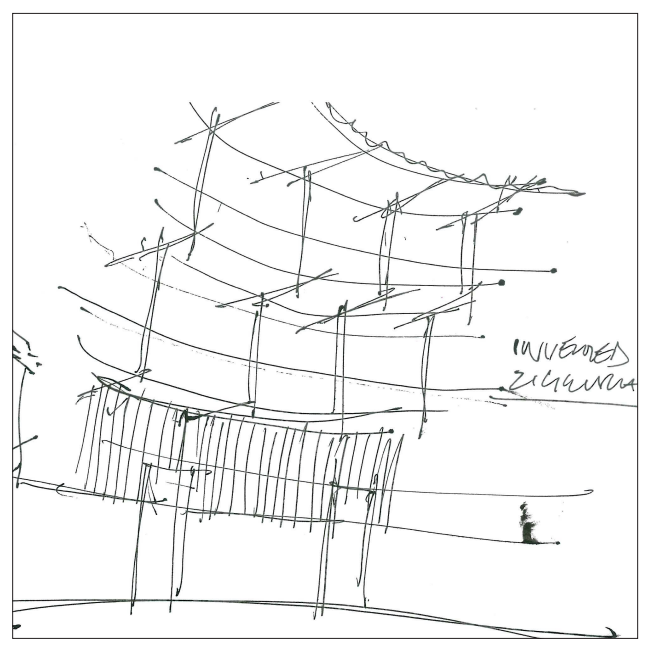

13.0c: Courtyard with Inverted Ziggurat

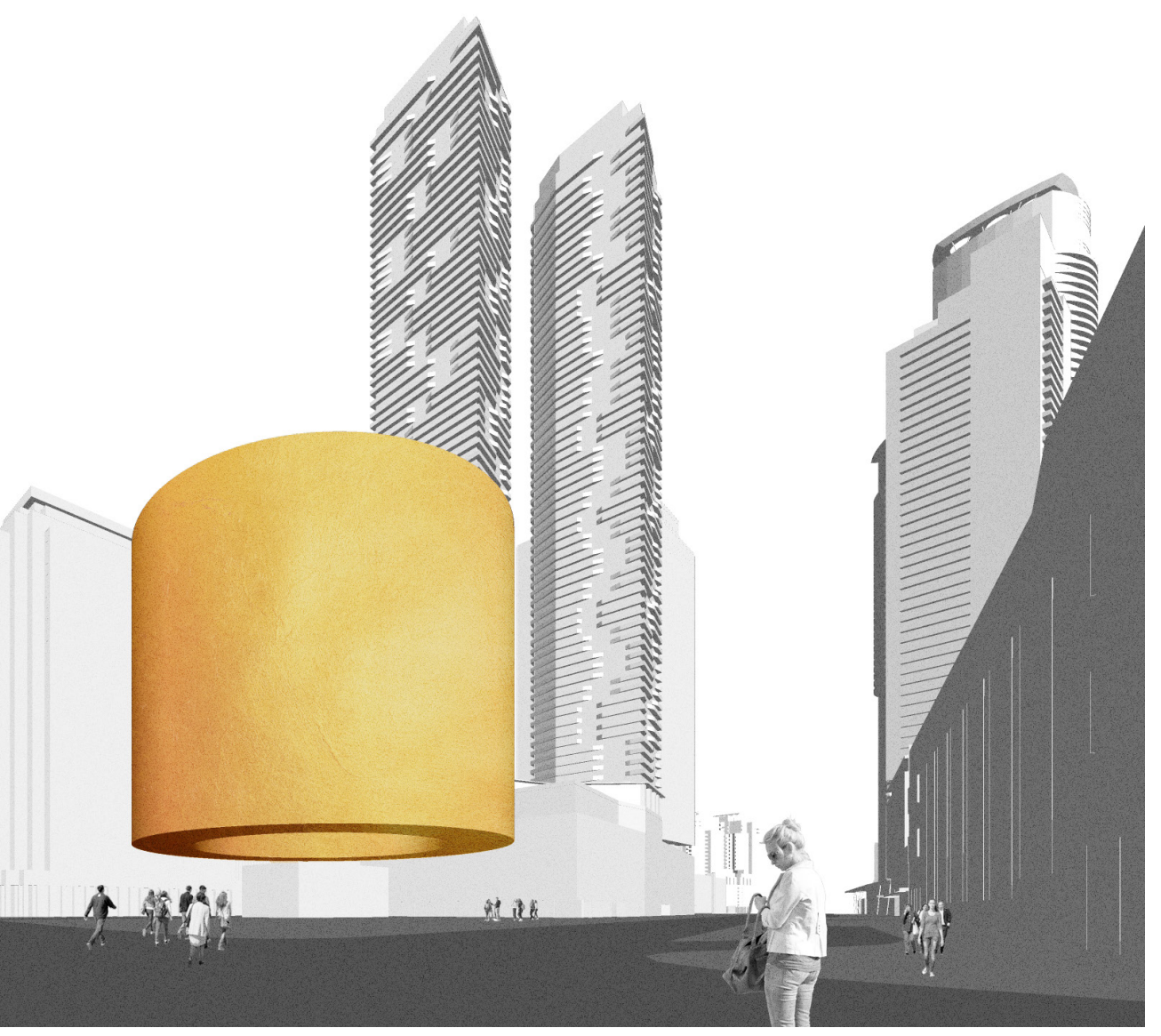




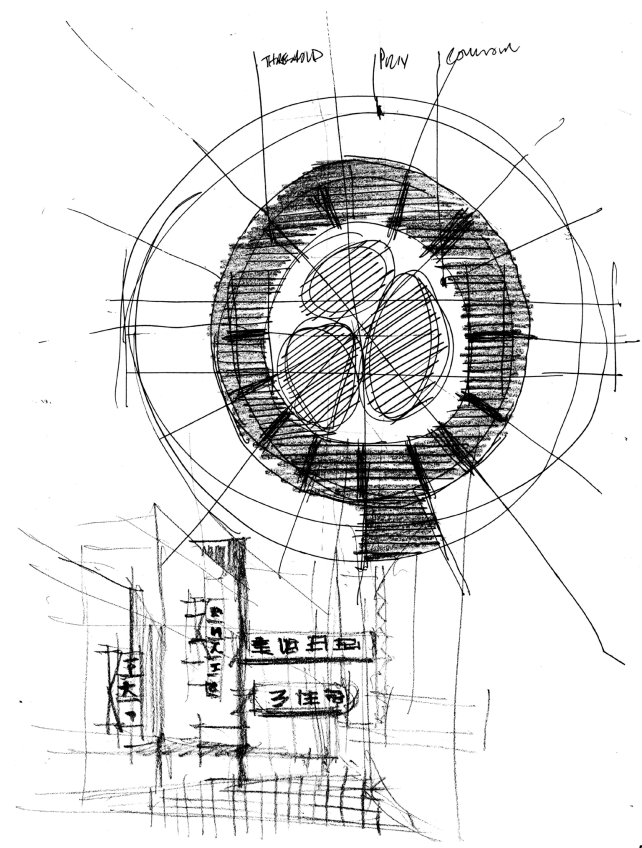

13.0e: Internalized Programming

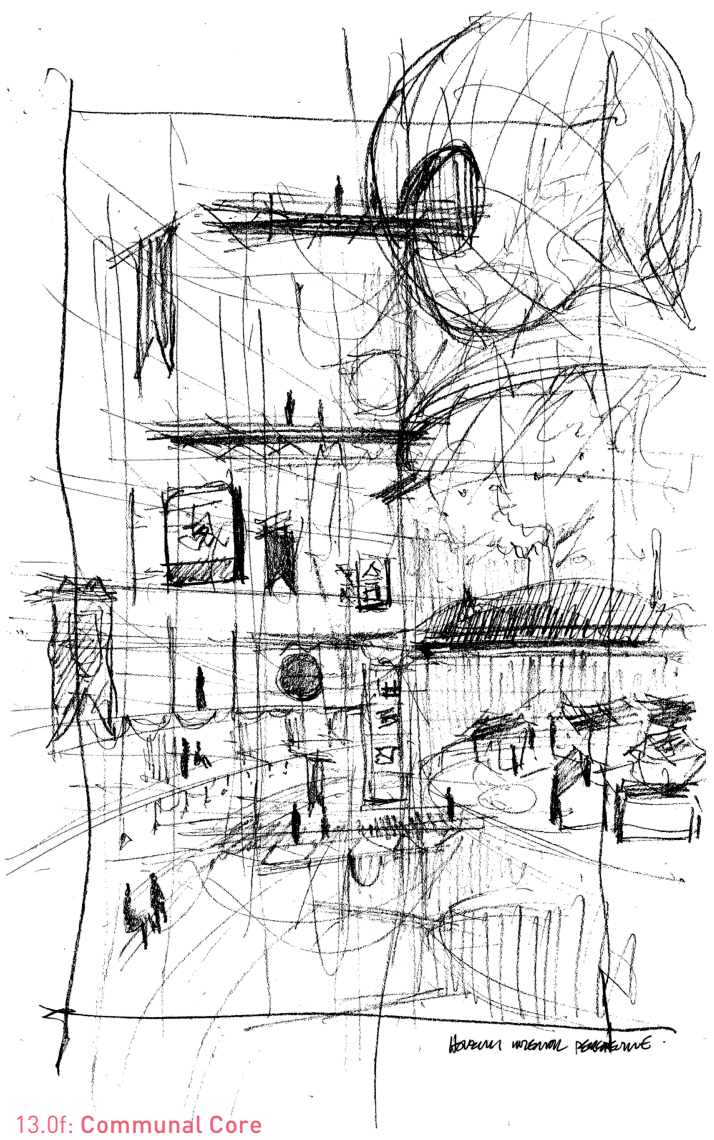




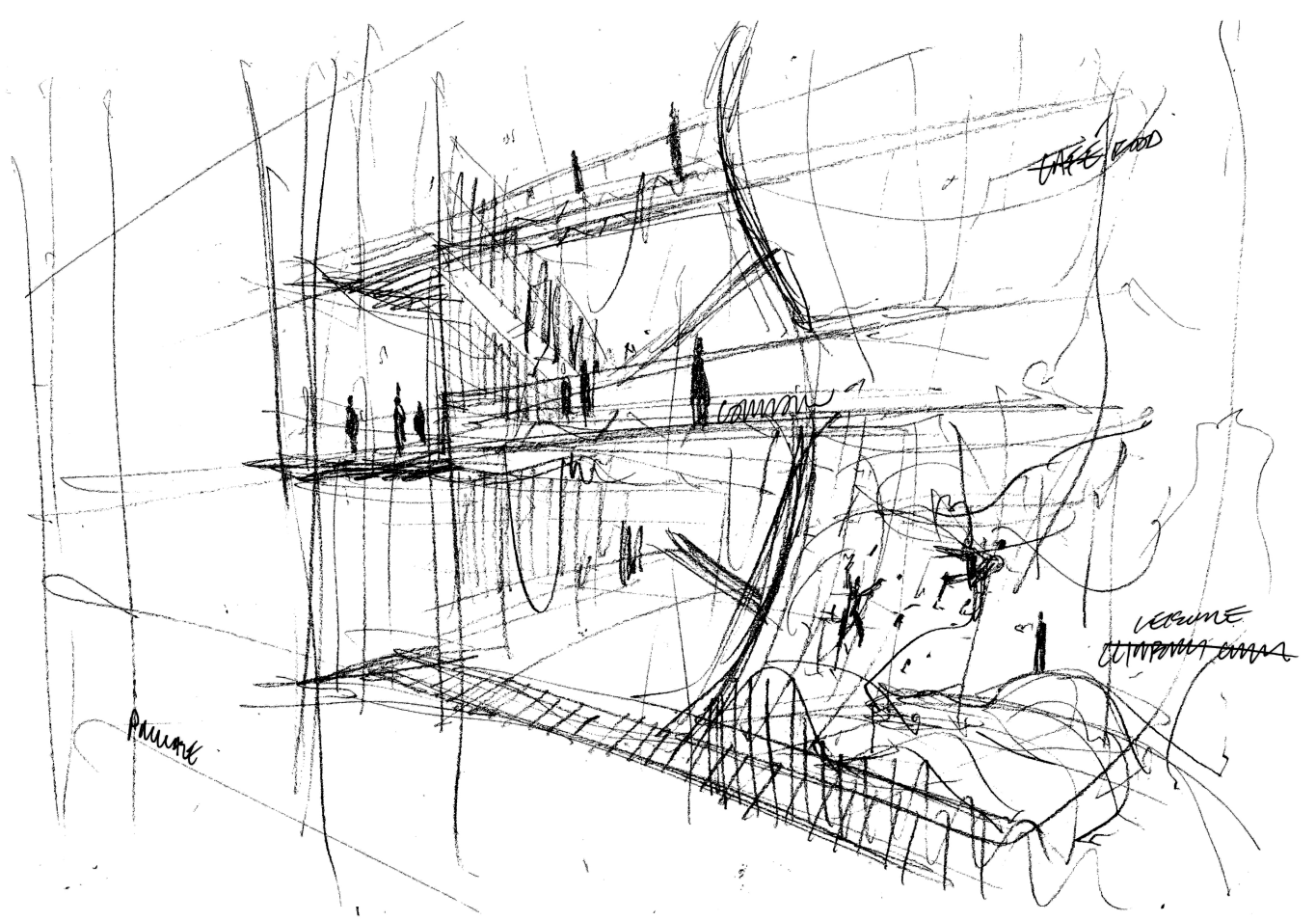

13.0g: Liesure as Central 


\subsection{Fujian Toulou Homes}

The Toulou is an agrarian area in Fujian province in China which contain 46 buildings erected between the 15th and 20th centuries. These, typically 4 storey tall buildings, were built by farming communities cultivating tea, rice, and tobacco. Fortified earthen construction allowed the buildings to stand up to $22 \mathrm{~m}$ high. The cylindrical morphology enabled a unique form of communal living for an entire village in which numerous families lived in units that were divided vertically, with each family occupying two to three rooms on each floor.

With only one entrance, limited openings to the outside world, and bare exterior walls, the architecture is defensive and inward looking. In effect, the stark and lifeless exterior stands in contrast to the highly decorated surfaces and lively condition of the interior. ${ }^{4}$ The Fujian Toulou typology is an example of a high-density building which offers an authentic form of communal living unlike the point tower commonly found in modern cities.
Defensible Space

Elaborated by Oscar Newman in the 70's, the defensible space theory posits that a sense of ownership and responsibility by the citizens leads to a safer community. Environmental design factors such as territoriality, natural surveillance, image, milieu, and safe adjoining areas are used to make defensible spaces. ${ }^{5}$

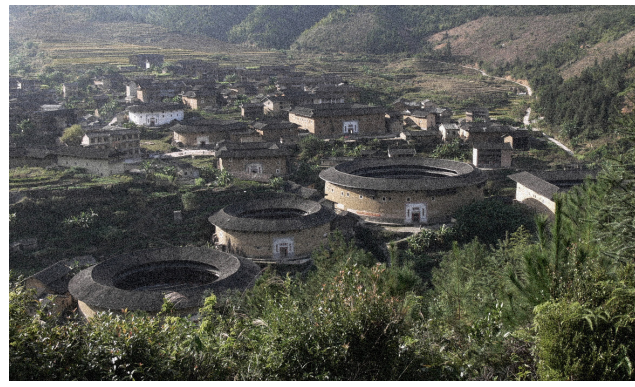

13.1h: Toulou Homes in Fujian, China

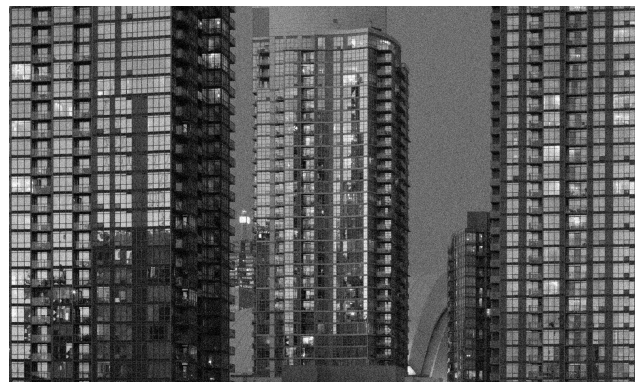

13.1i: Condominium Development, Toronto 
14.0

Monument to

Institution 



\subsection{Monument to Institution}

Without the need for work, institutions that are in the business of training and educating the population risk becoming obsolete. Paying for education might become redundant. Instead, government incentives in the form of payments can help to preserve a general level of literacy for an educated and engaged society under automation.

An infosphere - like typology placed at the periphery of a university campus, bordering between public and institutional territories can generate a polemic against the exclusionary practices of institutions. The infosphere elevates social consciousness by inviting access to all citizens; the typology deinstitutionalizes access to, and the production of, knowledge. Furthermore, this monument attempts to shift the agenda of established institutions away from "packaged" knowledge, instead, allowing any individual to freely pursue his/her true interests in whatever subjects they desire.

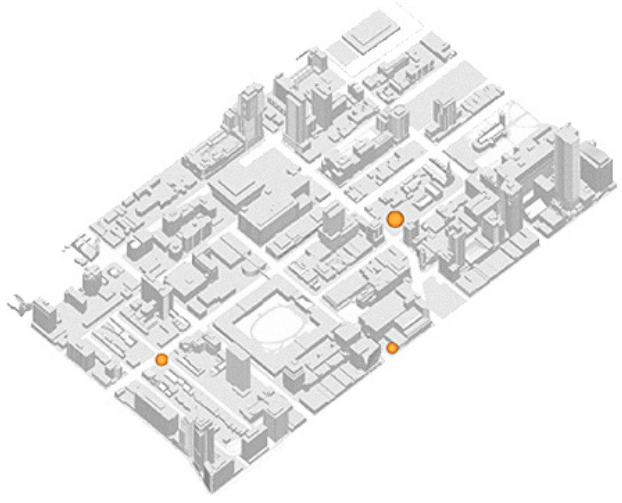

This synthetic typology is a combination of makerspace, community space, and library that makes knowledge universally accessible, irrespective of the education level. It is a place where people can collectively gather to learn, make, explore, and discover by using a variety of tools and materials.

The infosphere is not polluted by the structural dogma of capitalism that subjects and inhibits the creative potential of individuals. Once liberated from the economic context of exchange value, citizens can produce knowledge and discover new truths. The word school has origins to the term skole, which is Greek for leisure. Instead of teaching citizens how to work, schools will teach people how to be free. 


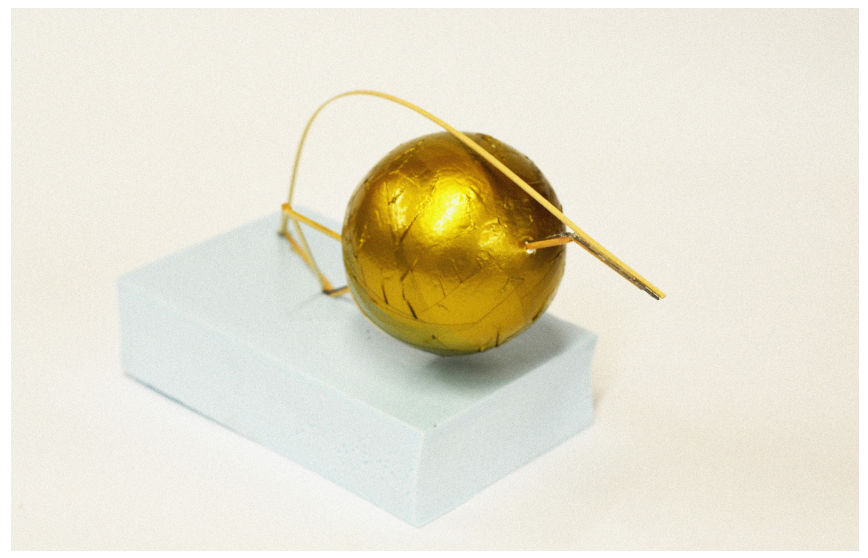

14.0b: Sketch Model

\section{Characteristics}

- Typology inserted at the border of public realm and educational institution territory

- Government pays people to go to school instead of the other way around

- Preserves the status quo of an educated and engaged society under automation

- Deinstitutionalizes the production of and access to knowledge

- Elevates social consciousness

- Includes a library, makerspace/ fabrication labouratory

- 3D printers decentralize production

- Promotes collective and creative acts of making instead of large scale capitalist production

\section{Infosphere}

A term used to describe

a place populated with

information such as the

cyberspace. R.Z. Sheppard

first describes the concept

as "...that encircling layer of

electronic and typographical

smog composed of

clichés from journalism,

entertainment, advertising

and government."1

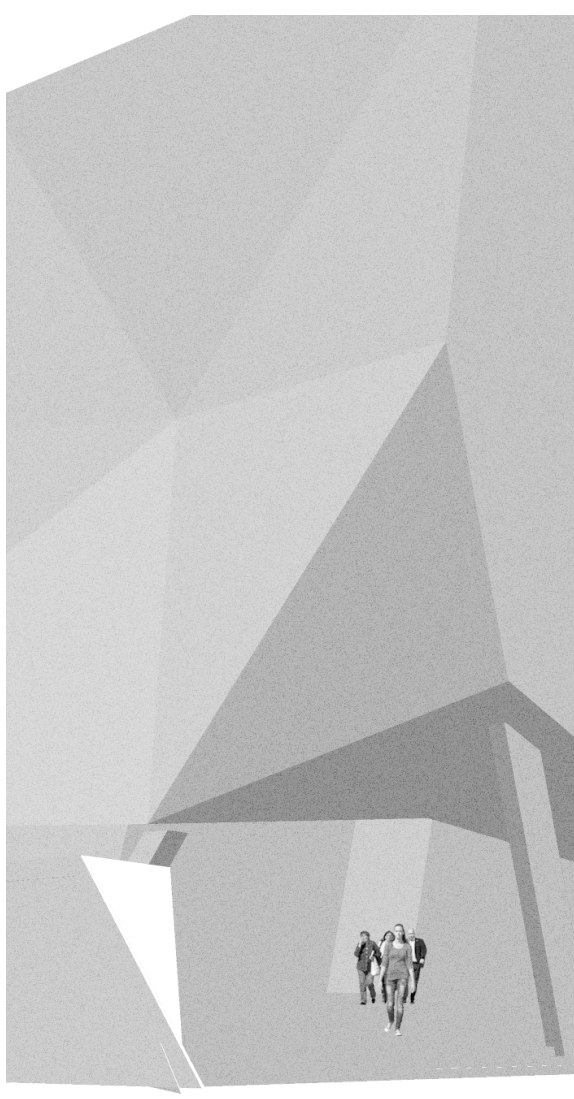




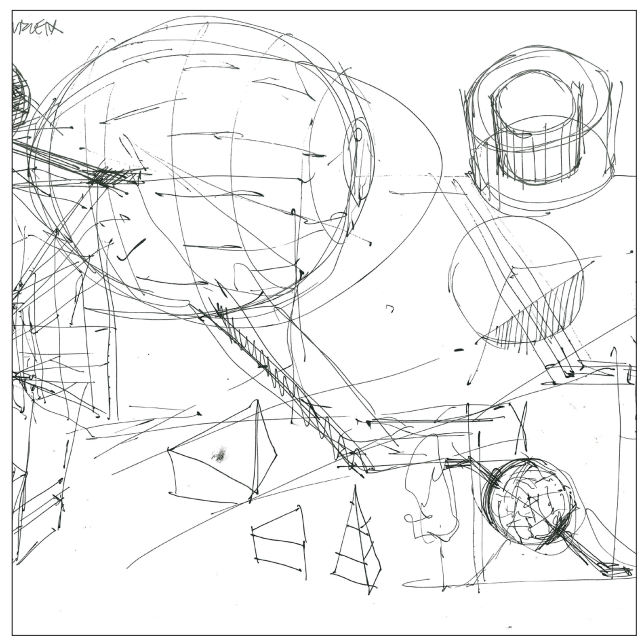

$\bar{\sigma}$

14.0c: Infosphere 


\subsection{Infosphere: Expo 67 US Pavilion}

Housed in a geodesic dome designed by Buckminister Fuller for the Montreal Expo 67, the United States pavilion focused on delighting its visitors through an exhibition of American culture instead of posturing the country's technological achievements to the world. The Cambridge Seven Group themed the exhibition "Creative America" to illustrate American invention through familiar and approachable content for the visitors. The first gallery contained an exhibition of ordinary objects invented by Americans to illustrate the inventiveness of the nation. American cinema and music were also used to represent popular content to the visitors. ${ }^{2}$

The display of ordinary objects in a gallery setting was considered avant-garde in the 60's, but this approach has become a common technique applied in contemporary museology. The Cambridge Seven Group cleverly dismantled the value placed on hi / lo art by using content and a narrative that is inclusive and non-esoteric.
Buckminister Fuller

The expo 67 dome

expresses Buckminister

Fuller's technological

positivism and constant research in material efficiency, structural integrity, and modularity. Bucky would have embraced automation as an innovation to be used for the good of mankind.

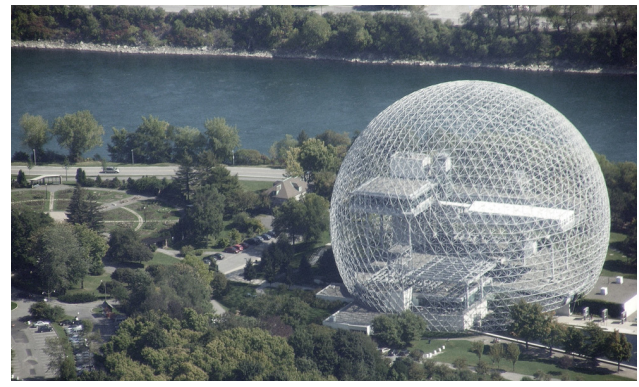

14.1e: Dome as Heterarchical

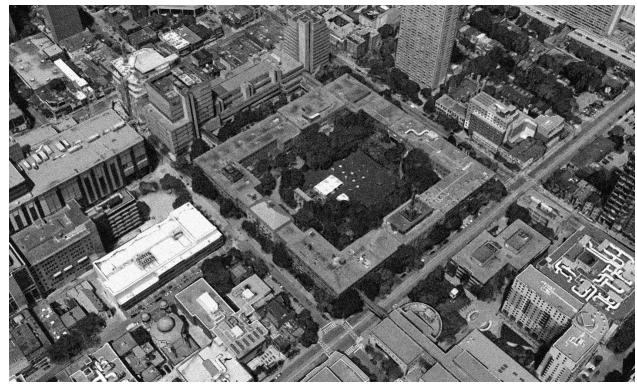

14.1f: Institutions as Exclusionary 
15.0

Monument to Recreation 



\subsection{Monument to Recreation}

Factories are designed to house machines for manufacturing and people are only there to serve the machines. Industries treat human bodies as tools for manufacturing. Mundane and repetitive work constrain the body into specific and efficient movements.

In a fully automated process, human labour will be completely removed from the production of goods. A Monument to Recreation transforms zones of industry into places for recreation.

Nieuwenhuys designed New Babylon to enable the nomadic life of Homo Ludens, a term borrowed by Huizinga which translates to "Man at play(chapter 4.2)." In a world without work, people would have the freedom to devote much of their time to creative play. A Monument to Recreation is a space in which people can explore their freedom through creative play, adventure, and collective experiences in varying atmospheric environments (chapter 4.1).
The biggest side effects of unemployment are loneliness, and an erosion of community pride. In the absence of employment, a monument to recreation can serve as a public space where citizens can meet, learn skills, and connect through sports and crafts.

Industrial complexes in the urban core will be left vacant in a postwork economy. As such, places of manufacturing can be repurposed and given new life as recreation centers. The grain silos found in the Portlands in Toronto, are a relic of a typology rendered obsolete in the contemporary urban fabric, thus making the site ideal for its conversion into a Monument to Recreation.

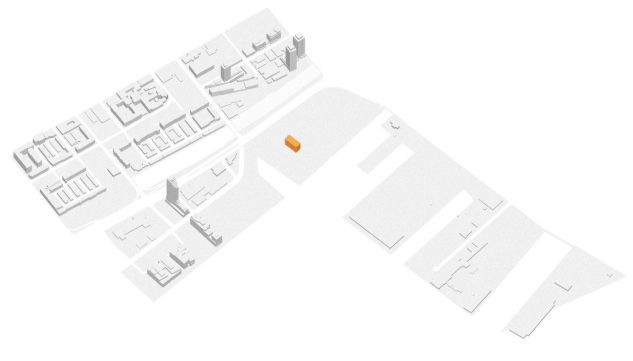




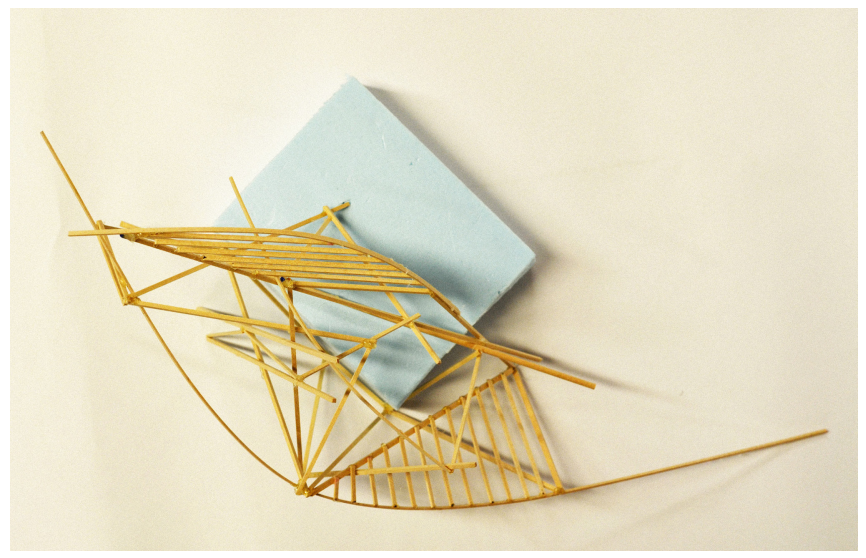

15.0b: Sketch Model

\section{Characteristics}

- Recreation center for a life of leisure

- More numerous and larger recreational complexes will be needed for the post-work future

- 24-hour access

- Modeled after Constant Nieuwenhuys' New Babylon

- Located in the current industrial zones of the city

- Commentary on factories that use humans as tools of production

- From tool of production with limited physical movement to the freedom to wander

- Homo Ludens live in a creative state of play
Play

Play if often perceived as an unproductive use of time in today's overworked culture. But research indicates that, much like with children, recreational activity for adults promotes creativity, problem solving, builds relationships, and emotional intelligence. ${ }^{2}$ Under full automation, play instead of work will become an essential activity to seek fulfillment in our lives.

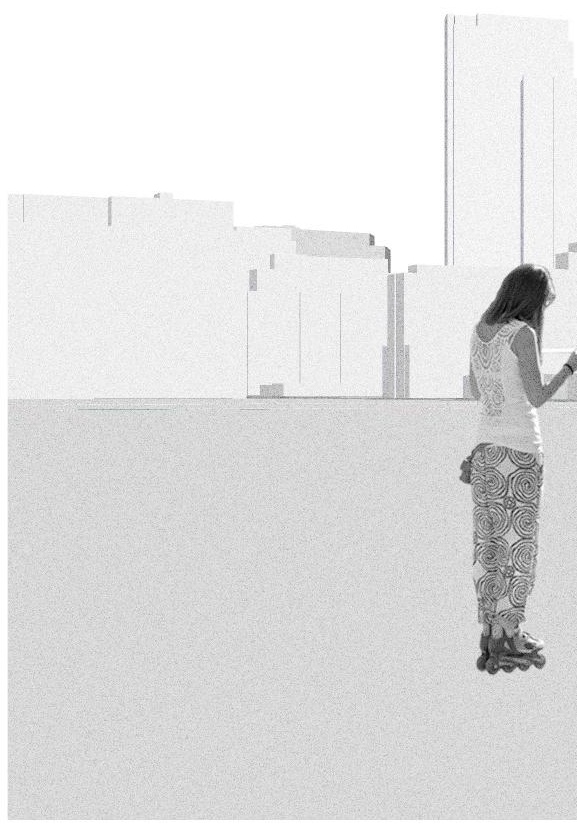




\subsection{Playground for the Flaneur / Dérive}

Flaneur is a term (Chapter 4.1) coined by Charles Beaudelaire in the 19th century to describe the experience of people as they pass through the urban fabric of the city. Emerging from the post-industrial urban setting, the flaneur is a passive figure, an observer who experiences the city from a detached point of view. ${ }^{3}$

The Surrealist used this concept to insert random and chance interventions to disrupt the malaise of the city. The group attempted techniques such as guiding oneself through the city using a map of another city to dissolve everyday reality into a surreal and higher form of experience.

The dérive is a term popularized in the seminal "Theory of the Dérive" by Guy Debord, founder of the Situationist International. Debord builds on the concept of the flaneur as a polemic against the structural barriers of the built environment. Debord's dérive attempts to reframe the urban fabric by placing emphasis on psychogegraphical conditions, instead of geographical divisions as determined by class and social status. ${ }^{4}$ Debord's scenario proposes spontaneous journeys through the urban landscape in which participants "...let themselves be drawn by the attractions of the terrain and the encounters they find there." 5 The "Theory of the Dérive" had a major influence on Constant Nieuwenhuys' concepts put forward in his work on New Babylon.

\section{Psychogeography}

Term invented by Guy

Debord to describe the effect of a geographical location on the emotions and behavior of individuals.

${ }^{6}$ The flaneur is guided by his / her emotional responses instead of the functional need of getting from point a to b. Psychogeographical maps promote a playful exploration of architectural spaces in the urban environment.

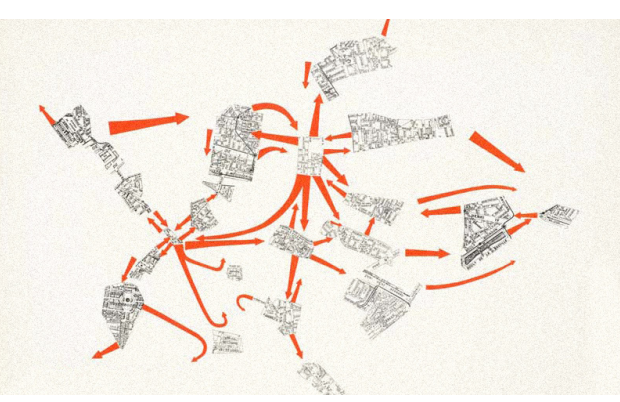

15.1e: The Naked City

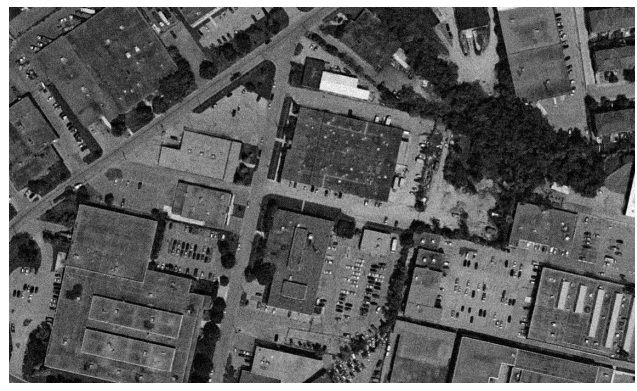

15.1f: Factories as Corporeal Suppression 
16.0

The

Uncanny 



\subsection{The Uncanny as Cultural Innovation}

An analysis of the uncanny through the lens of theories proposed in "On the New" by Boris Groys provides critical perspectives of the system that governs what is deemed culturally valuable from the culturally worthless.

This section begins with an investigation of the definition and cultural mechanisms that regulate the uncanny. What follows is an exploration into the use of the uncanny as a strategy to generate the new and the culturally innovative. Finally, a methodology will be proposed to fabricate and preserve the idea of a post-work world via the new. The insights gained from this study will be deployed to formulate a compelling argument for a new and socially significant truth in the face of a precarious future under automation. 


\section{Profane as Uncanny}

Groys uses the term extra-cultural or profane to describe "...something that the culture does not know or that conceals itself from culture, something that is not controlled by culture and thus determines it." Similarly, Freud states "...what is uncanny is frightening precisely because it is not known and familiar." ${ }^{2} \mathrm{He}$ used the concept of unheimlich to define "the concealed", "kept out of sight", "withheld from others. ${ }^{3}$ Although there are differences between the two meanings, the concept of the profane and the uncanny are invariably interlinked. Groys does not make use of the term uncanny in "On the New". Instead, the term profane is used abundantly to formulate his ideas. As such, I have taken the liberty to equate and freely substitute the term uncanny and profane for the purposes of this investigation.

In order to examine the uncanny, we need to first understand the culturaleconomic logic that governs culture. Groys argues that the culturally valued is recognized and adopted into archives through institutions of power. Museums, libraries, and other archives serve to establish and perpetuate cultural memory; beliefs, explanation, perception, and values. Cultural archives contain truths: artefacts and signifiers of a time and place that become cultural models. ${ }^{4}$

Groys notes that everything that is valorized is subsequently commercialized. And everything that is commercialized eventually loses cultural value due to our limited capacity for the preservation of cultural memory. The outcome of this condition is an innovative and perpetual exchange between the uncanny and the culturally established. ${ }^{5}$ The profane or uncanny thus serves as an integral part of culture as it guarantees permutations in the system. Without the extracultural, culture remains stagnant and only maintains existing traditions.

Ultimately, things that are not incorporated into the cultural archives reside in the profane realm. And it is only by being outside of the established culture that the profane can exert influence on established cultural hegemony. Indeed, valorized culture is identified with privileged classes while the profane is usually found in sub-cultures. To the established culture, the profane is valueless, non-descript, extra-cultural, irrelevant, and transitory. Waste and discarded products of valorized culture subsequently make their way down to the realm of the profane. The oppressed classes appropriate the profane to threaten the destruction of valorized culture and the elimination of cultural hierarchy.

The idea of a post-work world is a profane proposition that threatens to destabilize established cultural values. As elaborated throughout this thesis, automation combined with universal basic income has the potential to empower the masses and destabilize class hierarchies produced by contemporary capitalism.

The profane can also serve to critically challenge the established values of contemporary architecture grounded in the ideologies of relational methods. Indeed, since Modernism, 


\section{Uncanny as the New}

architecture has moved away from the discourse of the architectural object towards the discourse of the architectural field. ${ }^{6}$ The contemporary discipline is now primarily concerned with analytical, ecological principles, network relations, parametricism etc.

What was once the essence of architecture: craft- the act of making through exploration has now become an irrelevant, extra-cultural, and meaningless task. Arguably, the discourse of the architectural object has been devalorized, deemed worthless, and relegated to the realm of the profane. A return to a craft developed through the making of the architectural object could reveal new truths, ontologies, and hidden logics. These insights could be used to construct signs that generate tensions between the highest culturally valued (architectural field) and the most profane (architectural object).

The following section investigates methodologies and processes that apply the profane to produce an innovative signifier of a new postwork cultural paradigm while simultaneously challenging the familiar mechanisms and operations used to create architecture under the cultural-economic logic of contemporary capitalism.
As argued previously, semiotics and capital are deeply intertwined. Viewed through the lens of structuralism la movement that posits all things in the world as signs of a hidden system of meanings, logics, and languages), ${ }^{7}$ architecture serves to materialize and reinforce the institutional framework of capitalism. As such, the process of making architecture has become locked in linear methodologies and logics of this overarching system and its means of production.

A crafting of the architectural object via the combination of chance operations, prototyping, and iterative processes can be used to explore and uncover an innovative methodology, one that leads to the construction of semiotics that challenge the established language of capitalism. It is important to note that this innovative language does not call for a destruction of capitalism but rather attempts to align capitalism towards a post-work trajectory. Groys argues that a successful critique results in the simultaneous devalorization of existing cultural values and the valorization of the proposed innovation. Thus, an architectural language made by using profane methodologies can transcend onto the most culturally valuable to reprogram the language of capitalism under a post-work condition.

Groys notes that the most effective strategy for innovation is to make a critique by via the use of negative adaptation. ${ }^{8}$ Unlike positive adaptation, negative adaptation attempts to make a work not to resemble traditional models but to set in contrast with them. The critique needs to be simultaneously 


\section{Post-work Preserved Via the New}

referential and oppositional to the language of capitalism.

He emphasizes that the proposed critique accedes to cultural memory only when it successfully establishes a new comparison in something not compared before, and when it makes use of the profane to challenge concrete cultural values. The critique reveals a new truth when it brings into question the "... ideological fiction designed to justify the domination of certain institutions of cultural power." 9

Gold has historically and continues to be used as one of the main standards for measuring and preserving wealth. To this day, gold continues to be the preferred commodity to conspicuously display capital, power, and status. To make use of gold as a strategy to frame uncanny architectural constructs works in twofold. Gold has been traditionally a signifier of capital power. As such, the use of gold as the exterior shell ascribes the object a value similar to the surrounding financial towers locked in the semantic codes of capitalism. The semantic code of the golden exterior shell is subverted of its meaning when set in contrast with its internal space. In effect, the revaluation of values is triggered when one experiences the interior with its profane or uncanny architectural constructs that bear no logical resemblance to the surrounding financial towers locked in the predictable and cartesian constructs of capitalism. This technique of maximum juxtaposition creates a linkage between the new truth and existing logic. Innovation occurs when cultural attitude towards the subject is re-framed, and new meanings are established.

\begin{abstract}
"The new is more valuable than the merely different; it lays claim to social significance and aspires to being the truth of its time. The new claims to be preserved for the future by the mechanisms of cultural memory." 10
\end{abstract}

The strategies discussed in this chapter are deployed to ensure that the polemic is not a utopian proposition that exists in a vacuum. As noted, the success of an alternative truth depends on its relationship to the existing culturaleconomic theories. Failing to relate to tradition and to work as a polemic against the established culture makes the proposition valueless.

This thesis ultimately seeks to formulate a new and necessary truth in the face of an uncertain future under automation. A monument to a post-work world attempts to gain access to the cultural archives through the discourse of a profane yet ideal scenario for the future. If successfully embraced by the cultural-economic mechanisms, the proposed truth can lead to a shift in the cultural hegemony of capitalism, so that we can avoid "setting off in the wrong direction".

Admittedly, once the innovation is archived and valorized, the next profane truth will dislodge the established, yet a concerted effort must be made to present the real concerns of society in the advent of automation. 


\subsection{Automation as Uncanny}

Unraveling the etymology of the word uncanny reveals a multi-faceted and evolving definition.

Freud examines the uncanny through a psychoanalytical lens in a seminal essay written in 1919. The term unheimlich, which derives from German term "not of the home", is used to explore relations between the human psyche and the dwelling. ${ }^{1}$ The uncanny is elaborated as what is hidden from the public eye due to its threatening and abnormal nature. Indeed, he describes the term uncanny as "...belonging to all that is terrible - to all that arouses dread and creeping horror..." From a Freudian point of view, the uncanny is therefore the forbidden and repressed ego: impulses, emotions, desires that are controlled by the ID.

Freud also analyzes the division between what is heimlich and unheimlich- what is familiar and what is concealed. This separation is described as a threshold that negotiates the two: the process of turning the uncanny (unfamiliar) into the canny (familiar). He describes that a feeling of strange discomfort is experienced when one is exposed to an unfamiliar condition that is without reference to the familiar. In an effort to suppress the anxiety produced by the uncanny, dominant meanings are used to inevitably codify the as-yet-unknown into the comforting familiar. ${ }^{3}$

Derrida builds on Freud's ideas of the uncanny through the discourse of semiotics. Looking through a lens of representation, he notes "the uncanny lurks behind the unstable links between signifier and signified." ${ }^{\prime \prime}$ As the father of the deconstructivist method, Derrida examines the uncertainty between the material form (signifier) and the mental concept (signified). The concept of Ghosts (elaborated by Derrida in discourses on Hauntologyl provides key insights into the uncanny. ${ }^{5}$

The figure of a ghost is an uncanny concept as it signifies a temporal, historical, and ontological disjunction. A ghost has no true identity: ghosts arrive from the past and appear in the present. Derrida uses the allusion of the ghost to critically examine
Uncanny + Art

The uncanny as an abomination hidden from the public eye inspired countless surrealist artists in their exploration of the unconscious imagination. This enduring theme continues to be investigated by contemporary artists who fabricate objects with aesthetics that provoke an uncanny effect. The lasting appeal of this theory resides in its loose/ subjective interpretation.

Derrida + Uncanny

Derrida draws a bridge between psychoanalytic theory and architecture by translating Freud's theories into the realm of semiotics. As such, deconstructivist architects such as Tschumi and Eisenman were heavily influenced by his philosophy. 
the origin of identity and history. ${ }^{6} \mathrm{~A}$ ghost reveals the vulnerability of concepts while simultaneously undermining the origin of identity and history. Derrida's uncanny or unsettling experience is felt when confronted with a haunting presence that causes "...discomfort and unbalancing of expectations." 7

In the 1990's, Derrida explored concepts of temporality such as: revenant; déjà vu; time-out-ofjoint; and l'avenir (the future) that served as the basis for his discourse on Hauntology. This idea proposes a reconceptualization of temporality in which, much like the uncanny nature of the ghost, the past is a fabricated and inaccessible version of reality that is used to construct the future. ${ }^{8}$ In his reading of Hamlet, Derrida states that "...the future can only be for ghosts." Here, Derrida is suggesting a paradoxical condition in which the past is used to construct a memory of the future.

Freud's concept of unheimlich and Derrida's Hauntology highlight the future as a constant source of anxiety. The following section will further develop the discourse on automation and the future of work as an uncanny scenario that produces a dominant source of anxiety in contemporary political, economic, and socio-cultural spheres.

There is a dichotomy surrounding the future of work in the advent of automation. As explored earlier, automation can, on the one hand bring us liberation from the coercive structures of labour, while the other scenario is an accelerated form of capitalist exploitation that can potentially lead to the extermination of the working class. Alarmingly, much of the contemporary discourse in media and politics is focused on the latter scenario- choosing to emphasize the destabilizing effects of automation. This deep anxiety about the future is an impulsive reaction to the unknown and unfamiliar labour conditions associated with automation. Thus, in an attempt to suppress and negotiate the uncanny into the canny, the events and ideas of the Industrial Revolution (familiar) are conjured up to codify our meanings and attitudes towards automation (unfamiliar).
Spectre

Derrida's concept of spectral as a ghost of the past that haunts the present is appropriated by poststructuralist architects to explore themes of trace and palimpsest. The spectre or traces of the site was acknowledged and integrated into the architectural whole of the new building. 
The concept of Spectre was developed within Derrida's discourse on hauntology. The term can be loosely defined as a ghost of the past, a lost future that never arrived..$^{10}$ I believe that a spectre of the Industrial Revolution is haunting the contemporary discourse on capitalism. This spectre limits our ability of envisioning a post-work future. As a result, we are unable to see the potentials of automation beyond the familiar and restricted framing of industrialization. We remain haunted by the pains and unrest of the industrial revolution and are unable to grasp an alternative vision of the future under automation.

The contemporary attitude towards automation is akin to what the Luddites experienced at the advent of Industrialization. These were skilled textile workers who lost their jobs to production factories employing machinery and unskilled labour. As a response, they formed an armed militia movement to revolt against the "fraudulent and deceitful"11 use of machines. This marginalized group feared that the deskilling of their profession would lead to their obsolescence. In reaction to their loss of employment, they destroyed the machines and factories that enabled line production. Much like the effects of the assembly line on craft labour, automation now threatens the deskilling of not only manual but also cognitive work.

The current anxiety in the face of automation is consistent with how the Luddites reacted to the painful transitions of the industrial revolution.
Automation, much like industrialization is a critical threshold in time that causes a temporal disjunction- the continuous process of projection and actualization that forms the basis of identity making becomes estranged when we are unable to imagine our role in a post-work automated world.

The industrial revolution was a destabilizing threshold in time that accelerated production of goods at the expense of the livelihood of workers. But this difficult transition has also drastically increased the pace of technological and social innovation that has led to improved living standards for much of the world.

The spectre of industrial revolution is exacerbating the process of turning the unheimlichness of automation into the heimlich. Moving past the uncanniness of automation can help us frame an alternative future without the anxiety of unemployment. Rather than contributing to the discourse on the disruptive effects on automation, we need to unravel trajectories in which automation can lead us to a postwork world. 

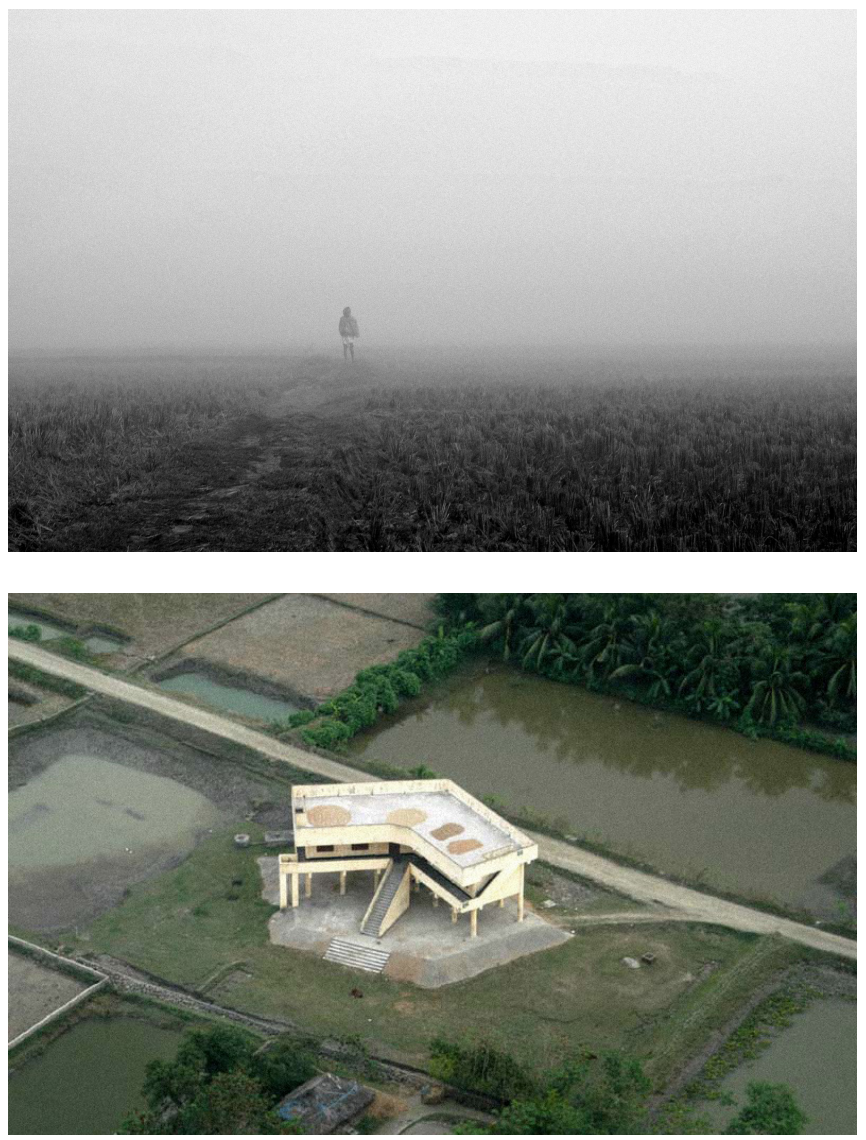

16.2a, b: Cyclone Shelter in Rice Fields of Bangladesh 


\subsection{Architecture as Uncanny}

In 1985 Jacques Derrida was brought in as a consultant by Bernard Tschumi to work with Peter Eisenman for the design of a garden for the Parc de la Vilette in Paris. The design produced by the collabouration of Derrida and Eisenman wasn't executed but Derrida's deconstructivist ideological framework, particularly that of the uncanny, strongly resonated with Eisenman's design philosophy. An interview conducted by Mark Wigley between Derrida and Eisenman for the New Yorker Magazine in 1988 provides insights into the impact of Derrida's uncanny on Eisenman's approach to architecture. ${ }^{1}$

“Everything I like is bizarre, uncanny," Derrida explains. "It's less uncanny now as your get more familiar with it." Eisenman intends his designs to be uncanny. "Uncanny," in fact, is a key Eisenman word. He likes the uncanny photographs of Cindy Sherman and that classic of the uncanny, Blue Velvet. What Eisenman particularly admires about the movie, to which he devotes entire lectures, is the way it explores how the apparently normal can fall apart to reveal the strange and the disturbing- and that it makes this neither layer intensely erotic. The scene he singles out is the one in which, during a frightening kidnapping, the action suddenly stops and one of the kidnappers sings "In Dreams," along with a Roy Orbinson tape. "That scene is just electric to me," Eisenman says. "It's a 'between' thing. Between beauty and horror. It's what Edgar Allen Poe was writing about. It's the grotesque." 2

Speaking against the prevailing ideas of bourgeois comfort, Eisenman goes on to state that "My work has nothing to do with beauty and comfort... It's dislocating; it's not serene. It takes risks. People like risks." ${ }^{3}$ Here, Eisenman highlights the need for an architecture that is unbalancing as much as an architecture that is comforting. In effect, he makes use of architecture to disturb and arouse through the grotesque and the uncanny.
Cyclone Shelter

Climate change has

accelerated the rate of natural disasters in

Bangladesh. As a response, cyclone shelters have been built around the country to defend against an increasingly devastating future threat. The hyper utilitarian buildings erected in mainly rural areas stand in stark formal and programmatic contrast to the local vernacular. The insertion of this foreign signifier has strengthened communal bonds and improved resiliency in the face of an uncertain future. 
The impact of Derrida's philosophy of language and meaning (signifier and signified) on Bernard Tschumi is evident in his avant-garde techniques of defamiliarization applied in the schemes for the Follies in Parc de la Vilette. Tschumi dismantles notions of the park as escapism from the urban conditions, instead choosing to dissolve the boundaries between park and city.

The cubes, also known as "folies" or "cases vides", are found at the intersection of the horizontal and the vertical grid. Painted red, these $10 \times 10 \times 10 \mathrm{~m}$ buildings, of which no two are the same, lack any preprogrammed functions. Superimposed on the grid is a second layer of linear axes and waving pathways for pedestrian traffic. While the northsouth and east-west axes connect to the entrances of the park, they deviate from classical axial designs of gardens. The axes, combined with the undulating pathways, do not terminate in a monumental experience, but instead work to enable the flaneur. ${ }^{4}$ By providing alternate choices of movement, the pathways operate outside the limitations that the clarity of a single narrative or meaning would demand. This condition leads to an unbalancing of expectation whereupon arbitrariness and chance take over. The experience is akin to the technique of surrealist automatism- the conscious control over the expectations is suppressed and instead, the visitor abandons his/her experience to chance operations. The third layer consists of surfaces that enable large group gathering for communal activities.
Speaking on Tschumi's notational system, Wigley states: " [the]...series of ambiguous intersections between systems in which the status of ideal forms and traditional composition is challenged. Ideas of purity, perfection, and order, become sources of impurity, imperfection, and disorder." 5 Indeed, the purity and rationality of the geometrical systems superimposed on the topography leads to an expected and stable condition, while the impurity is found at the intersection and juxtaposition of the systems.

Tschumi's strategies weaken our trust of each of the ordering systems that serve to construct the Parc de la Vilette. Via techniques of deconstruction, he is able to undermine visitors' expectations. One's trust of the ordering systems that govern the park is challenged, thus provoking an uncanny feeling. As noted, Parc de la Villete is an extension of, and quite possibly an allusion to, the larger urban condition of the city. The layers that serve as ordering systems for the park parallel the ordering systems of the city. Thus, by dismantling and subsequently revealing the flaws and vulnerabilities of the park, Tschumi leads the visitor to question ontological truths which govern the construction and experience of everyday reality. ${ }^{6}$ 


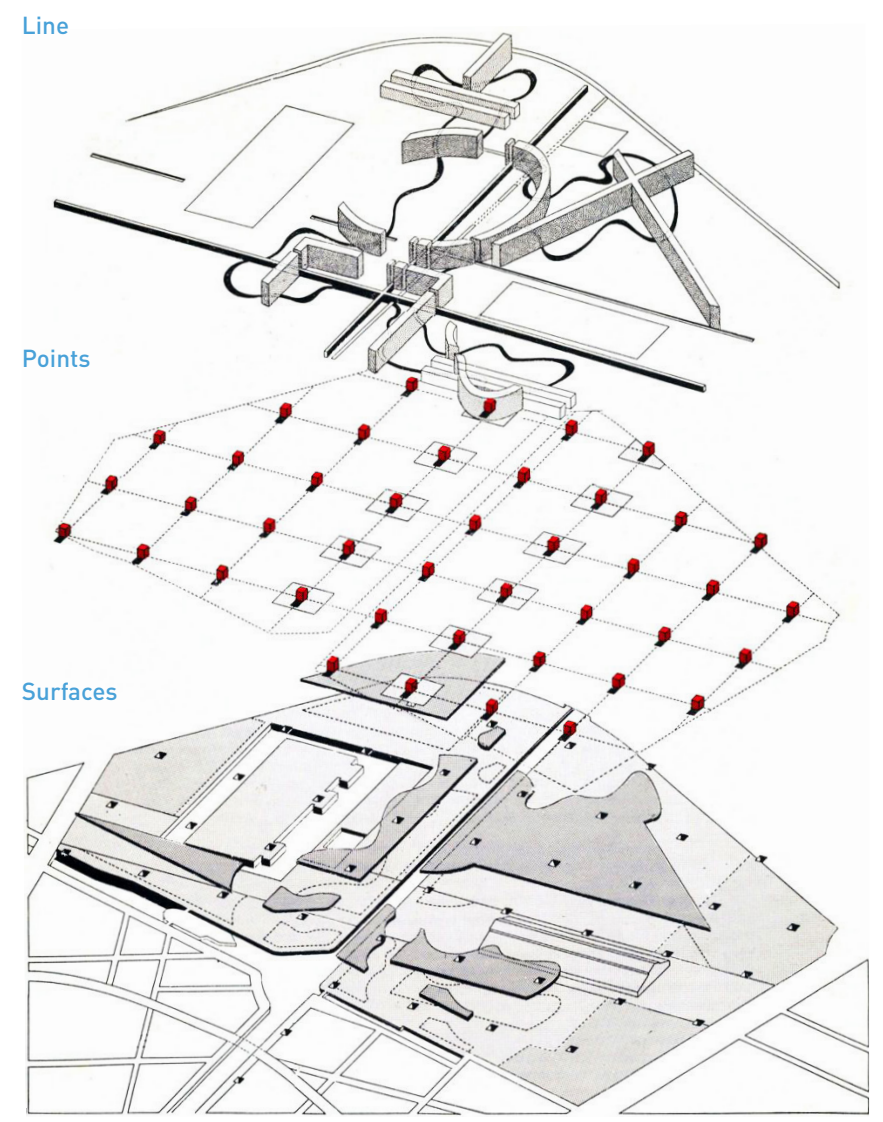

16.3c: Parc De La Villette, Axonometric

“...the structure of the grid and each cube...

leaves opportunity for chance, formal invention, combinatory transformation, wandering."7 

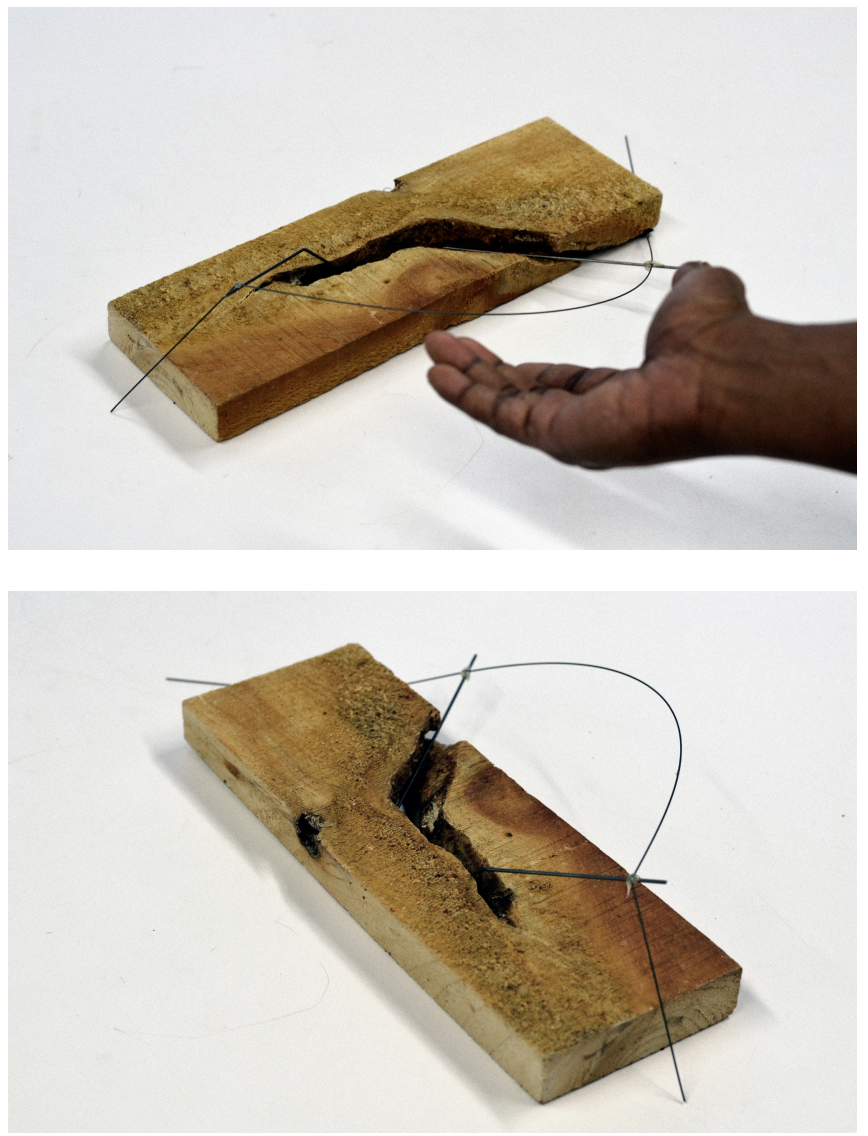

16.4d,e: Strange Objects as Revealing 


\subsection{Strange Objects as Uncanny}

David Ruy in "Returning to (Strange) Objects" argues that the architectural object is being marginalized because of the discipline's attempts at expanding the field of architecture. He observes that architects are operating in a state of insecurity.

"Since the mid-nineties, architecture has accelerated its move away from the discourse of the architectural object towards the discourse of the architectural field. The vicissitudes of the architectural object has lost its uncanny appeal, and recent work is more often than not circumscribed by the mental image of an underlying network of relations that is deep, dynamic, and more real than the object itself." ${ }^{2}$

Afraid of being insular and consequently being left behind, contemporary architects apply architectural thinking to expand the profession into all kinds of other networks and fields. Ruy notes that it is this desire to maintain importance in the current field of networks that has de-emphasized the architectural object. In effect, the global network of relations is diluting the essence of architecture. The essence that is found in the crafting of architecture as an object is being lost. ${ }^{3}$

The current relationship with architecture and nature is argued as the culprit for the professions' weakening. Nature is not used as a source of inspiration and / or abstraction in the contemporary landscape. Instead, architecture is shifting towards a new form of practice based heavily on ecological principles. This move towards ecology is in parallel to other fields that observe the built environment as a critical area of improvement. A by-product of this creeping has been the undermining practice of viewing architecture / objects merely as a quantitative set of measurements. This predominant framing effectively removes the uniquely 'strange' traits of architecture / objects. ${ }^{4}$
David Ruy

Architect, professor, and theorist David Ruy operates at the intersection of architecture, nature, and technology. In his influential paper "Returning to (Strange) Objects", Ruy investigates the contemporary practice of architecture moving towards a process-oriented way of working which has led to the diminishing authority of the profession.

Instead, he calls for a return to the crafting of strange objects. 
Ruy refers to Graham Harman's theory on Object Oriented Ontology (000) to advance his argument. 000 posits that the objects withdrawal from one another and that objects are more than the relations we ascribe to them. There is a "dark nucleus of objects" that will always be elusive to other objects. ${ }^{5}$ Thus, objects embody an uncanniness that is always beyond reach. In effect, objects have ontologies that are nonquantifiable. Objects are more than the sum of all the theories we ascribe to them. There is an uncanniness about them that is unidentifiable. The interactions between objects express abstract, irreducible, unpredictable, and unquantifiable relationships such as the maker and its relationship to materials. Arguably, it is the maker's las an object) interaction with other objects that is able to accelerate the discovery of strange embodiments.

Ruy points out that instead of making objects through methodologies that align with network theories, architects should explore craft, and the mysterious power of making. Craft is described as the relationship between the object that is made and the maker- who is also an object. The learned methodology is as irreproducible as the essence of the object that is made because it embodies the unique qualities of the [hand and mind] of the maker. ${ }^{6}$

Viewed through the lens of the uncanny, objects are unheimlich. As theorized by 000 , there is a concealed strangeness about the object that is always beyond reach. The strange anxiety caused by the unfamiliar qualities of the object can be used for dislocation.
As examined in the previous chapter, deconstructivist architects have attempted political engagement via strategies of reformation. Tschumi's layered planning of objects and experiences for Parc de la Villete demonstrates that architectural constructs can induce a sense of the uncanny, leading to the reorganization of society. In effect, the Park de la Villete is architecture with critical engagement that works to first untangle, then challenge the hegemonic structures of society by employing the uncanny. A "Return to (Strange) Objects" hints that making and exploring via objects and materials is a fundamental methodology available to architects. A craft developed through the making of objects captures and reveals the hidden essence of the objects. These insights become sources of abstraction that unravel new logics and mysteries about architecture. 


\subsection{Making the Uncanny Object}

The discipline of architecture has a deep-rooted tradition of provocation via the image. To provide a few examples: Archigram's collages were used to propose avant-garde ideas; Lebbeus Woods' line drawings helped him theorize a polemic against repressive conditions; and Zaha Hadid's deconstructivist paintings were made to explore abstract architectonic constructs. Such images operated as seductive, yet strange expressions infused with radical propositions.

Architects have historically and continue to make use of the image to explore unfamiliar constructs.' Yet it can be argued that in the contemporary age of ubiquitous virtual simulation, the architectural image has lost its ability for critical provocation. In parallel with Ruy's position, it can be argued that the architectural image (as object) has been marginalized to the point where it has lost its ability to provoke via the uncanny. In effect, there is an oversaturation of the image in today's occulocentric media culture. We have exhausted the image. Seductive architectural images are constantly being generated in the mass media to be readily consumed by the public. The contemporary architectural image is dominated by elaborate visions that are often made via procedural techniques in an attempt at new provocations. But the architectural image falls short as the medium has become too predictable, and too familiar. Derrida's discourse of semiotics reveals that "The uncanny lurks behind the unstable links between signifier and signified."2 Thus, examined through the lens of representation, the architectural image has lost its uncanniness because the links between the architectural image and its concepts have become too stable. In other words, the architectural image is now unable to conjure feelings of anxiety.

An alternative to the architectural image as provocation is the architectural artefact. As stated, the architectural object is an artefact that contains a strangeness that is always withdrawn. A "Return to [Strange] Objects" proposes a return to an uncanniness of the object that is discovered through craft - the ability to poetically assemble objects and materials.

\section{Artefact}

In the contemporary

practice of architecture, artefacts are often used

as representational

forms subservient to the final building. Dictatorial technologies enabled by digital production are limiting the exploration of the architectural object. Instead, a crafting of an artefact can be used to freely explore architectural ideas, and maintain a critical methodology. 
Parallels can be drawn between David Ruy's critical position of object as strange and Marco Frascari's concept of Cosmopoiesis, a term used to unravel the architects' "act of world making".

Within poetic artefacts, the intent lays in the edifying understanding of materials, in how the ingredients are ranked in culture, the distillation of the objects' essence in the acts of making; consequently the fundamental role of the maker becomes a process based on nurturing, discovering, and revealing. Cosmopoietic artefacts always give a feeling that something strange concerning their nature is not completely revealed but is still contained in them. ${ }^{3}$

Frascari, like Ruy speaks of the object's essence as the concealed strangeness that becomes revealed through the act of making (craft). It can thus be hypothesized that the act of making can be as uncanny as the created object. Strange interactions between objects can lead to strange expressions. As such, the interaction between the maker and the tools and materials necessitate a methodology that is beyond normative relational methods in order to achieve a defamiliarization of the known qualities of the object. A methodology that returns to a state of abstract curiosity can accelerate the process of nurturing, discovering, and revealing. 


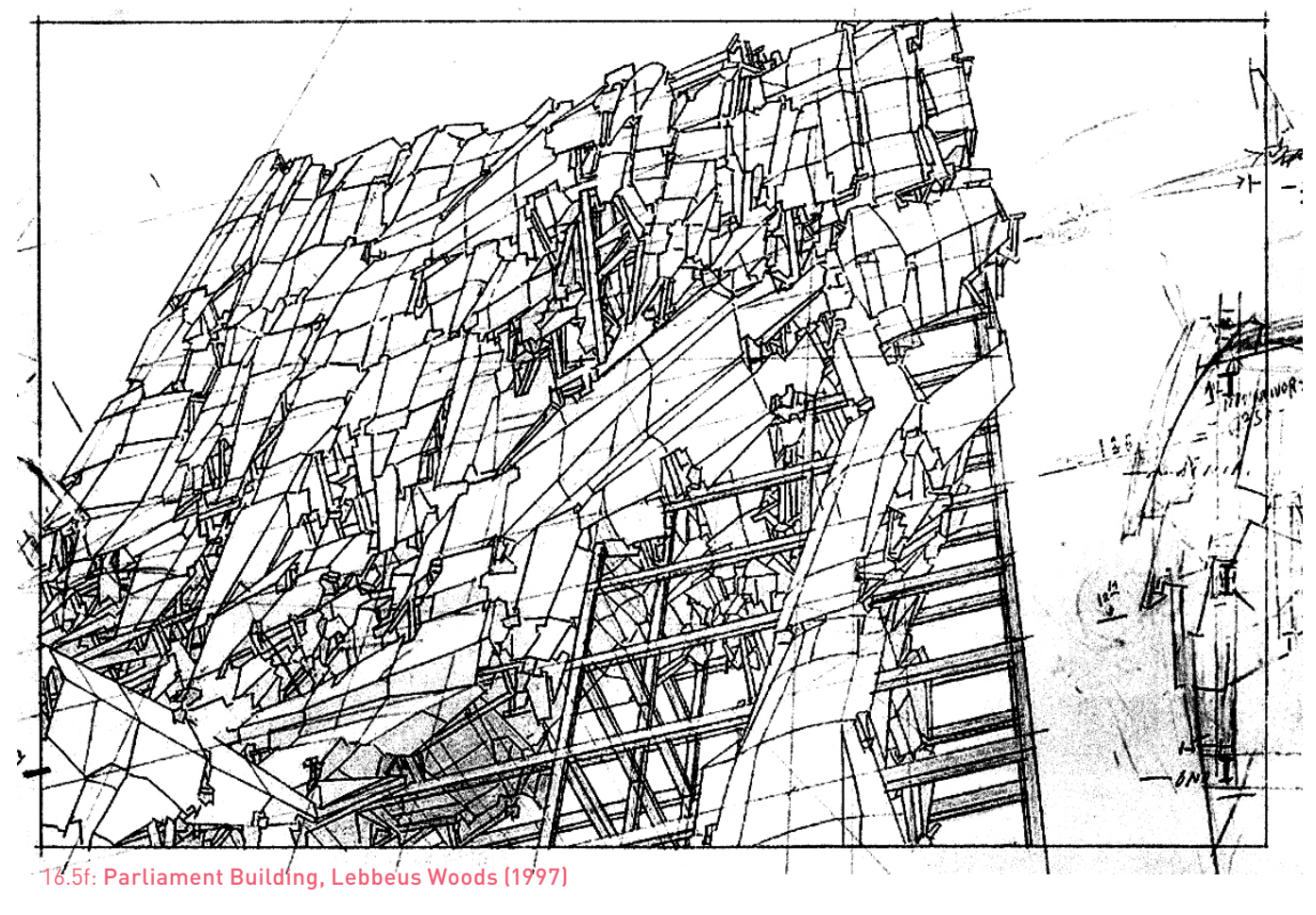

“...architecture whose forms and spaces are the causes of rebellion, against them, against the world that brought them into being- architecture drawn as though it were already built- architecture built as through it had never been drawn."4 


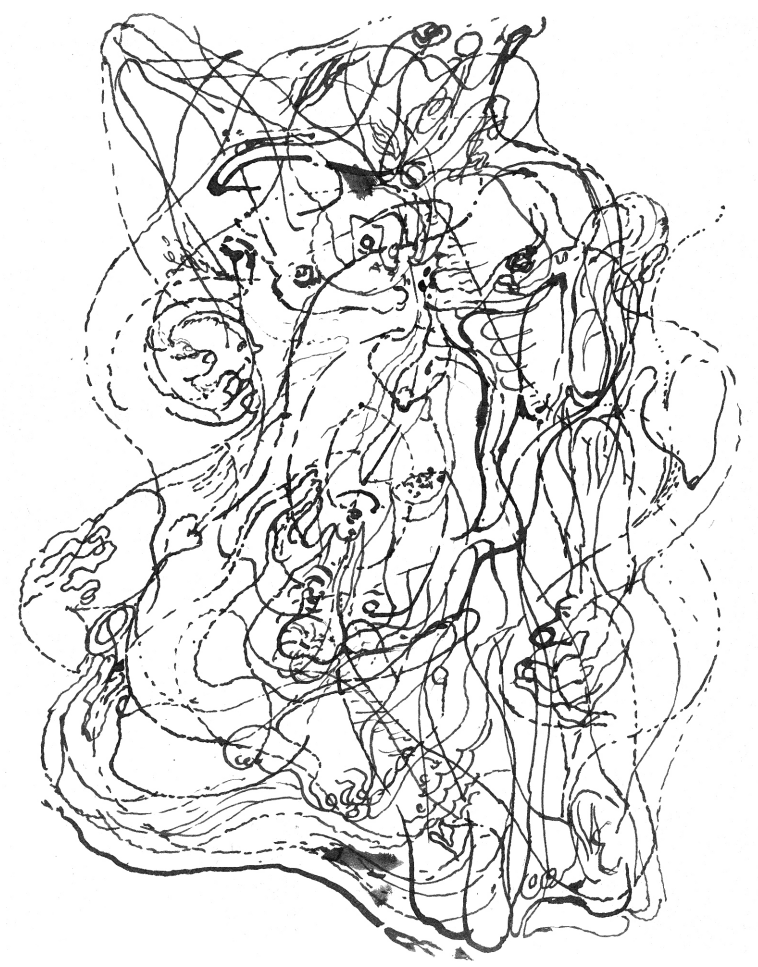

16.6g: Automatic Drawing, Andre Masson (1924)

\section{Les Champs Magnetiques}

It was the end of sorrow lies. The rail stations were dead, flowing like bees stung from honeysuckle. The people hung back and watched the ocean, animals flew in and out of focus. The time had come. Yet king dogs never grow old they stay young and fit, and someday they might come to the beach and have a few drinks, a few laughs, and get on with it. But not now. The time had come; we all knew it. But who would go first? ${ }^{3}$ 


\subsection{Uncanny Methodologies for the Uncanny Object}

As noted, established, and standardized processes in architectural thinking that are grounded in relational models limit the potential for reformation in architecture. Surrealist Automatism is a methodology that suppresses conscious control over the making process to reveal and encourage strange interactions between the object being made and the maker (also an object). ${ }^{1}$ Techniques of automatic writing, drawing, and painting were commonly used by surrealist artists such as Salvador Dali and Andre Masson to express the uncanny qualities of the subconscious. Impulses, emotions, and desires that are otherwise controlled by the id are revealed through the process of making. ${ }^{2}$
Applying techniques that are inspired by surrealist automatism allows a revealing that is achieved via abstractions, experimentation, and discovery. Not having a clearly defined process suggests an intuitive crafting, through the interactions between objects. Using chance as part of the equation along with a suppression of conscious controls, by letting the hands do the thinking; this can result in figurative representations from which suggestive qualities can then be extrapolated.

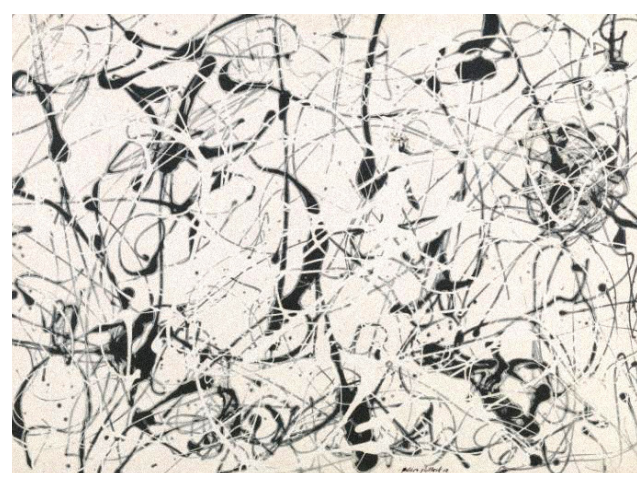

16.6h: Number 23, Jackson Pollock (1948) 
A critical opposition against the established cultural norms results in innovations that propose new truths. The uncanny is a constant source of anxiety, a new truth threatening to erupt at any moment to destroy the existing reality. When successfully devised, the extra-cultural becomes absorbed by culture, and in the process shifts the cultural hegemony in a different direction.

A post-work world is a claim to a new truth; a polemic that is more real and more important than the established and outmoded form of capitalism increasingly under pressure under automation.

Architecture is invariably a part of the cultural-economic system of capitalism. A focus on the architectural artefact reveals a process to devise an innovative signifier for a new truth. The discovered avant-garde semiotic code is a language of rebellion against the established hierarchies of contemporary architecture. 
17.0

\section{Architecture for a Post-work World}





\section{Introduction}

The Monument to Culture works as a critique of the structural barriers as exemplified by the surrounding commercial tower typologies grounded in modernist and cartesian ideals. The underlying aim for the Monument to Culture was to make an object through which to explore a kind of profane architecture that works to dismantle the familiar and the inescapable logic of capitalism.

The Monument to Culture is an architecture for a post-work world intended to simultaneously challenge present urban conditions and propose alternative futures for a post-work society. The typology proposes a slow recomposition from within; for a realignment of capitalism toward the production of social good. It is important to note that The Monument to Culture embodies three fundamental principles: (1) criticism through strategic insertion, (2) polemic through morphology and program, (3) strategy of withdrawal. In addition, qualities and methodologies of the uncanny will be used to craft the uncanny monument. 
The design of the Monument to Culture required a variety of experimentation. The selected processes involved inserting items such as balloons, straws, and various styrofoam objects into a rectangular prism shaped form work. Plaster was then poured inside, resulting in an object that appeared from the outside to be monolithic. In the next step, the prism was sliced open longitudinally to reveal two halves. Finally, the cast-in items (conceived of as sacrificial form work) were removed to expose voids that produced unforeseeable qualities of the section. The resulting objects served as the base artefacts on which to take action; to make, reveal, and deploy to alternative and iterative methodologies in order to discover the concealed strangeness within.

It is important to note that there is a danger in the process of transliterating objects (signifier) into words (signified). Semiotics with slippery meanings require an openness of interpretation when extrapolating the abstract qualities suggested 
by the experiments. Despite being chronologically ordered, there is a plurality in the discourse as each iteration offers a unique ontological perspective of the architectural artefact.

The following section is an inventory of the design research investigating an architecture for a post-work world. The deployed methodologies and processes attempt to destroy the familiar mechanisms and operations used to create architecture under contemporary capitalism. The range of experiments result in uncanny objects with hidden logics. These architectural artefacts are used to capture and reveal a new semiotic code; an innovative language to formulate a new signifier, a new truth for a post-work world. 



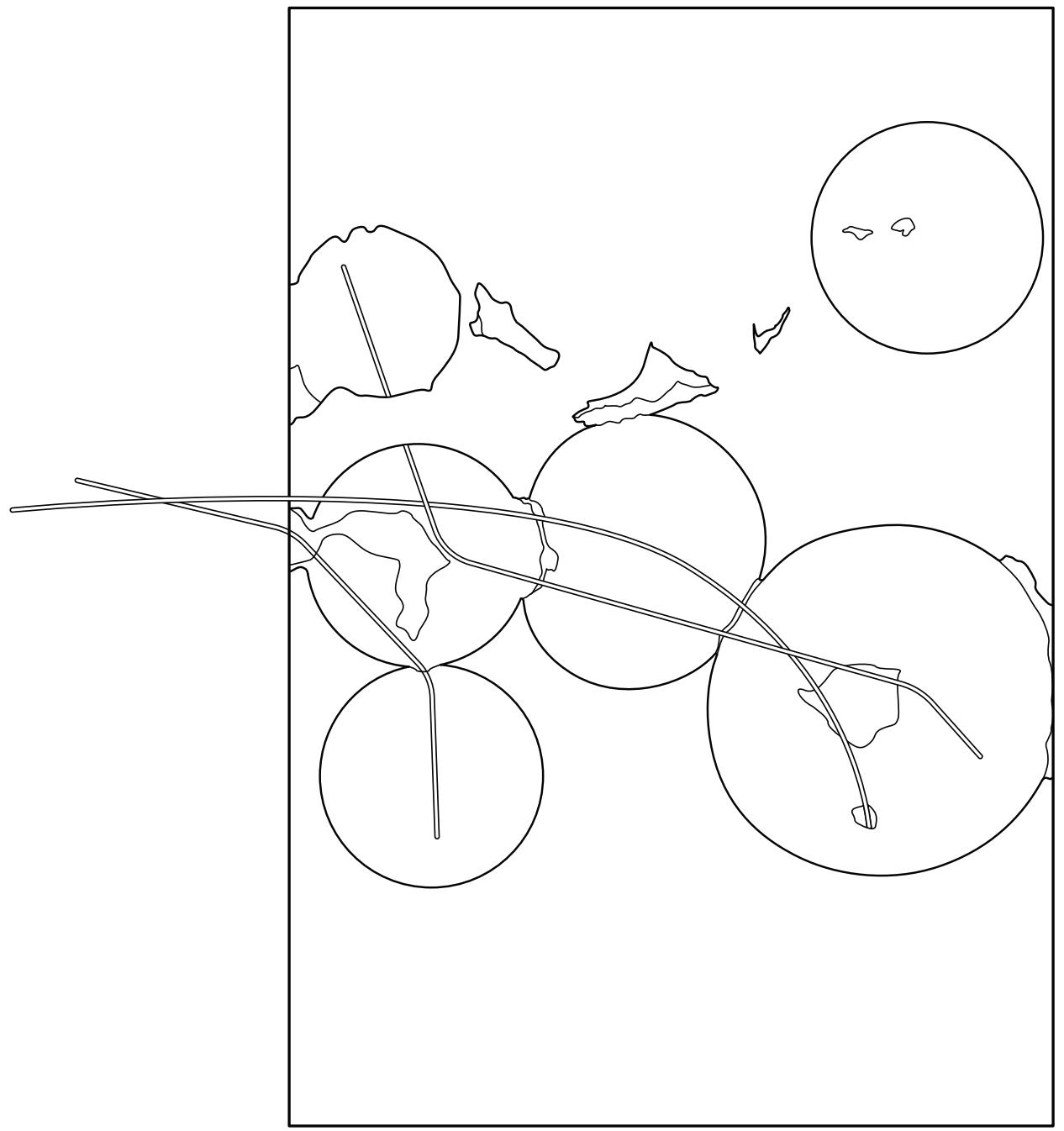

17.0a: Sectional Condition of Monument 



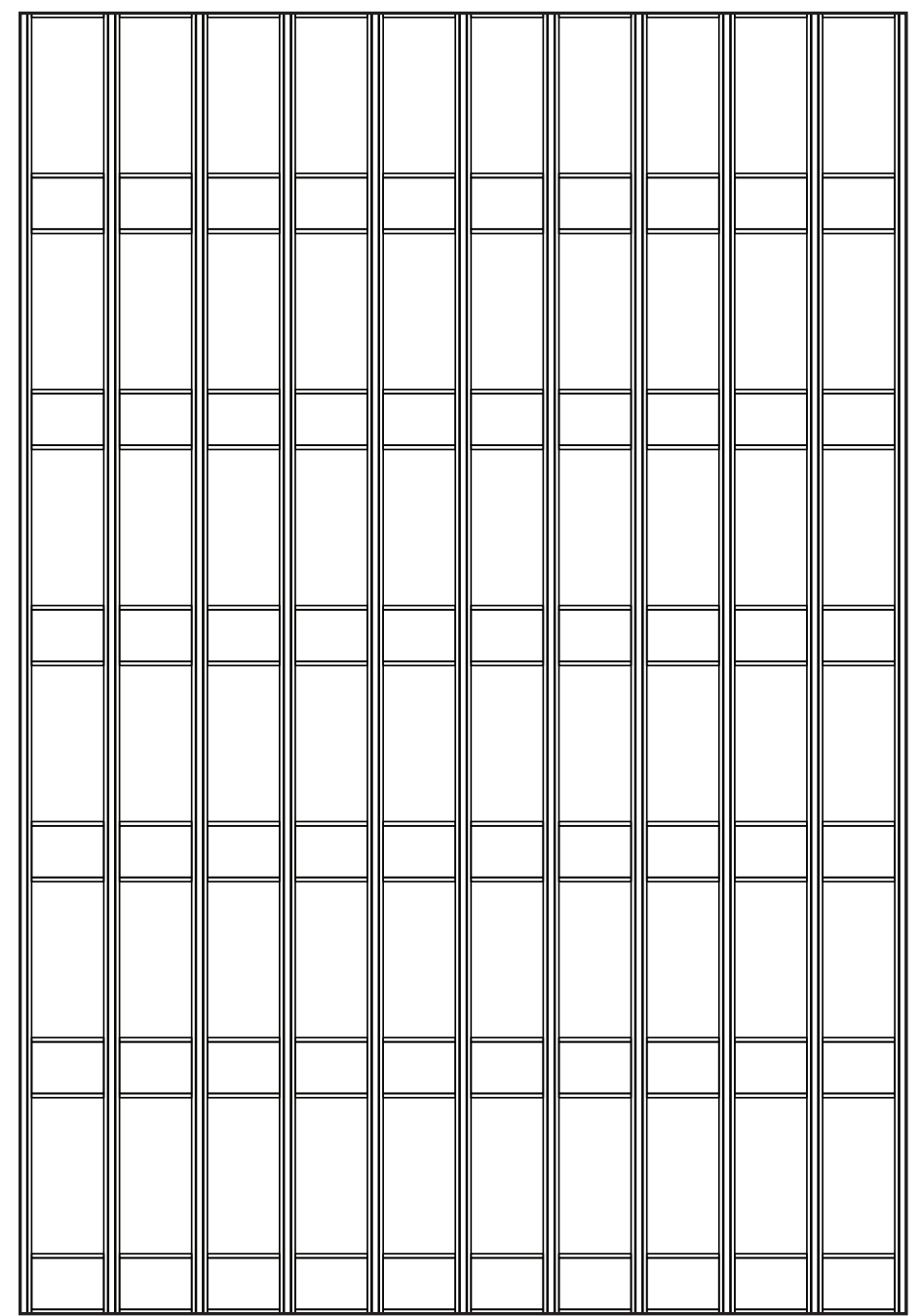

17.0b: 'Cartesian' Facade of Mies Towers in Toronto's Financial District 


\subsection{Discovery via the Architectural Object}

During the casting process, the objects placed inside the formwork float and interact at the surface level. The collision of surfaces results in thresholds between the volumes revealed only when the solid plaster block is cut in section. The smooth textures and forms of spherical and organic volumes are in contrast to the linear saw cut texture of the section plane and the rectilinear edge condition. The plastic properties of plaster allow the material to take on the characteristics of the formwork. In effect, the forms and textures are largely dependent on the design of the formwork.
Inconsistencies produced by the form work at the pouring stage of the plaster have resulted in surrealist geometries. Such unintended imperfections become opportunities for new explorations.

Scanning the sculptures on a flat bed reveals a new spectrum of qualities about the object. In effect, the figure - ground relationship is amplified in a two-dimensional capture as the negative areas without plaster expose the exterior shell of the object. Another interesting condition is the effect captured by the scanning process. The horizontal gradient created by the moving light source captures the depth of the negative volumes.

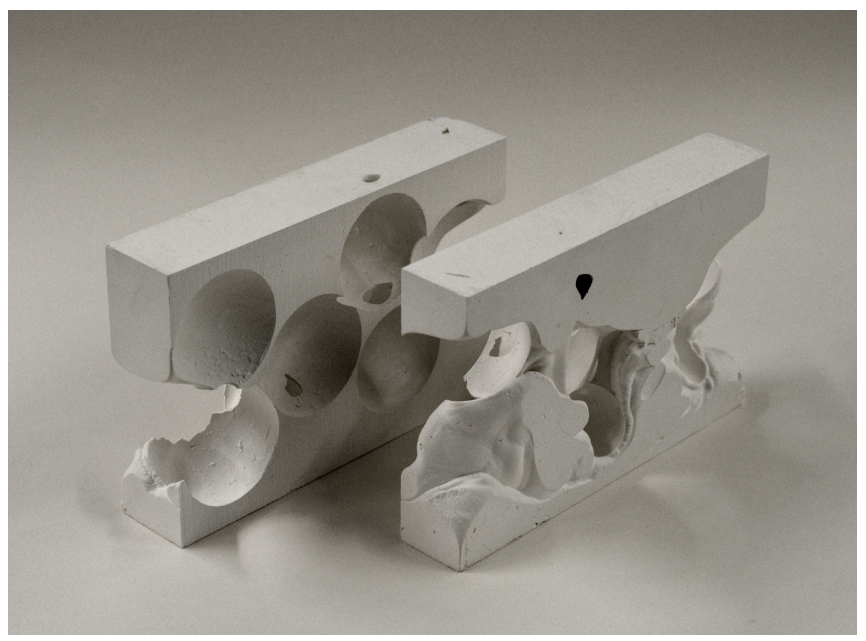

17.1a: Architectural Object: Conceptual Model 01 

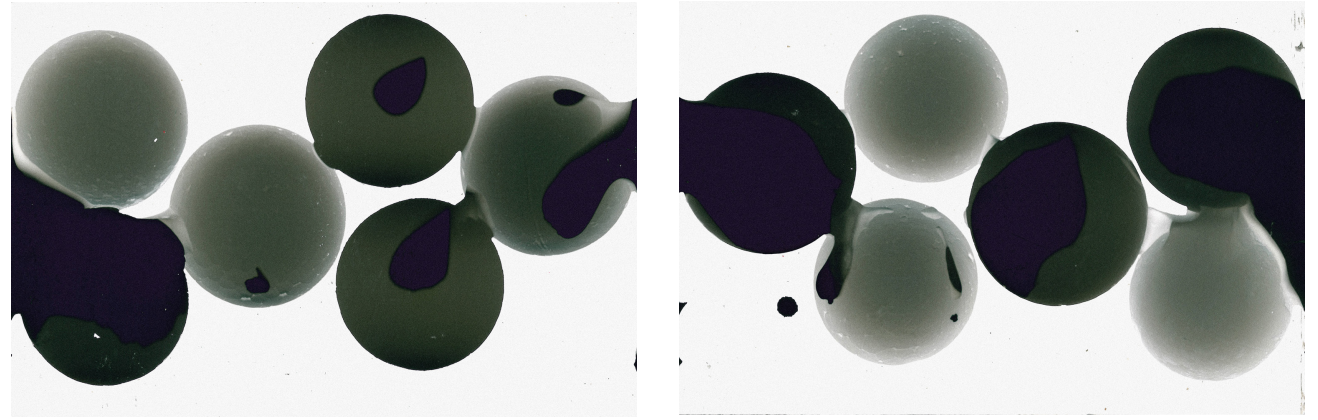

17.1b: Sectional Qualities

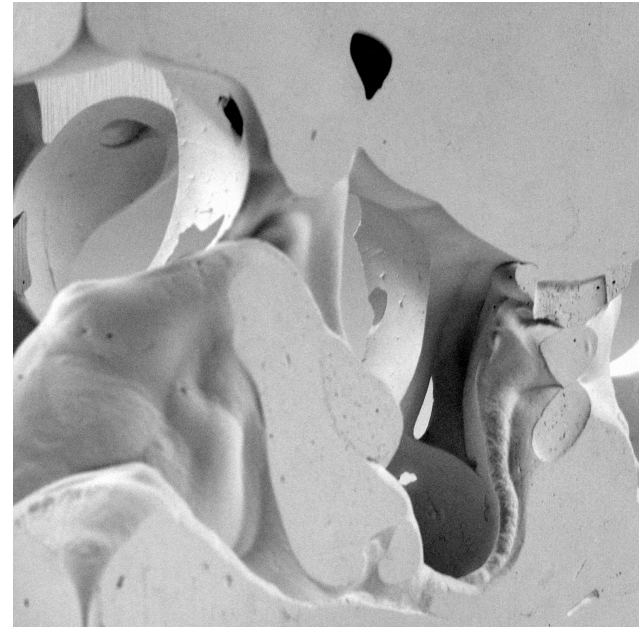

17.1c: Sculptural/ Formal Qualities 01

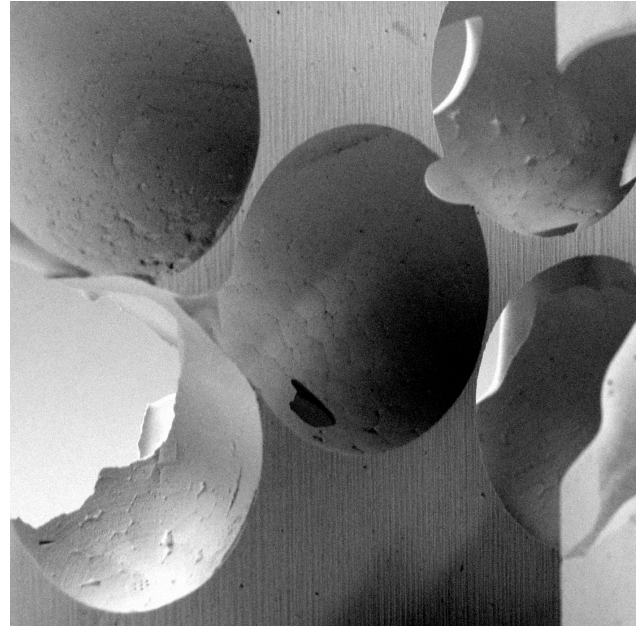

17.1d: Sculptural/ Formal Qualities 02 


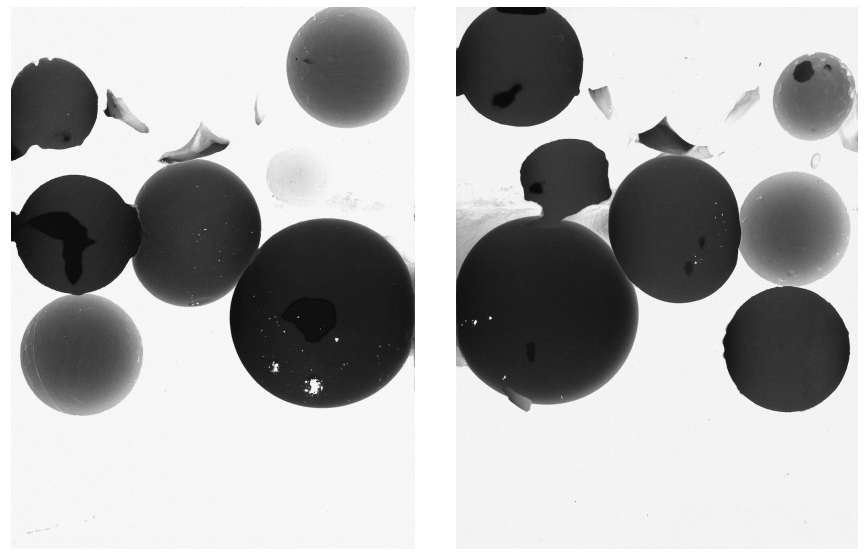

17.1e: Architectural Object B1, B2: Longitudinal Section

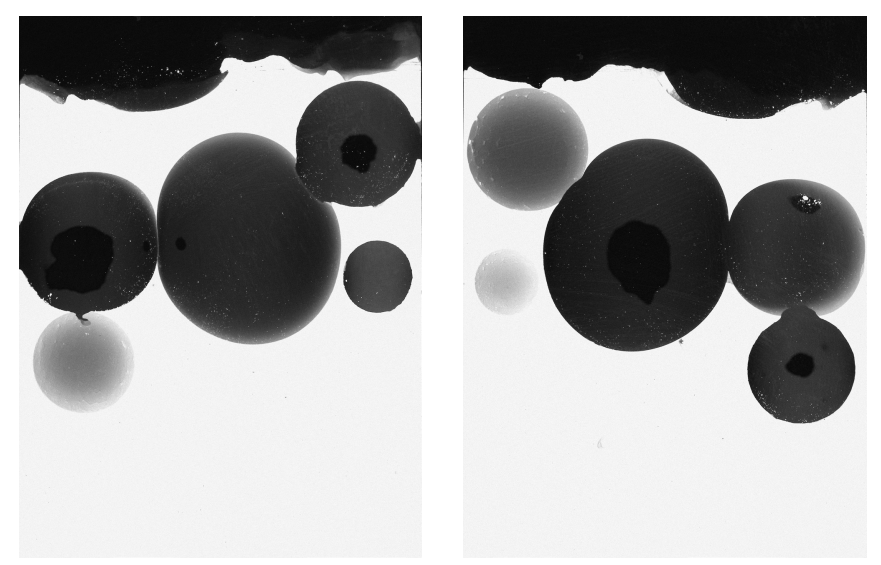

17.1f: Architectural Object C1, C2: Longitudinal Section 

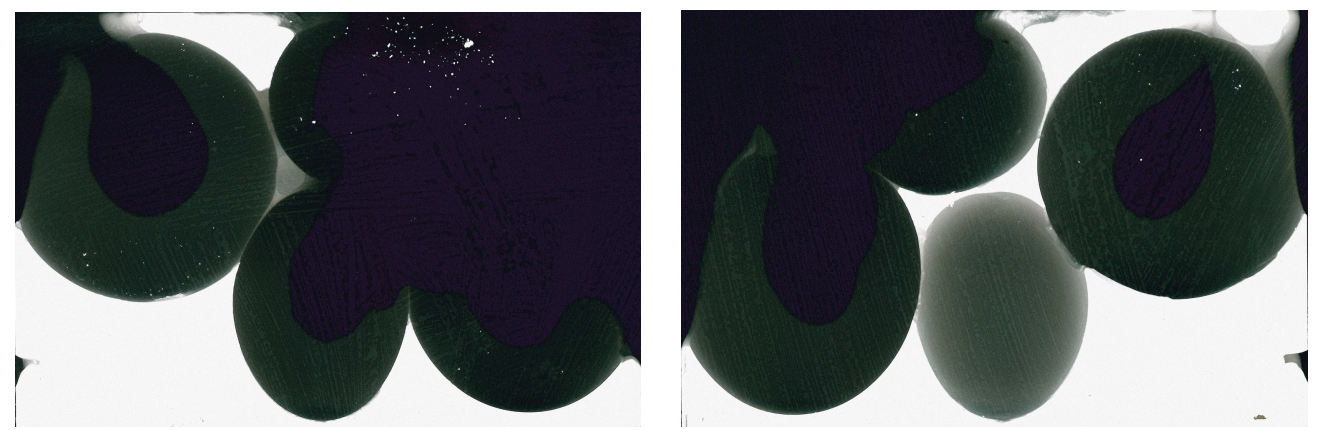

$\stackrel{m}{m}$

17.1g: Architectural Object: Conceptual Model 02, Section
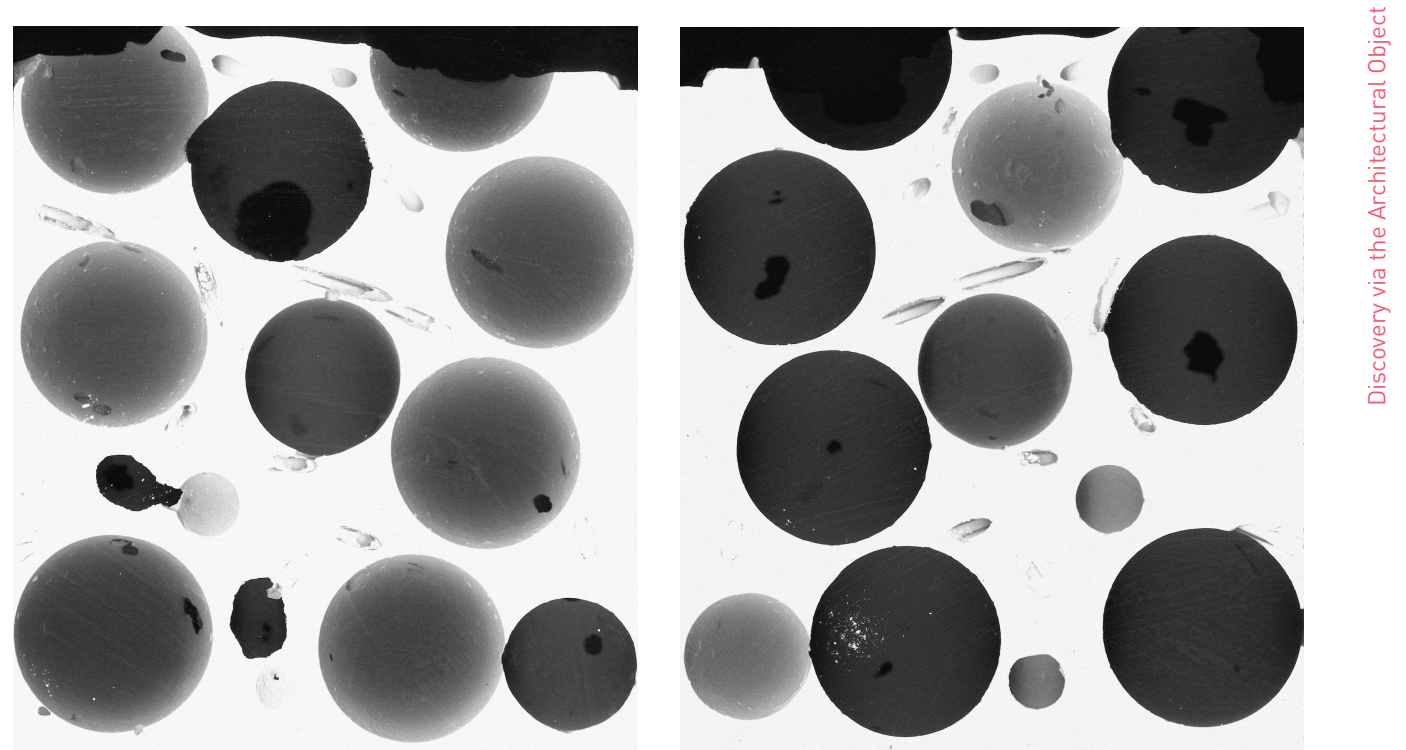

17.1h: Architectural Object A1, A2: Longitudinal Section 


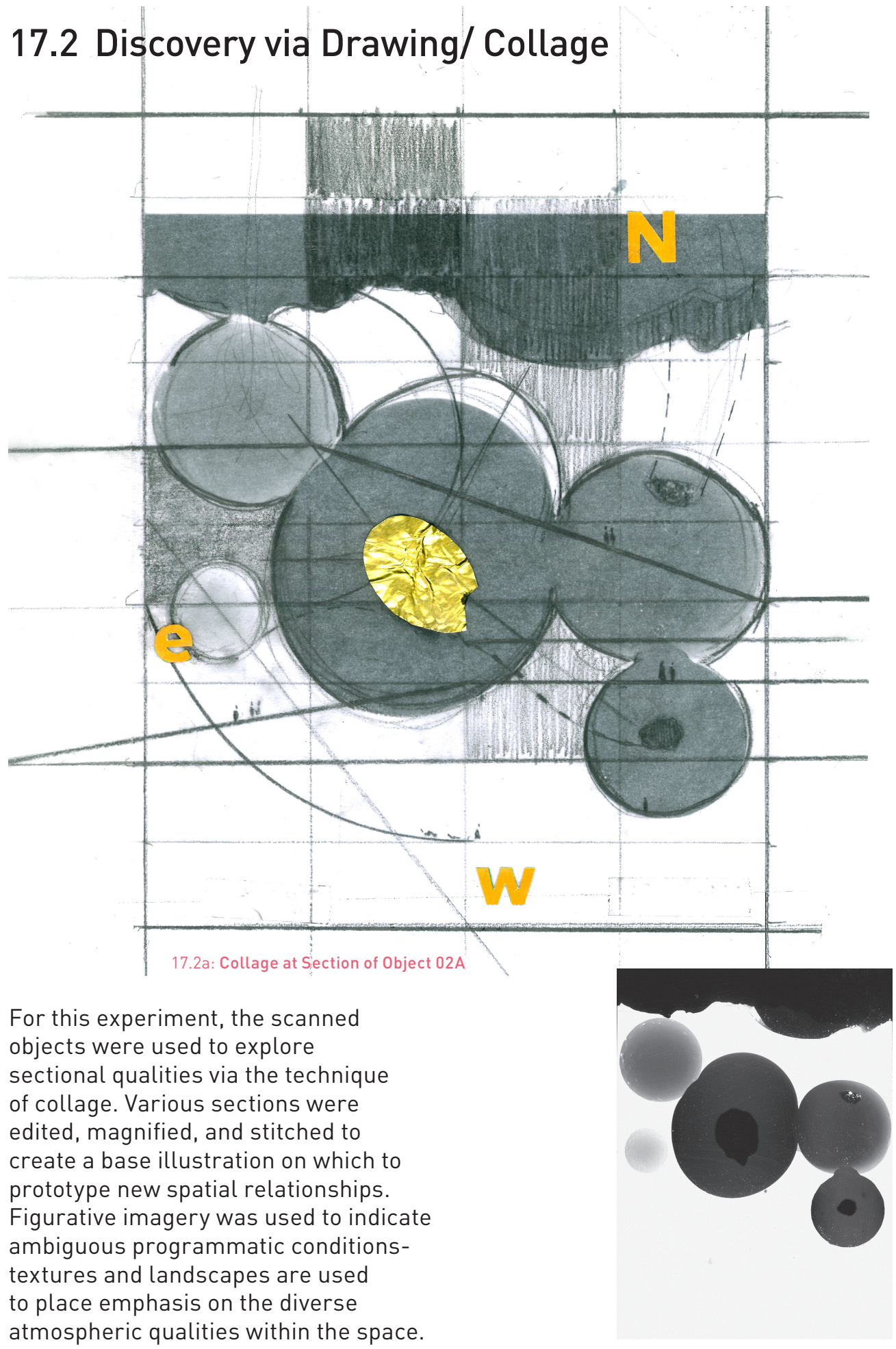


The superimposition of a grid adds a structural logic to the section that implies a "free section" in which pavilions float and merge within large spaces. A free-standing structural frame allows for the insertion of continuous floors and ramps that enables the dérive to flow from one situation to another. And, extending the ramps and floors beyond the frame suggests a dontinuation of program and circulation.
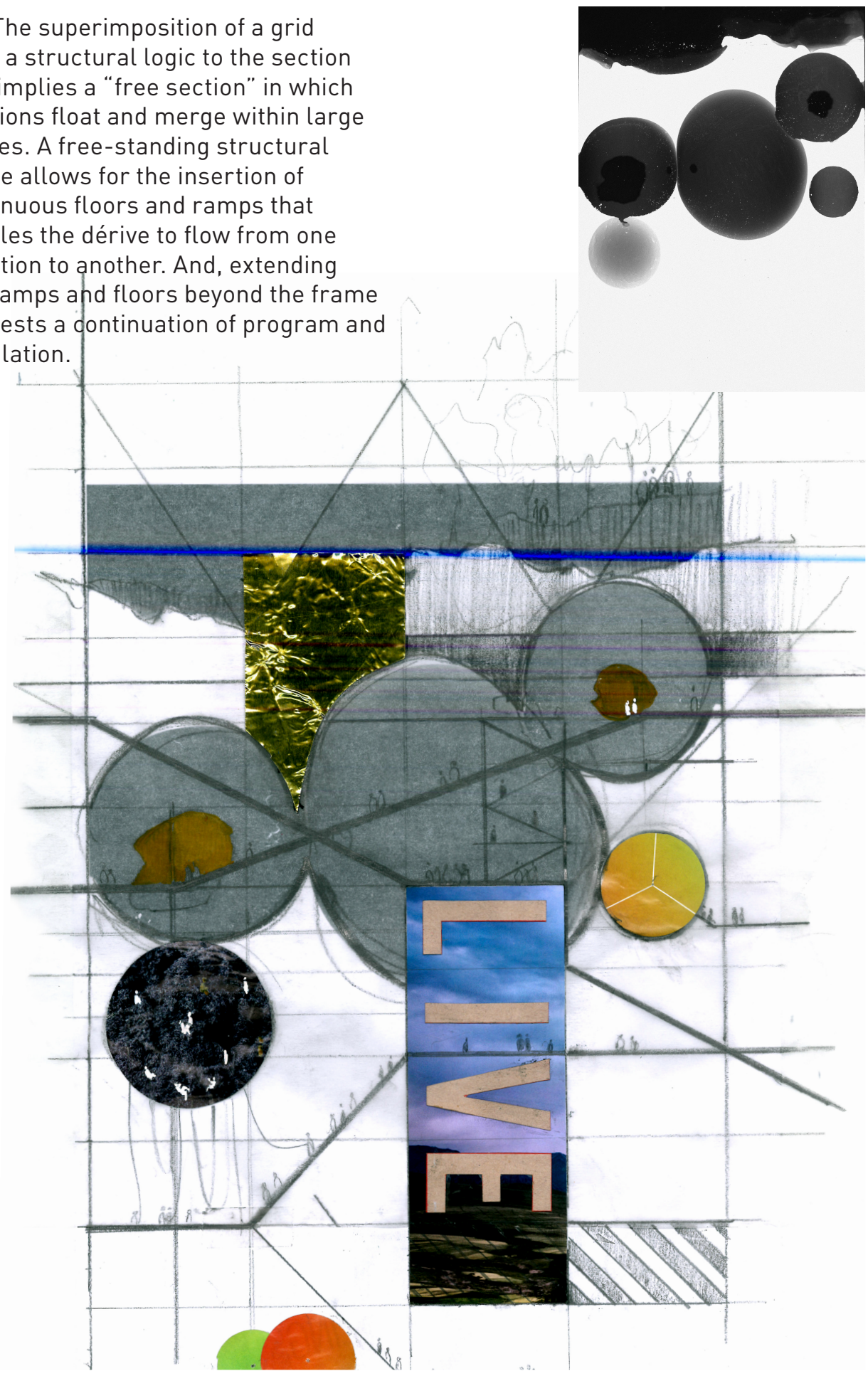

17.2b: Collage at Section of Object 02B 


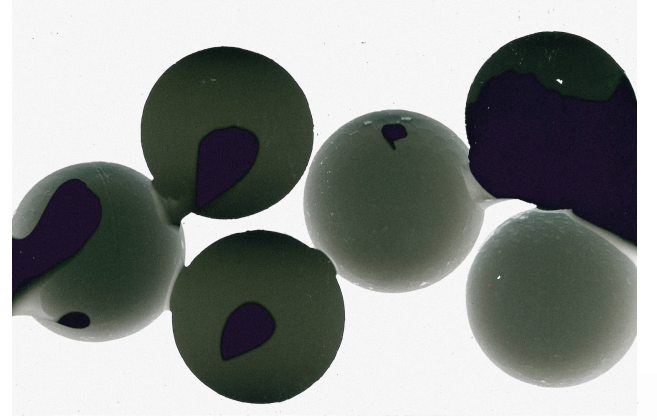

Adding figures to the collage invariably adds scale and proportion to the represented space. Figures meander playfully across each captured sectional frame.

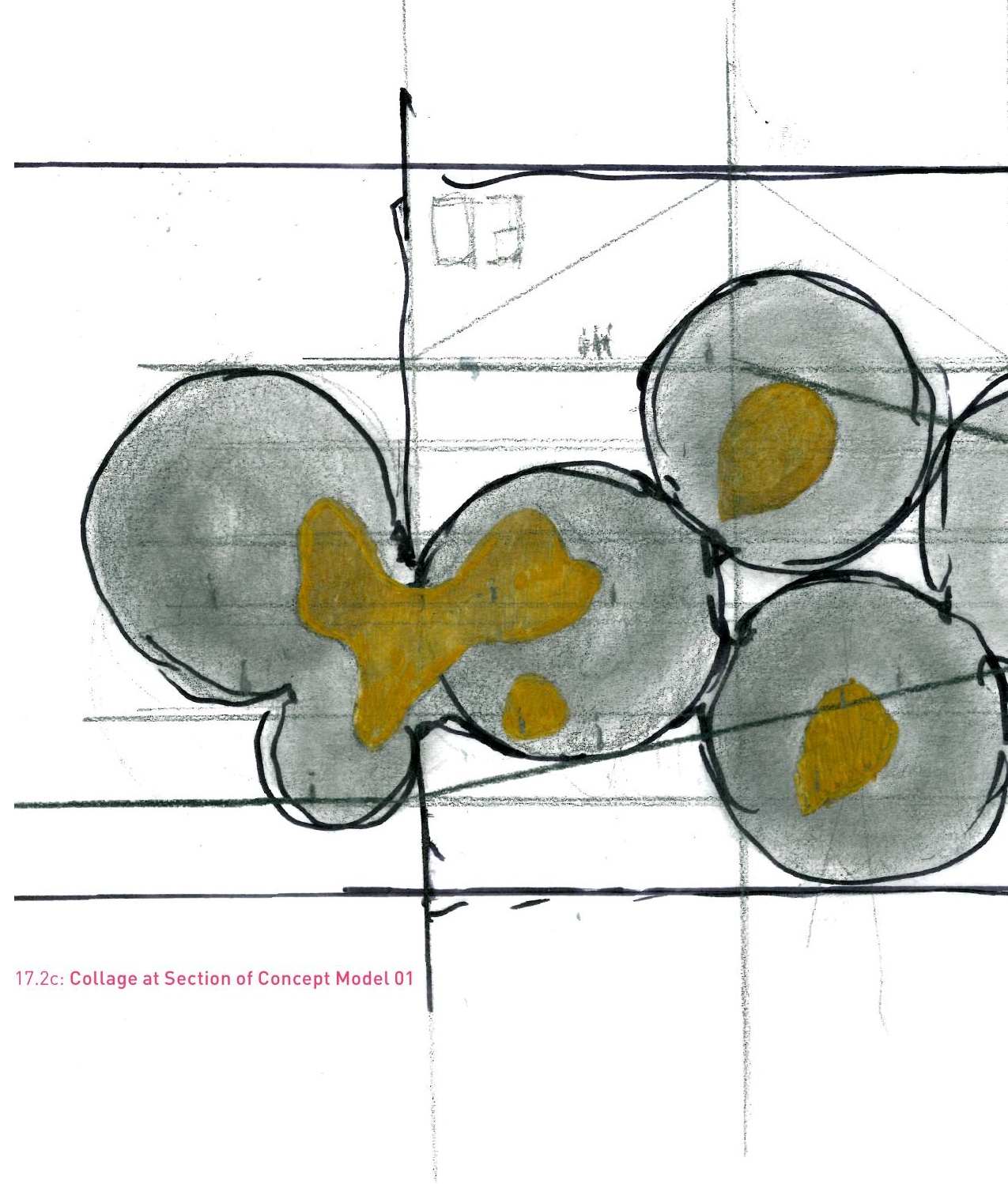





\subsection{Discovery via the Architectural Artefact}

In this process, the object was first photographed, then traced via an isometric line drawing, and finally encoded with a logic to capture various elements.

A similar logic to that of Park de la Villette is applied. Negative volumes are translated as surfaces, steel wires as lines, and perimeter as points. The wires were intuitively inserted into the two halves, to explore dynamic relationships of space, material, form, and sculpture. Wires work as lines that can be abstracted as architectural elements such as planes, ramps, stairs, corridors, bridges, slides, light wells, support armatures, etc.

Lines serve as notation for meandering. They offer heterarchical, non-linear circulation as wires merge, intersect, interweave, expand, contract, etc. 
17.3a: Drawing of Architectural Artefact (02B)

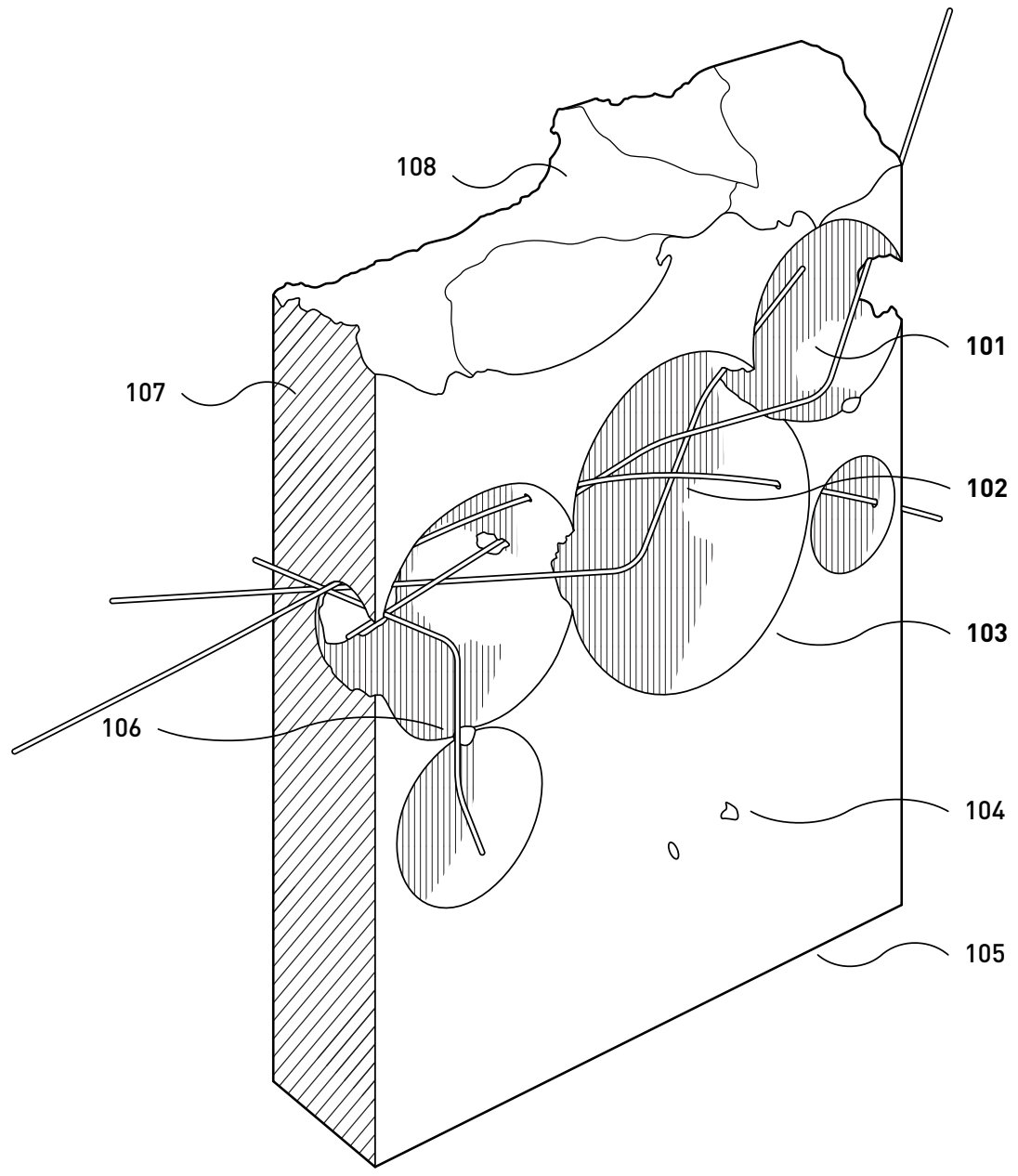

101. Surface

102. Lines

103. Points

104. Imperfections

105. Base/ Ground Plane

106. Threshold

107. Sectional Condition

108. Topographical Condition 



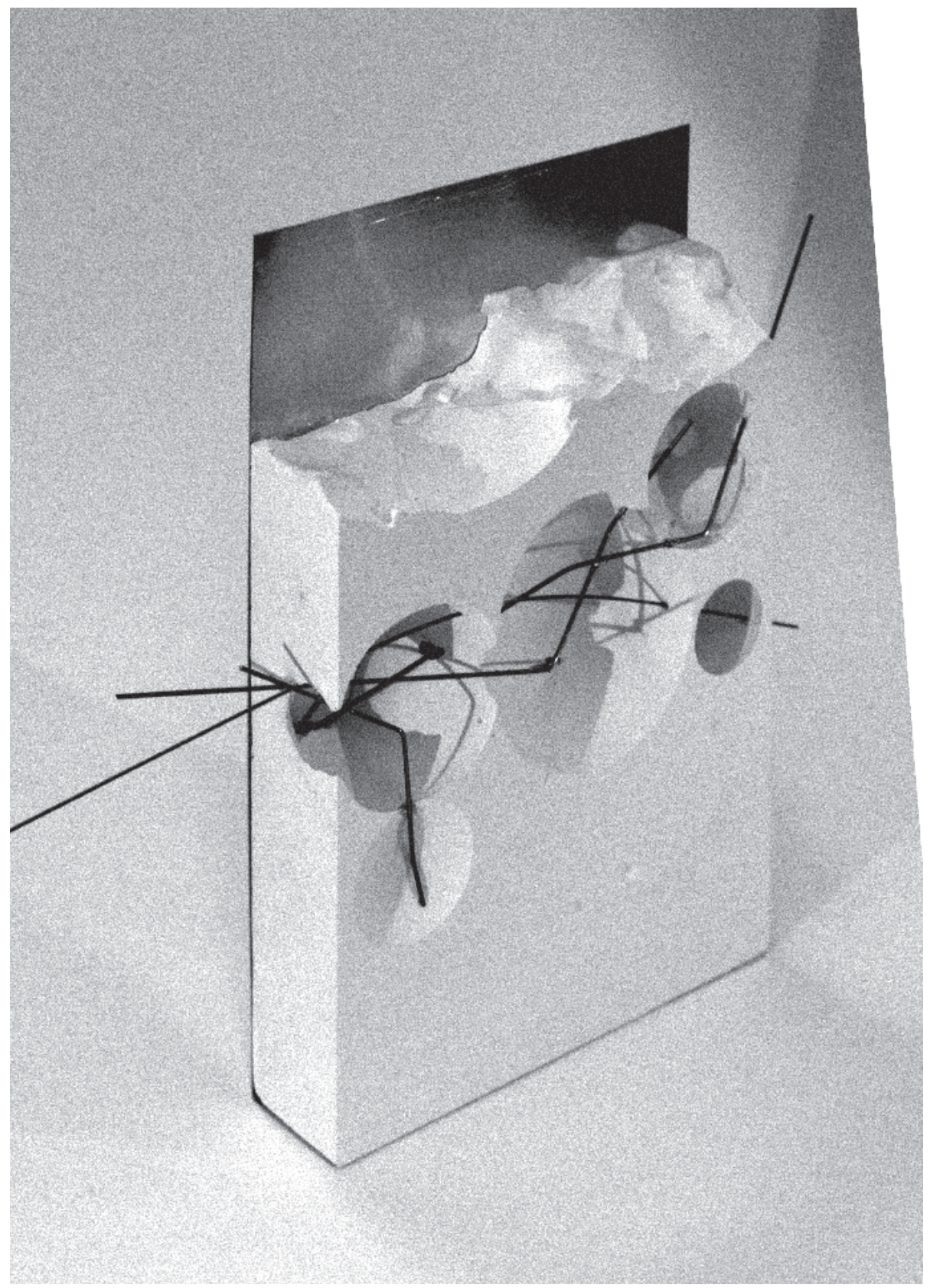

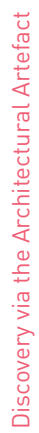

17.3b: Photo of Architectural Artefact (02B)

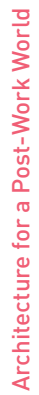




\subsection{Discovery via Scanning}

Intended for two

dimensional images, a flat-bed scanner has a shallow depth of field and a unique illumination. Processing three dimensional objects on the scanner produces an in focus foreground, while the while the wires and plaster pockets diffuse in the background. Due to the flatness of the light source, the digitized image of the object has a strange visual quality resembling an $\mathrm{x}$-ray of plate photography. The scanning process also amplifies any smudges and marks left on the glass bed. Another notable quality is the casting of horizontal instead of spherical shadows achieved because of the linear movement of the light bar.

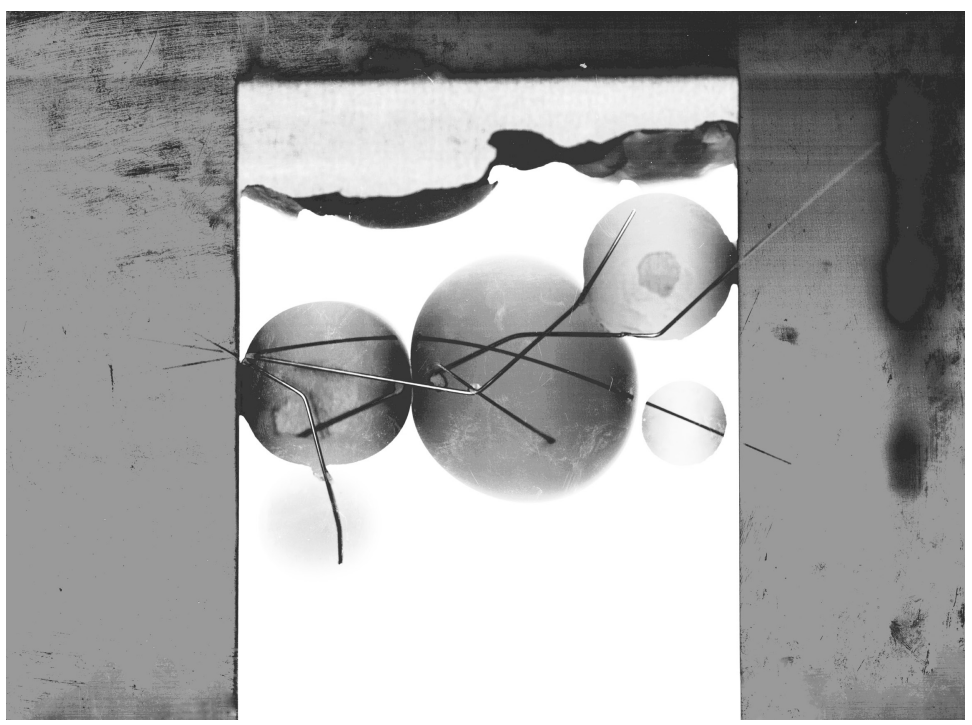

17.4a: Architectural Artefact C2 


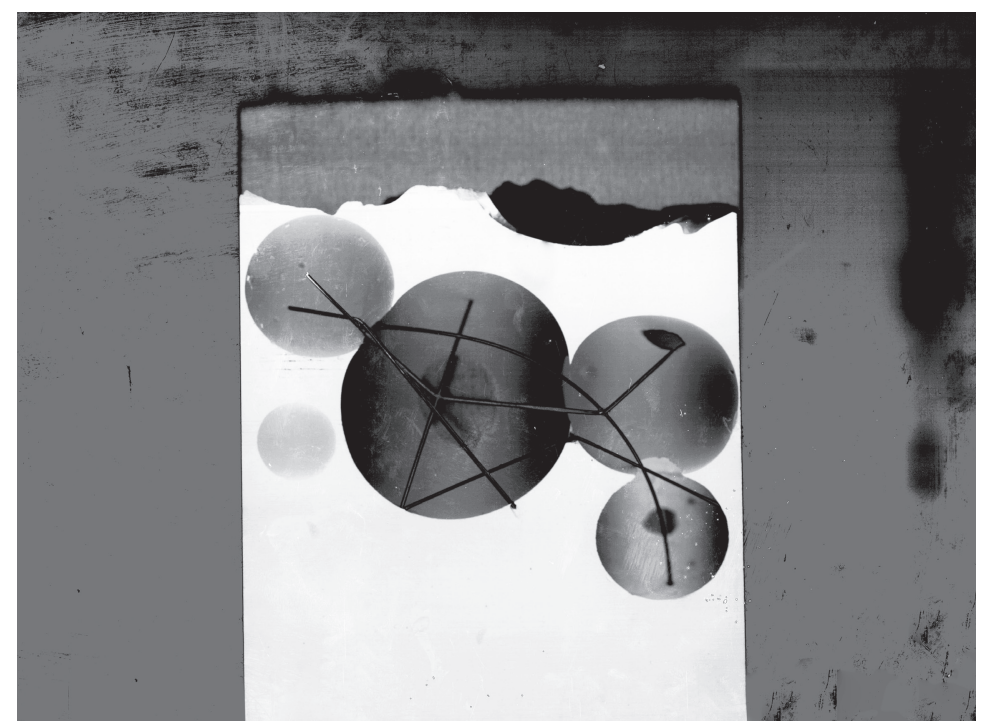

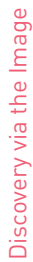

17.4b: Architectural Artefact C1 


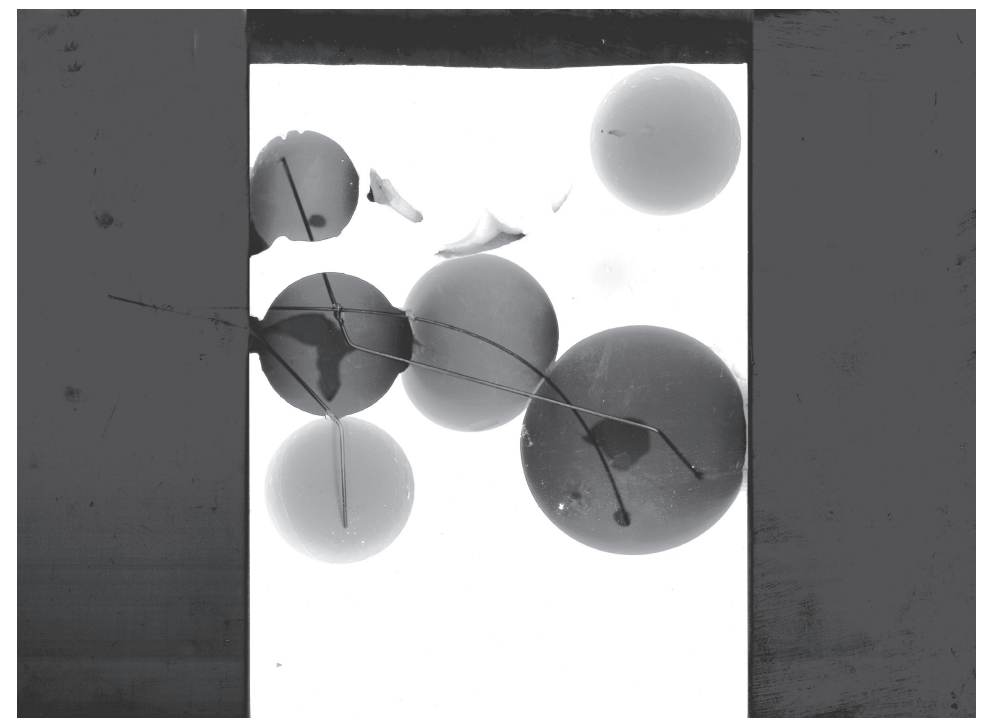

17.4C: Architectural Artefact B2

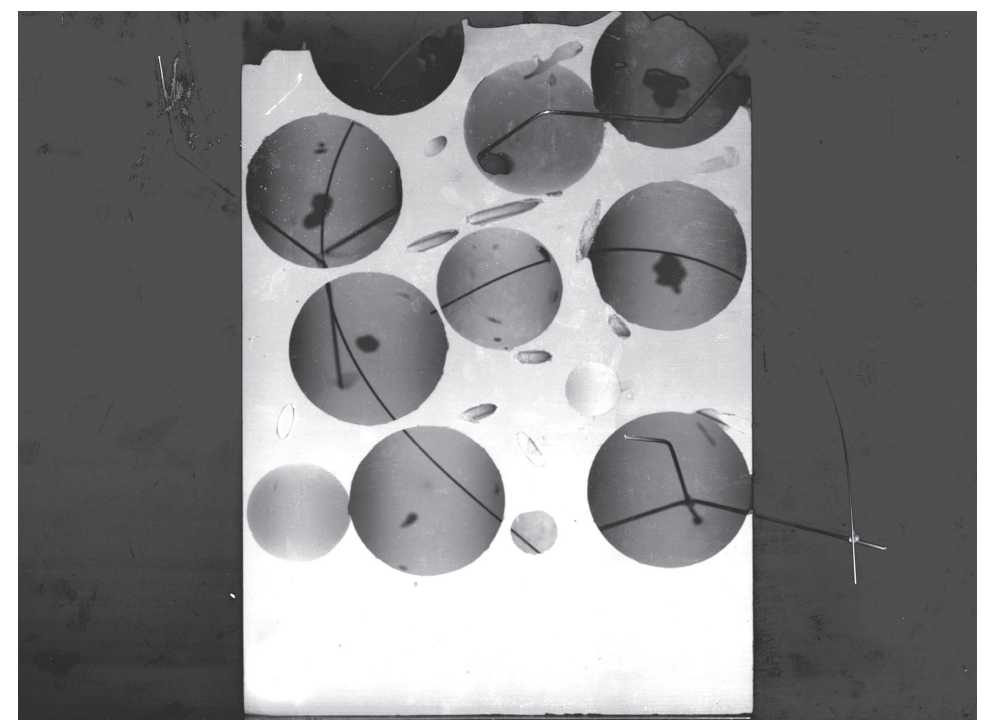

17.4d: Architectural Artefact A1 


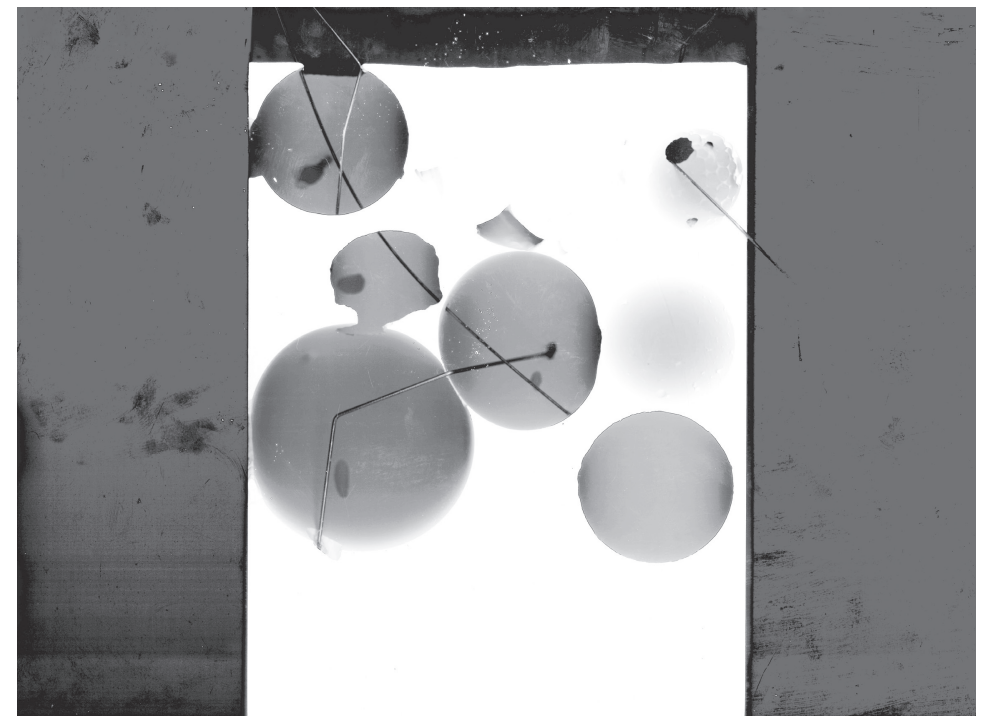

17.4e: Architectural Artefact B1

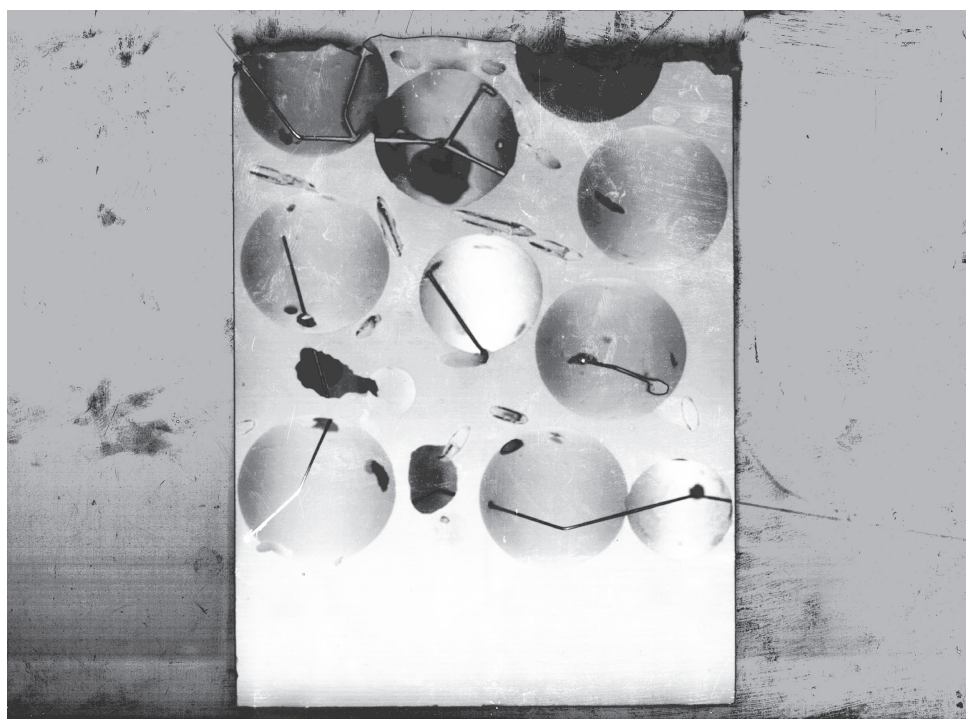

17.4f: Architectural Artefact A2

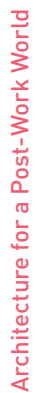




\subsection{Discovery via Light and Shadows}

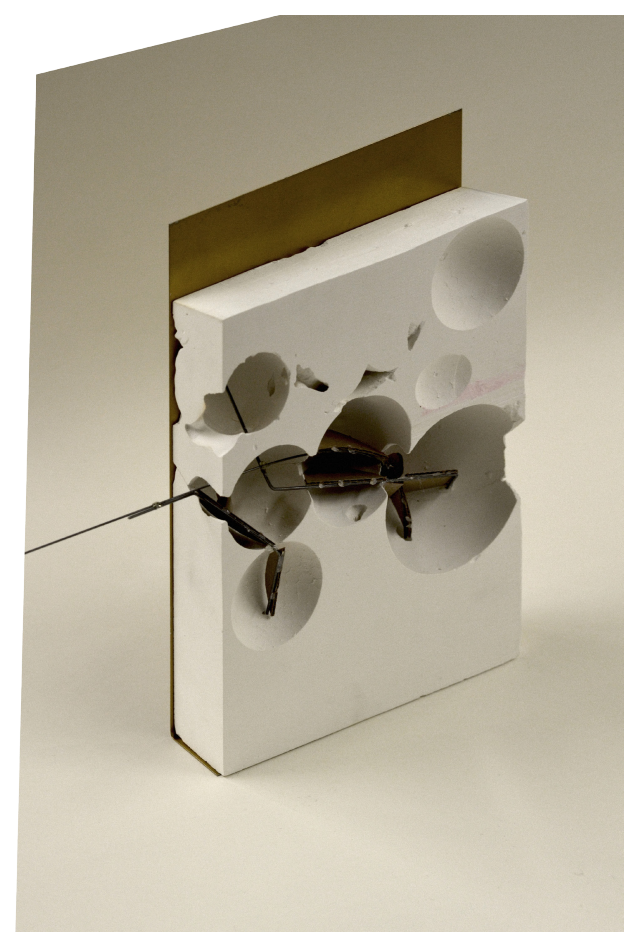

A focused point light source directed on the wires was used to cast shadow lines onto the plaster which were then translated into surfaces that interface with the voids. This technique allows for multiple surfaces to be produced from a single line. A line can be used to simultaneously represent a wall, floor plane, and / or a ramp. This is similar to cubist techniques, as multiple perspectives may be simultaneously displayed.

17.5a: Architectural Artefact B2

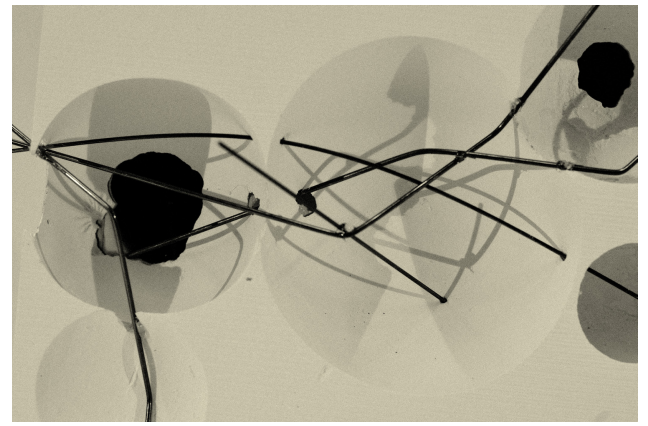

17.5b: Light Study 01 


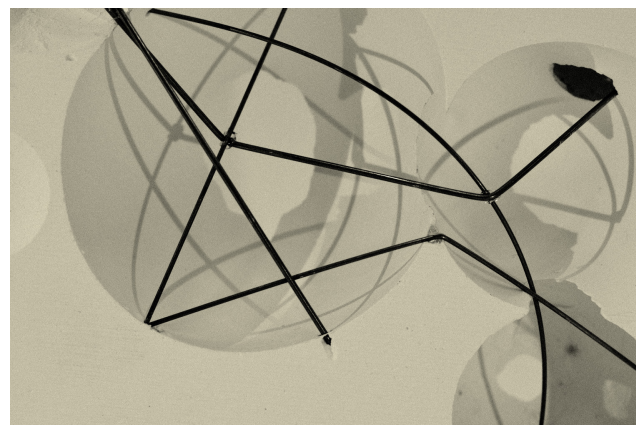

17.5c: Light Study 02

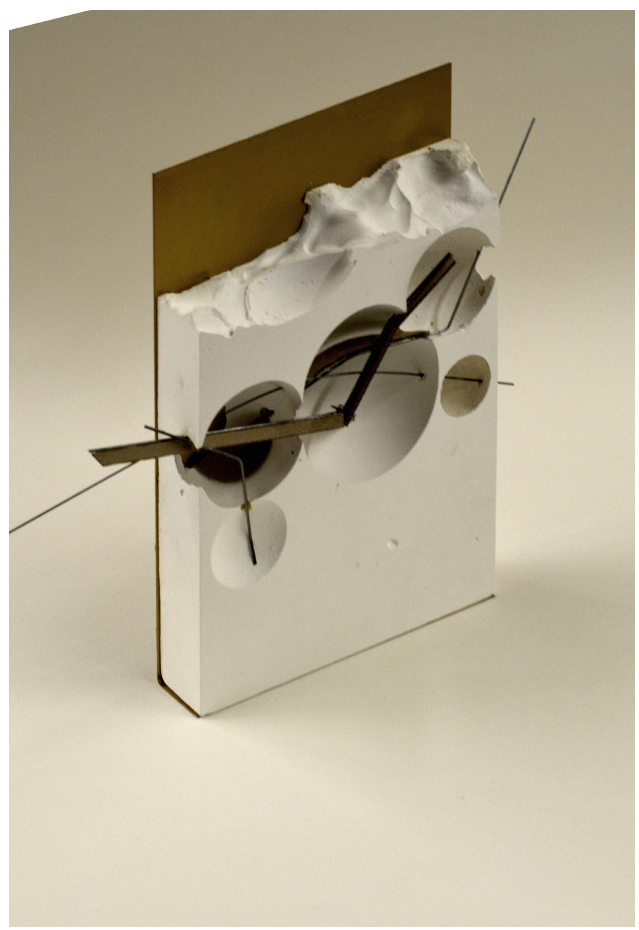

17.5d: Architectural Artefact C2 


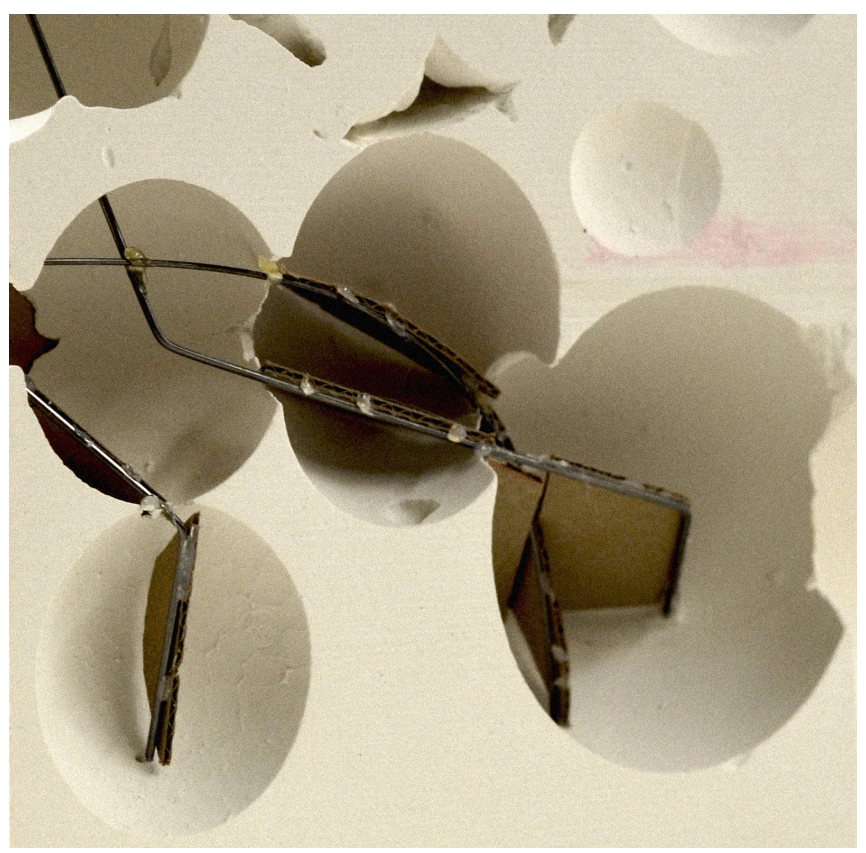

17.5e: Architectural Artefact B2 with Multiple Perspective Extrusion 


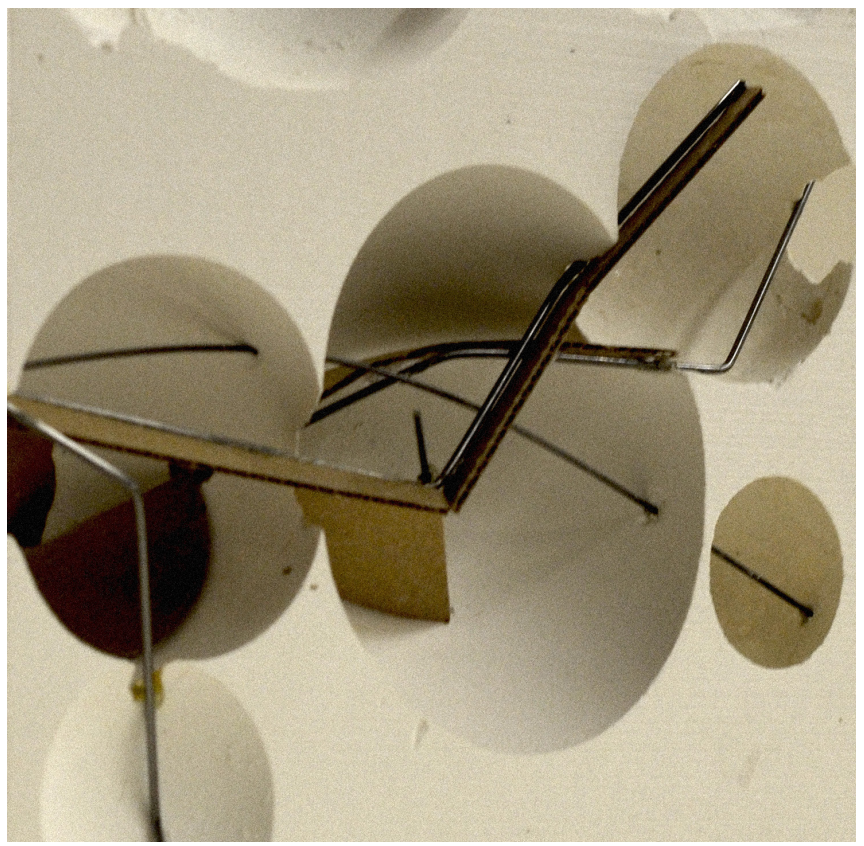

17.5f: Architectural Artefact C2 with Multiple Perspective Extrusions 


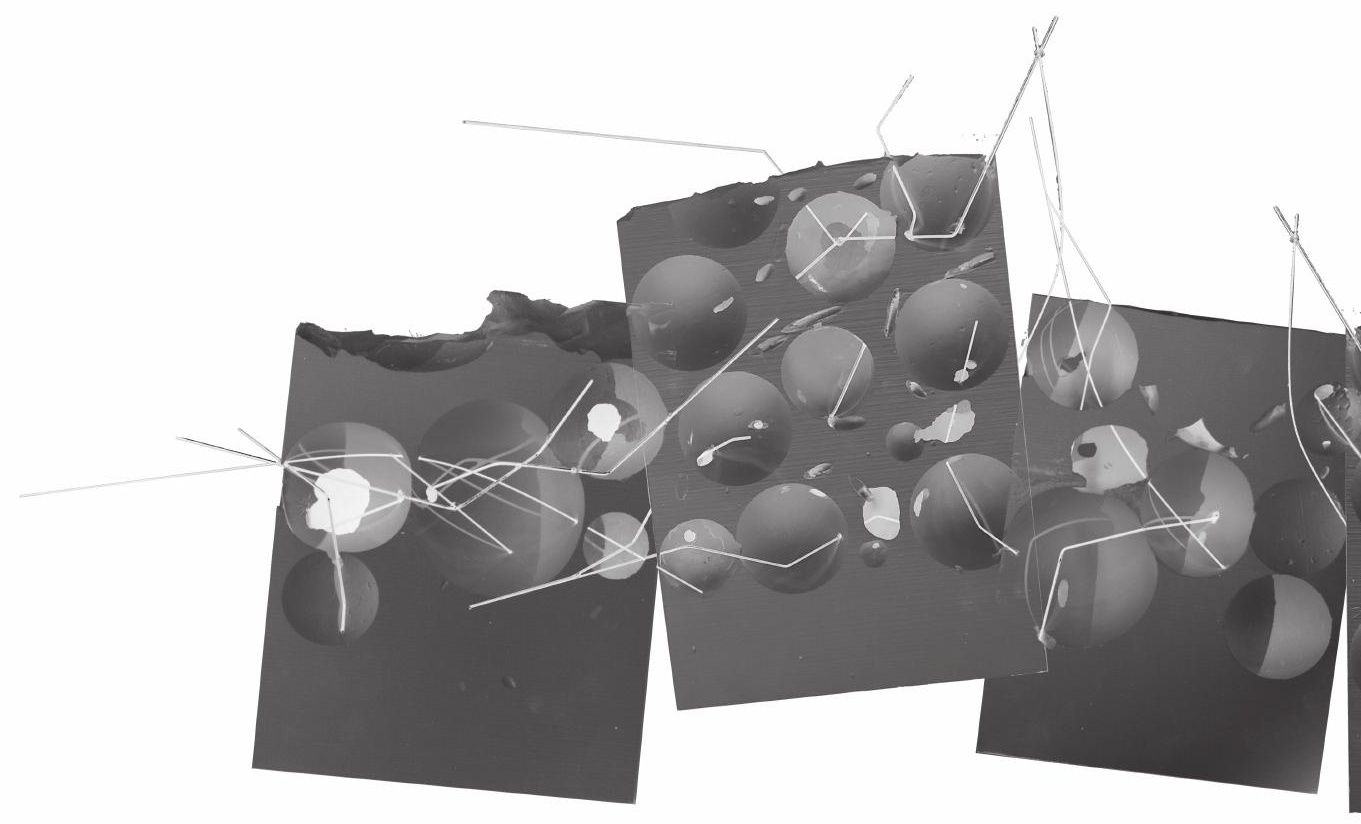

17.5g: Longitudinal Collage 


\subsection{Discovery via Extrusion}

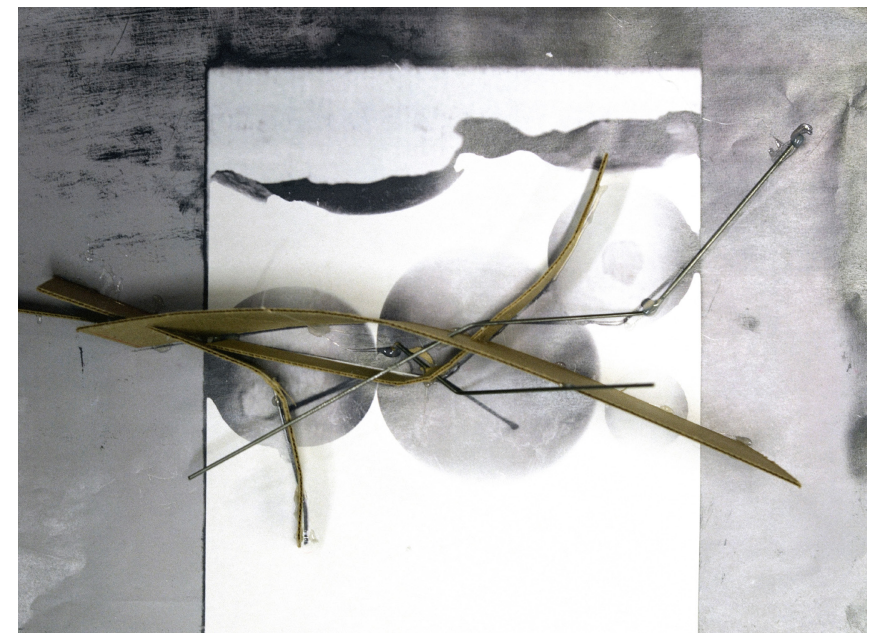

17.6a: Extruded Object: Plan

In this experiment, the scanned object and its lines are extruded into surfaces that intersect and interweave like the metal wires. This setup facilitates experimentation with planar conditions in which dynamic qualities of the lines are further amplified by tilting planes. 


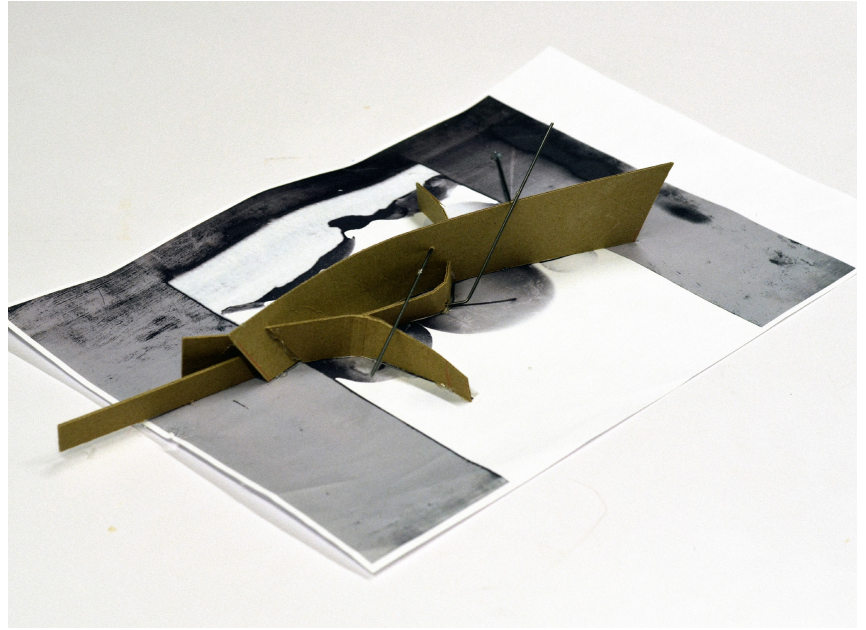

17.6b: Extruded Object: Isometric View 


\subsection{Discovery via Photography}

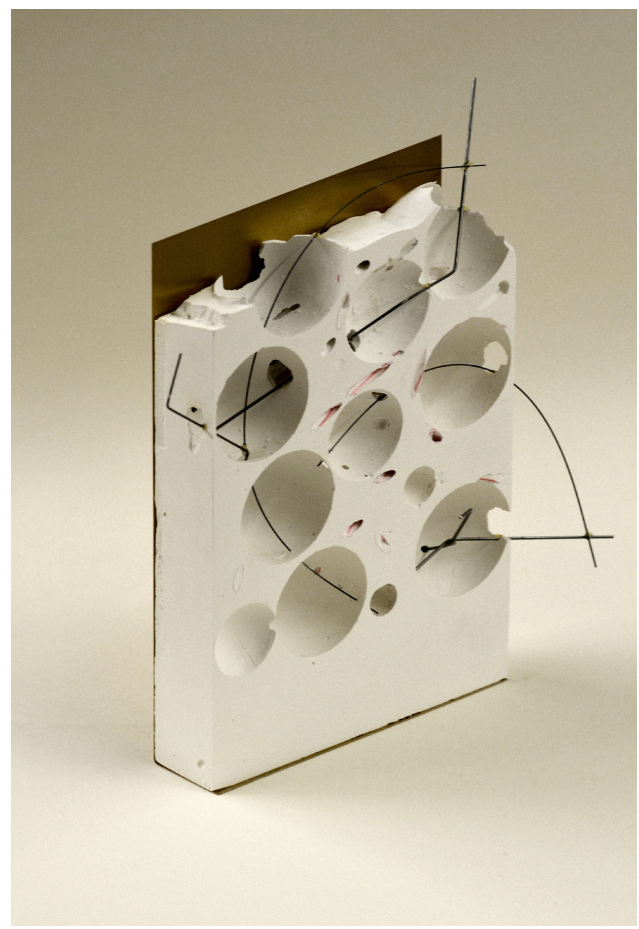

17.7a: Architectural Artefact A1

Photographs of the models were taken from a bird's eye isometric view to catalogue the objects. But the lens was also used to reveal new perspectives through which to capture and codify spatial moments. Moving the camera around reveals alternate horizons and situations for the flaneur to stream through. Looking at the model at a macro level frames rich experiential conditions of transitions through various surfaces, points, and lines.

Finally, the photos were translated into vignettes to codify various elements such as lines, surfaces, and points.

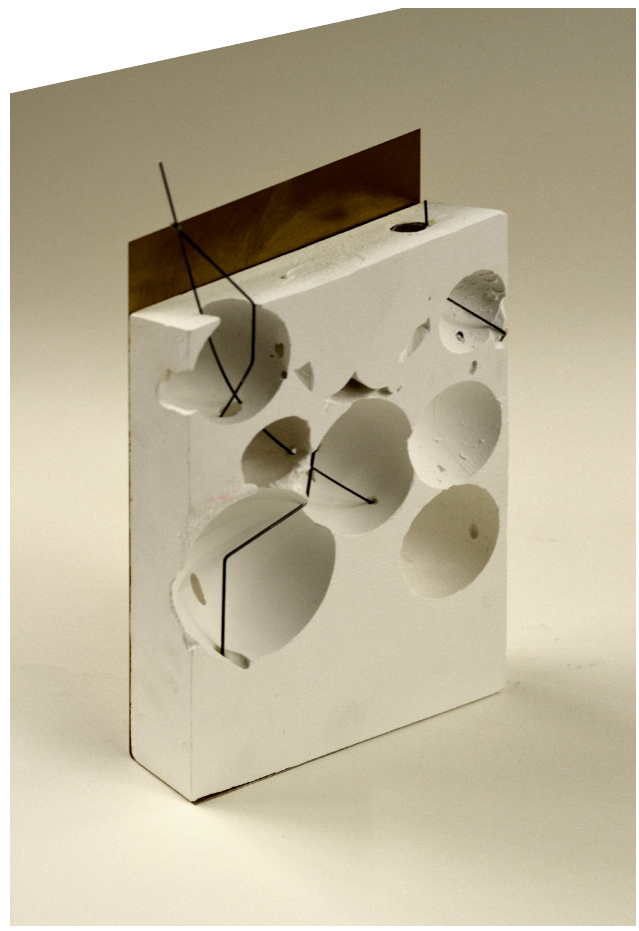

17.7b: Architectural Artefact B1 


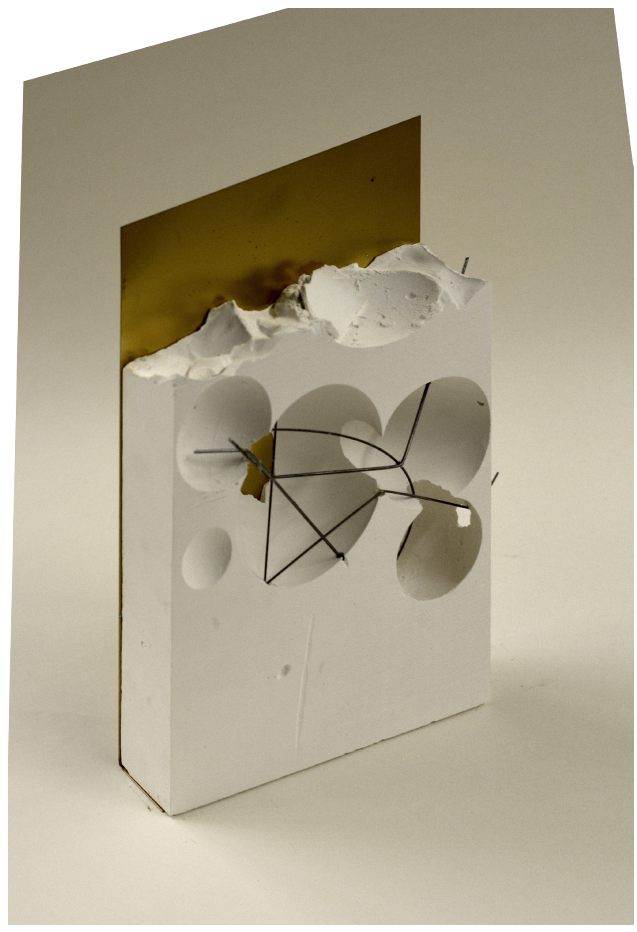

17.7c: Architectural Artefact C1

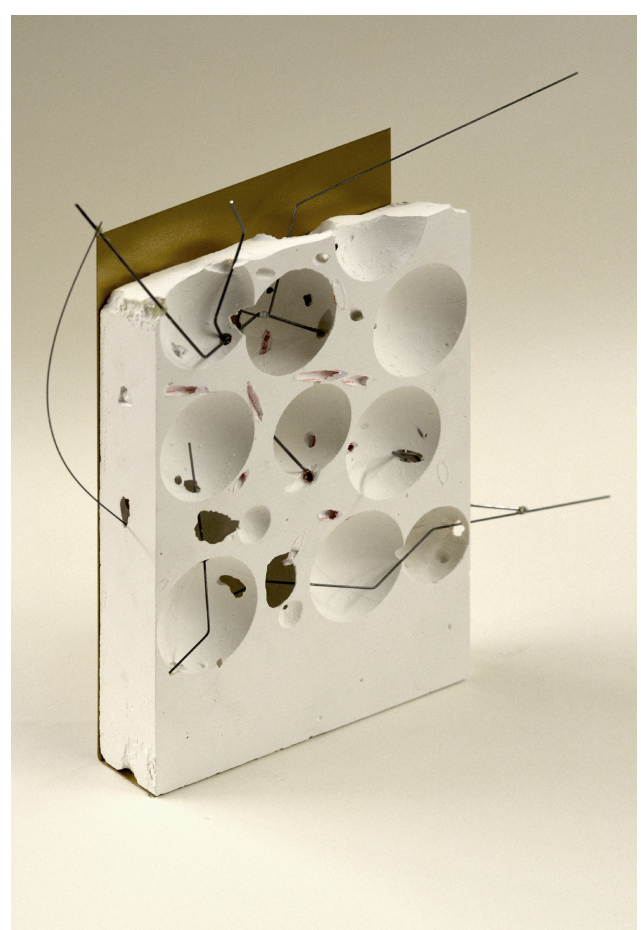

17.7d: Architectural Artefact A2 



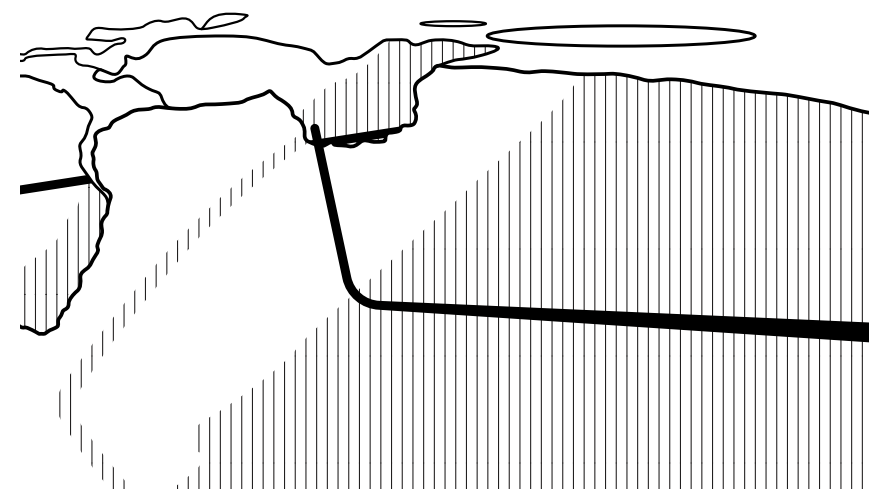

17.7e: Line Drawing of Moment 02 


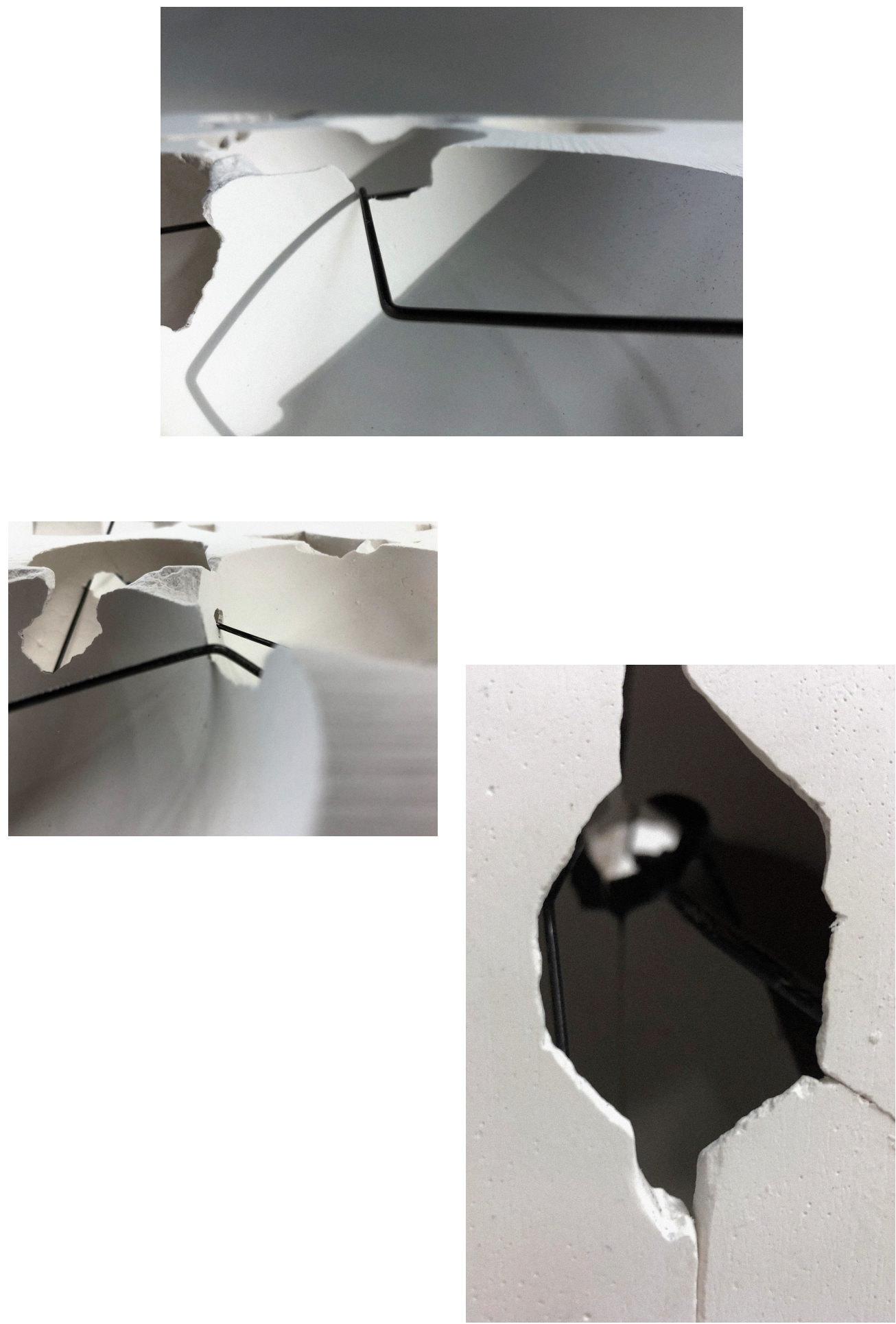

17.7f: Moment 01,02,03

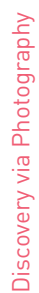

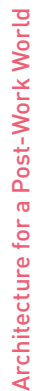




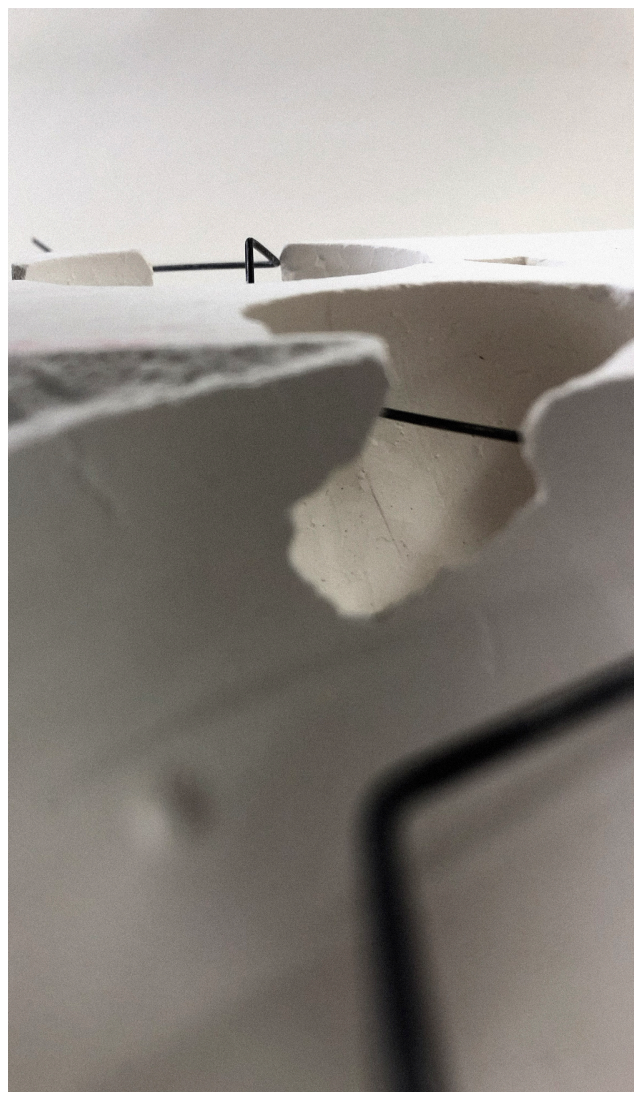

17.7g: Moment 04 


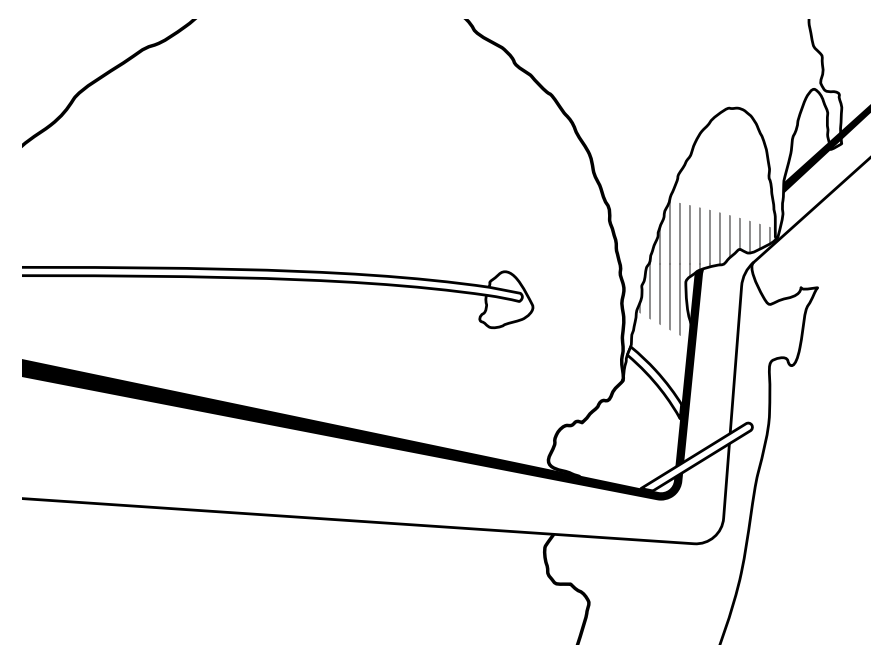

17.7h: Line Drawing of Moment 08 


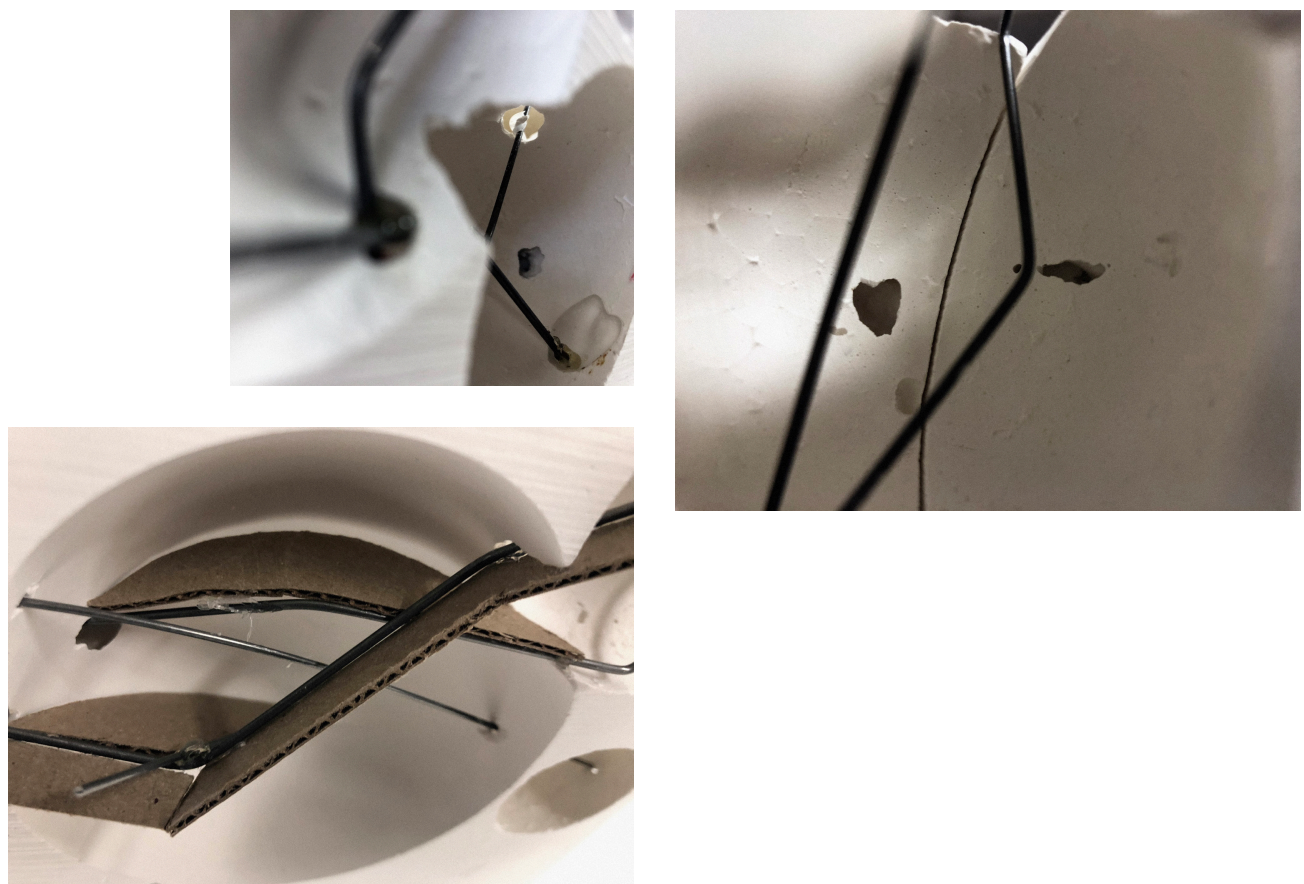

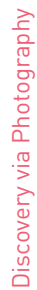

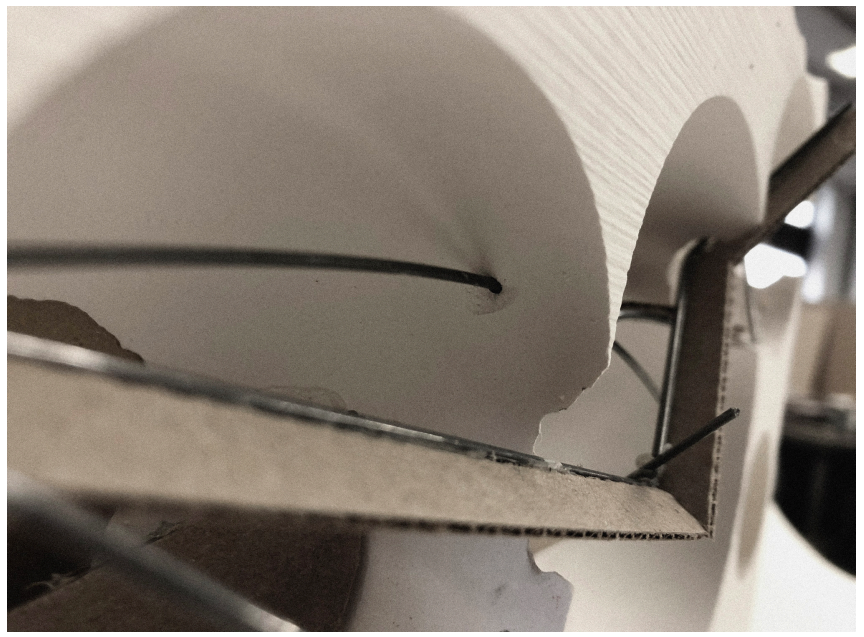

17.7j: Moment 08

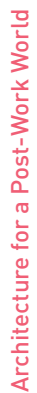



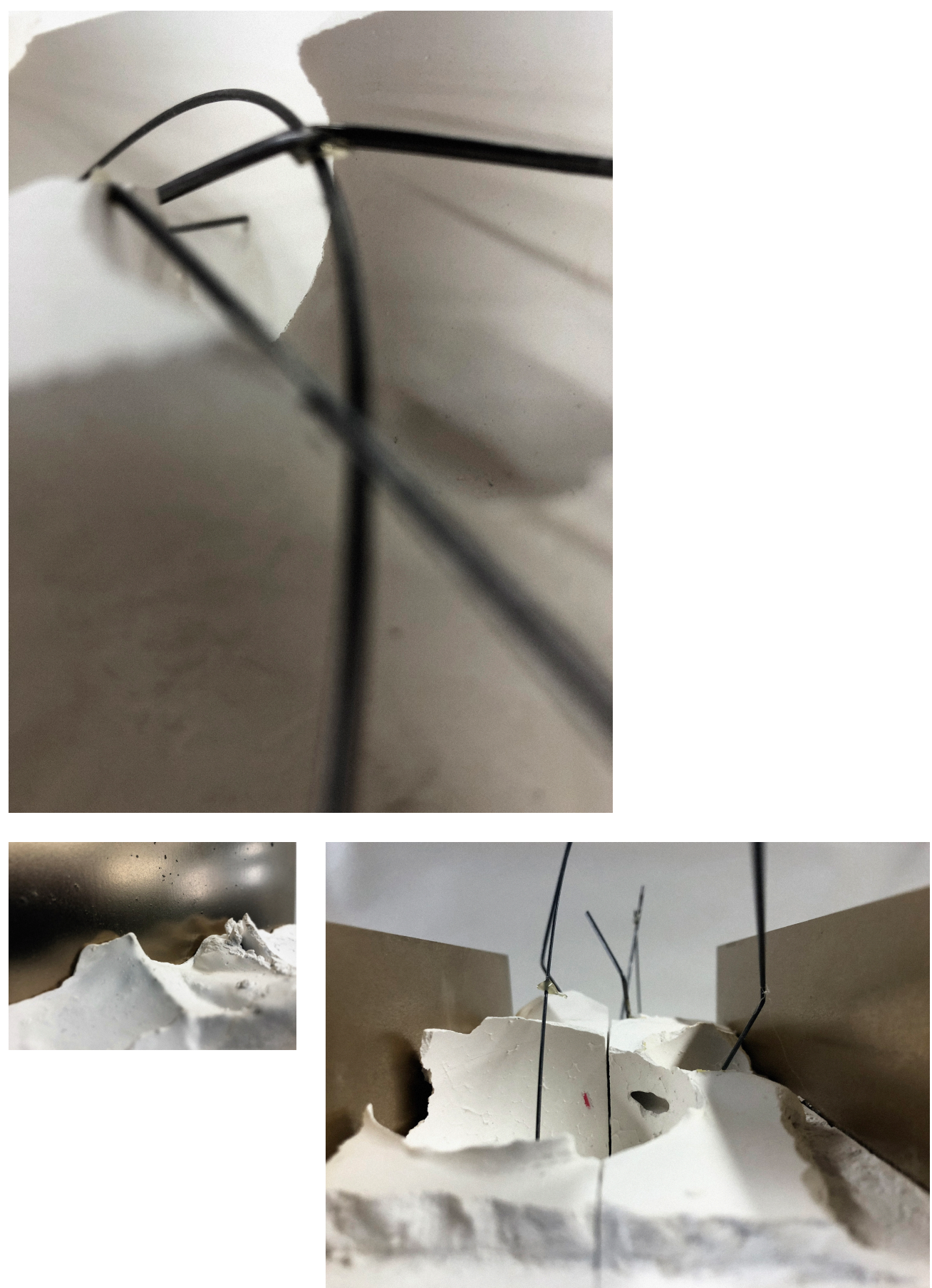

17.7k: Moment 09,10,11 

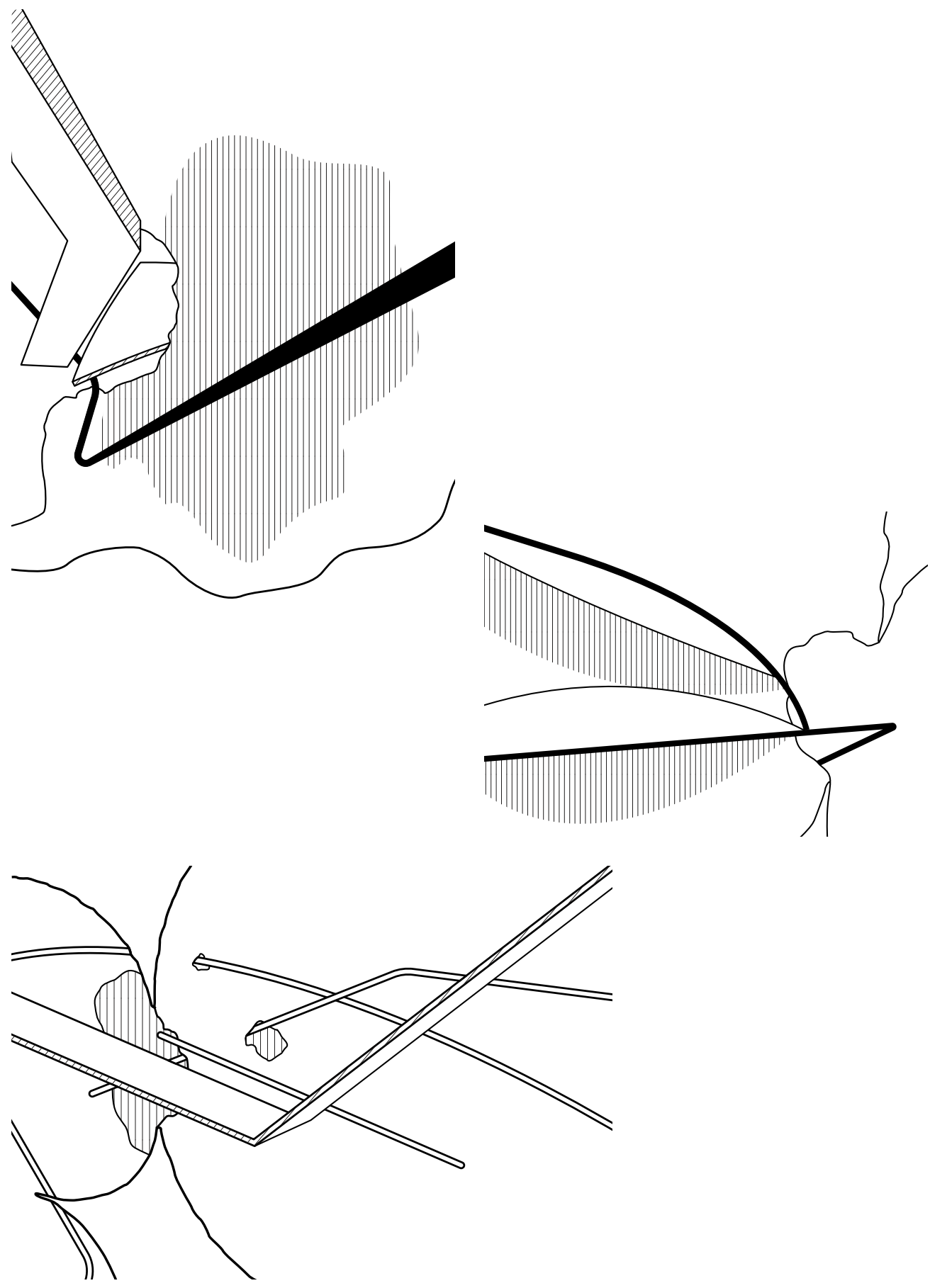

17.7l: Line Drawing of Moment 12,13,14 


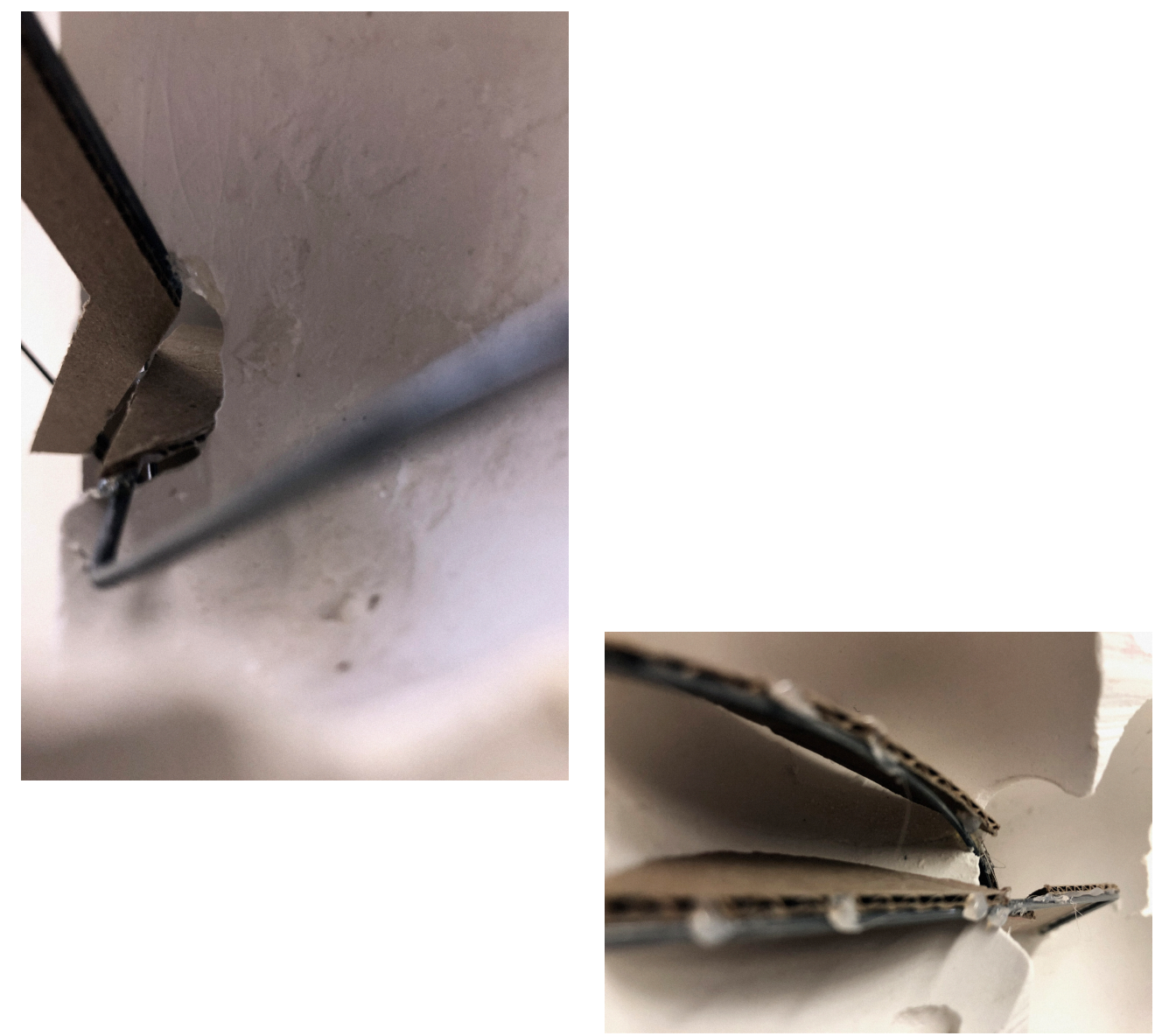

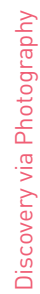
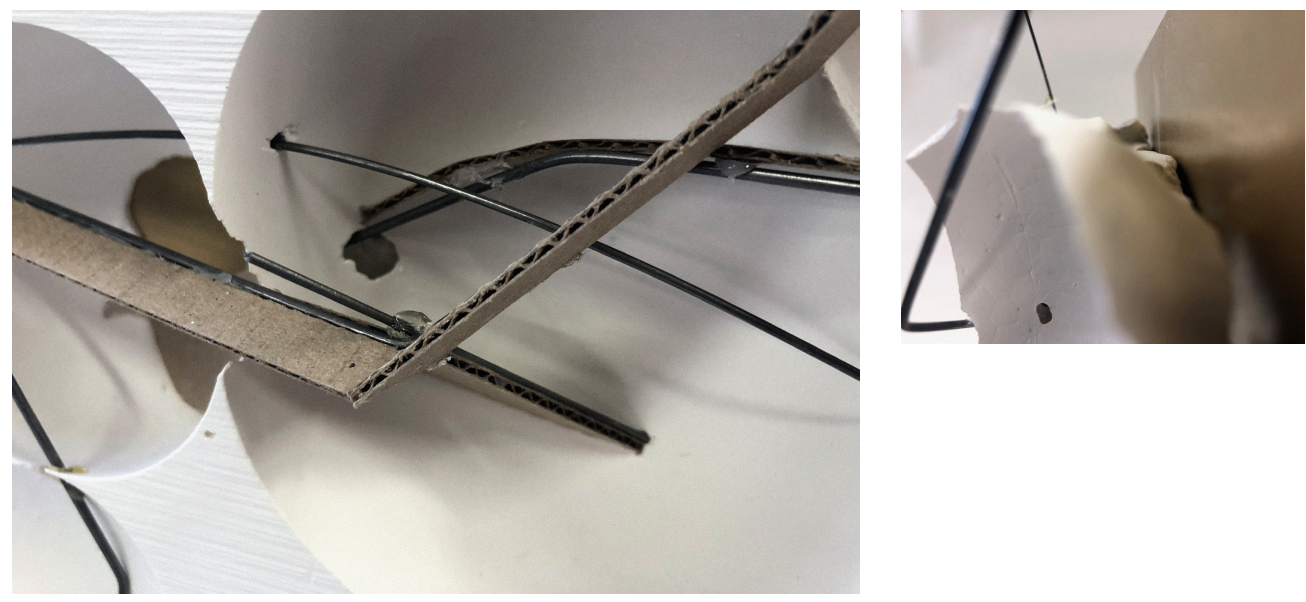

17.7m: Moment 12,13,14,15

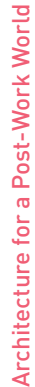



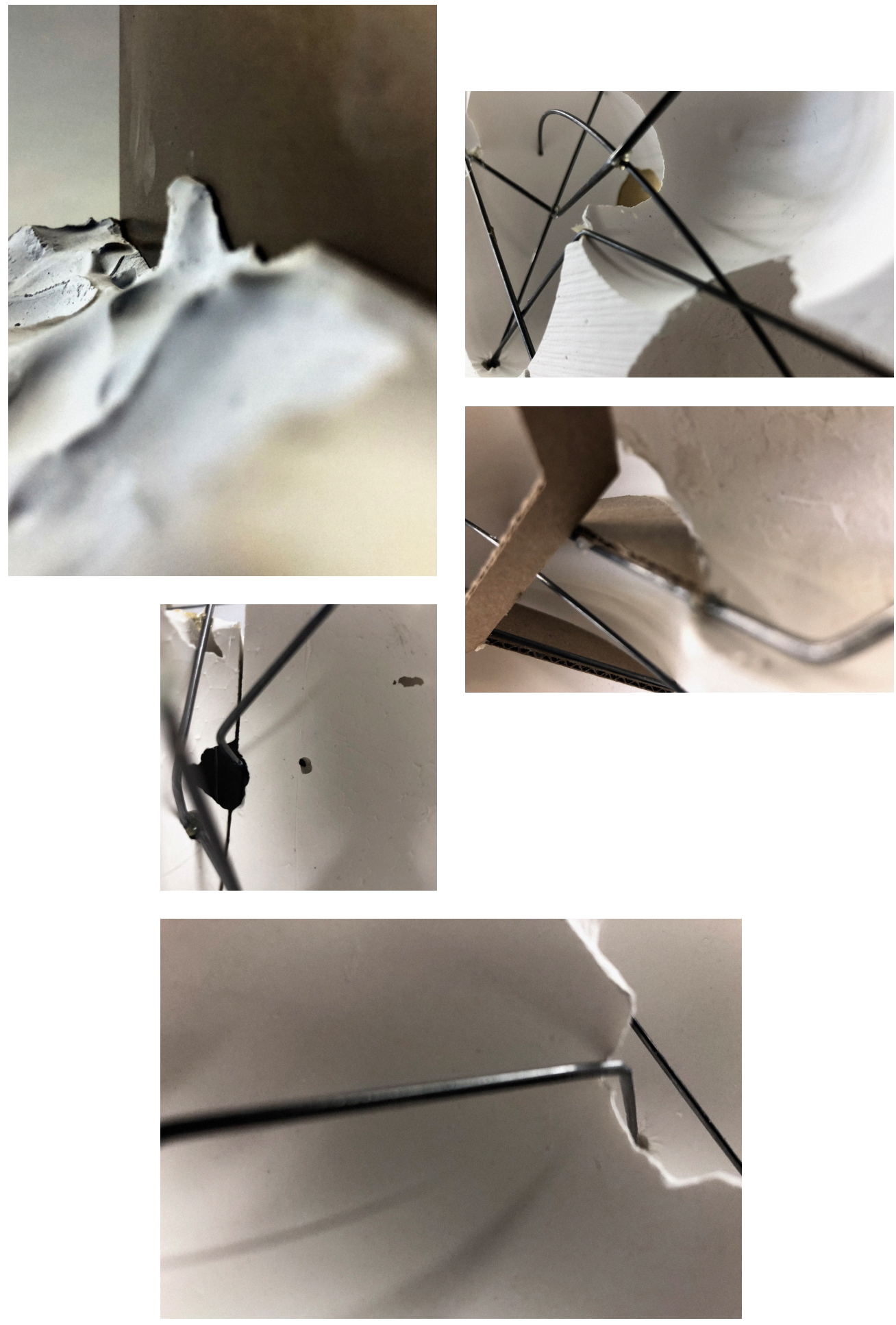

17.7n: Moment $16,17,18,19,20$ 


\subsection{Discovery via Photogrammetry}

The technique of photogrammetry achieves a highly detailed digitization of the crafted object. A photo-realistic three-dimensional capture of the artefact allows for easy manipulation using the tools available in software such as Rhino.

Curiously, photogrammetry also produces mutations in the model. Unintended geometries are generated due to imperfections in the digitization process. Zooming into the geometry offers new modes of seeing in three-dimensional detail. Selected moments can be captured, magnified, modified, and replicated via 3D printing.

This technique subverts the prevailing contemporary design attitude of digital first and physical object second (solely as documentation). Here, the artefact is not determined by the logic and tools of the software but instead, software is integrated into the prototyping process to enhance and reveal new qualities of the artefact. 

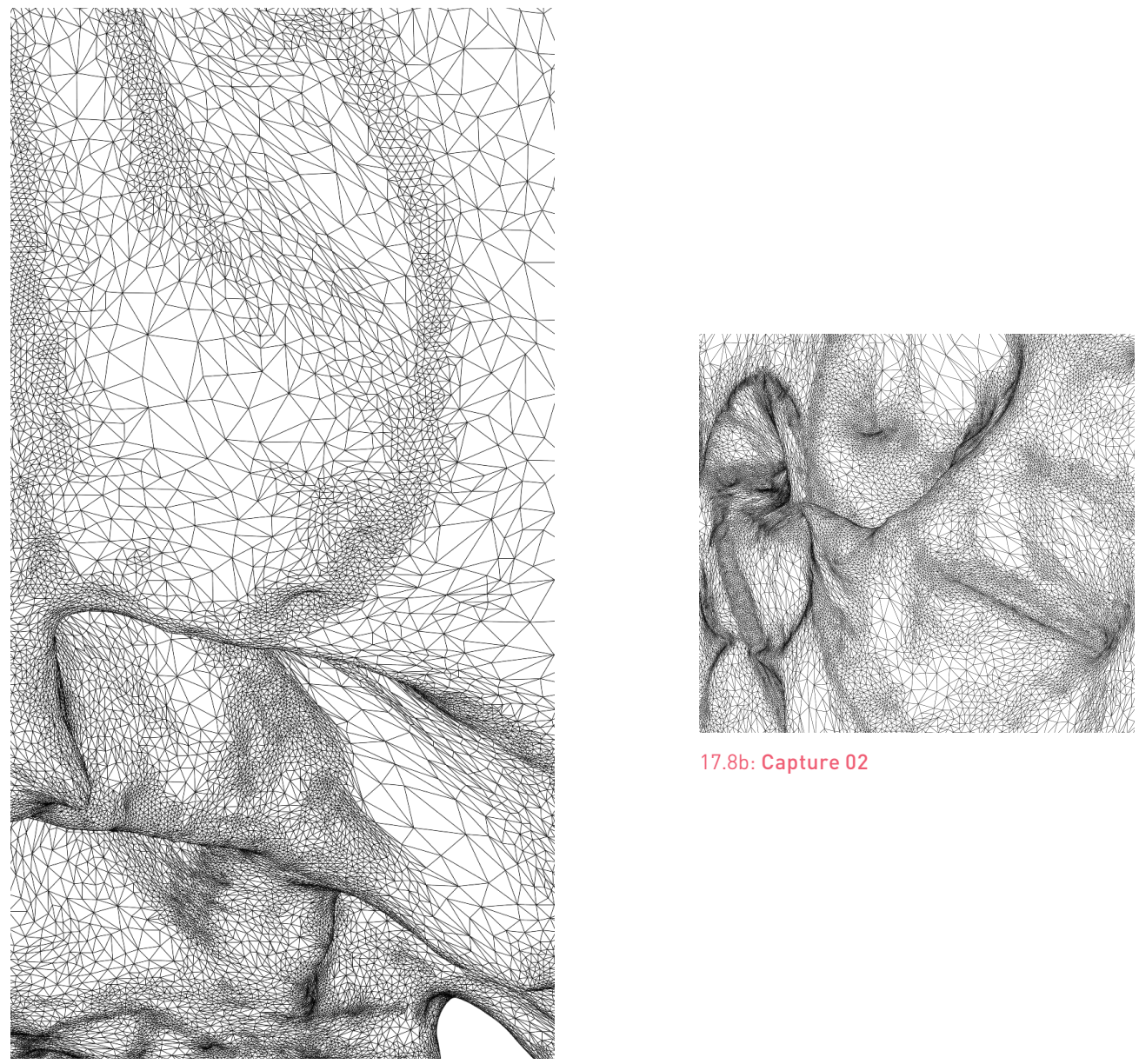

17.8b: Capture 02

17.8a: Capture 01

\section{Transfiguration}

The translation from physical to digital is an act of transfiguration. The digital model glorifies the artefact by recording minute details through a infinitely expandable geometric mesh. The copy is simulacrum: more real than the real and operating at an elevated state, freed from the constraints of physicality.

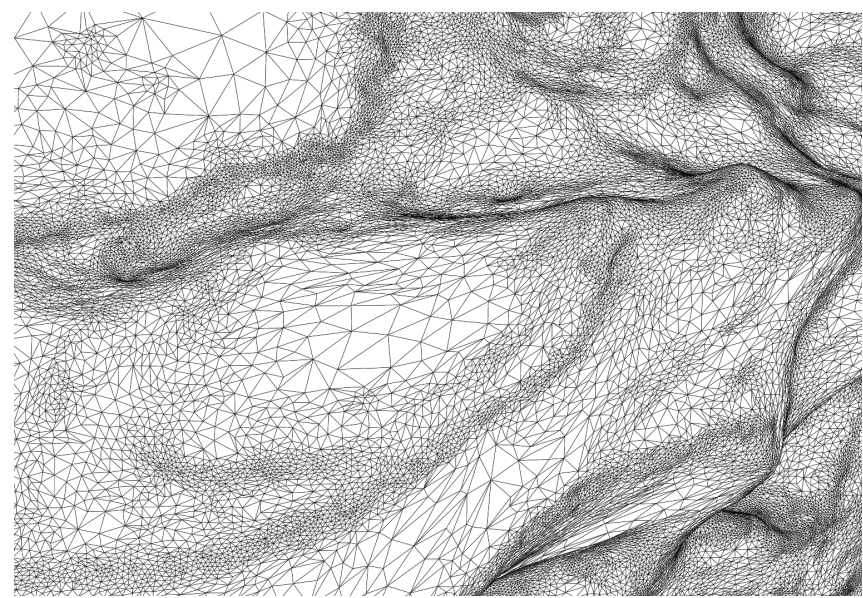



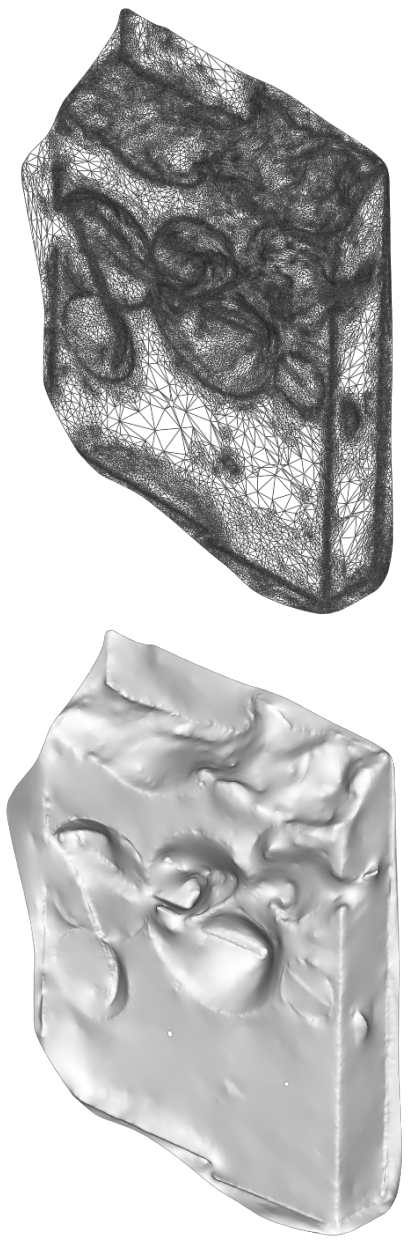

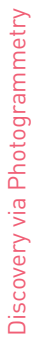

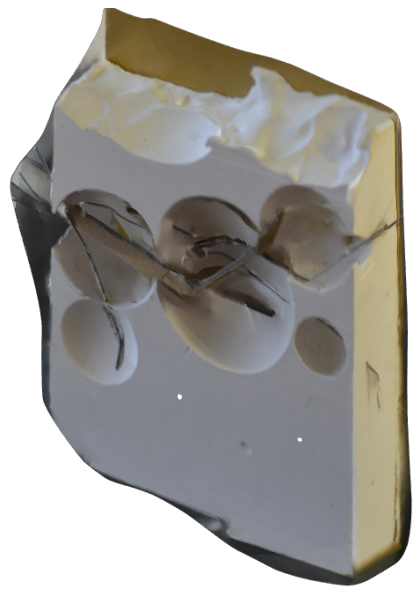

17.8d: Architectural Artefact C2

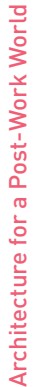




\section{Phantasmagoria}

Like a digital dream, the

flaneur drifts through a

geometric phantasmagoria.

The Monument to Culture

inspires discovery, learning,

and making through

unpredictable moments,

spontaneity of situations

and profane environments.

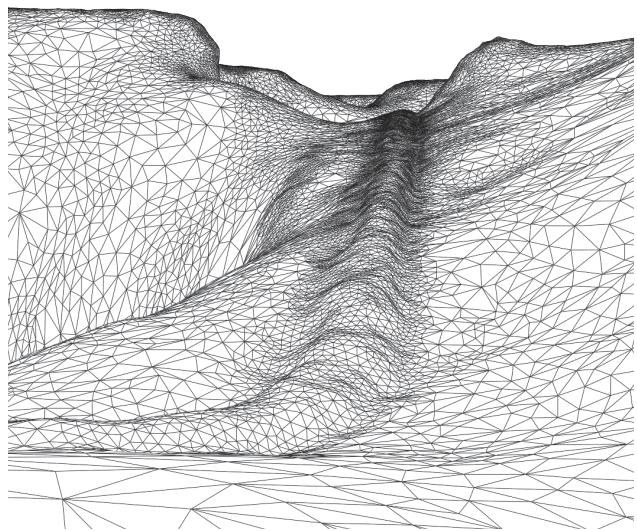

17.8e: Capture 04

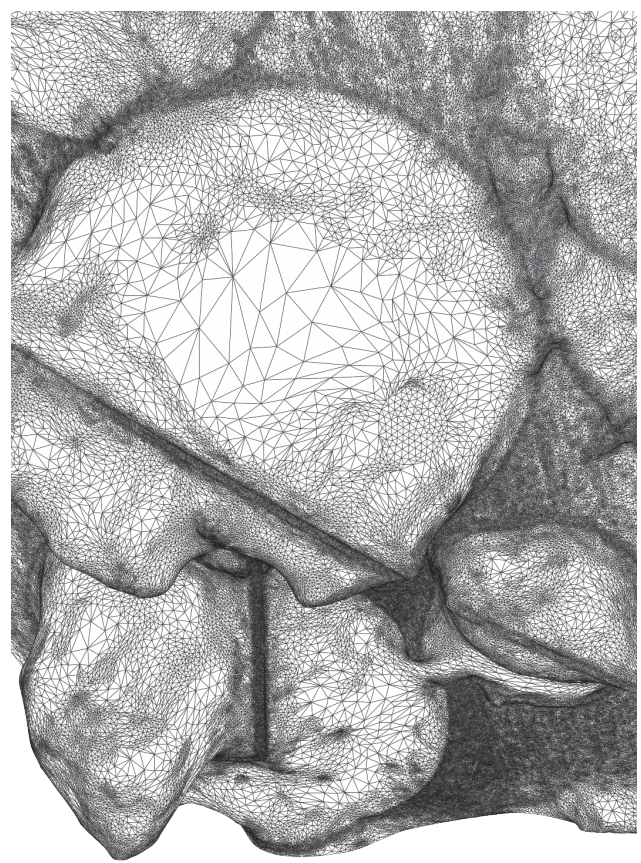

17.8f: Capture 05

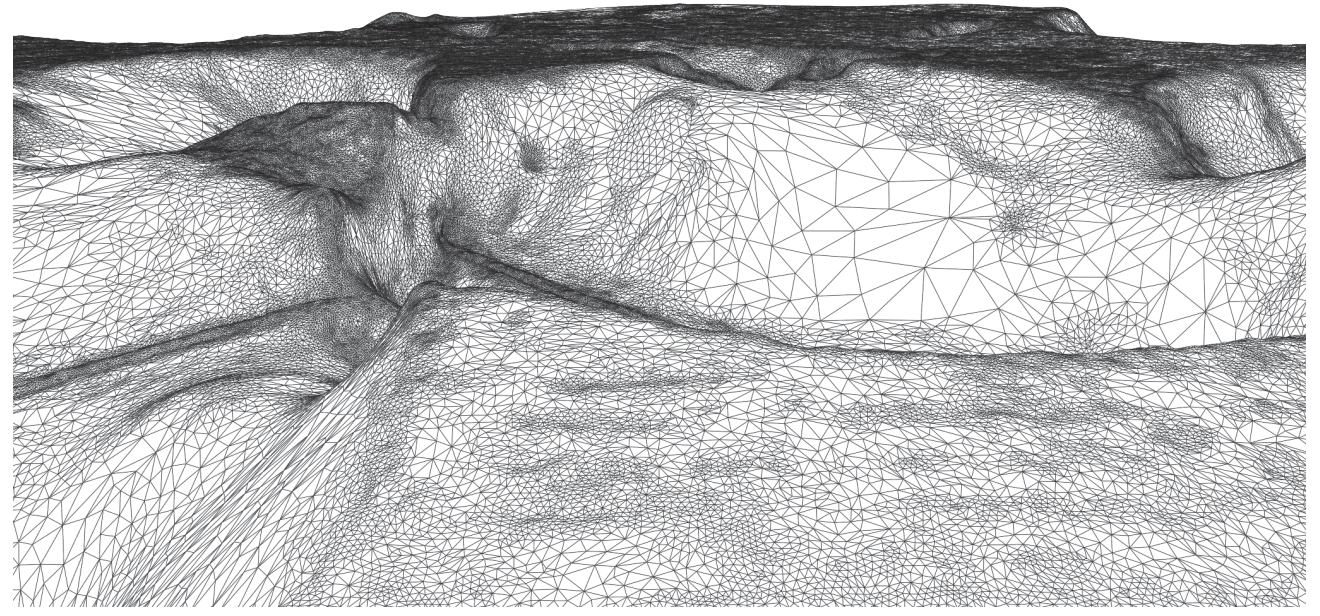

17.8g: Capture 06 

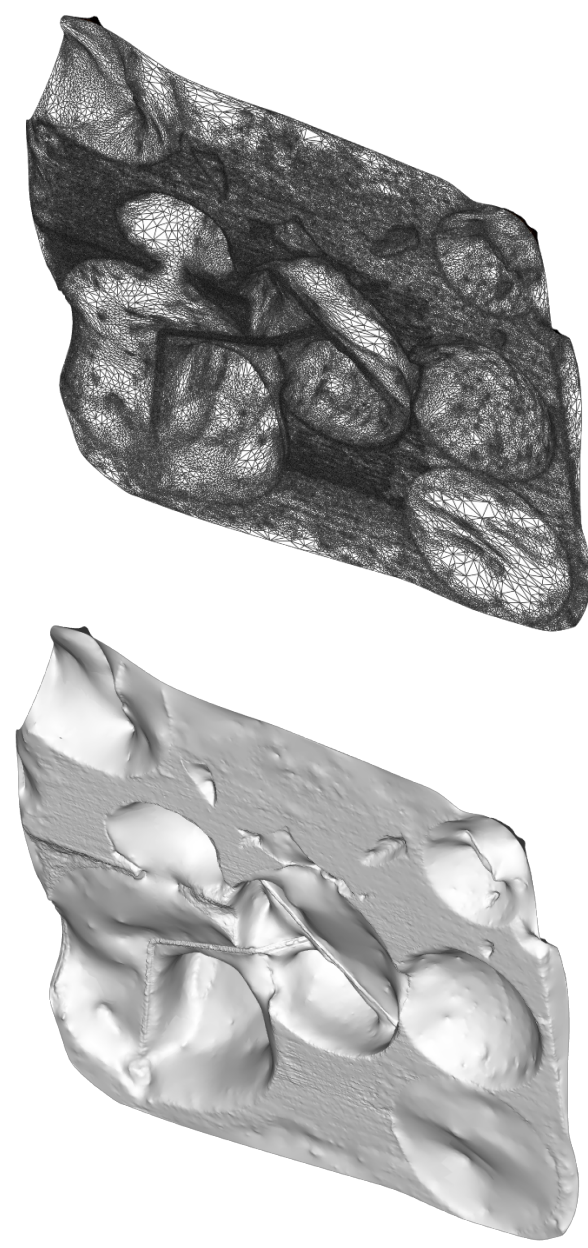

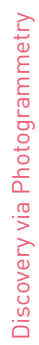

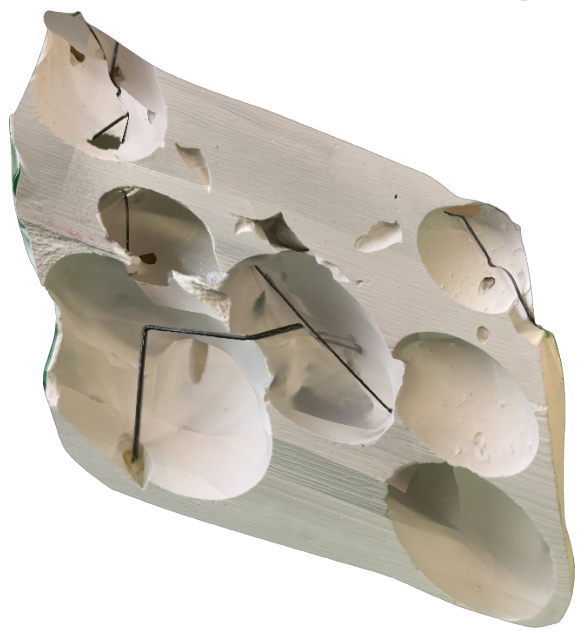




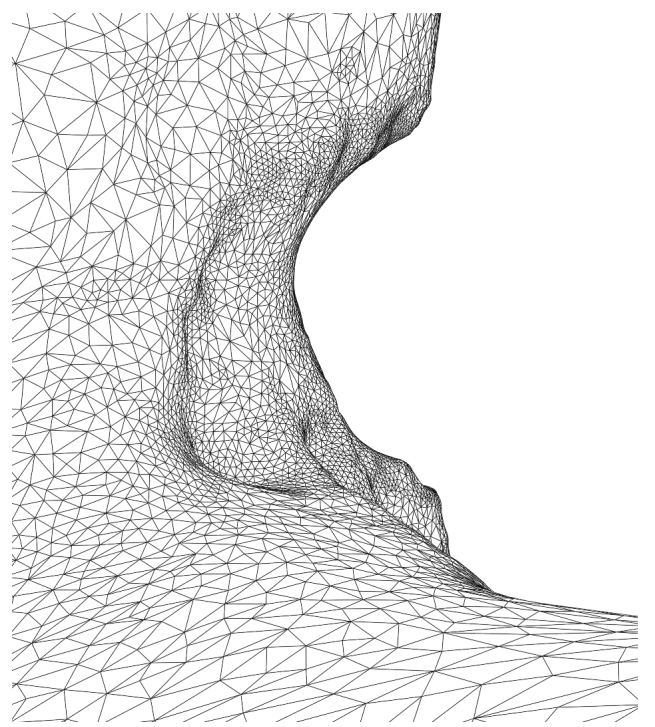

17.8i: Capture 07

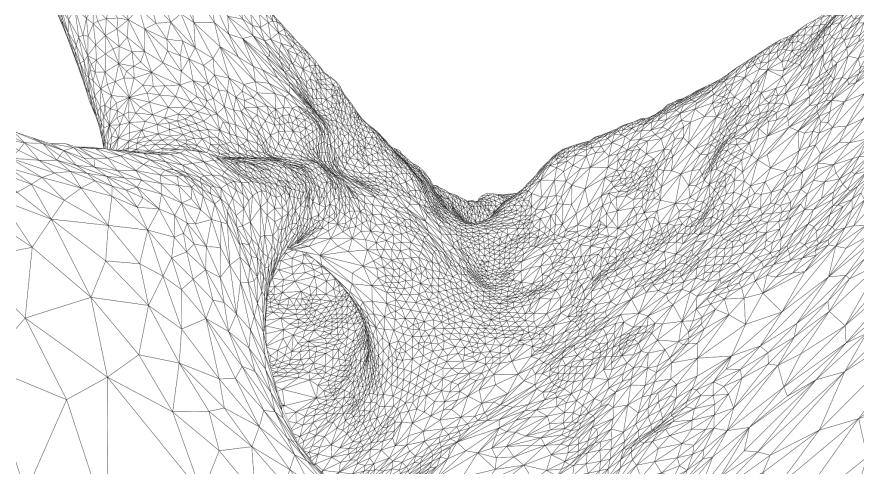

17.8j: Capture 08

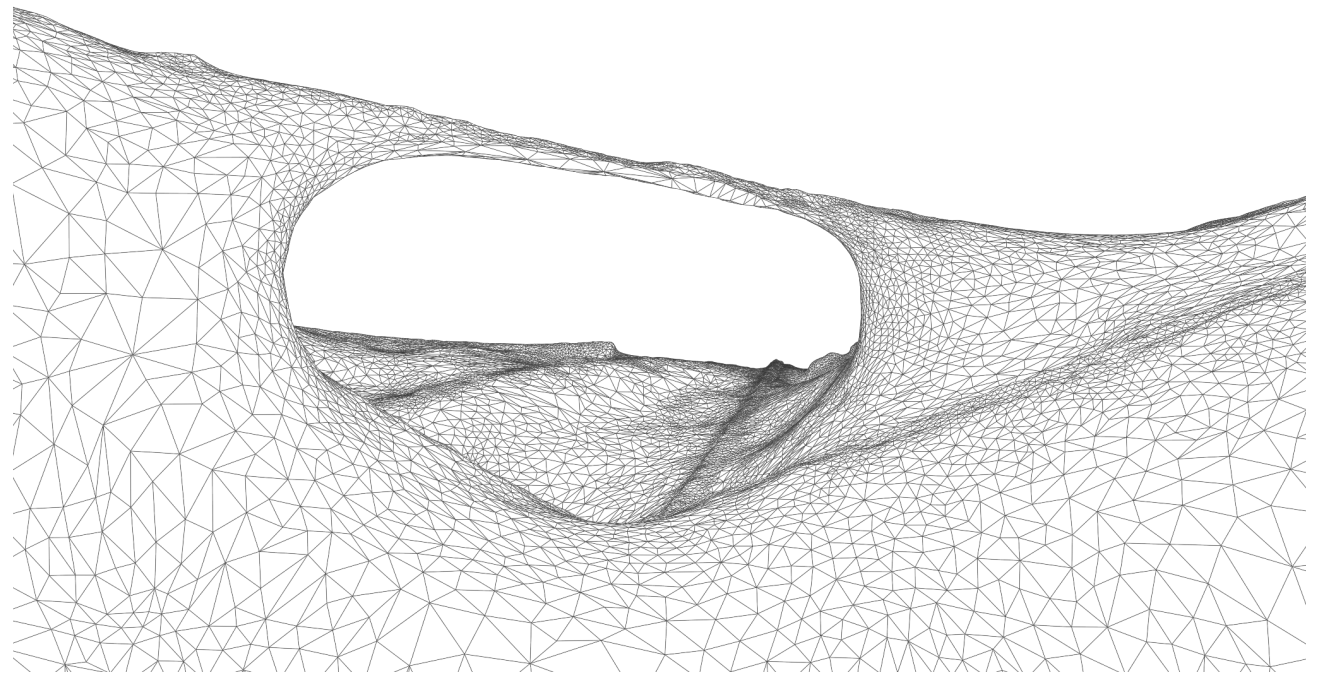

17.8k: Capture 09 

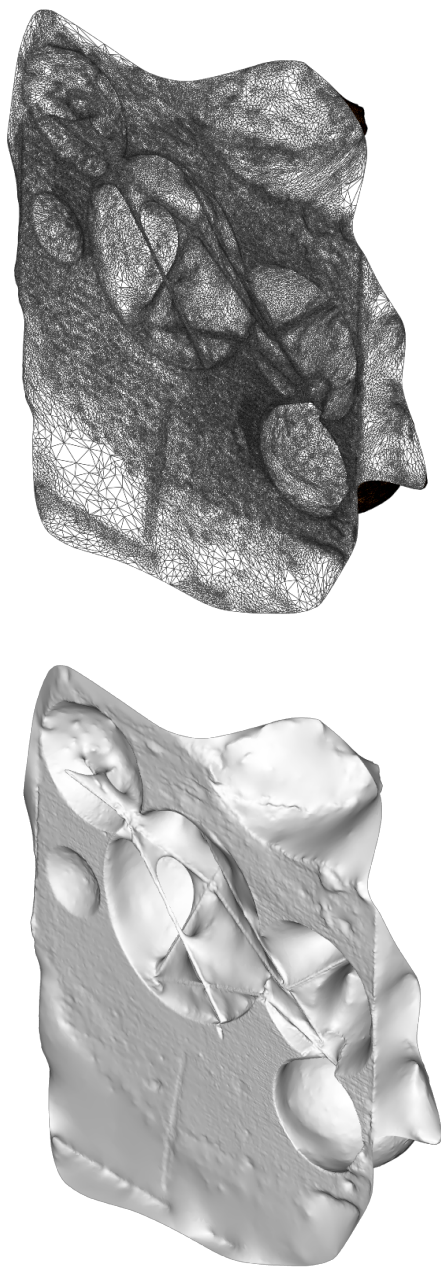

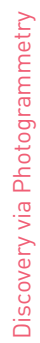

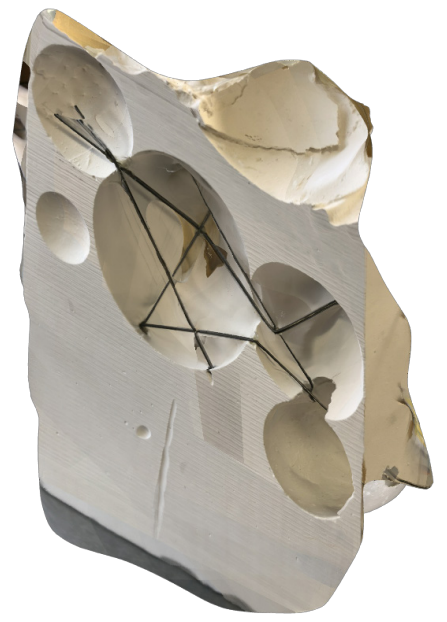

17.81: Architectural Artefact C1 


\subsection{Discovery via Duplication}

The highly detailed environment captured via photogrammetry allows for interactions with the object at the macro-level with the aid of digital software. Situations rich in textures, geometry, latent architectonic qualities are located, then excavated. The sample is scaled and then 3D printed to reveal a physical ontology of the moment.

The samples are mutated in the imaging and printing process; the geometric shapes of the negative areas get distorted due to shadows in scanning; plaster and steel wires begin to merge at certain thresholds, and surfaces and textures are altered because of the layered depositing mechanism of the 3D printer.

The printed artefact looks like a cross - section of a synthetic topographical formation. This reading is reinforced by the contour - line combined with an enclosed volume. Unlike the plaster model, there is also a strong surface reflectance to the printed ABS plastic. 
ミ

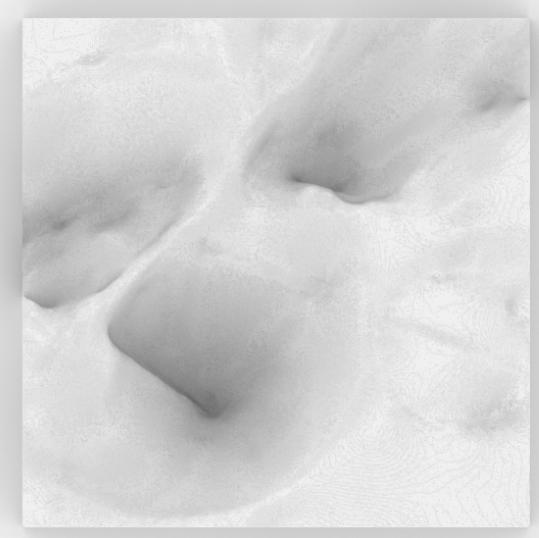

17.9a: Moment 7, 3D Capture 

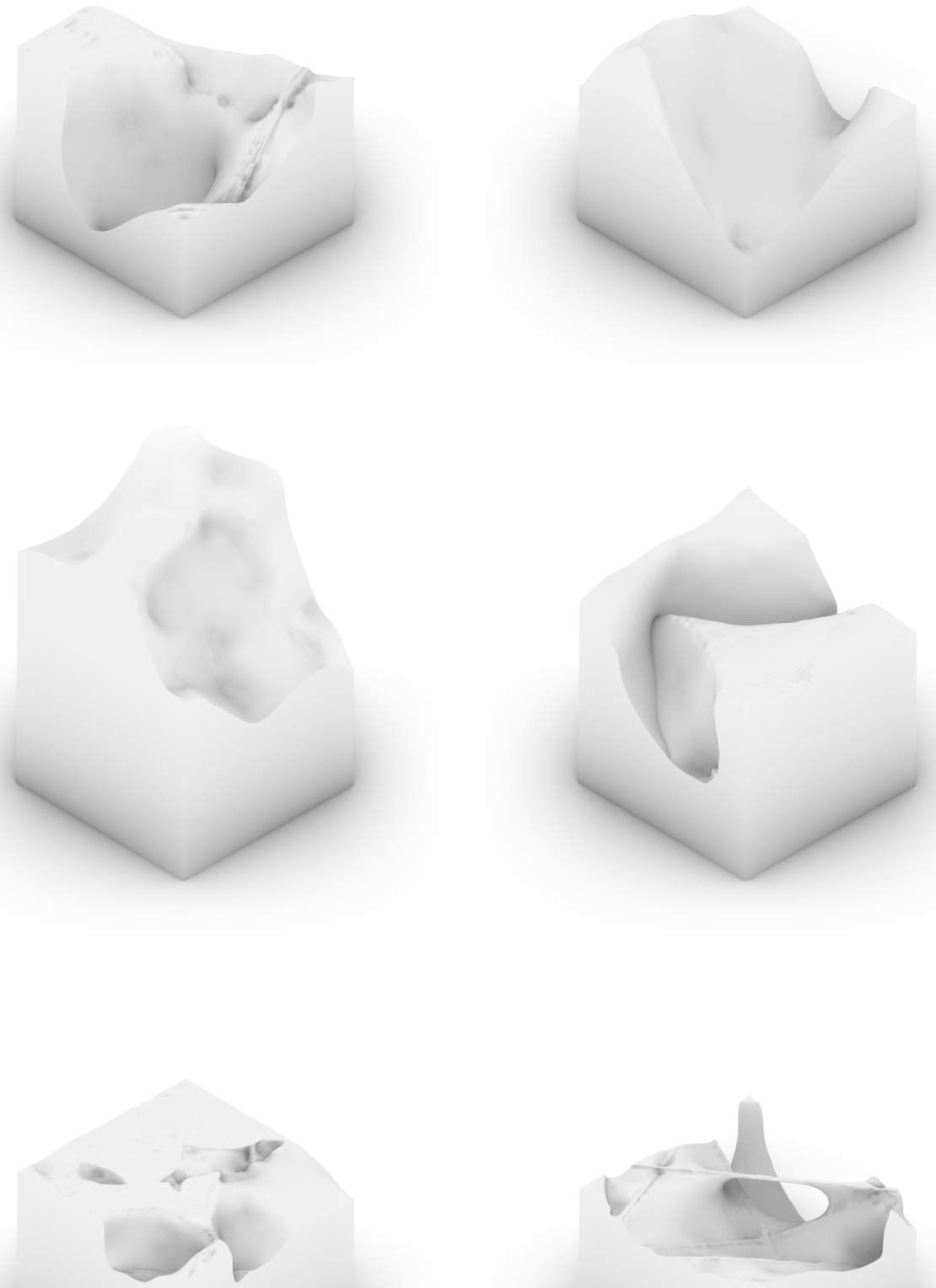

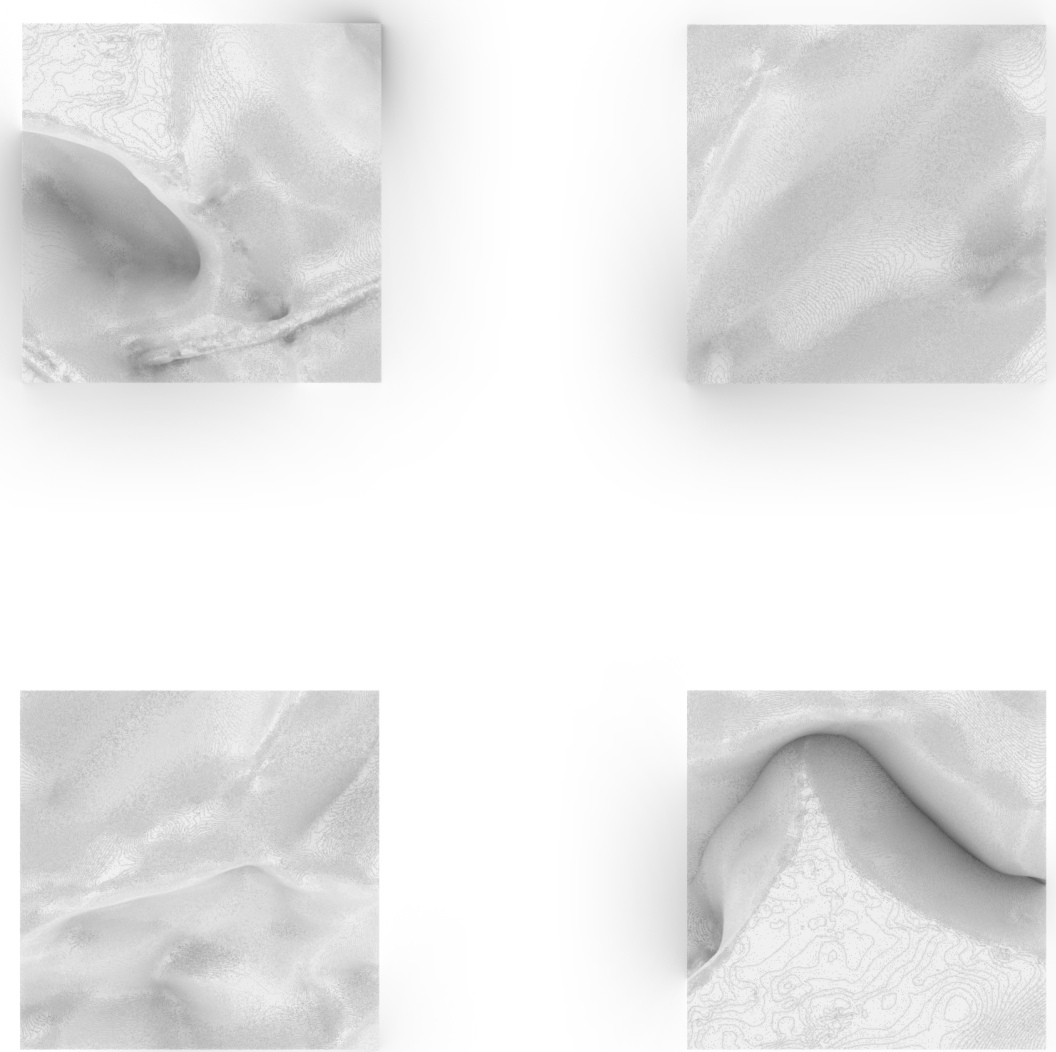

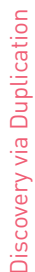
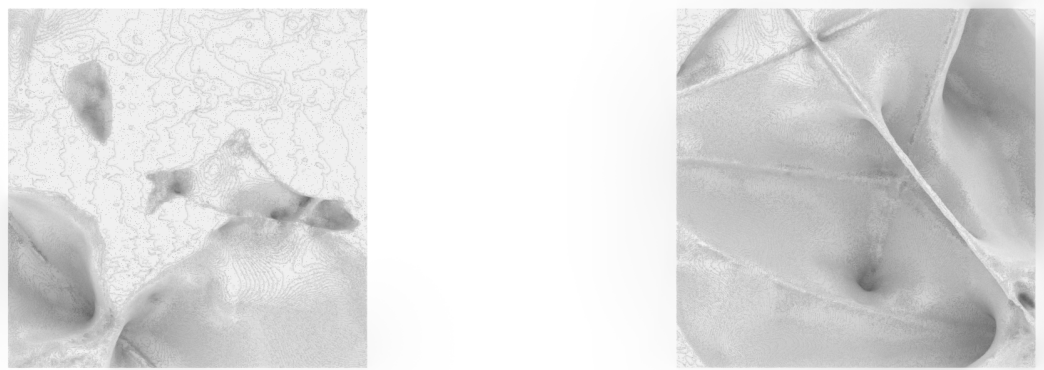


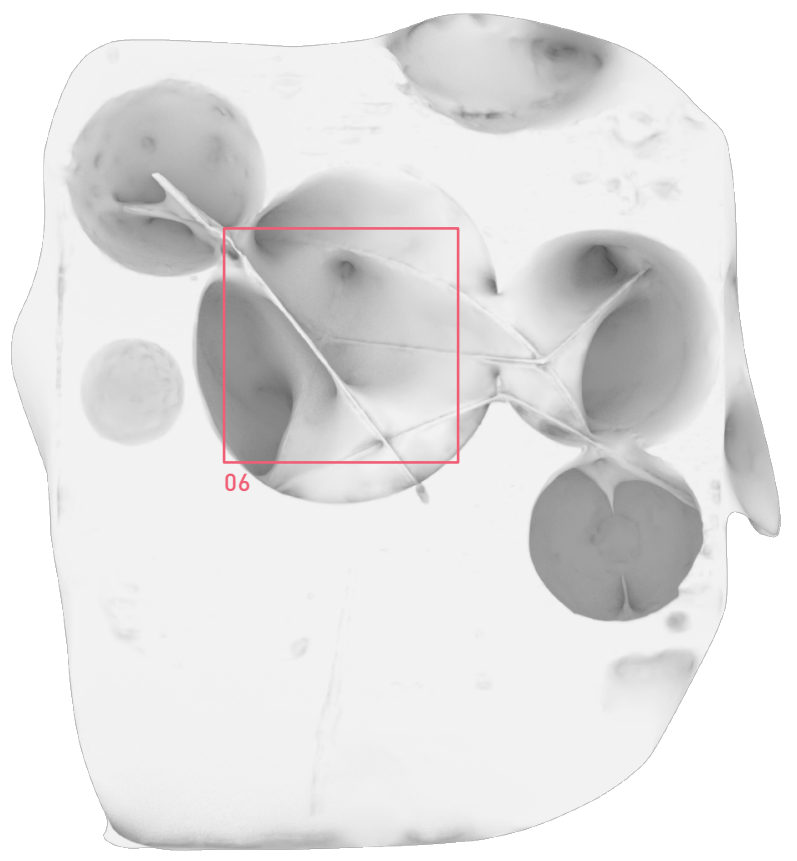

17.9e: Artefact C1, 3D Capture 


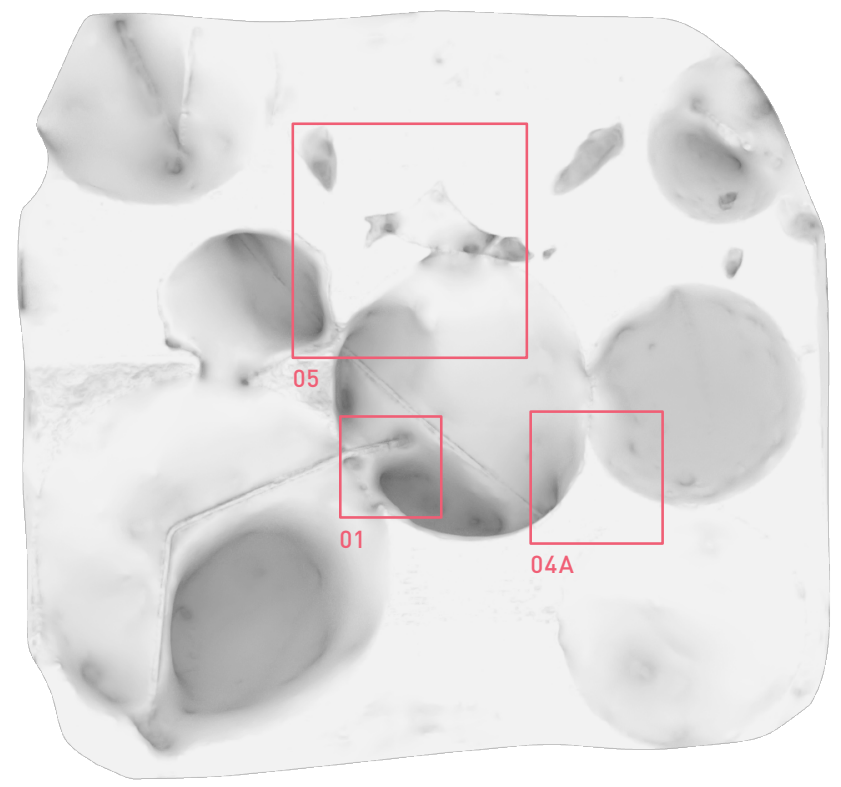

17.9f: Artefact B1, 3D Capture 


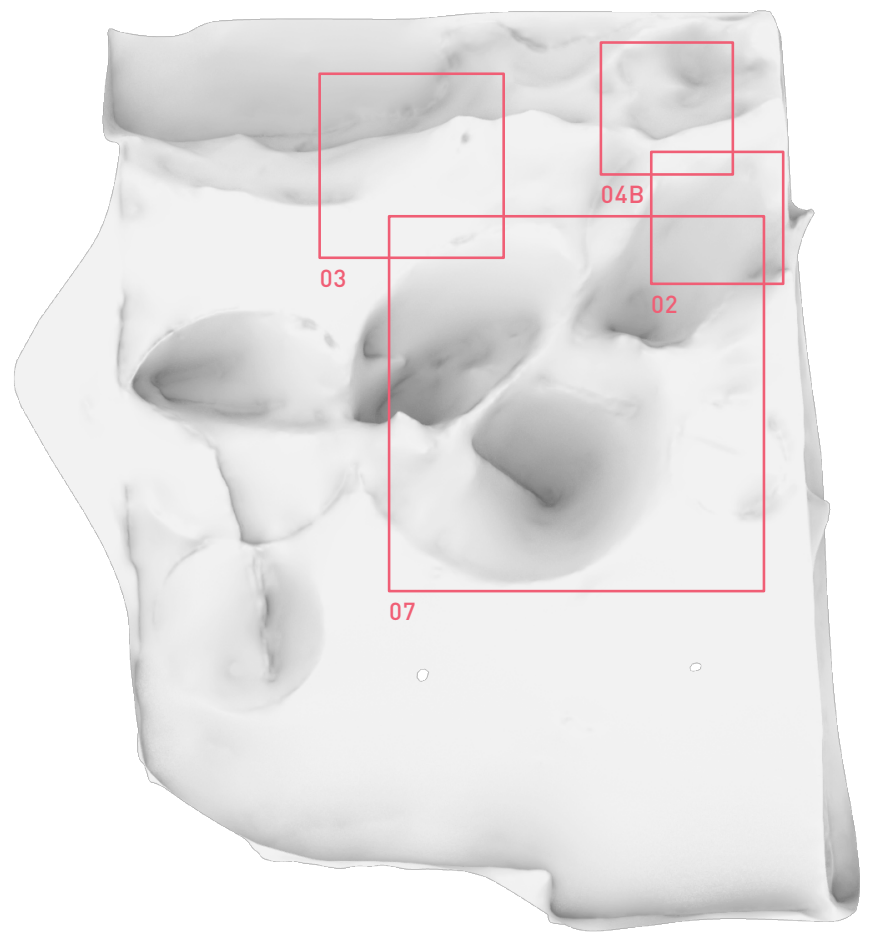

17.9g: Artefact C2, 3D Capture 


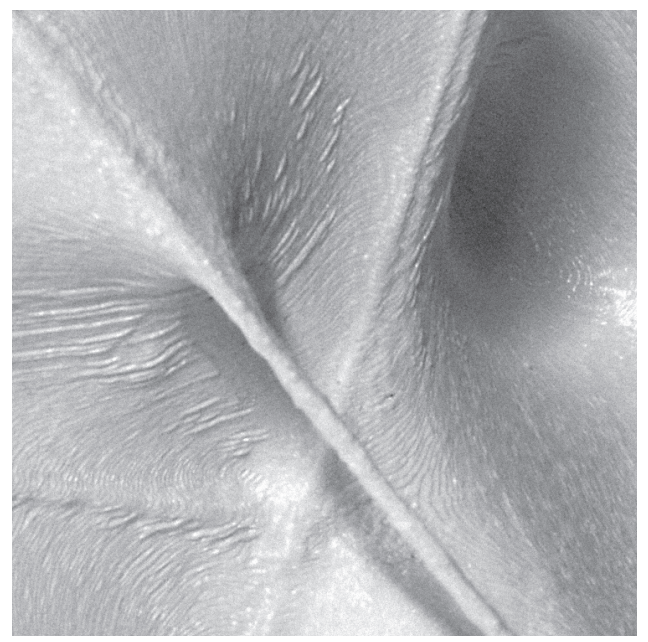

17.9h: Moment 06, Detail
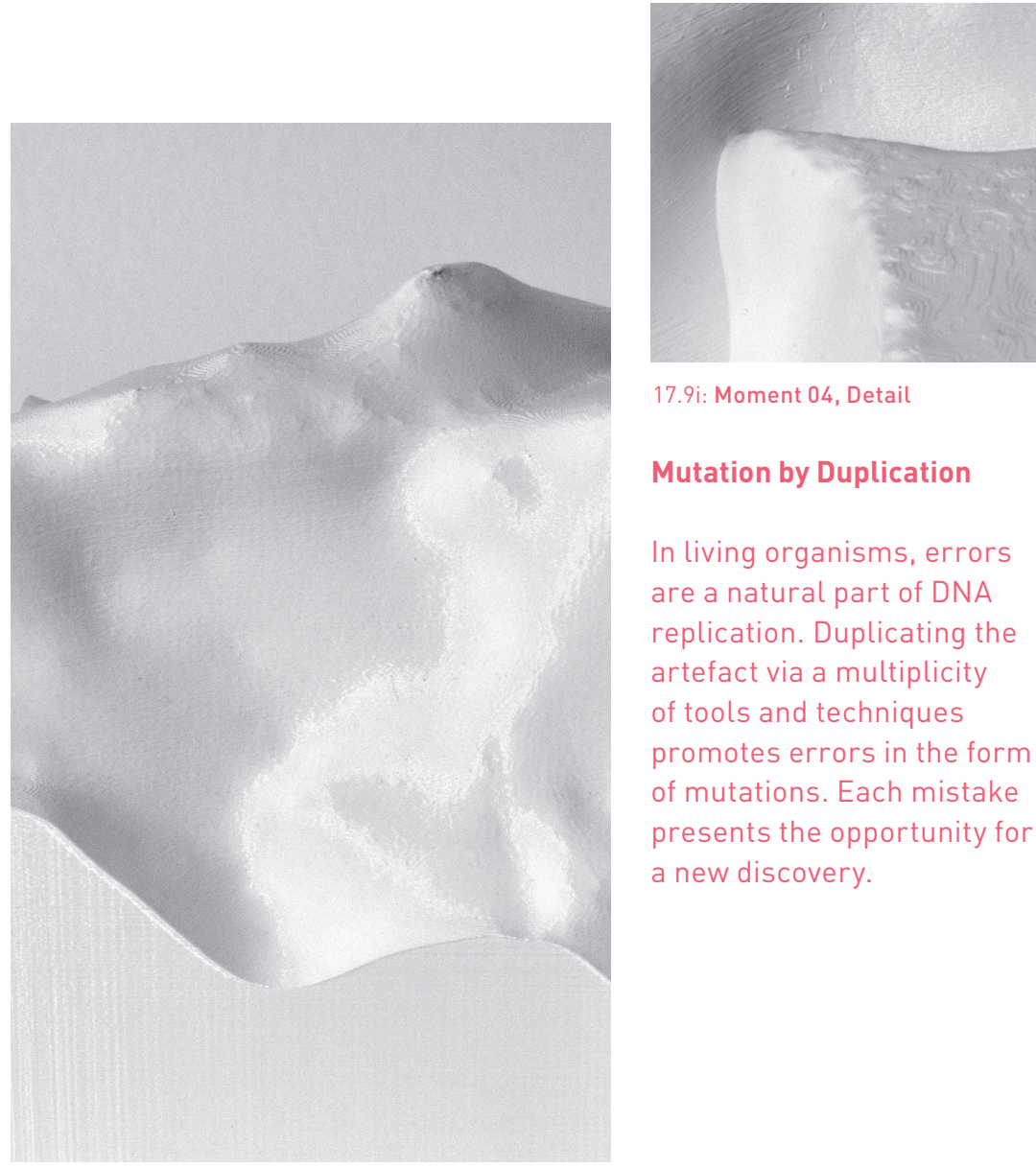

17.9i: Moment 04, Detail

\section{Mutation by Duplication}

In living organisms, errors are a natural part of DNA replication. Duplicating the artefact via a multiplicity of tools and techniques promotes errors in the form of mutations. Each mistake presents the opportunity for a new discovery. 


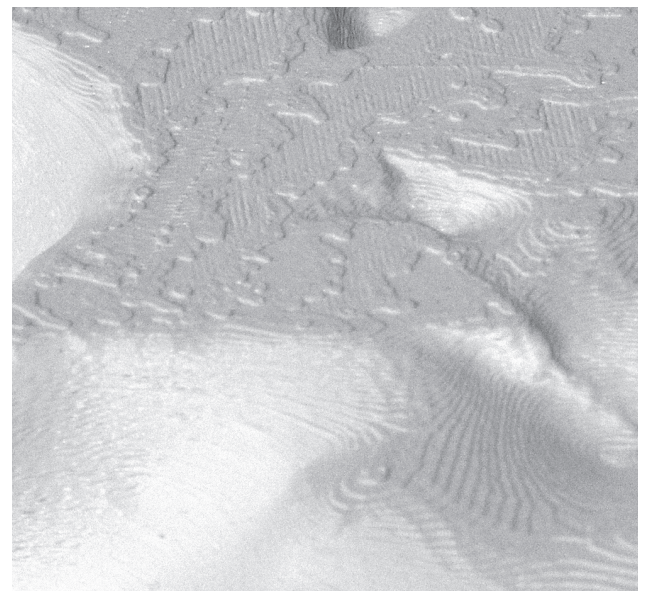

17.9k: Moment 05, Detail

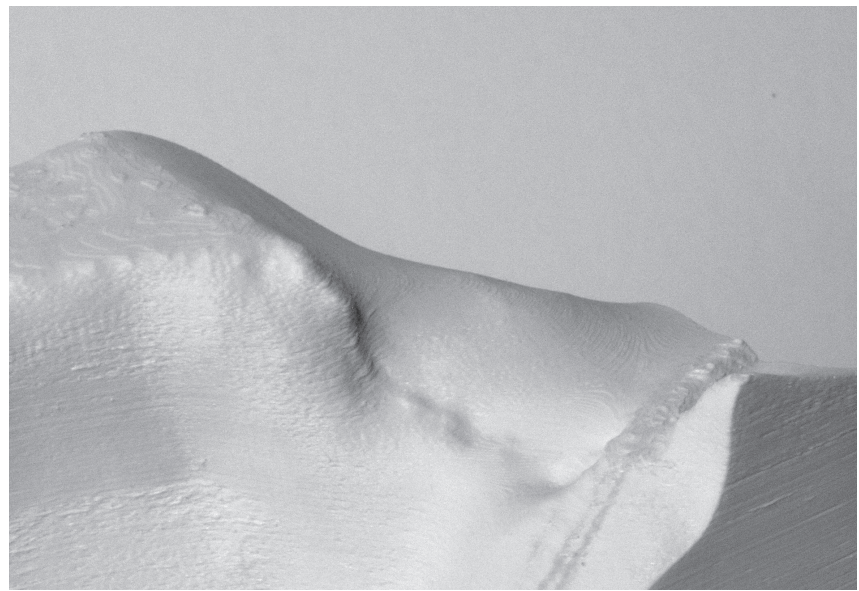

Topographic Identities

The cross-sectional

qualities as well as the layered depositing process of the printer head, results in an artefact with semiotics resembling landscapes/ topographical constructs.

17.9l: Moment 02, Detail

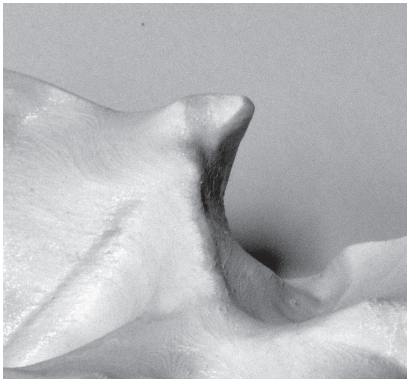

17.9m: Moment 07, Detail

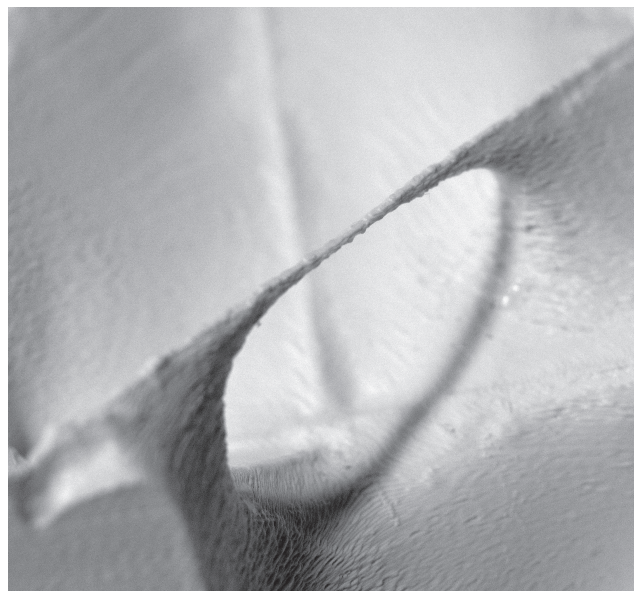

17.9n: Moment 06, Detail 


\subsection{Discovery via Extraction}

For this experimentation, only the upper surface was reproduced using a resin printer to achieve a higher resolution in the surface quality. Surfaces of moments 01,02 were duplicated in a translucent plastic with a blue tint, and moment 05 was completed in an opaque white plastic.

Unlike the previous artefacts, which allowed for a limited examination of volume and texture, these thinly extracted surfaces permit the discovery of spatial constructs rich in detail.

The surface of the artefact is made up of multiple layers; the combination of microscopic pathways ingrained by the printer head, triangulated surface geometries, residual points from the support armature, and the translucency of the plastic, results in the artefact having a unique, spectral quality. There is an uncanny softness to the emitted light and shadows. 


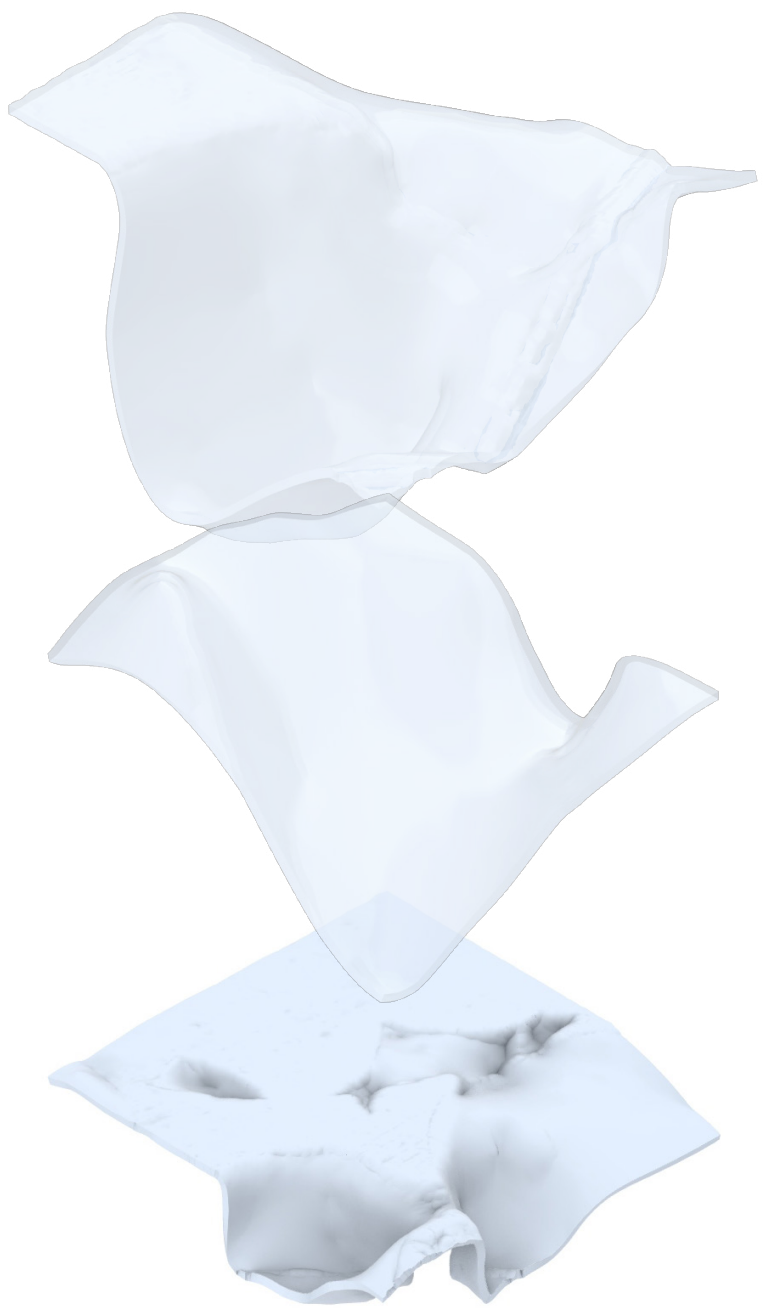

17.10a: Moment 01,02,05 Surface Capture 

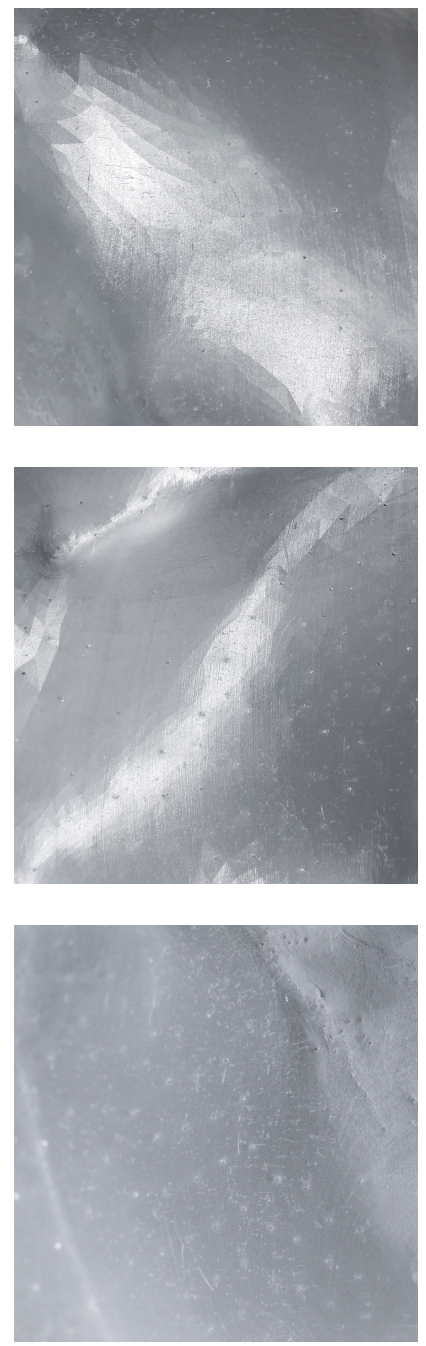

17.10b: Moment 01, 02 Surface Details

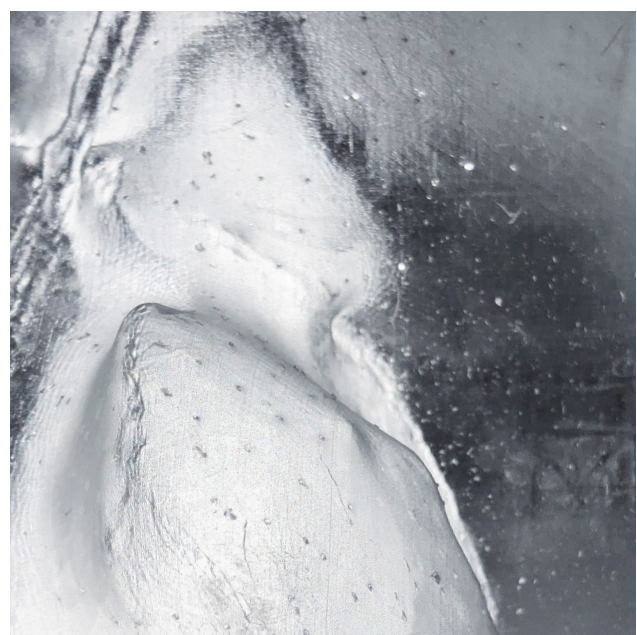

17.10c: Moment 01, Translucency Detail

\section{Polygonal System}

The triangulation of

the geometry is made apparent in light. Free

flowing and wavy surfaces shaped in triangulated polygons resemble a panelized system.

\section{Bump Map}

An exceptional level of surface texture was achieved in the photogrammetry process. The magnified textures are close to that of the original; capturing the smoothness of the negative pockets and the coarseness of the saw cut.

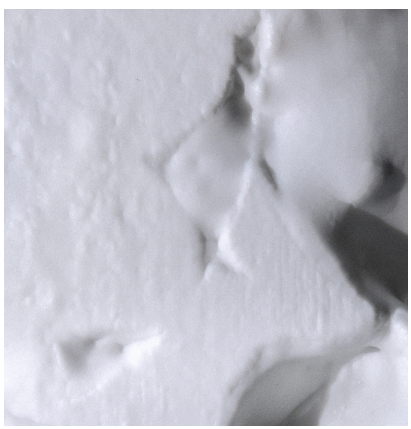

17.10d: Moment 05, Surface Detail 

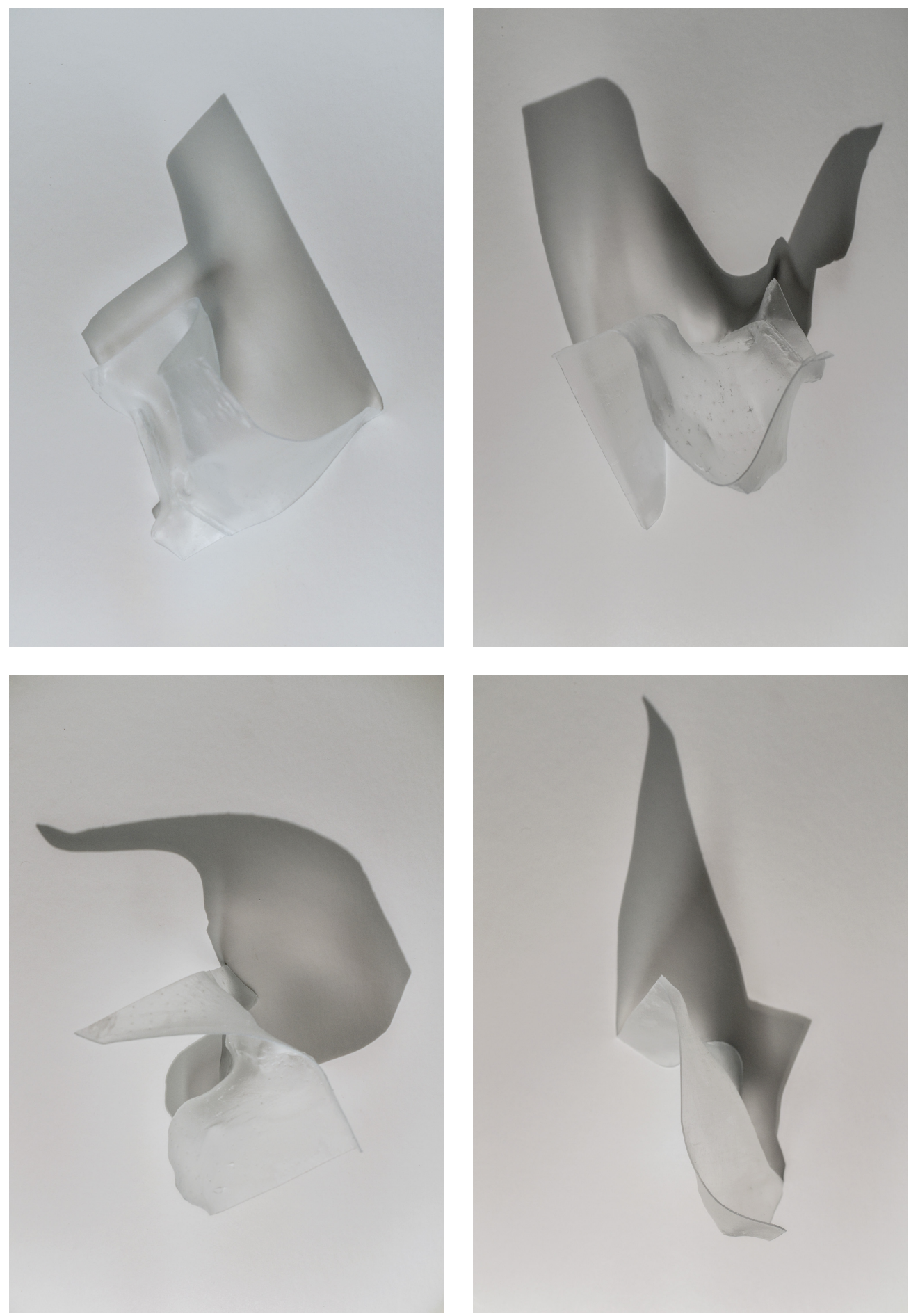


\subsection{Discovery via Prototype}

For this artefact, Moment 07 was vacuum formed with a thin sheet of polycarbonate to capture both its surface and volume. The resulting artefact was duplicated three times to quickly prototype speculative spatial constructs in plan, inverted-plan, and elevation-section.

Orienting the artefact in the respective axis allows for a simultaneous operation at the level of surface and volume. The addition of figures in the artefact immediately provides a sense of scale, occupation, and dynamism. As discussed in section 18.3, the metal wires can be read as lines of flight, weaving through, thresholds, and planes. The lines puncture through the transparent membrane, indicating heterarchical circulation, zones of occupation, and spatial relationships.

The complete transparency of the plastic artefact seemingly lacks any texture but, using a point light reveals richly textured shadows. 


\section{Prototype A: Plan}

The plan is the generator. Rhythm, proportions, volumetric and spatial relationships are examined in this artefact. Occupation is available at the surface level, beneath, through, and over. Pathways interweave through the moment.

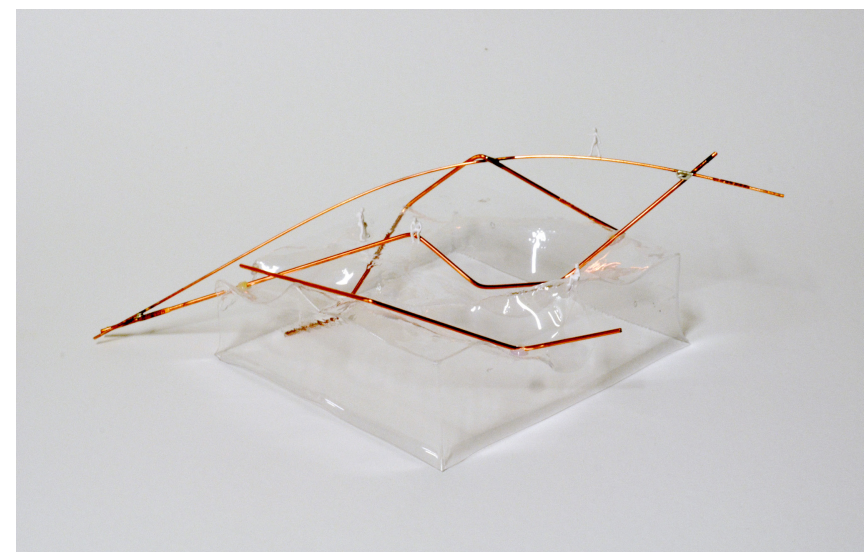

17.11a: Prototype A

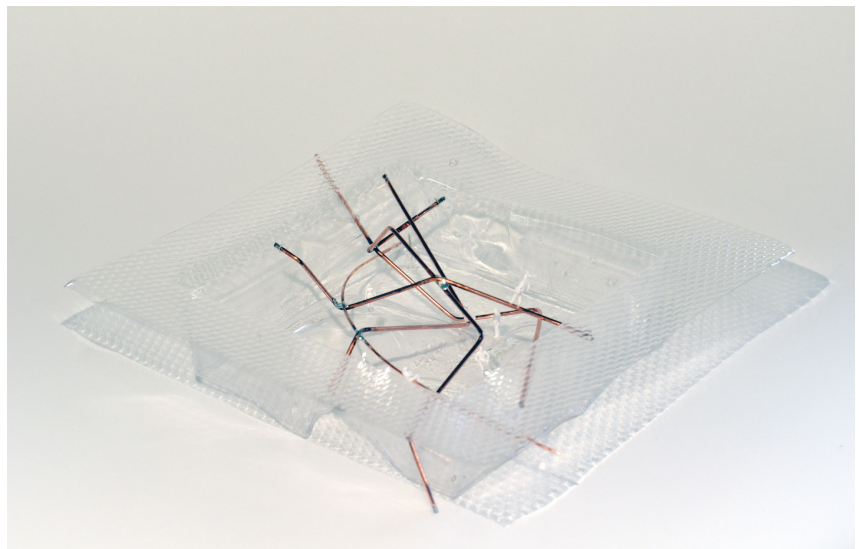

Prototype B: Inverted Plan

Flipping the artefact inverts the surface, thus revealing a very different territory to experiment on. Pathways snake around the convex landscape.

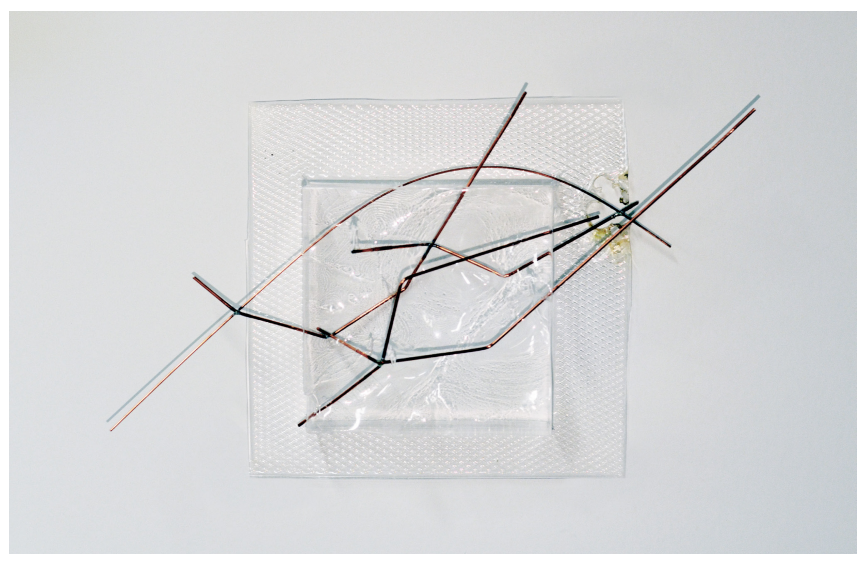

Prototype C: Elevation/ Section

Rotating the model along the $\mathrm{X}$-axis allows for an exploration at the level of section. Occupation seamlessly flows from interior to exterior continuing the uninterrupted adventure. 


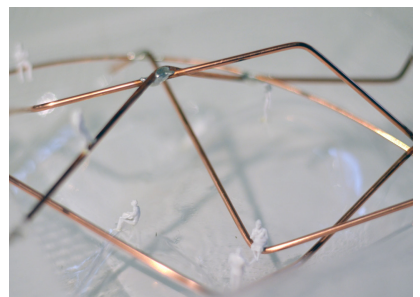

17.11d: Prototyped B: Detail
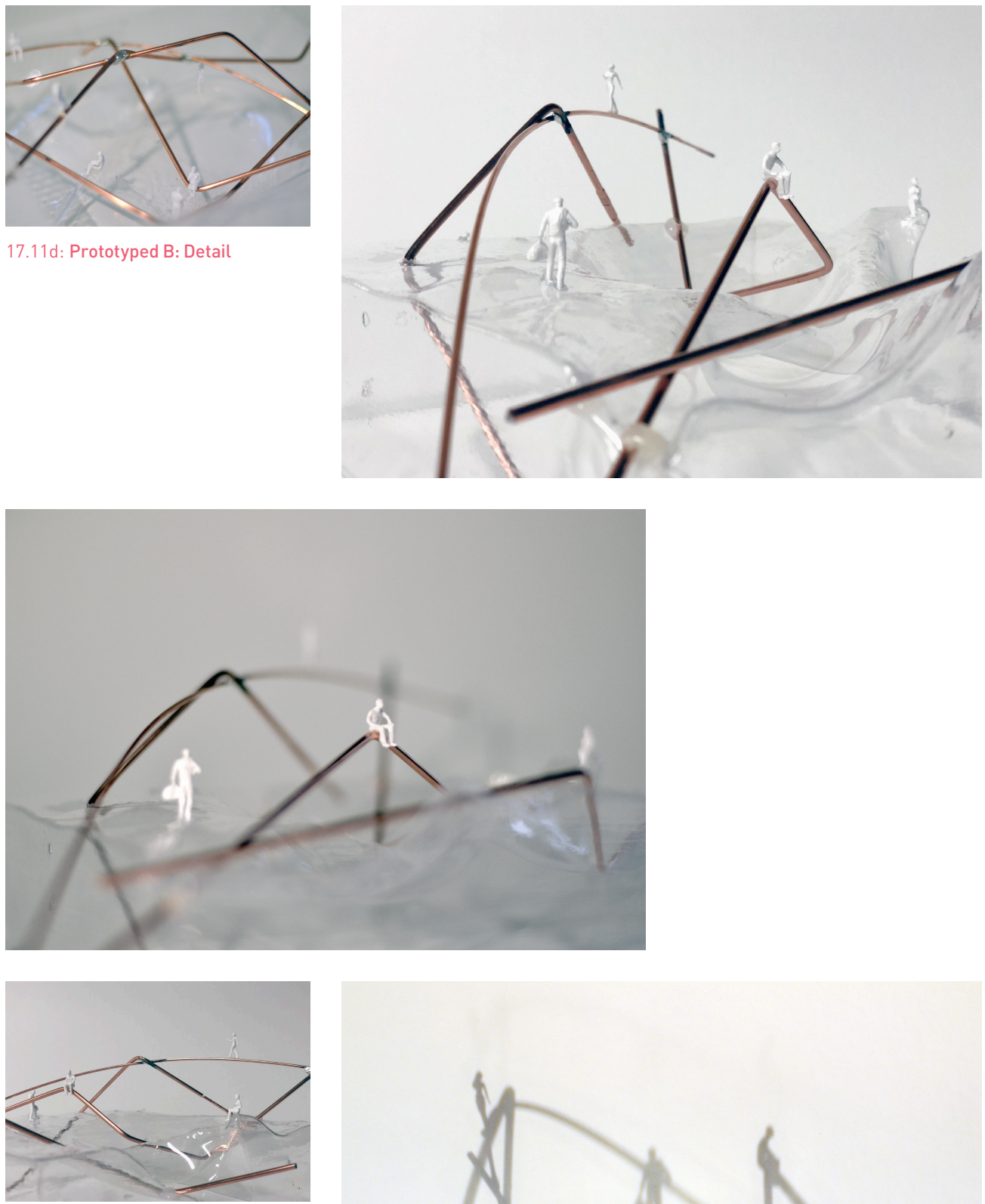

17.11e: Prototype A: Details

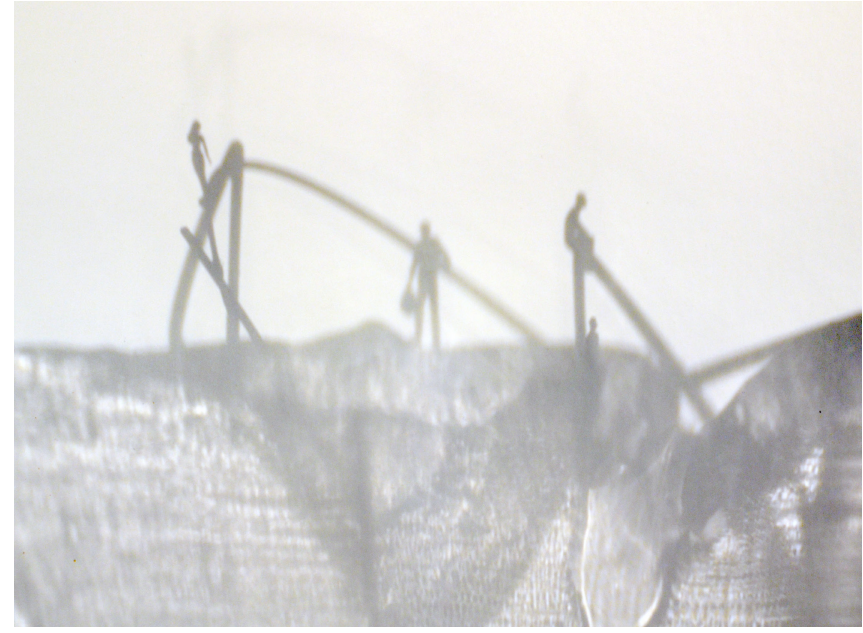




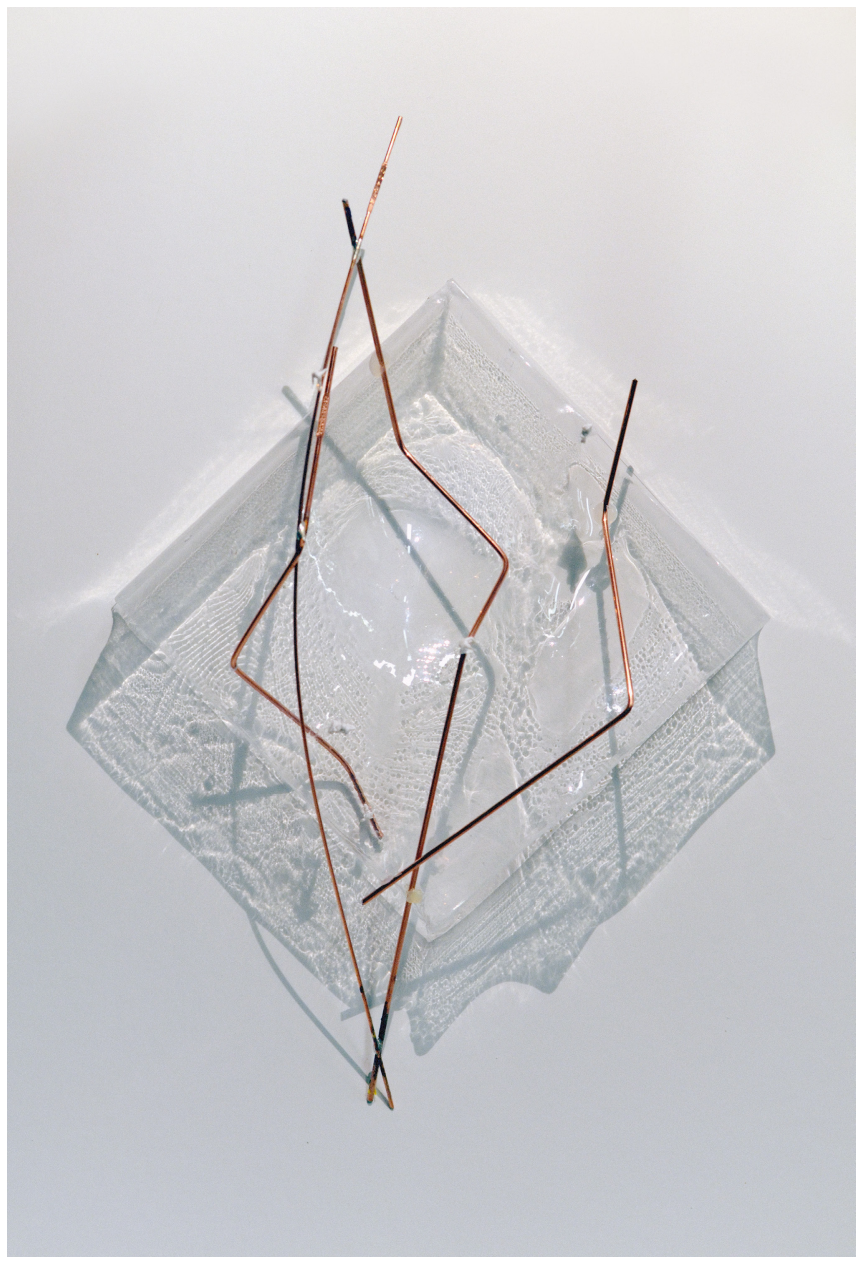

17.11g: Prototype A: Light \& Shadows 

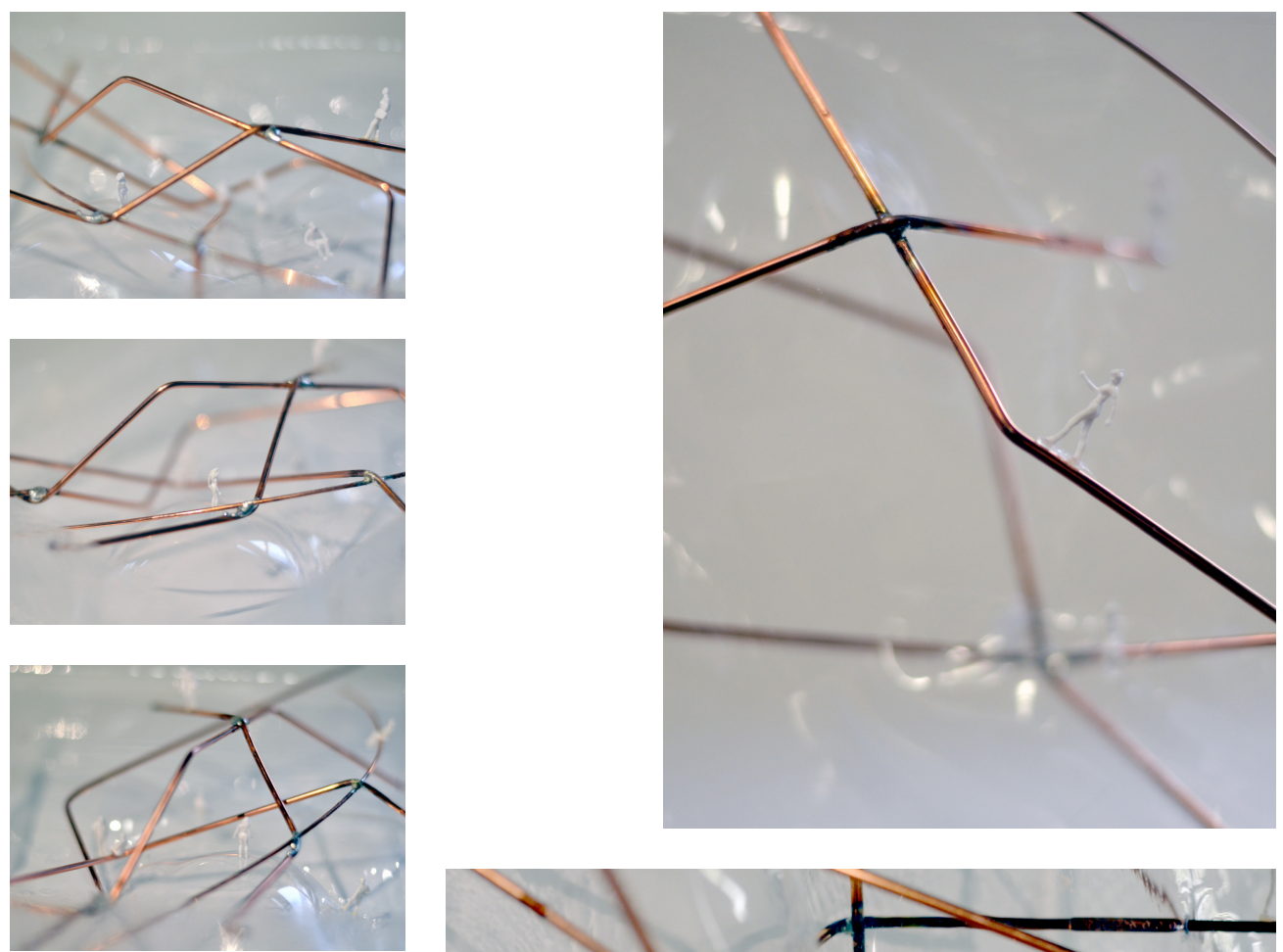

17.11h: Prototype B: Details

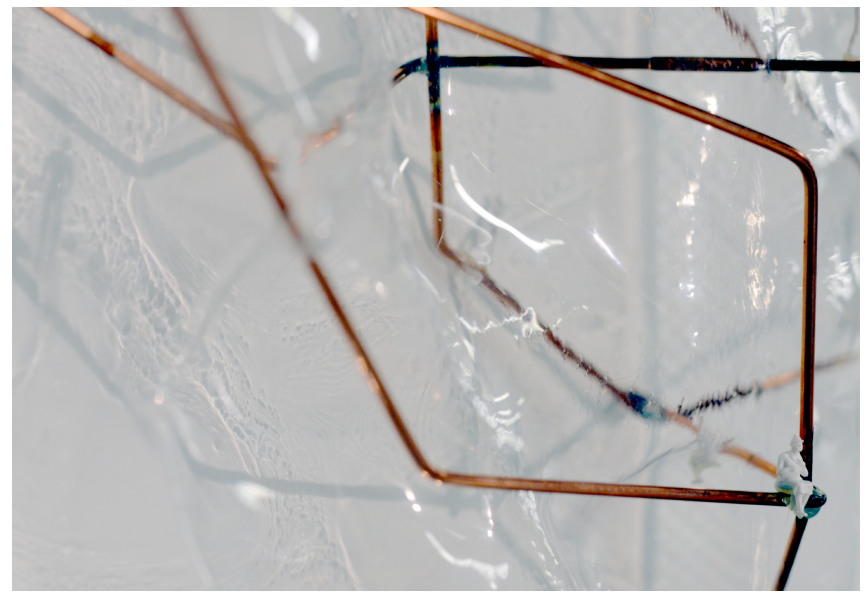

0
0
0
0
0
0
0
$\frac{0}{2}$
2
$\frac{1}{0}$
0
0
0
0
0

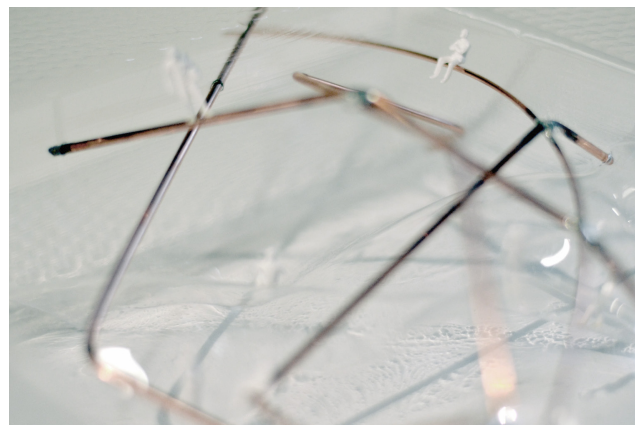

17.11i: Prototype C: Details 


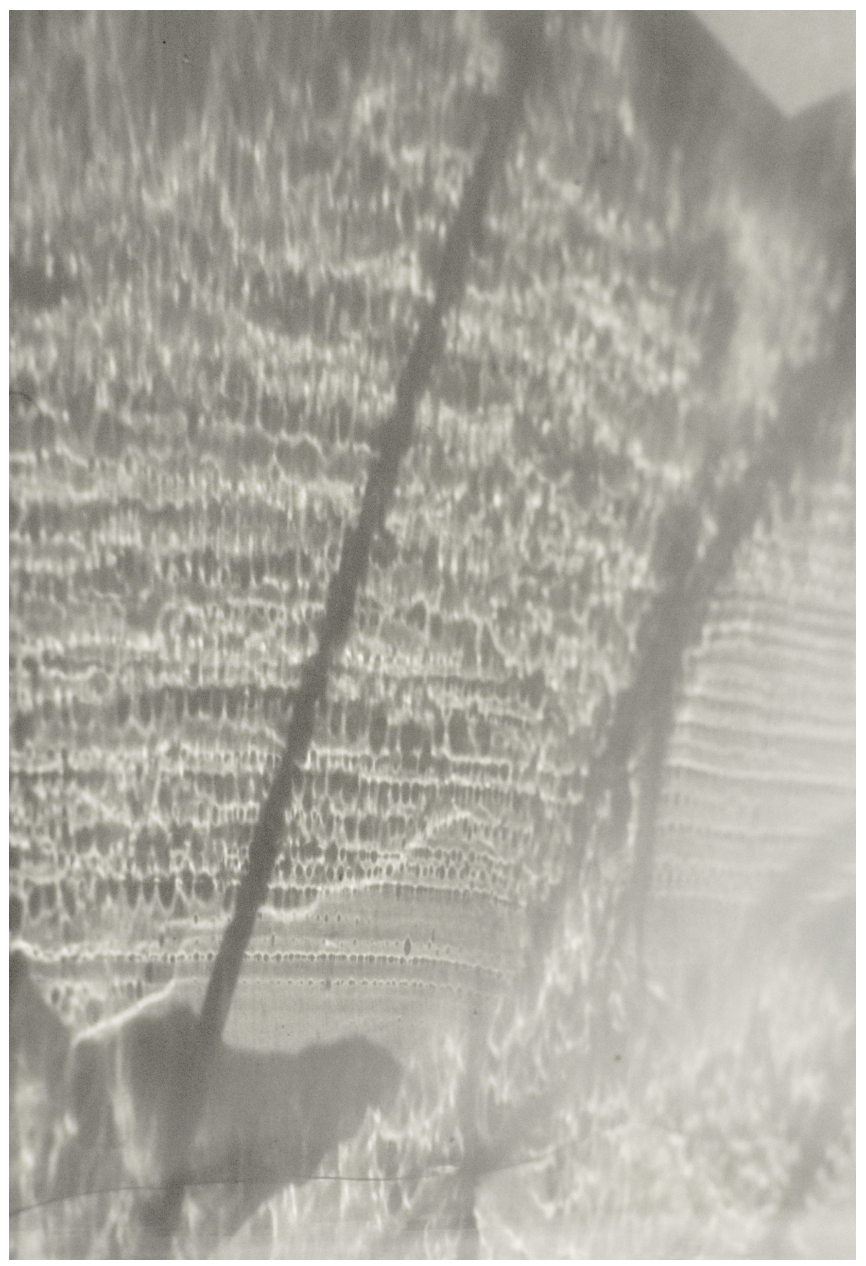

17.11k: Prototype A: Light \& Shadows 


\section{Conclusion}

A post-work-world is predicated on being liberated from labour. And by extension liberated from the semiotics of contemporary capitalism that has established the urban fabric of the modern metropolis. Logics of efficiency, power, and predictability are conditions that reinforce a familiar and canny world.

The proposed architectural tectonics are a polemic against this condition. The Monument to Culture is an oppositional typology. It's formal, experiential, and spatial logics attempt to disrupt the contextual codes of the financial district, to challenge current conditions, to align the future toward a post-work-world.

The experiments I conducted look at expanding techniques of representation via an investigation of the boundaries imposed by each medium of expression. These architectural artefacts demonstrate that theory can emerge out of design research. The work is a non-linear proposition in which architectural logic is discovered, not 
enforced by the normative and established cultural mechanisms. It isn't the locked-in logic of popular theories that determine the work. Instead, theories are revealed in the same way ontologies are.

A new system of ideas, principles, and logics emerges in the process of crafting the architectural artefact; through the interaction between the object, the maker, and the tools that are employed. 


\section{R References}

Works Cited

“Antilia (building)." Wikipedia. July 25, 2018. Accessed July 27, 2018. https:// en.wikipedia.org/wiki/Antilia_(building).

Attali, Jacques. A Brief History of the Future: A Brave and Controversial Look at the Twenty-first Century. New York: Arcade Pub., 2011.

Berardi, Franco. Precarious Rhapsody: Semiocapitalism and the Pathologies of Post-alpha Generation. London: Minor Compositions, 2010.

Berardi, Franco. After the Future. Oakland, CA: AK Press, 2011.

Beton, Andre. "Les Champs Magnétiques." Wikipedia. July 27, 2018. Accessed July 31, 2018. https://en.wikipedia.org/wiki/Les_Champs_magnétiques.

Broadbent, Geoffrey. Deconstruction a Student Guide. London: Academia, 1991. Brooks, James. "Cyborgs at Work: Employees Getting Implanted with Microchips." AP News. April 03, 2017. Accessed July 27, 2018. https://www.apnews. com/4fdcd5970f4f4871961b69eeff5a6585.

Brumfiel, Elizabeth M., Robert M. Ehrenreich, Janet E. Levy, and Carole L. Crumley. Heterarchy and the Analysis of Complex Societies. Arlington: American Anthropological Association, 1995.

Byrnes, Mark, and CityLab. "A Look Back at Expo 67's U.S. Pavilion." CityLab. April 27, 2017. Accessed July 28, 2018. https://www.citylab.com/design/2017/04/a-lookback-at-expo-67s-us-pavilion/524589/.

UN Environment Program. “China Consolidates Position as Global Leader on Green Finance, Says New Research." News release, November 11, 2017. UN Environment. Accessed July 28, 2018. https://www.unenvironment.org/news-andstories/press-release/china-consolidates-position-global-leader-green-financesays-new.

CNBC. "A Swedish Start-up Has Started Implanting Microchips into Its Employees." CNBC. April 03, 2017. Accessed July 27, 2018. https://www.cnbc.com/2017/04/03/ start-up-epicenter-implants-employees-with-microchips.html.

Conniff, Richard. “What the Luddites Really Fought Against." Smithsonian.com. March 01, 2011. Accessed July 31, 2018. https://www.smithsonianmag.com/ history/what-the-luddites-really-fought-against-264412/?no-ist=\&page=2. 
Debord, Guy. "Theory of the Dérive." Situationist International Online. Accessed July 28, 2018. https://www.cddc.vt.edu/sionline/si/theory.html.

Derrida, Jacques, and Peggy Kamuf. Specters of Marx: The State of the Debt, the Work of Mourning, and the New International. New York, NY: Routledge, 2011.

Deutsche Welle. “Free Money - Germany's Basic Income Lottery I DW | 06.10.2015." DW.COM. Accessed July 27, 2018. http://www.dw.com/en/free-money-germanysbasic-income-lottery/a-18764779.

Dunne \& Raby. Accessed July 28, 2018. http://www.dunneandraby.co.uk/content/ bydandr/13/0.

Ferro, Shaunacy. "What If Tech Companies Owned Your City?" Fast Company. February 18, 2015. Accessed July 27, 2018. https://www.fastcompany. com/3042529/what-if-tech-companies-owned-your-city.

Frascari, Marco. Eleven Exercises in the Art of Architectural Drawing: Slow Food for the Architects Imagination. London: Routledge, 2011.

Frase, Peter. “Four Futures.” Jacobin. Accessed July 28, 2018. https://www. jacobinmag.com/2011/12/four-futures/.

Frase, Peter. Four Futures. London: Verso, 2015.

Freeman, Richard. "Who Owns the Robots Rules the World." IZA World of Labour, 2015. doi:10.15185/izawol.5.

Freud, Sigmund. The Uncanny. Accessed July 31, 2018. http://web.mit.edu/ allanmc/www/freud1.pdf.

“Fujian Tulou." UNESCO World Heritage Centre. Accessed July 28, 2018. https:// whc.unesco.org/en/list/1113.

“Google's Sidewalk Labs Signs Deal for 'smart City' Makeover of Toronto's Waterfront." The Globe and Mail. June 12, 2018. Accessed July 27, 2018. https:// www.theglobeandmail.com/news/toronto/google-sidewalk-toronto-waterfront/ article36612387/.

Grojs, Boris, and G. M. Goshgarian. On the New. London: Verso, 2014. Harman, Graham. Immaterialism Objects and Social Theory. Cambridge, UK: Polity Press, 2016. 
Henley, Jon. "Finland to End Basic Income Trial after Two Years." The Guardian. April 23, 2018. Accessed July 27, 2018. http://www.theguardian.com/world/2018/ apr/23/finland-to-end-basic-income-trial-after-two-years.

History.com Staff. “Works Progress Administration (WPA)." History.com. 2017. Accessed July 28, 2018. https://www.history.com/topics/works-progressadministration.

Huizinga, Johan. Homo Ludens: A Study of the Play-element in Culture. Mansfield Centre, CT: Martino Publishing, 2014.

Huizinga, Johan. Homo Ludens: A Study of the Play-element in Culture. Angelico Press, 2016.

Hunt, Shauna. "What Will It Take for Toronto to Continue to Sustain the Condo Boom?" CityNews Toronto. April 03, 2017. Accessed July 28, 2018. https://toronto. citynews.ca/2017/04/03/will-take-toronto-continue-sustain-condo-boom/.

"Impact of Automation on Developing Countries Puts up to 85\% of Jobs at Risk." Oxford Martin School. January 27, 2016. Accessed July 27, 2018. https://www. oxfordmartin.ox.ac.uk/news/201601_Technology_at_Work_2.

“Jacques Attali." Wikipedia. July 27, 2018. Accessed July 27, 2018. https:// en.wikipedia.org/wiki/Jacques_Attali.

Josie Cox Business Editor. "These Are the 10 Richest People in the World Right Now - and They're All Getting Even Richer." The Independent. January 02, 2018. Accessed July 28, 2018. https://www.independent.co.uk/news/business/analysisand-features/rich-world-billionaire-list-ranking-jeff-bezos-bill-gates-warrenbuffett-amancio-ortega-mark-a8131071.html.

Koolhaas, Rem, Bruce Mau, Jennifer Sigler, and Hans Werlemann. Small, Medium, Large, Extra-large: Office for Metropolitan Architecture, Rem Koolhaas, and Bruce Mau. New York: Monacelli Press, 1997.

Koolhaas, Rem. Delirious New York: A Retroactive Manifesto for Manhattan. New York: Monacelli Press, 2005.

“Les Champs Magnétiques." Wikipedia. July 27, 2018. Accessed July 31, 2018. https://en.wikipedia.org/wiki/Les_Champs_magnétiques. 
Manyika, James, Susan Lund, Michael Chui, Jacques Bughin, Jonathan Woetzel, Parul Batra, Ryan Ko, and Saurabh Sanghvi. "Jobs Lost, Jobs Gained: What the Future of Work Will Mean for Jobs, Skills, and Wages." McKinsey \& Company. Accessed July 28, 2018. https://www.mckinsey.com/featured-insights/future-of-organizations-and-work/Jobslost-jobs-gained-what-the-future-of-work-will-mean-for-jobs-skills-and-wages.

Miller, Frederic, Agnes Vandome, and John McBrewster. Infoshphere.

“Monument." Merriam-Webster. Accessed July 28, 2018. https://www.merriamwebster.com/dictionary/monument.

“Monument." Wikipedia. July 27, 2018. Accessed July 28, 2018. https://en.wikipedia. org/wiki/Monument.

“Mr. In-between." New York Magazine, October 17, 1988, 48-52.

Newman, Oscar. Defensible Space: Crime Prevention through Urban Design. Macmillan,: New York, 1972.

Pearch, Bill. “Salvador Dali: Master of Surrealism - Bill Pearch." Humzoo. Accessed July 31, 2018. http://www.humzoo.com/billpearch/blog/1243/.

Pineda, Mercedes, Constant, and Pedro G. Romero. Constant: New Babylon. Madrid: Museo Nacional Centro De Arte Reina Sofía, 2015.

Robinson, Lawrence, Melinda Smith, Jeanne Segal, and Jennifer Shubin. "The Benefits of Play for Adults: How Play Benefits Your Relationships, Job, Bonding, and Mood." Depression in Older Adults: Recognizing the Signs of Elderly Depression and Getting Treatment. Accessed July 28, 2018. https://www. helpguide.org/articles/mental-health/benefits-of-play-for-adults.htm.

Scott, Felicity Dale Elliston. Architecture or Techno-utopia: Politics after Modernism. Cambridge, MA: MIT Press, 2010.

Sector, Industry. "Interim Reports - Economic Strategy Tables." Corporations Canada. March 27, 2018. Accessed July 28, 2018. https://www.ic.gc.ca/eic/site/098. nsf/eng/h_00013.html.

Srnicek, Nick. Inventing the Future Postcapitalism and a World without Work. Verso, 2016.

Tate. "Automatism - Art Term." Tate. Accessed July 31, 2018. https://www.tate.org. uk/art/art-terms/a/automatism. 
Tempel, Benno, and Laura Stamps. New Babylon - to Us, Liberty: Constant. Ostfildern: Hatje Cantz Verlag, 2016.

Tester, Keith. The Flâneur. Abingdon, Oxon, United Kingdom: Routledge, 2015. Tschumi, Bernard. The Pleasure of Architecture. London: Architectural Design Magazine, 1977.

Ullah, Zahra. "How Samsung Dominates South Korea's Economy." CNNMoney. Accessed July 27, 2018. https://money.cnn.com/2017/02/17/technology/samsungsouth-korea-daily-life/index.html.

Van Der Straeten, Bart. "The Uncanny and the Architecture of Deconstruction." Image \& Narrative. Accessed July 31, 2018. http://www.imageandnarrative.be/ inarchive/uncanny/bartvanderstraeten.htm.

Veblen, Thorstein. The Theory of the Leisure Class: An Economic Study of Institutions. Breinigsville, PA: Nabu Press, 2010.

Vidler, Anthony. The Architectural Uncanny: Essays in the Modern Unhomely. Cambridge, Mass.: MIT Press, 1999.

Wainwright, Oliver. "'Everything Is Gentrification Now': But Richard Florida Isn't Sorry." The Guardian. October 26, 2017. Accessed July 28, 2018. https://www. theguardian.com/cities/2017/oct/26/gentrification-richard-florida-interviewcreative-class-new-urban-crisis.

Wilkinson, Tom. "Typology: Skyscraper." Architectural Review. Accessed July 28, 2018. https://www.architectural-review.com/essays/typologyskyscraper/10019237.article.

William, Eli K. P. Cash Crash Jubilee. Place of Publication Not Identified: Talos, 2016.

Wong, Natalie, and Stefanie Marotta. "Who Just Beat the Bay Area in Tech Jobs? Toronto." Bloomberg.com. July 24, 2018. Accessed July 28, 2018. https://www. bloomberg.com/news/articles/2018-07-24/toronto-beats-bay-area-in-new-techjobs-and-new-york-in-talent.

Woods, Lebbeus. Radical Reconstruction. New York: Princeton Architectural Press, 1997. 
Woods, Lebbeus. Bridges: Mathematical Connections in Art, Music, and Science: Heterarchy of Space - Abstract. Winfield: Southwestern College, 2002. Woods, Tim. Beginning Postmodernism. Manchester: Manchester University Press, 2013.

World Trade Center Site Memorial Competition. Accessed July 28, 2018. http:// www.wtcsitememorial.org/. 


\section{EN End Notes}

P $\quad \underline{\text { Preface }}$

1 Frey, Carl Benedikt, and Michael A. Osborne. "The Future of Employment: How Susceptible Are Jobs to Computerisation?" Technological Forecasting and Social Change 114 (September 2017): 254-80. doi:10.1016/j.techfore.2016.08.019.

2 Nick Srnicek, Inventing the Future Postcapitalism and a World without Work (Verso, 2016), 99.

3 Frase, Peter. Four Futures. London: Verso, 2015.

$1.0 \quad$ Introduction

$1 \quad$ "The Third Industrial Revolution." The Economist. April 21, 2012. Accessed July 27, 2018. http://www.economist.com/leaders/2012/04/21/the-third-industrialrevolution.

2 Miscovich, Peter. "The Future Is Automated. Here's How We Can Prepare for It." World Economic Forum. Accessed July 27, 2018. http://www.weforum.org/ agenda/2017/01/the-future-is-automated-here-s-how-we-can-prepare-for-it/.

3 Srnicek, Nick. Inventing the Future Postcapitalism and a World without Work (Verso, 2016), 97.

$4 \quad$ Ibid.

5 "Impact of Automation on Developing Countries Puts up to 85\% of Jobs at Risk." Oxford Martin School. January 27, 2016. Accessed July 27, 2018. https://www. oxfordmartin.ox.ac.uk/news/201601_Technology_at_Work_2.

6 Deutsche, Welle. “Free Money - Germany’s Basic Income Lottery I DW | 06.10.2015." DW.COM. Accessed July 27, 2018. http://www.dw.com/en/freemoney-germanys-basic-income-lottery/a-18764779.

$7 \quad$ Henley, Jon. "Finland to End Basic Income Trial after Two Years." The Guardian. April 23, 2018. Accessed July 27, 2018. http://www.theguardian.com/world/2018/ apr/23/finland-to-end-basic-income-trial-after-two-years.

8 "Ontario to Roll out Basic Income in Three Cities." The Globe and Mail, The Globe and Mail, 27 Apr. 2017, www.theglobeandmail.com/news/national/what-is-basicincome-and-who-qualifies/article34795127/.

$9 \quad$ United States, Congress, “American Time Use Survey Summary: 2017 RESULTS." Bureau of Labour Statistics.

10 “Is Work in Crisis? Dr. Nick Srnicek." Autonomy Institute, www.autonomyinstitute. org/portfolio/the-future-of-work/.

11 Fruman, Cecile. "Keeping pace with Digital Disruption: Regulating the Sharing Economy." Governance for Development. June 22, 2016. Accessed August 30 , 2018. http://blogs.worldbank.org/psd/voices/keeping-pace-digital-disruptionregulating-sharing-economy. 
2.0 Design Project Outline

1 Huizinga, Johan. Homo Ludens: A Study of the Play-element in Culture. Angelico Press, 2016.

3.0 Indented Design Research

1 Tempel, Benno, and Laura Stamps. New Babylon - to Us, Liberty: Constant. Ostfildern: Hatje Cantz Verlag, 2016.

2 Rem Koolhaas, Delirious New York: A Retroactive Manifesto for Manhattan (New York: Monacelli Press, 2005), 84.

3 Tempel, Benno, and Laura Stamps. New Babylon - to Us, Liberty: Constant. Ostfildern: Hatje Cantz Verlag, 2016.

\subsection{Background: Constant Nieuwenhuys}

1 Benno Tempel and Laura Stamps, New Babylon - to Us, Liberty: Constant(Ostfildern: Hatje Cantz Verlag, 2016).

$2 \quad$ Ibid, 211.

$3 \quad$ lbid.

$4 \quad$ Ibid, 70.

$5 \quad$ Ibid, 120-121.

6 Mercedes Pineda, Constant, and Pedro G. Romero, Constant: New Babylon(Madrid: Museo Nacional Centro De Arte Reina Sofía, 2015), 26.3

$7 \quad$ Ibid, 120-121.

8 Huizinga, Johan. Homo Ludens: A Study of the Play-element in Culture. Angelico Press, 2016.

$9 \quad$ lbid.

10 Huizinga, Johan. Homo Ludens: A Study of the Play-element in Culture (Angelico Press, 2016), 8-10.

5.0 Jacques Attali: A Brief History

1 “Jacques Attali." Wikipedia. July 27, 2018. Accessed July 27, 2018. https:// en.wikipedia.org/wiki/Jacques_Attali.

2 Jacques Attali, A Brief History of the Future: A Brave and Controversial Look at the Twenty-first Century (New York: Arcade Pub., 2011), 166.

$3 \quad$ Ibid, 175.

$4 \quad \mathrm{Ibi}, 179$.

$5 \quad$ 'Google's Sidewalk Labs Signs Deal for 'smart City' Makeover of Toronto's Waterfront." The Globe and Mail. June 12, 2018. Accessed July 27, 2018. https:// www.theglobeandmail.com/news/toronto/google-sidewalk-toronto-waterfront/ article36612387/.

6 Jacques Attali, A Brief History of the Future: A Brave and Controversial Look at the Twenty-first Century (New York: Arcade Pub., 2011), 171.

$7 \quad$ Brooks, James. "Cyborgs at Work: Employees Getting Implanted with Microchips." AP News. April 03, 2017. Accessed July 27, 2018. https://www.apnews. com/4fdcd5970f4f4871961b69eeff5a6585.

8 Jacques Attali, A Brief History of the Future: A Brave and Controversial Look at the Twenty-first Century (New York: Arcade Pub., 2011), 176.

$9 \quad$ Ibid, 179. 
10 Terry, Ken. "Number of Health Apps Soars, but Use Does Not Always Follow." Medscape. Accessed September 01, 2018. https://www.medscape.com/ viewarticle/851226.

11 Ferro, Shaunacy. "What If Tech Companies Owned Your City?" Fast Company. February 18, 2015. Accessed July 27, 2018. https://www.fastcompany. com/3042529/what-if-tech-companies-owned-your-city.

12 Ullah, Zahra. "How Samsung Dominates South Korea's Economy." CNNMoney. Accessed July 27, 2018. https://money.cnn.com/2017/02/17/technology/samsungsouth-korea-daily-life/index.html.

13 "Polycentrism | Definition of Polycentrism in English by Oxford Dictionaries." Oxford Dictionaries I English. Accessed September 06, 2018. https:// en.oxforddictionaries.com/definition/polycentrism.

6.0 A Commodified Future: Cash Crash Jubilee

1 Eli K. P. William, Cash Crash Jubilee (New York: Talos, 2016), 130.

2 Ibid, 11.

$3 \quad$ Ibid, 185.

$4 \quad$ “Antilia (building)." Wikipedia. July 25, 2018. Accessed July 27, 2018. https:// en.wikipedia.org/wiki/Antilia_(building).

$5 \quad$ Eli K. P. William, Cash Crash Jubilee (New York: Talos, 2016),110.

\subsection{Four Futures}

1 Peter Frase, Four Futures (London: Verso, 2015).

2 Frase, Peter. "Four Futures." Jacobin. Accessed July 28, 2018. https://www. jacobinmag.com/2011/12/four-futures/.

3 Freeman, Richard. "Who Owns the Robots Rules the World." IZA World of Labour, 2015. doi:10.15185/izawol.5.

$4 \quad$ Veblen, Thorstein. The Theory of the Leisure Class: An Economic Study of Institutions. Breinigsville, PA: Nabu Press, 2010.

$5 \quad$ Lee, Timothy B. "The Author of Rise of the Creative Class Is Grappling with Its Dark Side." Vox. May 09, 2017. Accessed September 01, 2018. https://www.vox.com/new

$6 \quad$ Frase, Peter. "Four Futures." Jacobin. Accessed July 28, 2018. https://www. jacobinmag.com/2011/12/four-futures/.

$7 \quad$ Ibid.

8 Peter Frase, Four Futures (London: Verso, 2015), 128. Josie Cox Business Editor. "These Are the 10 Richest People in the World Right Now - and They're All Getting Even Richer." The Independent. January 02, 2018. Accessed July 28, 2018. https://www.independent.co.uk/news/business/analysis-andfeatures/rich-world-billionaire-list-ranking-jeff-bezos-bill-gates-warren-buffettamancio-ortega-mark-a8131071.html.

10 Frase, Peter. “Four Futures.” Jacobin. Accessed July 28, 2018. https://www. jacobinmag.com/2011/12/four-futures/.

11 UN Environment Program. “China Consolidates Position as Global Leader on Green Finance, Says New Research." News release, November 11, 2017. UN Environment. Accessed July 28, 2018. https://www.unenvironment.org/news-and-stories/pressrelease/china-consolidates-position-global-leader-green-finance-says-new. 


\subsection{Return to Critical Architecture}

1 Scott, Felicity Dale Elliston. Architecture or Techno-utopia: Politics after Modernism. Cambridge, MA: MIT Press, 2010.

2 Berardi, Franco. After the Future. Oakland, CA: AK Press, 2011.

3 World Trade Center Site Memorial Competition. Accessed July 28, 2018. http:// www.wtcsitememorial.org/.

$4 \quad$ Franco Berardi, After the Future (Oakland, CA: AK Press, 2011), 192.

$5 \quad$ Ibid, 197.

6 Felicity Dale Elliston Scott, Architecture or Techno-utopia: Politics after Modernism (Cambridge, MA: MIT Press, 2010), 264.

7 Franco Berardi, Precarious Rhapsody: Semiocapitalism and the Pathologies of Post-alpha Generation (London: Minor Compositions, 2010), 46.

8 Felicity Dale Elliston Scott, Architecture or Techno-utopia: Politics after

9 Rem Koolhaas et al., Small, Medium, Large, Extra-large: Office for Metropolitan Architecture, Rem Koolhaas, and Bruce Mau (New York: Monacelli Press, 1997), 5.

10 Dunne \& Raby. Accessed July 28, 2018. http://www.dunneandraby.co.uk/content/ bydandr/13/0.

\subsection{Government as Leading Innovation}

1 Manyika, James, Susan Lund, Michael Chui, Jacques Bughin, Jonathan Woetzel, Parul Batra, Ryan Ko, and Saurabh Sanghvi. “Jobs Lost, Jobs Gained: What the Future of Work Will Mean for Jobs, Skills, and Wages." McKinsey \& Company. Accessed July 28, 2018. https://www.mckinsey.com/featured-insights/future-oforganizations-and-work/Jobs-lost-jobs-gained-what-the-future-of-work-willmean-for-jobs-skills-and-wages.

2 Sector, Industry. "Interim Reports - Economic Strategy Tables." Corporations Canada. March 27, 2018. Accessed July 28, 2018. https://www.ic.gc.ca/eic/ site/098.nsf/eng/h_00013.html.

3 Wong, Natalie, and Stefanie Marotta. “Who Just Beat the Bay Area in Tech Jobs? Toronto." Bloomberg.com. July 24, 2018. Accessed July 28, 2018. https://www. bloomberg.com/news/articles/2018-07-24/toronto-beats-bay-area-in-new-techjobs-and-new-york-in-talent.

11.0 Monuments to The Future

1 "Monument." Merriam-Webster. Accessed July 28, 2018. https://www.merriamwebster.com/dictionary/monument.

2 Franco Berardi, After the Future (Oakland, CA: AK Press, 2011), 228.

3 Felicity Dale Elliston Scott, Architecture or Techno-utopia: Politics after Modernism (Cambridge, MA: MIT Press, 2010), 280.

12.0 Monument to Culture

$1 \quad$ Benno Tempel and Laura Stamps, New Babylon - to Us, Liberty: Constant(Ostfildern: Hatje Cantz Verlag, 2016), 211.

2 Elizabeth M. Brumfiel et al., Heterarchy and the Analysis of Complex Societies(Arlington: American Anthropological Association, 1995), 3.

3 Lebbeus Woods, Bridges: Mathematical Connections in Art, Music, and Science: Heterarchy of Space - Abstract (Winfield: Southwestern College, 2002), 311. 
$1 \quad$ Hunt, Shauna. "What Will It Take for Toronto to Continue to Sustain the Condo Boom?" CityNews Toronto. April 03, 2017. Accessed July 28, 2018. https://toronto.citynews. ca/2017/04/03/will-take-toronto-continue-sustain-condo-boom/.

2 Wilkinson, Tom. “Typology: Skyscraper." Architectural Review. Accessed July 28, 2018. https://www.architectural-review.com/essays/typology-skyscraper/10019237.article.

$3 \quad$ “Fujian Tulou." UNESCO World Heritage Centre. Accessed July 28, 2018. https://whc. unesco.org/en/list/1113.

$4 \quad$ Ibid.

$5 \quad$ Newman, Oscar. Defensible Space: Crime Prevention through Urban Design. Macmillan,: New York, 1972.

\subsection{Monument to Institution}

1 Miller, Frederic, Agnes Vandome, and John McBrewster. Infoshphere.

2 Byrnes, Mark, and CityLab. “A Look Back at Expo 67's U.S. Pavilion." CityLab. April 27, 2017. Accessed July 28, 2018. https://www.citylab.com/design/2017/04/a-lookback-at-expo-67s-us-pavilion/524589/.

\subsection{Monument to Recreation}

1 Tempel, Benno, and Laura Stamps. New Babylon - to Us, Liberty: Constant. Ostfildern: Hatje Cantz Verlag, 2016.

2 Robinson, Lawrence, Melinda Smith, Jeanne Segal, and Jennifer Shubin. “The Benefits of Play for Adults: How Play Benefits Your Relationships, Job, Bonding, and Mood." Accessed July 28, 2018. https://www.helpguide.org/articles/mentalhealth/benefits-of-play-for-adults.htm.

3 Keith Tester, The Flâneur (Abingdon, Oxon, United Kingdom: Routledge, 2015 ), 1.

$4 \quad$ Benno Tempel and Laura Stamps, New Babylon - to Us, Liberty: Constant(Ostfildern: Hatje Cantz Verlag, 2016), 120-121.

5 Debord, Guy. "Theory of the Dérive." Situationist International Online. Accessed July 28, 2018. https://www.cddc.vt.edu/sionline/si/theory.html.

6 Ibid.

16.0 The Uncanny

16.1 The Uncanny as Cultural Innovation

1 Boris Grojs and G. M. Goshgarian, On the New (London: Verso, 2014), 26.

2 Sigmund Freud, The Uncanny, 2, accessed July 31, 2018, http://web.mit.edu/ allanmc/www/freud1.pdf.

$3 \quad$ Ibid.

4 Grojs, Boris, and G. M. Goshgarian. On the New. London: Verso, 2014.

5 Ibid.

6 Ruy, David (2012). Returning to (Strange) Objects. _Tarp Archtiecture Manual_ (Spring):38-42.

7 Lisbeth Söderqvist (2011) Structuralism in architecture: a definition, Journal of Aesthetics \& Culture, 3:1, DOI: 10.3402/jac.v3i0.5414

8 Boris Grojs and G. M. Goshgarian, On the New (London: Verso, 2014), 100-110.

9 Ibid, 65.

10 Ibid, 50. 


\subsection{Automation as Uncanny}

1 Sigmund Freud, The Uncanny, accessed July 31, 2018, http://web.mit.edu/allanmc/ www/freud1.pdf.

$2 \quad$ Ibid, 1.

$3 \quad$ Ibid.

$4 \quad$ Anthony Vidler, The Architectural Uncanny: Essays in the Modern Unhomely(Cambridge, Mass.: MIT Press, 1999), 10.

5 Derrida, Jacques, and Peggy Kamuf. Specters of Marx: The State of the Debt, the Work of Mourning, and the New International. New York, NY: Routledge, 2011.

$6 \quad$ lbid.

7 Bernard Tschumi, The Pleasure of Architecture (London: Architectural Design Magazine, 1977), 214-218.

8 Jacques Derrida and Peggy Kamuf, Specters of Marx: The State of the Debt, the Work of Mourning, and the New International (New York, NY: Routledge, 2011), 21.

$9 \quad$ Ibid, 45.

10 Ibid, 10.

11 Conniff, Richard. "What the Luddites Really Fought Against." Smithsonian.com. March 01, 2011. Accessed July 31, 2018. https://www.smithsonianmag.com/ history/what-the-luddites-really-fought-against-264412/?no-ist=\&page=2.

\subsection{Architecture as Uncanny}

"Mr. In-between." New York Magazine, October 17, 1988, 48-52.

Ibid, 51.

$3 \quad$ Ibid.

$4 \quad$ Van Der Straeten, Bart. "The Uncanny and the Architecture of Deconstruction." Image \& Narrative. Accessed July 31, 2018. http://www.imageandnarrative.be/ inarchive/uncanny/bartvanderstraeten.htm.

5 Geoffrey Broadbent, Deconstruction a Student Guide (London: Academia, 1991), 17.

$6 \quad$ lbid.

7 Tim Woods, Beginning Postmodernism (Manchester: Manchester University Press, 2013), 107.

\subsection{Strange Objects as Uncanny}

1 Ruy, David (2012). Returning to (Strange) Objects. _Tarp Architecture Manual_ (Spring), 38-42.

$2 \quad$ Ibid, 38.

3 lbid.

$4 \quad$ Harman, Graham. Immaterialism Objects and Social Theory. Cambridge, UK: Polity Press, 2016.

5 Ruy, David (2012). Returning to (Strange) Objects. _Tarp Architecture Manual_(Spring), 40 $6 \quad$ lbid. 
1 Jacob, Sam. "Architecture Enters the Age of Post-Digital Drawing." Metropolis. July 05, 2018. Accessed September 02, 2018. https://www.metropolismag.com/ architecture/architecture-enters-age-post-digital-drawing/.

2 Anthony Vidler, The Architectural Uncanny: Essays in the Modern Unhomely(Cambridge, Mass.: MIT Press, 1999), 9.

3 Marco Frascari, Eleven Exercises in the Art of Architectural Drawing: Slow Food for the Architects Imagination (London: Routledge, 2011), 70.

$4 \quad$ Lebbeus Woods, Radical Reconstruction (New York: Princeton Architectural Press, 1997), 17.

\subsection{Uncanny Methodologies for the Uncanny Object}

1 Tate. "Automatism - Art Term." Tate. Accessed July 31, 2018. https://www.tate.org. uk/art/art-terms/a/automatism.

2 Pearch, Bill. “Salvador Dali: Master of Surrealism - Bill Pearch.” Humzoo. Accessed July 31, 2018. http://www.humzoo.com/billpearch/blog/1243/.

3 Beton, Andre. “Les Champs Magnétiques." Wikipedia. July 27, 2018. Accessed July 31, 2018. https://en.wikipedia.org/wiki/Les_Champs_magnétiques. 


